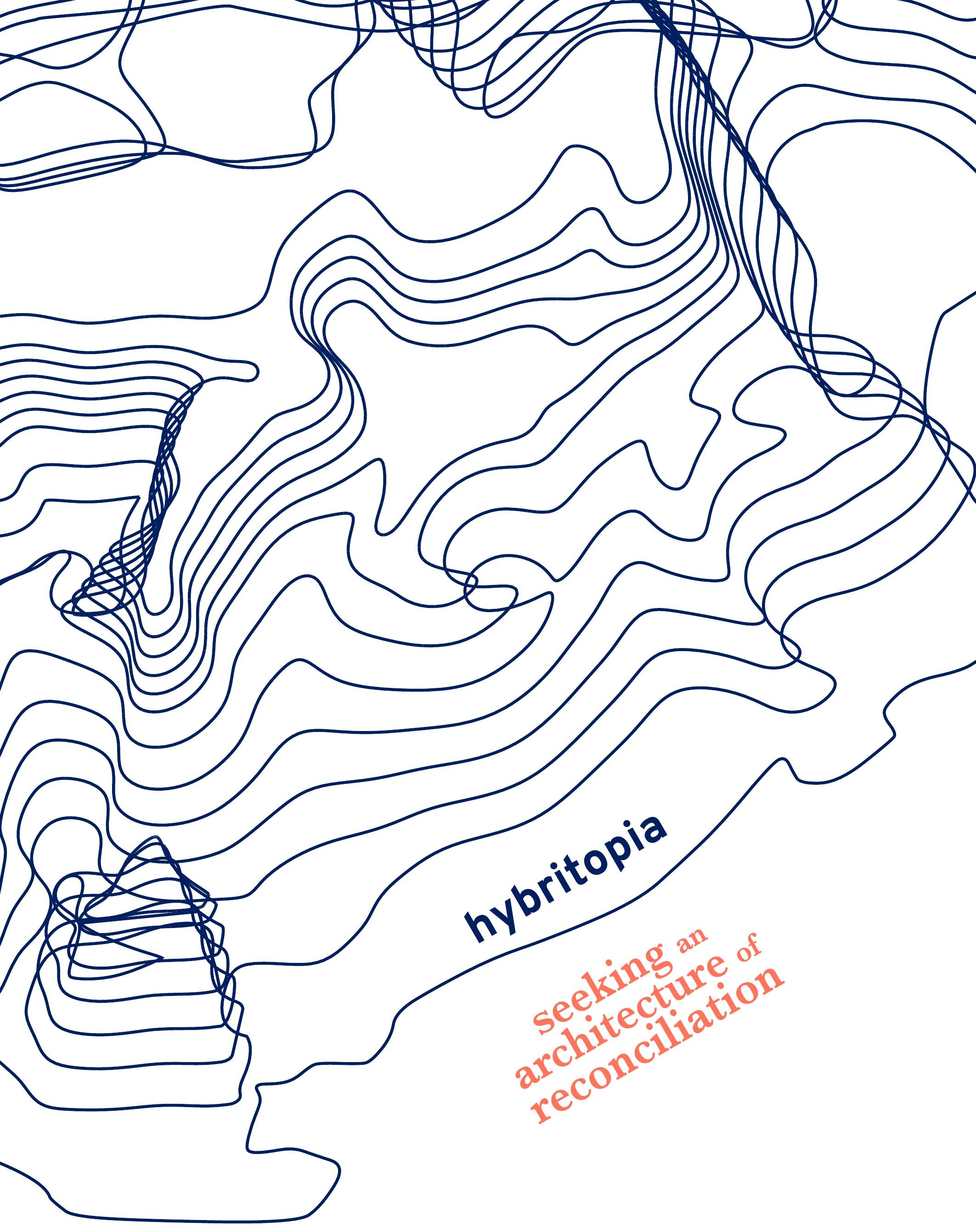





\title{
HYBRITOPIA: SEEKING AN ARCHITECTURE OF RECONCILIATION
}

\author{
by \\ Catalina Ardila Bernal \\ Bachelor of Architectural Science \\ Ryerson University \\ 2016 \\ A thesis \\ presented to \\ Ryerson University

\begin{abstract}
in partial fulfillment of the
Master of Architecture

in the

program of Architecture
\end{abstract} \\ requirements of the degree of
}

Toronto, Ontario, Canada, 2018

(C) Catalina Ardila Bernal 2018 
this page intentionally left blank 


\section{Author's Declaration}

I hereby declare that I am the sole author of this thesis. This is a true copy of the thesis, including any required final revisions, as accepted by my examiners.

I authorize Ryerson University to lend this thesis to other institutions or individuals for the purpose of scholarly research.

I further authorize Ryerson University to reproduce this thesis by photocopying or by other means, in total or in part, at the request of other institutions or individuals for the purpose of scholarly research.

I understand that my thesis may be made electronically available to the public. 


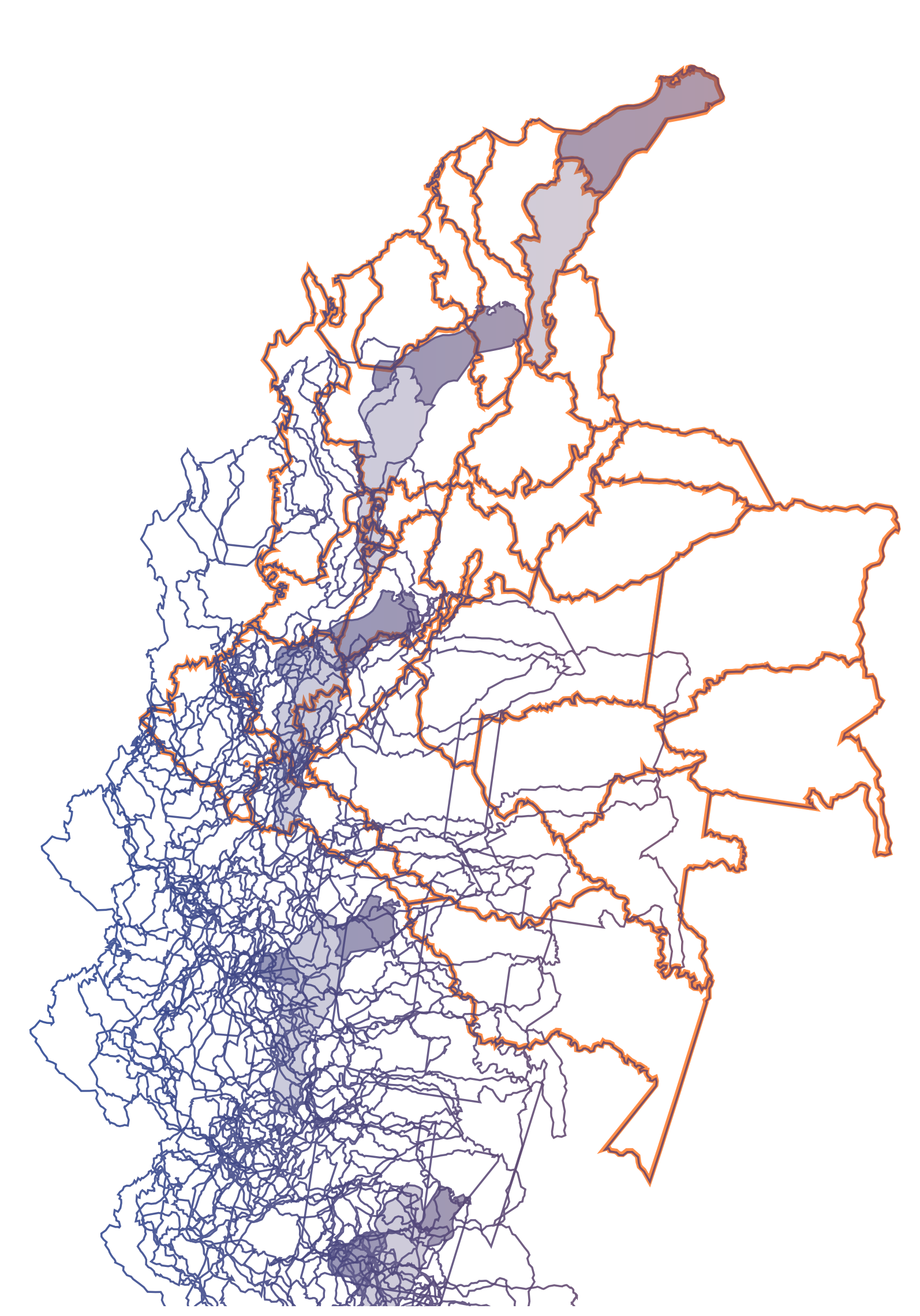




\author{
Hybritopia: Seeking An Architecture of Reconciliation \\ Catalina Ardila Bernal \\ Master of Architecture 2018 \\ Architecture Program, Ryerson University
}

\title{
Abstract
}

The rural landscape in the global south has become the subjectivation $^{1}$ of ruthless economies and the demand for detachment and independence has been building up since the time of Discovery. As contemporary colonization is slowly reaching a rupture point between the corporation and minorities, governments and locals, urban and rural, developed and developing, architecture can mitigate the impacts as an agent of reconciliation. A space designated for the revitalization of land degradation, not in the sense of making land fertile again, but from the standpoint of a new foundation of cultures, communities and traditions, and more importantly, a setting for celebrating rural human existence, from life to death and infinity. A sacred space, or a rural hybritopia, embodies the epitome of redemption, reconciliation and renewal for villages, towns, minorities and displaced communities. 


\section{Acknowledgments}

\section{Arthur Wrigglesworth}

for pushing the limits of my design, research and experimentation. The great conversations sparked new ideas that I will continue carrying.

I am truly grateful for your support in the most difficult times of this thesis, and for making me continue regardless of the circumstances.

\section{Scott Sørli}

whose interests and insights became valuable in the development of my thesis since day one of MArch. Your view towards arts has been, and will always be, very influential

and inspirational.

June Komisar

for your support, energy and feedback.

John Cirka

from your inputs and feedback in 4th year, I learned to critically analyze my own view towards architecture.

\section{Gracias}


En Dios está mi salvación y mi gloria;

En Dios está mi roca fuerte, y mi refugio.

Salmos 62:7 
To Jose Ardila

who gave me opportunity to experience the life in rural Colombia.

Without this, 99\% of my thesis would not have been possible. Your soul sought reconciliation and it has found it now.

To Alexandra and Vladimir

for witsnessing the ups and downs and supporting me all the way through since day one of architecture school. 


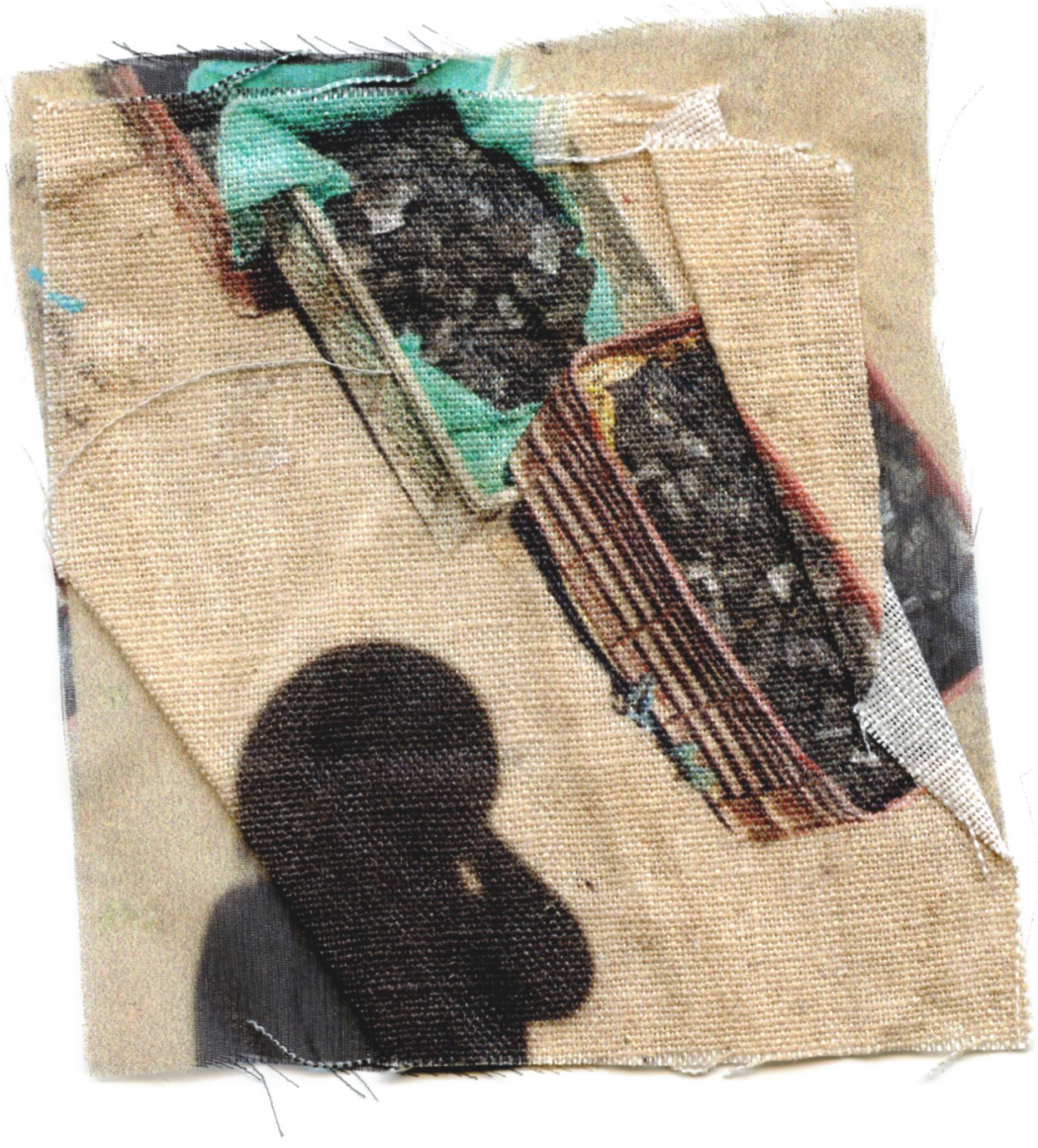




\section{My Preamble}

Colombia was my home for 15 years until my parents decided to move to Canada. Although safety was certainly a motive, their main reason was to seek a future full of opportunities for me.

After 10 years away from Colombia's culture, context, food, and family, I decided to go back and explore it with a new perspective for my thesis. After several visits during these years, the last one, during December 2017-January 2018, certainly had the most impact in the outcome of this research because I lived, saw, and documented rural areas, rural houses, mines, and sacred spaces. Moreover, this month was also the most important one at a personal level because I built a lot of memories that soon after would become impossible to erase, forget or ignore.

The new lenses for seeing the country were developed through architecture, as well as my own personal experience with a cultural exchange: being too Colombian for Canada, and being too Canadian for Colombia. This familiarity yet distance allowed me a slightly removed perspective that provide me a particular access to insights of how people live and organize their lives in these areas, and how rich rural traditions are (from New Year's celebration to the after-work routine in small towns). For these reasons, and many more, I chose Colombia as my thesis site; I knew it could give me the opportunity to examine the other Colombia we seldom see when we live in the country, because it has elements of magic realism and real maravilloso that we rarely perceive in countries like Canada, and because everything in the country (crafts, colours, textures, photography) needs to be captured and translated to unfamiliar audiences. 
Author's Declaration $\quad$ iii

Abstract v v

Acknowledgments vii

Dedication $\quad$ ix

My Preamble $\quad$ x

List of Figures $\quad$ xiv

$\begin{array}{ll}\text { Prelude } & 4\end{array}$

7 Genesis 10

${ }^{1}$ Colombia's Eden: The wealth of the land 11

$\begin{array}{ll}{ }^{2} \mathrm{NeO}-\text { colonialism vs. post-colonialism } & 14\end{array}$

$\begin{array}{ll}{ }^{3} \text { Mining } & 17\end{array}$

${ }^{4}$ Cesar 20

${ }^{5}$ La Guajira 22

${ }^{6}$ Genealogy: The role of each actor on the land 24

${ }^{7}$ Corporations 25

$\begin{array}{ll}{ }^{8} \text { Government } & 27\end{array}$

${ }^{9}$ Church 31

${ }^{10}$ Campesinos $\quad 36$

\&Life 42

$\begin{array}{ll}{ }^{1} \text { Dwelling } & 72\end{array}$

Trance $\quad \mathbf{8 0}$

${ }^{1}$ Slow Violence $\quad 82$

${ }^{2}$ Water

(9xodus $\quad 94$

$\longleftrightarrow{ }^{1}$ Displacement and Return 97

$\begin{array}{ll}{ }^{2} \text { Hauntology } & 100\end{array}$

${ }^{3}$ The void in the land, alienation \& spatial estrangement 104 
Sacred and Profane 128

$\triangle{ }^{1}$ Magic Realism vs New Objectivity 136

2 The Promised Land 148

$\begin{array}{ll}3 \text { Ambiguity } & 144\end{array}$

$\begin{array}{ll}{ }^{4} \text { The in-between and thirdspace } & 145\end{array}$

$\begin{array}{ll}{ }^{5} \text { Uncanny } & 150\end{array}$

${ }^{6}$ Homely - Unhomely 153

(2) Revelation

154

xiii

${ }^{1}$ Decolonization

157

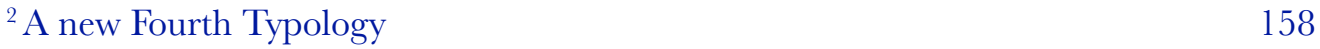

${ }^{3}$ Hybritopia 161

Epilogue

186

$\begin{array}{ll}\text { Appendix } & 192\end{array}$

$\begin{array}{ll}{ }^{1} \text { Reinterpretation of Paintings } & 194\end{array}$

$\begin{array}{ll}{ }^{2} \text { Reconciliation Tables } & 195\end{array}$

${ }^{3}$ The in-between of the Stations of the Cross 196

$\begin{array}{ll}{ }^{4} \text { Fragmentation as kintsugi } & 198\end{array}$

$\begin{array}{ll}{ }^{5} \text { A brief history of Colombia through models } & 199\end{array}$

${ }^{6}$ Water from the soil 200

$\begin{array}{ll}\text { Bibliography } & 202\end{array}$ 
List of figures

Cover

topography of Colombia's promised land

source Catalina Ardila Bernal

Page iv

fall of Colombia

source Catalina Ardila Bernal

Page $x$

self-portrait

source Catalina Ardila Bernal

Prelude

[title page]

source Catalina Ardila Bernal

Genesis

[title page]

source Catalina Ardila Bernal

figure 01 the main coal mines in the country

source

edited by Catalina Ardila Bernal

xiv

figure 02 coal reserves

source http://srvags.sgc.gov.co/Flexviewer/Mapa_Potencial_Carbonifero_Colombia/

edited by Catalina Ardila Bernal

figure 03 coal exportations

source UPME

edited by Catalina Ardila Bernal

figure 04 the mines is the regions of Cesar and Guajira

source google maps

edited by Catalina Ardila Bernal

figure 05 location of Cesar in Colombia

edited by Catalina Ardila Bernal

figure 06 feature in Cesar near the mines

source UPME

edited by Catalina Ardila Bernal

figure 07 location of la Guajira in Colombia.

edited by Catalina Ardila Bernal

figure $\mathbf{0 8}$ the contracts for the mining operations in la Guajira and Cesar edited by Catalina Ardila Bernal

figure 09 the role of the government is semi-transparent

source Catalina Ardila Bernal 
figure 10 monument to coal in Albania, La Guajira, Colombia source Catalina Ardila Bernal

figure 11 salt mine in Zipaquira, Colombia

source Catalina Ardila Bernal

figure 12 typology of churches

source Catalina Ardila Bernal

figure 13 and figure 14

source Catalina Ardila Bernal

figure 15 the soil and the impact of water from mining source Catalina Ardila Bernal

figure 16 relationship between the actors and the open-pit source Catalina Ardila Bernal

figure 17 different interposition of the actors with the land source Catalina Ardila Bernal

Life

[title page]

edited by Catalina Ardila Bernal

figure 01 Sierra Nevada de Santa Marta aerial photograph 1938 - 1946

source Archivo General de la Nacion - Colombia (National Archieves)

figure 02 Photograph taken 1938 - 1946

source Archivo General de la Nacion - Colombia (National Archieves)

figure 03

source Archivo General de la Nacion - Colombia (National Archieves)

figure 04

source Archivo General de la Nacion - Colombia (National Archieves)

figure 05 to figure 26

source Catalina Ardila Bernal

figure 27 superstudio's ceremonia

source https://www.youtube.com/watch? $v=k X r W r 8 z L R N Y$

figure 28 typology of rural houses in Colombia

source Catalina Ardila Bernal

figure 29 four rural houses in Colombia

source Catalina Ardila Bernal

figure $\mathbf{3 0}$ one rural house in Colombia

source Catalina Ardila Bernal

Trance

[title page]

edited by Catalina Ardila Bernal 
figure 01 slow violence

source Catalina Ardila Bernal

figure 02 life and slow violence

source https://bit.ly/2KfiwQe

figure 03 slow disappearance of some waterbodies in Cesar near the mines source Geographic Institute Agustin Codazzi

edited by Catalina Ardila Bernal

figure 04 slow disappearance of some waterbodies in La Guajira near the mines source Geographic Institute Agustin Codazzi

edited by Catalina Ardila Bernal

figure 05 absortion of water into the soil as a result of the use of explosives for mining source Catalina Ardila Bernal

figure 06 hypothetical emergence of water inside the mine

source Catalina Ardila Bernal

\section{Exodus}

[title page]

source Catalina Ardila Bernal

figure 01 the actions done over land

source Catalina Ardila Bernal

$x v i$

figure 02 return and returns

source Catalina Ardila Bernal

figure $\mathbf{0 3}$ the Colombian terrain hideas a secret

source Catalina Ardila Bernal

figure 04 the secret is revealed, yet it is not clear of what it is source Catalina Ardila Bernal

figure 05 some geometries appear, or disappear, to the ground source Catalina Ardila Bernal

figure 06 view of one of the pits at Cerrejon, La Guajira, Colombia. edited by Catalina Ardila Bernal

figure 07 plan view of one of the mines at Cesar and Colombia source google maps

edited by Catalina Ardila Bernal

figure 08 plan view of one of the mines in La Guajira and Colombia source google maps

edited by Catalina Ardila Bernal

Death

[title page]

edited by Catalina Ardila Bernal 
figure 01 the void in the land represents a new territory for life source Catalina Ardila Bernal

\section{Reconciliation}

[title page]

edited by Catalina Ardila Bernal

figure 01 table study

source Catalina Ardila Bernal

figure 02 reforested pit

source Catalina Ardila Bernal

figure $\mathbf{0 3}$ another pit during operations

source Catalina Ardila Bernal

figure 04 the relationship between 'table' and house

source Catalina Ardila Bernal

Sacred \& Profane

[title page]

edited by Catalina Ardila Bernal

figure 01 the Tabernacle

edited by Catalina Ardila Bernal

figure 02 Eliade's sacred space and sacred time interpretation source Catalina Ardila Bernal

figure $\mathbf{0 3}$ the overall relationship between sacred and profane in terms of reconciliation source Catalina Ardila Bernal

figure 04 nature becomes essential in the process of recuperation source Catalina Ardila Bernal

figure 05 the new objectivy in Colombia edited by Catalina Ardila Bernal

figure 06 the promised land is born from the fragmented landscape generated by mining edited by Catalina Ardila Bernal

figure $\mathbf{0 7}$ the promised land is the creation of a new culture edited by Catalina Ardila Bernal

figure $\mathbf{0 8}$ The promised land is a combination of all the largest mines in the northern region of Colombia edited by Catalina Ardila Bernal

figure 09 third spaces as hybridity, history and equality edited by Catalina Ardila Bernal

figure $\mathbf{1 0}$ third spaces as hybridity

edited by Catalina Ardila Bernal 
figure 11 third spaces as history

edited by Catalina Ardila Bernal

figure 12 third spaces as equalitarian

edited by Catalina Ardila Bernal

figure 13 uncanny as a "metaphor for a fundamentally unlivable condition"

edited by Catalina Ardila Bernal

figure 14 Peter Eisenman's Fin d'ou T Hou S'

source https://eisenmanarchitects.com/Fin-D-Ou-T-Hou-S-1983

figure 15 the domestication of space

source Catalina Ardila Bernal

Revelation

[title page]

source Catalina Ardila Bernal

figure $\mathbf{0 1}$ fragments and how to reconstruct it within a given framework

source Catalina Ardila Bernal

figure 02 Reconstucted fragment within a given framework

source Catalina Ardila Bernal

xviii

figure 03 Foucault's heterotopia represented by a water body outlining the mine.

source Catalina Ardila Bernal

figures from page $166-185$

source Catalina Ardila Bernal

Epilogue

[title page]

edited by Catalina Ardila Bernal

figure 01 genesis, exodus and revelation.

source Catalina Ardila Bernal

figure 02 epilogue

source Catalina Ardila Bernal

Appendix

[title page]

edited by Catalina Ardila Bernal

figure 1a the Colombian shipwreck by Goya

source https://biblioklept.org/2013/02/26/the-shipwreck-francisco-goya/

edited by Catalina Ardila Bernal

figure 1b siege of Colombian Kosel by Wilhelm

source https://www.sammlung.pinakothek.de/de/artist/wilhelm-von-kobell/die-belagerungvon-cosel

edited by Catalina Ardila Bernal 
figure 1c woman in Colombian morning light by Caspar David

source https://fr.wikipedia.org/wiki/Femme_devant_le_coucher_de_soleil\#/media/File:Cas-

par_David_Friedrich___Frau_vor_untergehender_Sonne.jpg

edited by Catalina Ardila Bernal

figure 1d the castle in the ColombianPyrenees by Magritte

source http://archiveofaffinities.tumblr.com/post/26191320224/ren\%C3\%A9-magritte-the-

castle-in-the-pyrenees-1959

edited by Catalina Ardila Bernal

figure 2a under the table by Robert Therrien

source Catalina Ardila Bernal

figure $\mathbf{2} \mathbf{b}$ Colombian peace dialogues

source https://barrancabermejavirtual.net/wp/wp-content/uploads/2013/11/dialo-

gos-de-paz-La-Habana.png

figure 2c plegaria muda by Doris Salcedo

source http://www.nashersculpturecenter.org/art/exhibitions/exhibition?id=326

figure 3a lookout point by HHF architects

source https://www.dezeen.com/2011/05/31/ruta-del-peregrino-lookout-point-by-hhf-architects-2/

figure $\mathbf{3 b}$ sanctuary circle by Dellekamp and Periferica

source https://www.dezeen.com/2011/06/03/ruta-del-peregrino-sanctuary-circle-by-delleka-

mp-and-periferica/

figure 3c cerro del obispo lookout point by Christ \& Gantenbein

source https://www.dezeen.com/2012/11/04/ruta-del-peregrino-cerro-del-obispo-look-

out-point-by-christ-gantenbein/

figure 3d lookout point by Elemental

source https://www.dezeen.com/2011/06/25/ruta-del-peregrino-crosses-lookout-point-by-elemental/

figure 3e sanctuary by Ai Weiwei

source https://www.dezeen.com/2011/06/07/ruta-del-peregrino-sanctuary-by-ai-weiwei/

figure 4 via dolorosa in Jerusalem

source https://www.youtube.com/watch?v=LSPAL2cJp0k

figure 5 fragmentation as kintsugi

source Catalina Ardila Bernal

figure 6 the brief history of colombia through models

source Catalina Ardila Bernal

figure 7 water from the soil

source Catalina Ardila Bernal 


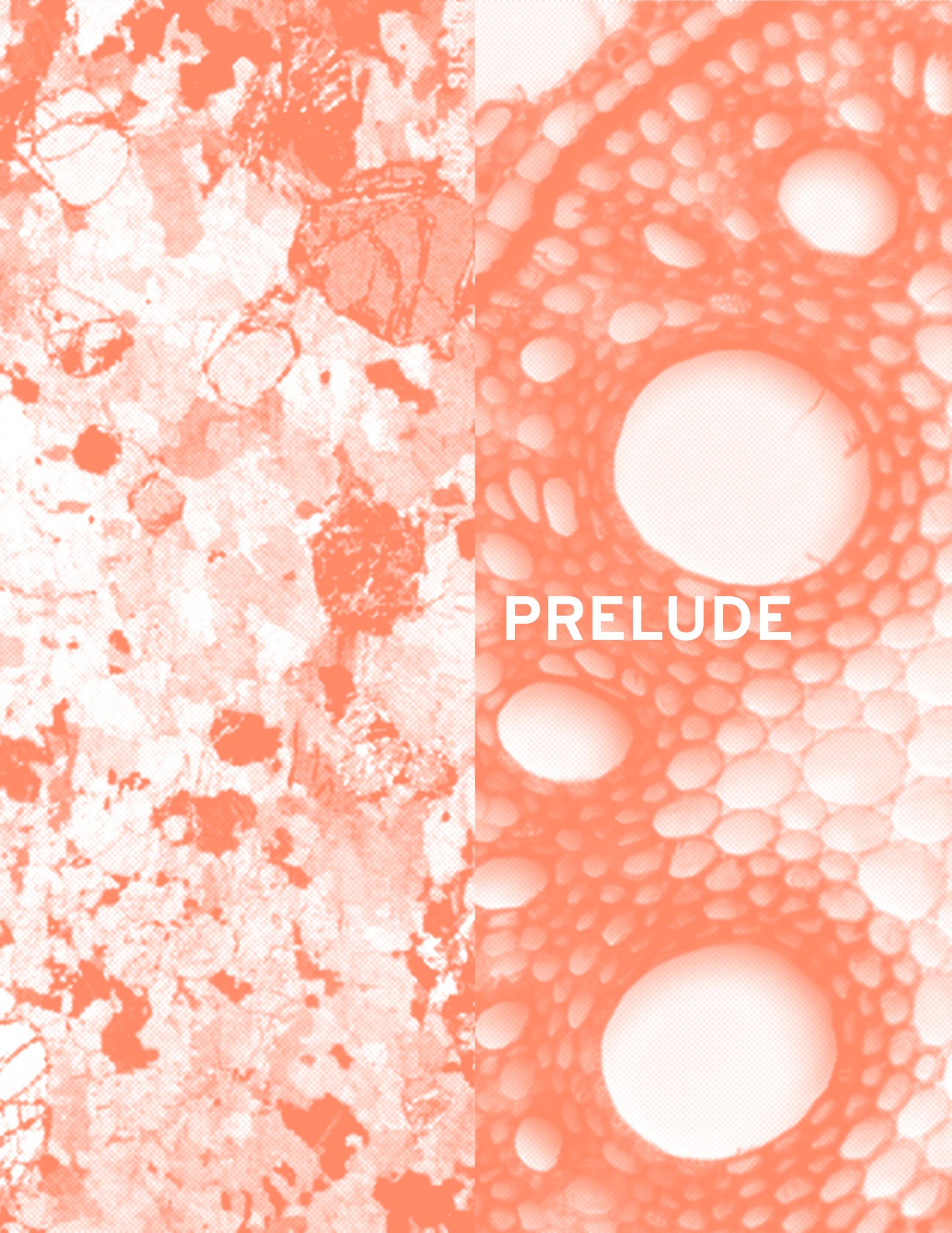




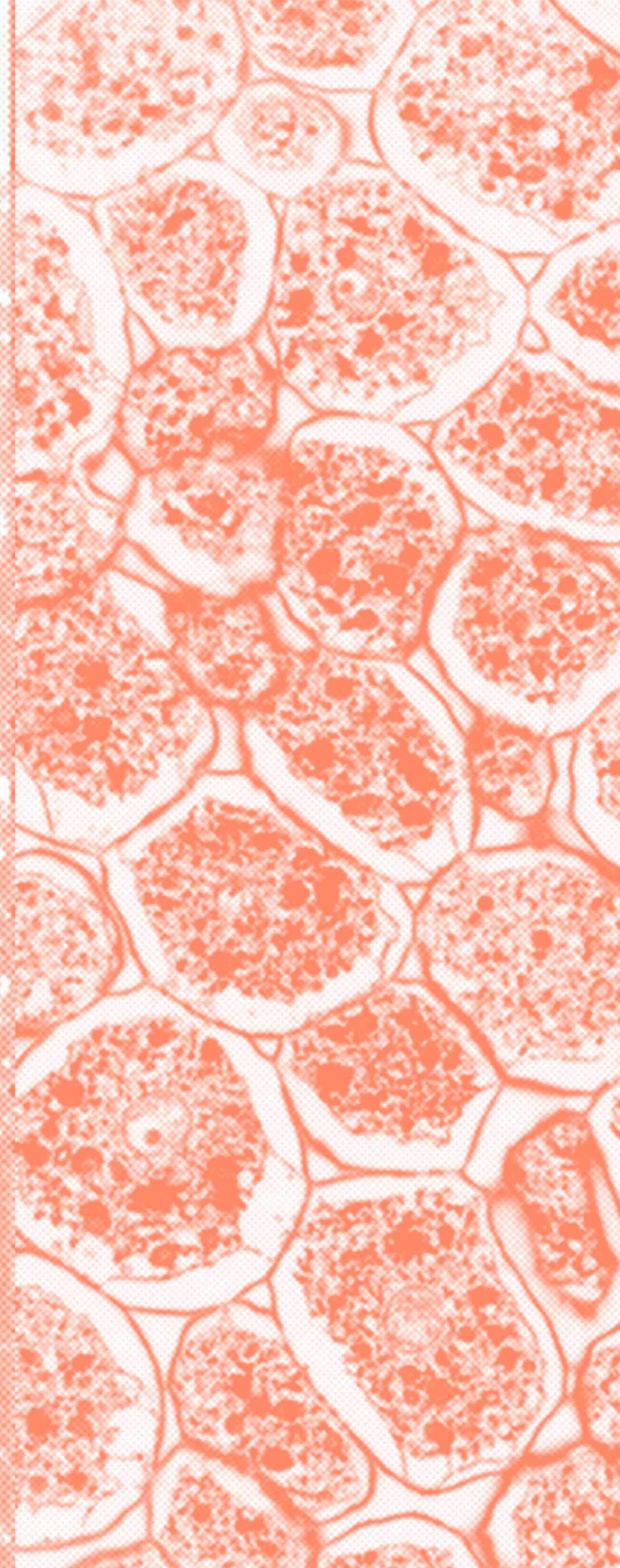


The development of global economies is happening at an exponential pace, where communities, who are not ready for such changes, are faced with unexpected and potentially catastrophic challenges. The colonization that has perpetuated in Latin America since its discovery is very palpable today, in a time where urbanization in this region is reaching almost $80 \%$ and where the gap between rich and poor, and urban and rural is very drastic. Since most of the government attention is being paid to the improvement and development of cities and the 'urbanization' of the rural landscape, the question to be answered is what the requirements and needs are for the $20 \%$ of the population still living in rural areas.

The pattern of occupation of developing countries is usually determined by the availability to its availability of natural resources. The process starts with resource exploration, and later on exploitation, usually disregarding the short and long-term consequences and seldom concerned with the post-extraction condition and rehabilitation steps. Although developed countries, like Canada, also undergo a similar process where corporate oversight and lack of governance affect indigenous communities and minorities, particular attention ought to be paid to the global south. Countries like Colombia are affected by the weak (often completely lacking) governance and control from the government, by the international and local companies' investment without proper planning and execution and the little-to-no voice, of the affected communities throughout the process.

Compared to Chile, a country with mining as its primary economic driver, Colombia wants to immerse itself more within the industry and become the next hub for mining exploration and exploitation in the continent (Castro, 2006). In a report published in 2006, the Colombian government forecasts the economic progress to 2019 of the mining industry. Through exploitation of minerals and gemstones, the country proposes the strategic techniques used by each particular Department (political division used in Colombia) to become the potential source of economy, work, opportunities and production at both local and national levels. However, the main purpose and reasons are aimed to attract corporate investment to those particular regions and not enough is mentioned on social strategies or toward the protection of communities.

Mining itself is a generator of opportunities, energy, money, and even innovation. Nonetheless, the negative connotation it carries, environmentally and socially, leads to a strong opposition from communities and minorities. The benefits of mining to the rural areas include the job opportunities and economic development at the local, regional and national level. However, the drawbacks usually outweigh the benefits: campesinos (farmers) and other rural inhabitants are subjected to forced displacement, as well as their land being valued when sold, and no long-term planning for the living arrangements of the affected communities nor alternatives for their no longer useful manual labour skills. 
Architecture can step into this problematic situation as an agent of remediation ${ }^{1}$. It can be the tool to seek and synthesize while revealing problems, by creating a neutral space that balances the demands of the corporations and the needs of the community. But, how can a space be present where there is no possibility for setting the foundation of a new life, or a new beginning, since the man-made disruption of natural and cultural ecosystems interrupts the natural cycles?

In order to recognize the real impacts of the mining industry on the global south, it is important to understand the meaning of mining according to UPME (Mining and Energy Planning Unit - Unidad de Planeacion de Mineria Energetica). Mining is "a business based on adding economic value to subsoil resources through a series of activities beginning with the extraction of the mineralized material, followed by the exploitation of the mineral or its transformation into a byproduct and its commercialization" (Colombia Mineral \& Mining Sector Investment and Business Guide, 2012). However, the added value comes at the expense of other factors, such as communities and towns being used as the means of production rather than an end to be served, as local needs are made subservient to national agendas.

From this process, few financial resources or positive consequences are left to the immediate context where the companies have undertaken the extraction. After operations are over, the land becomes forensic evidence, that Eyal Weizman defines as the "ground as an architectural artifact" (Weizman, 2016) because mining turns the soil into an obsolete element, losing all of its bona fide qualities and its obsolescence will exist indefinitely due to the brutality of mining. The rural landscape conveys the unbalance of the system brought by mining, neglect of social aspects, and the thrust of slow violence. In the aftermath of mining, the resulting soil is a dormant, dominant vast pit and sublime infertile element, where communities and locals, inhabiting within and adjacent to the mining areas, are permanently reminded of the effects of colonization: from an object of production, to an artifact of pollution. This can be basically characterized as an ecocide. Defined as the "destruction of the natural environment, especially when deliberate" (Oxford), ecocides are the socio-cultural and environmental consequences of colonization, produced by human intervention.

One of the methods of mining is surface (strip or open-pit) mining, which has more serious environmental implications because it removes the arable top soil. This sets up for discussion of loss of agriculture and livelihood not just while mining but forever. The outcome of open-pit mining could be described in terms of L'espace indicible, or ineffable spaces. The expression, coined by Le Corbusier in his book New World of Space, has two meanings. Firstly, it is defined as "the occupation of the space is the first proof of existence" (Corbusier, 1948). Mining, as the evidence of colonization, urbanization, globalization and development of capital, becomes a first proof of the conquering of a land and the overwhelming lust for natural resources. On the other hand, ineffable space is the phenomenology of space and the architectural harmony being able to transport the user 
without the need for words. Among the victims of colonization, the empty and sterile land triggers the desire to create something new, to fill that emptiness. Architecturally speaking, phenomenology is achieved through the whimsical choices of elements that aspire to a unique experience. The most common typology of harmony is sacred space, as it represents the ideas of perfection, divinity and spiritual power. The sacred ${ }^{2}$, for Mircea Eliade, differs from the profane because it is the moment, or condition, where our attention is compacted and focused towards one particular subject. Churches allow the believers to disconnect from the surroundings, and converge into one single entity and look towards the Divine. Commonly designed to connect the Heavens and the Earth, to commemorate life and death, humans and God, Christian churches are spaces that celebrate the existence of human beings on earth, as well as to "recreate and reveal a world that otherwise ... would have remained hidden" (Barrie, House and Home: Cultural Contexts, Ontological Roles, 2017). Along with the use of architectural elements, its sacred connotation becomes more experiential and symbolic for the user in this thesis. The church ${ }^{3}$ becomes a catalyst for change between locals, corporations and the government. The permeability of sacred and religious architecture as a medium for memory and experience surpasses the architecture of building.

Sacred spaces, regardless of religious or secular intent, are designed as media for understanding life and our role on earth. In the early 1970s, Superstudio proposed a series of five films in which they explored a narrative of the Fundamental Acts of human existence - life, education, love, ceremony and death (Ghidoni, 2016). This storyline can be applied to mining, nature and the rural believer because each one goes through similar phases. The commonality for all these acts is the celebratory fact that we are living beings, and at each stage in life, we are accomplishing something new.

From a religious perspective, the rites of passage, or sacraments in Christianity - baptism, Eucharist, confirmation, marriage, ordination, reconciliation and anointing of the sick - mark the transitions from one human phase into another as well as evoking pilgrims to live a life according to the Christian mandate, to ultimately reach spiritual peace. In a similar way, the expansion of the mining industry is also organized through stages - exploration, mine design, mine construction, mineral extraction, closure and reclamation - showing the transition from a living, fertile soil to an infertile plot of land.

Superstudio's Fundamental Acts are also an analogy for the natural landscape because it encompasses the fragility, finitude and nourishment that's required to exist. The importance of nature in Christianity is introduced from the Garden of Eden to the extreme droughts and floods mentioned in the Bible, as well as being the resting place for Jesus. For the exploited landscape, it further develops the sublime of nature and invites reflection on its fragility, the finitude of resources, and to what extent man-made desires should alter the natural pattern. If the manipulation and

${ }^{2}$ Emile Durkheim would define sacred as the collective, in contrast to profane, which is more individualistic.

${ }^{3} 92 \%$ of the Colombian population is Christian (79\% Roman Catholic, 13\% Protestant) 
over-work of the land result in its depletion, how can we bring the sacred back into the profane? The disruption, greed and rupture of the natural resources, as a sacred and harmonious creation, create a profane condition resulting from the human intervention.

Although Superstudio's Fundamental Acts are divided into five stages, the three main components are Life, Death and Infinity. For them, life is defined as the "importance of individual identity" (Ghidoni, 2016). For Walter Benjamin, life is "more than just life" (Weigel, 2013) as it is part of the "divine creation" (Weigel, 2013). The implication with Death is that it is more than just stopping to exist: it is a migration or transition, the opposite of birth and life, and the halt of a state. Doubtlessly, Infinity is still a concept that overwhelms our existence: the idea of an afterlife and the unknown, as well as the permanent presence of something.

The relationship of us with nature must embody these stages of our human existence. However, if mining takes place and disrupts the habitat and landscape, it will be almost impossible to grow. From Jacques Derrida's deconstruction, the concept of finding meaning through an antonym can be tied to mining and rural living: the 'death' of the land highlights the limits of 'life' in a manufactured landscape $e^{4}$; the social 'rupture' caused by industry is then translated to the 'union' of the community; the absence of the soil makes longing and appreciation more substantial.

The purpose of this thesis is to create a space for redemption and renewal in places where the new economies have profoundly changed the rural landscape. It speculates within a dystopian environment where subjugation and oblivion are the main forensic evidence of mining's aftermath in the rural landscape of Colombia. The irreparable violence done to the land through mining demonstrates the profanity of globalization and its outcomes, as demonstrated by the disruption and destruction of communities and livable spaces. 


\section{GENESIS}
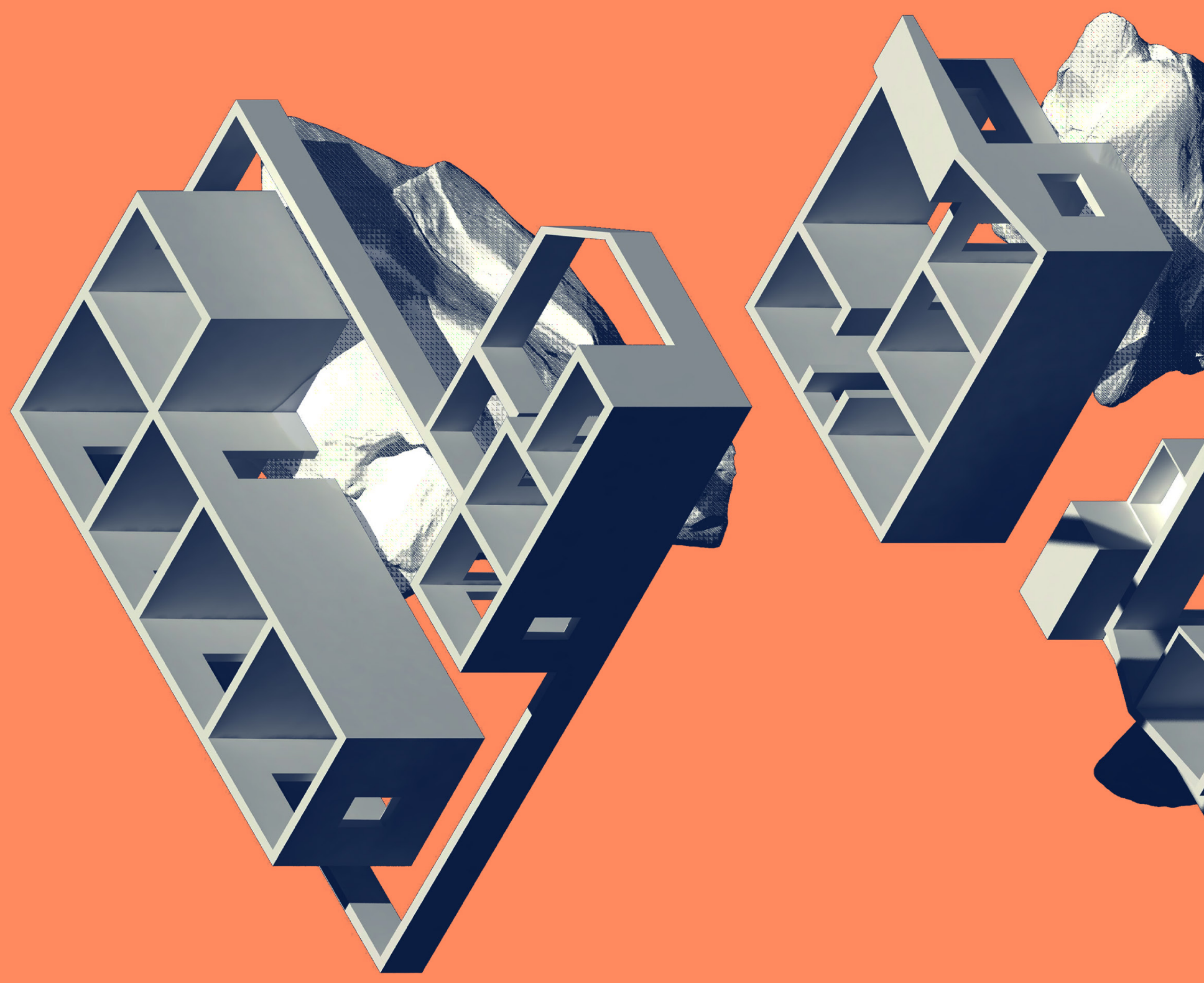


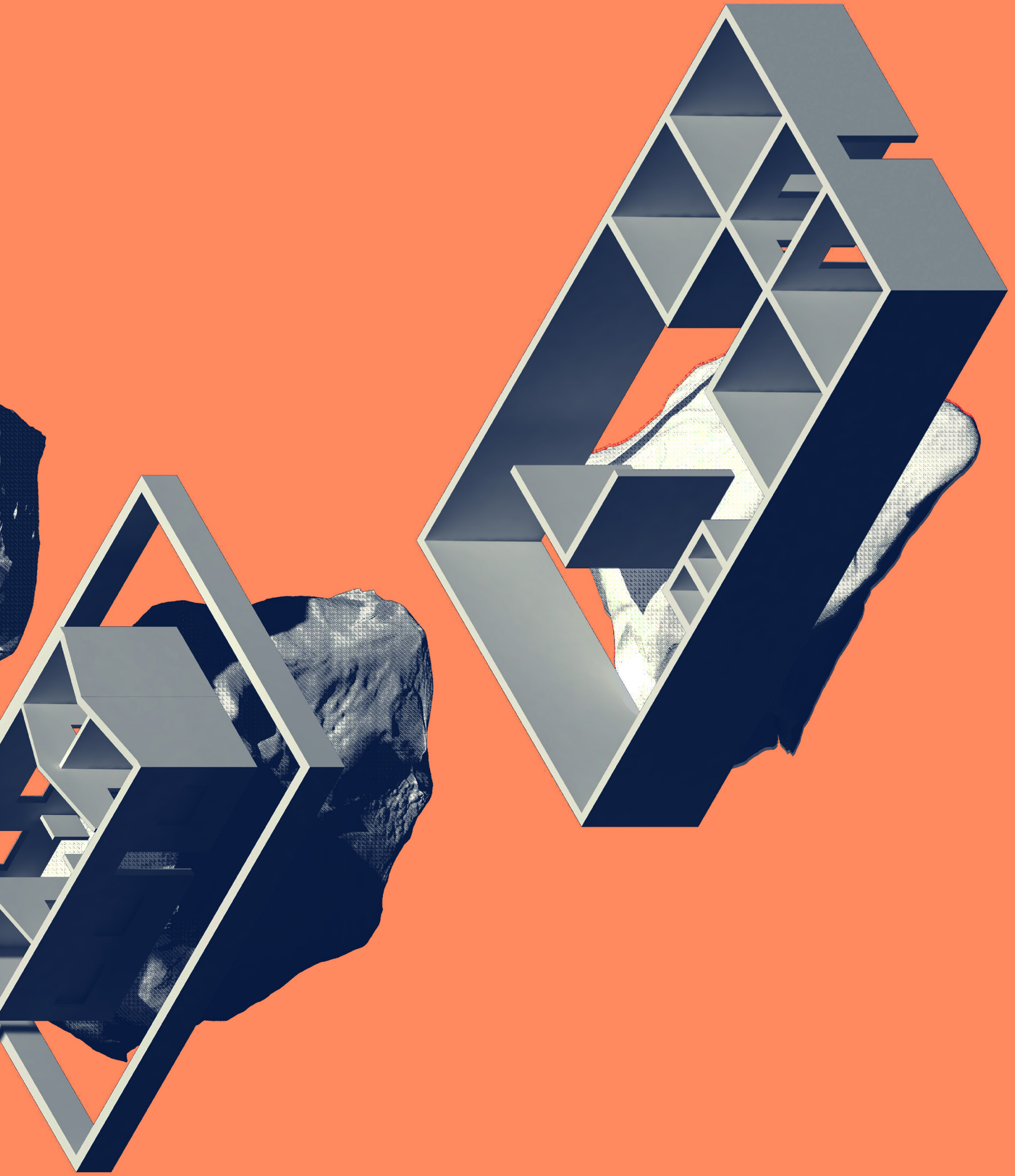


Genesis, with a capital $g$, is the religious narrative of the creation of the universe, human beings, as well as the first manifestation of sin and evil through its intrusion to the Garden of Eden, and impacting the course of human existence. When speaking of a beginning, it usually means that a pre-condition did not exist, was not present or has not been known. Defined as the "origin, or mode of formation or generation, of a thing" (Oxford), the term genesis, with lower case g, prescribes that anything created - an action, condition or physical manifestation - will influence, impact and react over 'a' particular event, person or object. In the context of Colombia, the different political ideologies - from the late 1940s (known as the period of La Violencia) to guerilla groups like M-19 who demanded a fairer and more transparent government - have produced long-term tensions - political, social, economic, cultural - that have been manifested in rural violence and "mass migration ...to cities and other lands, but in a form of invasion...the armed conflict has exhausted agricultural production, coffee production and ... generated unemployment" (FrancoCañas \& Ríos-Carmenado, 2011). This problem has had a lasting impact for many decades, as an internal conflict that has caused large rural displacements.

The long history of social, political and economic problems in the country can be rooted to the land: who has ownership, tenure, command and control. Although the state is the sole owner of the land, more specifically the subsurface and non-renewable natural resources, the main differences are assigned on who ultimately uses the land and for what purposes. From farmers, trying to make a living, to guerilla groups wanting to grow illicit drugs, and the government trying to really control and manage the expansion of illegal crops. In 1999, the government launched 'Plan Colombia' alongside the US government. Its main purpose was to fully eradicate illegal crops in the country. However, the tactics used chemicals released by planes, and ended up affecting villages, small rural areas, afro-Colombian communities, indigenous tribes and farmers (Quiñonez, 2016). Through the actions undertaken by both governments, it demonstrates the influence of the American government to control the rural landscape of countries like Colombia, the lack of planning, warning and immunization of the affected communities, particularly by the Colombian State, and the land becoming the focus of for problems, division and control.

In a hopeful perspective, genesis and/or Genesis means "free of problems and full of promise, beginnings stir hope and imaginative visions of the future" (Life Application Study Bible, 2015). But rural Colombia is currently seeing the opposite: conflict, division, marginalization and suppression. The Colombian (G/g)enesis is formed by darkness, from irreparable internal sociopolitical differences, as well as the neo-colonial 'spectrum' still visible today, and the neglect of ethnic minorities and especially the rural poor. In today's Colombian context, Genesis's actors involve the locals in rural areas, global, local and trans-national corporations, the State and the church (predominantly Roman Catholic). Each one of these actors has had a role in influencing the rupture of the social fabric though the pursuit of self-serving ambition, disregarding the needs of others. 


\title{
COLOMBIA'S EDEN
}

The wealth of the land

\author{
Earth is the serving bearer, blossoming and fruiting, spreading \\ out in rock and water, rising up into plant and animal. \\ Martin Heidegger
}

The Biblical Garden of Eden was paradise, a space where everything surpassed normal and was the epitome of natural expectations. It was also the first representation of a utopia, a closed community, a sacred space, where the relationship between humans and nature was at its peak. Colombia's geographic location makes it a Garden of Eden because it has a very diverse socioenvironmental ecosystem with a wealth of natural resources, flora, fauna, culture, and traditions. Located at the north-west tip of South America, between the Pacific and the Atlantic Ocean, the country becomes the gateway for South America, between the East and the West. By taking advantage of the natural and geographical qualities of the country, the Colombian government has planned out a National Plan for Development (Plan Nacional de Desarrollo) produced during the 2010-2014 presidency of Juan Manuel Santos. Although its emphasis is on peace, education and equality as the three main objectives, it identifies the land and rural areas as points that need to be rapidly transformed. Some of the other elements analyzed are the expansion of infrastructure, social mobility, security, justice and democracy for achieving peace and, lastly, good governance (Plan Nacional de Desarrollo: Todos por un nuevo país, 2015).

Although not fully visible or tangible, the wealth of the land is categorized by minerals and it is estimated that there is a coal reserve of approximately 15,500 millions of tons (Plan Nacional de Ordenamiento Minero PNOM, 2014), as of 2007. Colombia is one of the main producers of emeralds, with a production of nine million karats and one million ounces of gold. Other minerals are nickel, silver, natural gas, oil and copper. But of all mineral resources extracted in 2015, coal production was the highest value $65.9 \%$, in contrast to $33.9 \%$ from other minerals ( Política Minera de Colombia: Bases para la minería del futuro, 2016). The value of minerals like emeralds and gold are higher than coal, but the social disruption, environmental impact and commercial interests are equal for all of them.

In contrast to gemstones, coal exploitation is an oxymoron because, while it provides life through energy in other countries, it causes death to local cultures, values and traditions. Moreover, the mining techniques implemented in the extraction of coal, underground and surface, generate a huge environmental impact. Some of the consequences and impacts for underground mining are mitigated due to its lack of exposure to the immediate surroundings, whereas surface mining brings all kinds of pollutions from the use of explosives to the deviation of rivers, overuse of water, and finally, the permanent scarring left on a very large area of the land. These consequences have a longterm influence on communities adjacent to the mines and other mining infrastructure.

The Colombian government grants the legal rights for exploring and exploiting this wealth of land. It is through mining titles that the government controls, allows and prevents mining. The 
[this page] figure 01 the main coal mines in the country. [next page] figure $\mathbf{0 2}$ coal reserves in the country are mostly found along the Eastern Ranges of the Andes . The orange lines represent the waterbodies in the country. The teal circles show the location of coal basins.

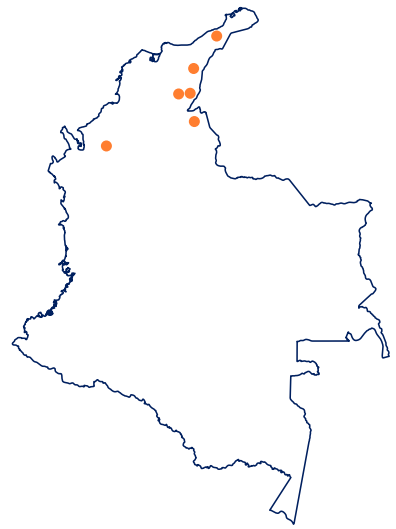

country's wealth extraction is divided by " $29.6 \%$ for construction materials, $19.3 \%$ for coal and $18.8 \%$ for precious metals, $4.9 \%$ for emeralds and 27.4\% for other minerals" (Projected Investment on Mine Development and Expansion Projects in Colombia; 2010 to 2020, 2010). This accounts for approximately 19,000 km2, or 1.7\%, of land being exploited (at different levels and scales). The National Plan for the Development (PND - Plan Nacional de Desarrollo) justifies this use of almost $2 \%$ of the land. Although the percentage might sound irrelevant, the impact does not only occur at that specifically designated area for mining. The infrastructure, tailings, the network of transportation systems, the relocation of rivers and communities, are some of the factors that impact much more of the remaining 98\%, generating a ubiquitous social fabric disruption of rural villages.

The exploitation of land is unavoidable because natural resource potential in Colombia represents a lot of economic prospects. Part of humanity's role is to work with the land, as noted from a biblical perspective, through the role of Adam and Eve in the Garden of Eden. Pope Francis denoted that "God placed man and woman in the garden he had created (cf. Gen 2:15) not only to preserve it ('keep') but also to make it fruitful ('till')" (Francis, 2015). But the challenge lies in doing this responsibly and sustainably, by following an integral ecology. Introduced in Pope Francis' Laudato Si, integral ecology "seeks to avoid the objectification of nature and ... compartmentalization... which is the primary analytical and problem-solving approach to the modern cyclical world-view" (Cooney, 2017). What Colombia is currently going through, as well as other areas rich in natural resources, is using land and nature as vehicles for production, disregarding anything that is inherently attached to the soil, like traditions, socio-cultural values, and legacies. The excessive and violent use of the land also goes for maximizing profit and gaining the most out of exploitation. Adding to this, resource explorations tend to be isolated from other problems that come with it. For example, when looking at the mining industry, socio-cultural and socio-environmental problems lack attention from the industry, governments, and even other locals. Such division, between what it's done to the land and what's done within the context of the land, is what the current Laudato Si seeks to bring attention. An integral ecology is much needed for the development of the rural area regarding opportunities for inhabitants and the usage of the wealth of the land. 


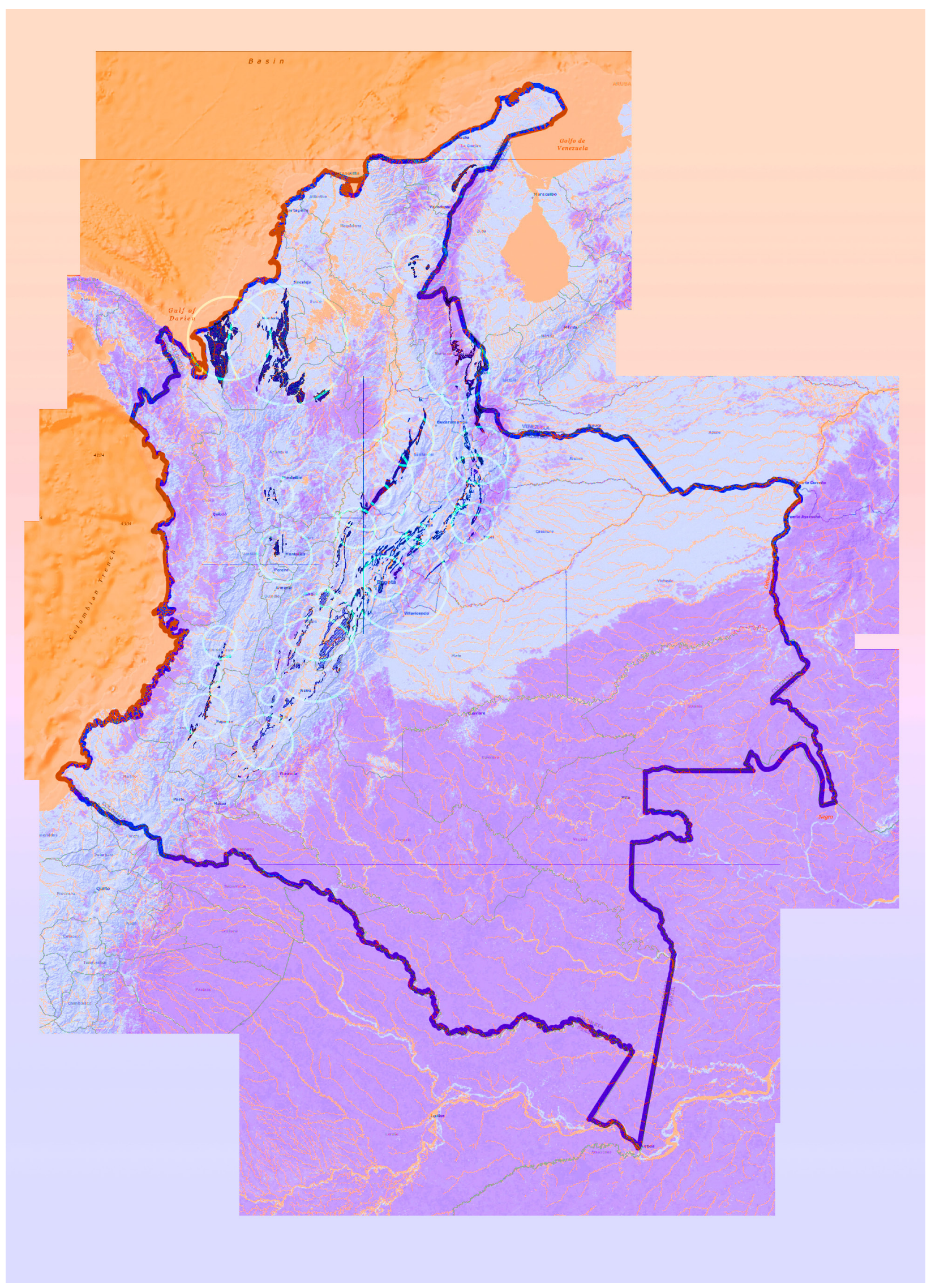




\section{NEO-COLONIALISM VS. POST-COLONIALISM}

Las cosas no son del dueño, sino de quien las encuentra

unknown

Ever since the Age of Discovery, the Americas soil has been seen as a source of wealth, power and domestication. The cultural clash between Spaniards and natives terminated in the mass depletion of lands, extinction of civilizations and rituals, but also the birth of new cultures. In the contemporary context, globalization has established a new system of domestication through free markets, foreign policies and investments. This new neo-colonial setting puts forward the problematic that, after centuries of subjugation, Latin American countries are still being subjected to an undermining of their capability to be independent and strong within the critical socio-economic and socio-political frameworks of today. T.J. Demos' Return to the Postcolony states that "neocolonial signifies the continuation of colonial rule by other means, by political and economic control rather than military occupation" (Demos, 2013), with an emphasis on the economic sector. In contrast, post-colonial, or a condition after colonialization, implies that colonization is not occurring anymore. Since it takes place after something is over, "postcolonial theorists have long noted the tendency of imperial powers to rename, re-map, and rebuild conquered spaces - to pursue projects that literally shift the ground beneath natives' feet" (Obert, 2016). This spatial rearrangement is not only geographical but also physical and psychological. The new borders connect and divide, but mostly divide and disperse people from people, people from nature, and people from their traditional values. Their division, which results in their relocation to new alienating environments, is a paradigm of colonialism being as a tool for re-mapping new spaces. Nevertheless, what it is taking place today is not any different from what happened in the 1490s during exploration leading to exploitation, the over-consumption and extraction of resources and the permanent impact on fragile neo-colonial communities.

Colonization, away from its historical meaning, is used metaphorically here in order to describe the dominance of a superpower over a third world country. In modern times, the role of colonization has been under the control of contemporary imperialism through new economic ideologies. In Critique of Everyday Life, Henri Lefebvre critically saw urbanization and defines colonization as being "used to capture the domination of everyday life by capital and state in the imperial metropole" (Kipfer, 2013). He also "recognizes colonization as a "new' form of alienation" (Kipfer, 2013). Vidler also determines that "the city was identified as the instrument of a systematized and enforced alienation" (Vidler, Agoraphobia: Spatial Estrangement in Georg Simmel and Siegfried Kracauer, 1991). Although his point of view is urban, it still connects to the result of colonization and globalization as vehicles of separation in the rural landscape. The introduction of foreign markets to developing countries clearly shows the withdrawal of a social structure in order to impose a system of global capital and mass generator of goods. For example, in 1991, the open 
market implementation in Colombia was intended to "improve the poverty situation" (Lay, 2003). However, the socio-economic changes between 1988-1995 "recorded some improvements in the urban areas but stagnated in the rural ones, and inequality registered a significant countrywide increase" (Lay, 2003). The widening gap between rich and poor, urban and rural, creates hostility in the socio-cultural setting. In Colombia, with a national population of 50 million, about $20 \%{ }^{1}$ is still rural. The 20-80 discrepancy puts forward the question of how architecture can re-direct the architect's interest from the dense-urban scope to the indispensable rural territory filled with natural resources. This requests a spatial change, from a colonized occupation to a heterotopia, or a newtopia, of change, new demands, and balance. Consequently, it will allow for a revival and restructure of that $20 \%$ within the current framework of neglect and marginalization.

Colonization does not only bring control and economic affairs to the rural areas, but it also divides and presents a blunter society. Rosa Luxemburg determined that this socio-economic breach to be the result of "capital accumulation depends on the destruction of pre-capitalist formations and 'an inverted world' of 'misery', 'permanent insecurity' and 'unbearable labour'” (Kipfer, 2013). Furthermore, Lefebvre developed his argument against capitalism through a critique of the everyday life and the organization of space by stating that this economic system has full control of space (agricultural, civic, mountains, etc.). A Social Space, for Lefebvre, "it subsumes things produced, and encompasses ... interrelationships in their coexistence and simultaneity” (Lafebvre, 1991).

In developing countries, the neo takes a defining role in shaping the socio-economic fragility of the system. Neoliberalism becomes a synonym of neocolonialism. These new depictions of power are intended to bring economic opportunities to the country and population as a whole. However, one of the main problems is the lack of control over international companies as well as the lack of protection to local economies. This contradiction could be interpreted within the framework of Speculative Realism, which "attempts to move...beyond the stale oppositions of the postmodern era between a reality-denying constructivism and a naïve objectivist realism" (Demos, 2013). The selective choices of facts, regarding the use and condition of the rural landscape, result in a misinterpreted analysis, understanding, and view of reality. This, then, results in a biased and misconceived certainty. The problem evolves toward the application of neo-colonization in developing countries, where poor politics and drastic social class distinctions shape the setting of the economy. For instance, when corporations begin explorations for natural resources, their attention is only on the product rather than the context. Although they declare their intentions regarding social responsibility through life cycle assessment and environmental protection, this is usually a pretext in order to facilitate the exploration phase and acquisition of mining titles, neglecting the full implementation of responsible strategies. 


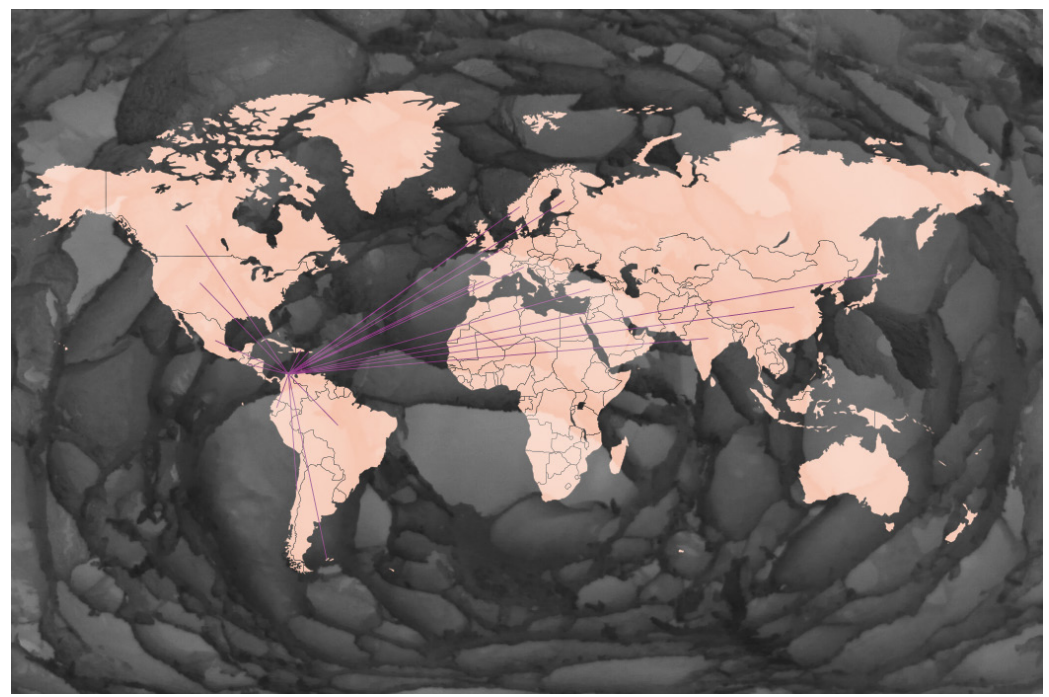

Colombia is particularly susceptible to the lack of overview from corporations and the Government. The overall context in the country is a constant struggle between internally displaced people, political corruption, internal conflict and poor management of natural resources. The root of this problem is not only about political differences of ideologies (between liberals, conservatives and other parties), but rather, about land ownership and tenure. Regardless of the type of problem, the rural population in the country, which now constitutes about $20 \%$ of the almost 50 million, faces a lot of stagnation in agricultural development for progress from the State. This is reflected in the poor quality and lack of facilities for education, recreation and health, little-to-no technologies for the betterment of agriculture, poor infrastructure and accessibility to roads. As a consequence, the prospect of international investment can create new opportunities and hopes for the people that they might not find coming from the government. This demonstrates how Colombia is still subjugated to neo-colonialism through globalization. 
If the earth is experienced as the mother, the cave must surely ... be the womb: the place in the body of the mother from which we enter the world ... the place to which we forever wish to return.

\section{Herbert Bangs}

The creation of the official landscape over a vernacular landscape $e^{2}$ has been palpable since the Age of Discovery. During this period, empires reached lands that were rich in natural resources, especially precious metals. Nowadays, exploitation of land occurs for fueling our basic needs, from heating to construction and even decoration. Before the intrusion of the land occurs, exploration studies investigate for prospect locations with valuable natural resources, which will allow for exploitation through the development of roads, access points to the mine and ports, and the demarcation of location points of deposits. But besides the outcome of mining (I.e exploitation), a concern always grows on locals who use the land: the fear of relocation, resettlement, and/or the permanent environmental aftermath in their rural context. Even though the Mining Ministry grants only one mining project out of 100 prospects (Mitos y realidades, n.d.), the impacts are still longlasting for the environment and the social values.

The mining methods, underground and surface, are conducted depending on the location of the mineral in relation to the ground level. Underground mining consists of a shaft, drift or slope mine penetrating the soil strata to reach the ore. This method is more common in the central, mountainous regions of the country where, in addition to generally deeper ore deposits, mining operates at a smaller scale, it is less technologically developed, more artisanal, and its environmental management is far less developed. FFor surface mining, more specifically open-pit, is mostly conducted in the northern regions of Cesar and La Guajira Departments, consists of layers of the soil being removed until the mineral is reached, leaving two mineral residues: one is the rock that does not contain any ore (overburden), and tailings, which are the leftovers from the industrial process. Not only is the impact made on the surface level with the removal of soil, but also generation of pollution from waste, overburden and tailings, and the lack of management, planning and control over those components. However, there are far more concerning residues that corporations, and even the State, seldom account for during the evaluation phase, such as: the overall rupture in the social fabric; health issues of the locals and employees from fly ash and noise pollution; lack of working opportunities for people who previously lived or continued living near mining sites; loss of traditional customs; loss of agricultural skills; the possibility of insurgency as a result of lack of army control; and economic reprimarization (Becerra, 2013).

Governmental regulations are always needed for sustainable development. For instance, in Canada the Mid-Canada Boreal Corridor is the area from east to west that houses $75 \%$ of the Aboriginal population, as well as $75 \%$ of minerals and natural resources. This strategic location could generate jobs, increase in the economy, and develop housing and infrastructure for members of the community and industry. The further expansion of the corridor has to happen "through

${ }^{2}$ For Robert Nixon an official landscape is referred as the land used by anyone other than the locals in order to gain something from it. A vernacular landscape is shaped by generations and it's an integral part to the 'socioenvironmental dynamics of community' 
effective planning and policy that addresses issues such as aboriginal rights, economic development and resource extraction, environment, infrastructure, housing and social services" (Nostrand, 2016). Similarly to this mindset of expansion, Colombia's interest is through mining seen as a synonym of progress, from the departmental level to the national. The national soil is known for its natural resources and the to-be-explored areas that need a promoter. Most of rural Colombia is like an object with a subject (farmers or peasants, natives or other minorities) that has little to no action over it. The real subject for Colombia's interests are people that make the economy flow in large quantities.

The Government has published a wide variety of reports in which it explains the tactics for exploitation of land. According to the National Plan of Mining Regulation (Plan Nacional de Ordenamiento minero - PNOM), coal basins are distributed along the central and northern regions of the country, where $10 \%$ of coal production is in the former and it is used locally. The other $90 \%$ is produced in the northern regions and aimed for exportation, demonstrating that this region is more prompted to social and environmental impacts. In this northern region, 55\% is found in the Department of La Guajira, in the municipalities of Albania, Barrancas and Hatonuevo, and 29\% in the Department of Cesar, in the areas of La Jagua de Ibirico, Chiriguaná, El Paso and Becerril. These two regions are known for being among of the poorest in the country, and where the presence of insurgents is perceptible.

In The Production of Space, Henri Lefebvre establishes relationships between production and product, particularly in the context of nature. Lefebvre states that "nature creates and does not produce; it provides resources for a creative and productive activity on the part of social humanity; but it supplies only use value, and every use value - that is to say, any product inasmuch as it is not exchangeable either returns to nature or serves as a natural good. The earth and nature cannot, of course, be divorced from each other" (Lafebvre, 1991). Essentially, man-made intervention fabricates artefacts and during the process, the earth and nature separate. To demonstrate this, mining creates separation of the people from the land. But nature, is not only perceived as the inherent qualities of something, or as in products from the earth, but can be analyzed as a "principle of life" (Etymonline). By detaching two elements that constitute a symbiosis, it conceives a society alienated from its own life.

Although the mining industry is seen as a fast generator of progress and economy, its side effects are permanent. And even more as in the case of open-pit mining where, in order to extract the mineral, it has to be dug from a depth of 300-350 meters. On the Laudato Si, Pope Francis writes that "after ceasing their activity and withdrawing, they leave behind great human and environmental liabilities such as unemployment, abandoned towns, the depletion of natural reserves, deforestation, the impoverishment of agriculture and local stock breeding, open pits, riven hills, polluted rivers and a handful of social works which are no longer sustainable" (Francis, 2015). These drawbacks bring stagnation to any culture and country. But the problem with developing countries, like Colombia, is that the intended progress proposed by the State becomes temporary and the heyday of the economy is cut short once operations stop. Adding to this, corruption leads to more social and economic regression. 

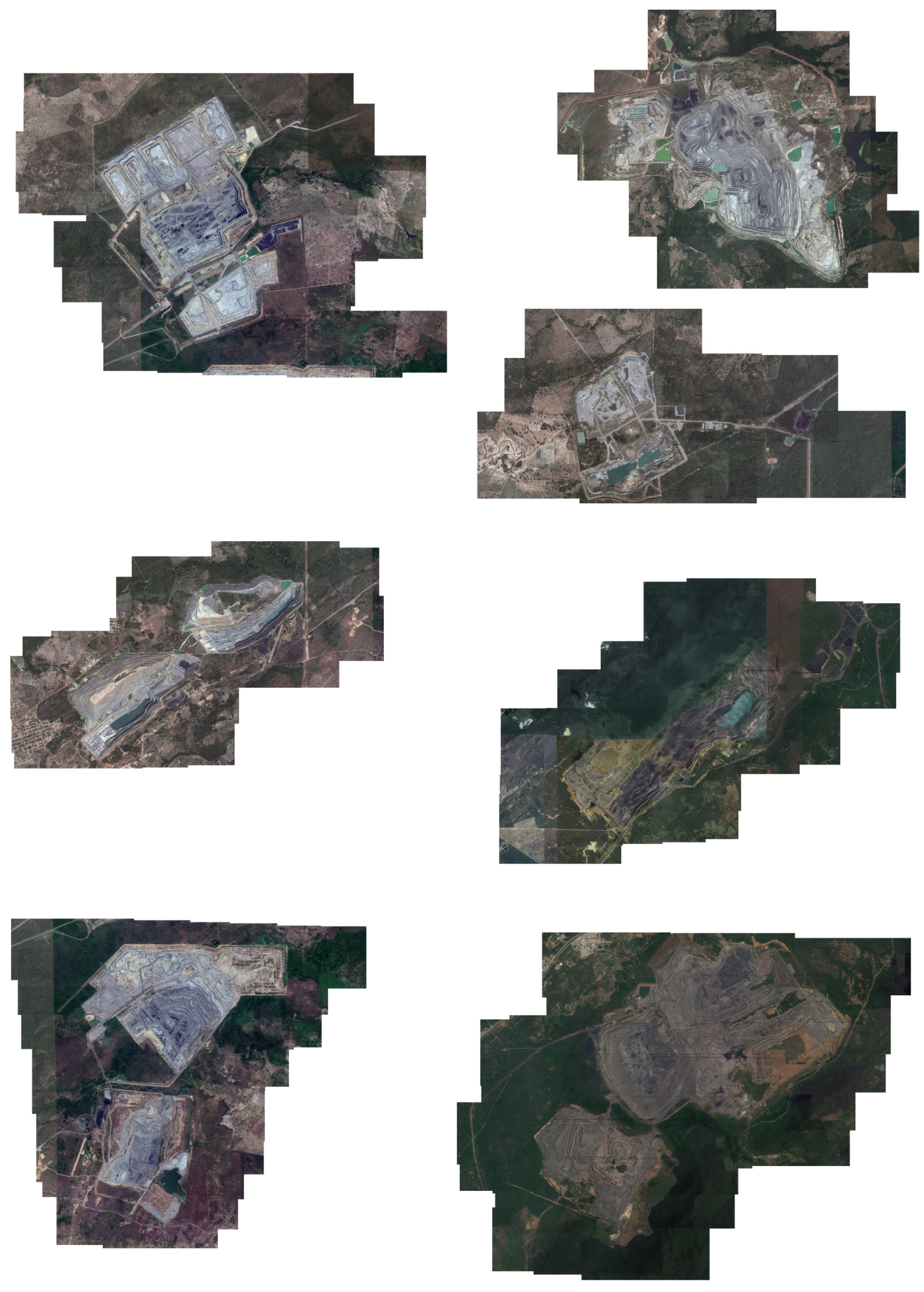


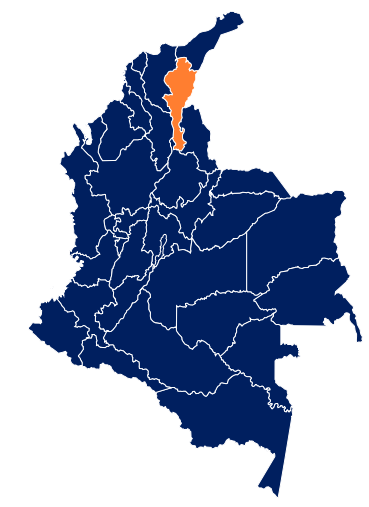

This department is known for being an area lacking a strong social presence protecting locals, and for being in a zone of medium to high internal conflict between the government and guerrilla groups. There have been reports of connections between the paramilitary and Drummond company, one the most influential, yet highly criticized American companies operating in the municipality of La Jagua de Ibirico. According to several reports, the company has been hiring subversives for invigilating the railway tracks from the mine to the port (Lievano, El legado de la Drummond, 2013), for controlling guerrilla activities towards the company, and for silencing social, union, and church leaders. The fact that a connection exists between Drummond and the rebels subjects the government to criticism for its lack of control, security and social regulation in this area, benefiting the company over the locals. Between 1996-2006, the region of Cesar, especially in the mining zones, were targets of violence and terror under the command of the paramilitary group of Juan Andres Alvarez Front (JAA): 499 civilians were part of massacres, at least 2,600 targeted killings (from the year Drummond began operations in 1985 to 2006), 2,089 people were forcedly disappeared, and 105,165 people were forcedly displaced between 2000-2006 (Moor \& Sandt, 2014).

In spite of the internal conflict and violence, the area of Cesar stocks $30 \%$ of the national coal basins, and are distributed in the municipalities of La Loma, el Descanso, Rincon Hondo, Similoa y Cerrolargo, Mina la Francia and Mina el Hatillo (Colombia Natural Resources operated under Murray Energy Corp. 2015, Goldman Sachs, previously owned by Coalcorp Mining Inc.), Mina Calenturitas and Mina la Jagua (Glencore, operated by Prodeco S.A) Mina Pribbenow and Mina el Descanco (Drummond). Within a radius of approximately $20 \mathrm{~km}$, there are seven open pit mines owned by three different companies. The land and locals enter a bureaucratic spectrum, and even a limbo, over which the company takes responsibility. This 'no man's land' is driven by whatever is in the subsurface.

International companies often overlook human rights violations, the long history of violence and vulnerability of campesinos, in order to impose themselves as vehicles of progress. Moreover, land tenure and ownership, contested between the three international companies, locals, farmers and the State, become 'no man's land'. 
[opposite page] figure $\mathbf{0 5}$ location of Cesar in Colombia.

[this page] figure 06 feature in Cesar near the mines - some of the main features near the mines in Cesar is the $193 \mathrm{~km}$ long railway that trasnports the coal to Cienega's port.

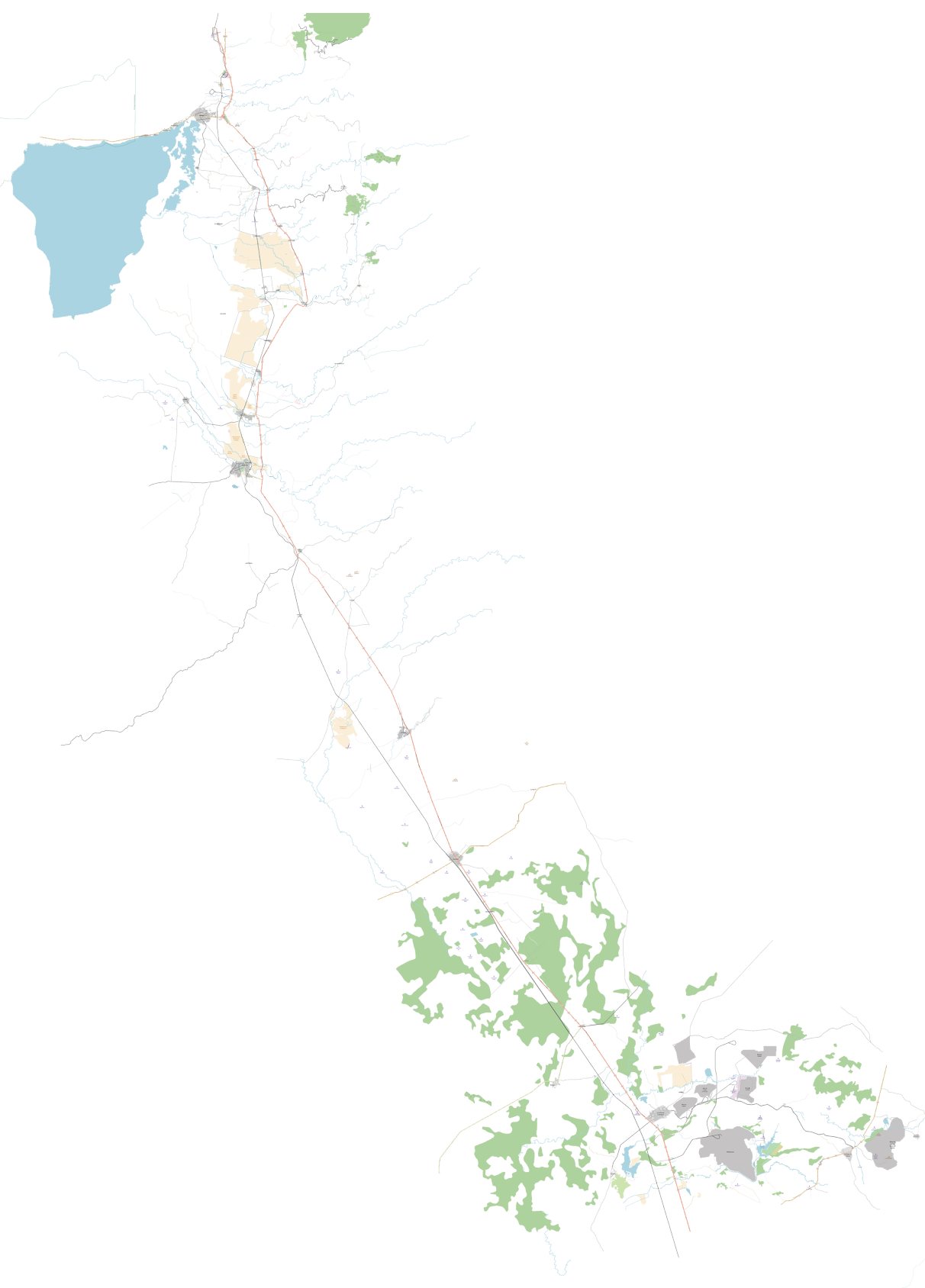




\section{La Guajira}

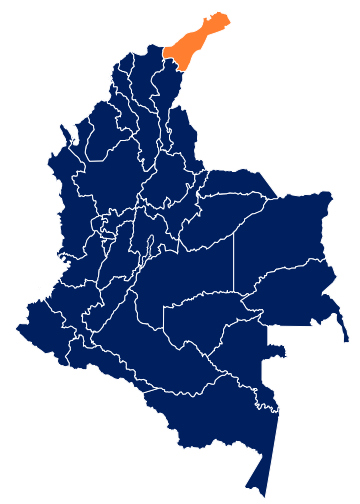

As one of the most arid regions in the country, as well as being the home of the largest indigenous community in the country, La Guajira, with a population of 902,386, is recognized as one of the major mining departments. Cerrejon, the number one coal producer in the country, is located in the municipalities of Albania, Barrancas and Hatonuevo, and has become a hub for employment opportunities. One of the largest open-pit mines in the world, el Cerrejon occupies an area of approximately $500 \mathrm{~km}^{2}$. Since its operations started in the 1970s, the Cerrejon has been growing and expanding. But, the municipalities where this is located have accounted for a lot of environmental issues such as fly ash, deforestation, drying up of rivers due to relocations, water pollution, and the reduction of land for agriculture (Plan de Ordenamiento de la cuenca del Rio Rancheria, 2011). Additionally, the residual and tailing disposal is located at the mine, within the area of concession assigned by the government. In a way, this prevents the operations from expanding to other areas and affecting other communities.

People from different areas of the country, as well as the department, desperately seek employment opportunities at the mine. According to a report by the Planning of Mining Energy, at least $3.3 \%$ of the population work in the mining industry, whilst coal represents at least $92 \%$ of the mining industry, followed by salt with $5 \%$ (Informe departamental minero La Guajira). The company, which is owned by three international companies, offers employment for almost 15,000 as of 2017 (Informe departamental minero La Guajira). However, the department has one of the largest index of poverty levels; compared to the $26.9 \%$ of the national poverty level, $52.6 \%$ live in poverty in this area (Pobreza Monetaria La Guajira Año 2017, 2018).

La Guajira is divided into 15 municipalities. Its proximity to Venezuela makes the department a hot spot for contraband of gasoline and goods. For instance, the town Cuestecitas, located $55 \mathrm{~km}$ from Guajira's commercial hub of Maicao, and $196 \mathrm{~km}$ from Maracaibo in Venezuela, is popularly known as the firework town. The town has been able to support itself through trafficking gasoline smuggled from Venezuela ever since the promises from the Cerrejon and the government, failed two decades ago (Torres, 2016). Driving on the Rioacha - Cuestecitas road, it is very obvious that every person in the town deals with gasoline and, block after block, the re-bottled Coca-Cola 1-lt bottles 
are now filled with gasoline. Police and indigenous communities in the nearby areas are aware of this, but the business is so big and many people depend on this, that instead of foreclosing and establishing penalty fees, both groups opt for 'charging a special fee' (Wills, 2017).

This is one of the regions in the country that has a strong cultural legacy at the national level. The Wayuu community, one of the largest indigenous ethnicities in the country, is structured in a way that women are head of the families and clans. They are seen as the embodiment of 'Mother Nature', or Mma in wayuunaiki, as a source of life(nature, through providing everything humans need and women, by giving birth and expanding the Wayuu culture) (Plan salvaguarda Wayuu Zona sur de la Guajira , 2014). Moreover, women are also in charge of taking care of any deceased member and organizing the burial (Pueblo Wayuu). One of the most characteristic activities that women have taken is the craftsmanship role of weaving accessories, like bags and hammocks. The vivid colours and unique patterns are a response to the Discovery Age, Christian missionaries, their daily life and their views of the cosmos (La mochila Wayúu, parte de la tradición de Colombia, 2014). The arrival of the Spaniards introduced them to fibers that had vibrant colours; at the beginning of the 20th century, nuns aided the communities with crafting techniques that would facilitate weaving; and the patterns, or Kaanás, follow views of the stars, genitals of donkeys, eye fish, cow's trips, and even the roof's rebar. The bags, which take almost 25 days to be made, are only done by women, and each bag represents their own character, and the kind of women they are (Así se hace una Mochila Wayuu, 2013).

Unfortunately, women have been victims solely because they are women, leaders and advocates for the protection of their culture. In April 18-20 2004, the paramilitary group of Frente Contrainsurgencia Wayuu (Wayuu Counterinsurgency Front) arrived at the small village of Portete Bay, an area near Puerto Bolivar, Cerrejon's port. They left six dead people (4 were women) and several displaced communities. Not only they were killed, but also raped and tortured. The main reason for such an attack was to establish and impose patriarchal values where women had previously held the most important role in society (Sanchez \& Obregon, 2010).

This region has a long history of traditions and a rich culture, where there is an important value given to women, craftsmanship, and nature. Although this region has been subjected to mining and conflict, the locals have been able to withstand these challenges through their beliefs and the practice of their customs. 


\section{GENEALOGY \\ the intervention and role of each of the players on the land}

Genealogies are intended to trace back the history of generations, becoming a source for understanding the current context. Each member of a genealogy becomes essential for its progress and evolution; without a previous one, there cannot be a next one. It also becomes a proof of ongoing relationships guided by combinations, unions and connections, leading to continuous expansion and ramifications of networks. Starting with the coalition of two, genealogies depend on symbiosis in order to guarantee its growth. Otherwise, an inevitable dissolution will happen.

Genealogy complexity results from odd alliances, just like Colombia's rural intervenors.

The current condition in rural Colombia has been the result of years of interest and neglect from different entities, governments, and people. Each one approaches the rural areas aiming for a particular purpose, none being worse or better than the other: corporations, both local and international, see the monetization of fertile soil as a vehicle for production; the local government supports and promotes such activities because it means that revenues and royalties are going to be produced; locals, including farmers, peasants, and anyone living outside urban districts, use the land for sustaining production of crops such as palm oil, coffee beans, corn rice to raising cattle, working and living. Although some aspects of artisanal agriculture are not better than industrialized, it does mean that locals have developed a system, method and/or technique that responds to their needs, even if it comes at an environmental cost.

This genealogy focuses on the implications and interventions of each member in the vicinity of the coal mines in the northern region of Colombia, located in the areas of La Guajira and Cesar. These two areas are known for having the largest deposits of coal in the country, and therefore, for being the largest exporters of the mineral, which places them in the center of international interest. The junction of a commodity and monetarization of it creates a blurred line of relationships between the new tenants (corporations), that were allowed by the government, neglecting the existing tenants (locals). Although the government has been able to establish institutions, regulations, and programs for protecting the environment and the campesinos, the financial agreement with corporations has outweighed any proposal for executing such plans. The church plays an invisible role in the sense of being an entity that establishes moral and spiritual values. Considering all these four members, it will be determined that the economic thrust will be on top of everything and everyone else has to concede for the national interest; the most affected ones are always the least fortunate. In the end, mining wins and rules. 


\section{Corporations}

corporacioun: persons united in a body for some purpose.

Our current economic system has been shaped by and for corporations, both national and international, as entities that move economies, open opportunities and bring innovation. However, as the system is designed, corporate participation ends up primarily benefiting the ' $1 \%$ ', thus bringing a whole new range of socio-economic problems. In the particular case of Colombia, international corporations acting and exerting control over Latin American soil, not only become a symbol of neo-colonialism but also a representation of monopolization, globalization and power. The weakness of Latin American governments is that they prioritize any international investments, but they provide very loose parameters and regulations. Another fault is the handover of nationalized companies to multinationals, usually encouraged by free trade agreements. These agreements open new opportunities for multinationals to accelerate the progress of developing and third world countries through improved industries. Regardless of economic agreements with the State, the industrialization of the rural areas still needs to undergo a process of approval from the population (I.e popular consultation), and tighter regulations from the State. These are ensured through fines, parameters, open communication, establishing a connection with communities and regulating working conditions. The overall objective is to encourage a sustainable and responsible way to utilize the land, in which locals feel safe and protected by corporations and the government.

The history of multinationals exerting some control on Colombian soil has been long and significant; one of the first multinationals that caused major change in rural Colombia was the American corporation United Fruit Company, now Chiquita Brands. The company was confronted by the employees for poor working conditions, and unfair pay at the banana plantations. This led to a strike in the $1920 \mathrm{~s}$, which ended in government intervention now known as Masacre de las Bananeras or the Banana massacre. This event demonstrates how both the government and company responded to the strike in a violent way, endangering the locals, who were already in neglect by the company. Although this event does not link to the coal and/or mining industry, it does exemplify the support and aid from local governments to multinationals, and the lack of assistance to the national labour.

Mining companies approach the expansion of projects through documentation and marketing of sustainability and by publicly announcing and reporting ways in which they will respond to and/or support locals. For instance, the mines in the northern region outline guidelines and plans for resettlement of communities, health assistance to both workers and nearby towns, education programs, the strengthening of local skill, among others. Information on these plans are openly accessible through their websites, but, in the case of Cerrejon's use of social media, it provides an understanding of responsible social and working practices only at a superficial level. The 
availability of these policies is mostly a public relations exercise aimed at closing the gap between the corporation and the people (anyone outside the company) who are dubious regarding the fairness and justice of these companies.

The entitlement of multiple countries over Colombian soil is depicted in mining rights and titles. At a national level, 90\% of mining rights are under Colombian companies, and 10\% (1000 titles) are run by multinationals. However, the coal mines in these regions, which started off being operated by Colombian companies, eventually were sold/bought by international companies. For instance, the largest and oldest operating coal mine is the Cerrejon (La Guajira), operating since 1975, was under the public company CARBOCOL (Carbones de Colombia) and INTERCOR, a subsidiary of Exxon. But in 2000, half of the shares were sold to Anglo American (UK), BHP Billiton Ltd. (Australia) and Glencore (Switzerland), while CARBOCOR still owned the other half. By 2002, the international companies had full ownership of the Cerrejon. In Cesar, Mina Calenturitas, owned by Colombian company Grupo Prodeco, was acquired by Glencore. However, Prodeco still operates the mine. In contrast to the tenure of these local companies, the American company Drummond Ltd. began explorations in 1985 and exploitation in 1995. Additionally, to land ownership, the mining soil is under temporal jurisdiction through concessions, which are granted and negotiated with the government. For instance, Cerrejon signed the contract in 1999 allowing it to operate till 2034. And, as of 2018, the company has the opportunity to extend the operating period. In Prodeco, the concession goes to 2031, and Drummond to 2019, with the possibility of a renewed contract for 30 more years. The concession agreement is estimated to be for at least 30 years, in which three years are dedicated for exploration, three years are for setting up industry and 24 years for exploitation.

Corporations, a group with the same objective, are seen as synonyms of economic progress. However, the loss of nationally owned enterprises is a clear representation of globalization and neocolonialism. This global interaction blurs the boundary between what's good and bad, what can cause harm or provide benefits. From a political eye, globalization is seen as a vehicle for development as local governments seek international investment to have more global recognition and participation; from a social perspective, it brings both opportunities to communities and minorities, by providing support and tactics to sustainably exploit the land. This might have even been seen as actions that the government might have neglected or lacked. Indeed, these companies do bring a lot of positive impacts at a regional and national level through royalties, employment, and growth in GDP. But, what they lack is a transparent and genuine response to the negative impacts of mining and the overall protection of their people. 


\section{Government}

\begin{abstract}
Government is understood as 'le conduire des conduits' - the
'conduct of conducts' - ... government is the form of power 'by

which, in our culture, human beings are made subjects.
\end{abstract}

Michel Foucault

The relationship between the government and all the other actors is a spectrum of different shades; to corporations, the responses are towards the development of the national interest; to the church, the State takes advantage by using its power to gain attention from the believers; to campesinos, promises are constantly made towards improvement and rural security. The relationship between the government and the farmers is mainly manifested in the Agrarian Reforms that are implemented in order to solve the pressing issues in the countryside. However, the scope of the reforms has slightly changed over time, from focusing on land ownership among campesinos to establishing guidelines for rural development. Regardless of the intention, some of the constant problems faced in the countryside are "the high concentration of properties and anti-economic fragmentation, the inefficient use of the soil, high index of rural poverty, inconsistent rural institutionality, destruction of natural resources and lack of participation in rural communities within the system of decisions... trade opening regulations, the weakness of investigation ... and the acquisition of land for illegal crops" (Franco-Cañas \& Ríos-Carmenado, 2011). These demonstrate that there is an unbalance in the development of the rural soil, where investment is encountered with stagnation in terms of living and working conditions, economic opportunities and, more importantly, the illegal use of the land for drugs. Although the problems are persistent, there was a shift of agrarian reforms during the period of 2003-2010. Under the presidency of Alvaro Uribe Velez, the reforms' main goals were "competitiveness, equity, sustainability, multifunctionality and de-centralization" (Franco-Cañas \& Ríos-Carmenado, 2011) as well as economic subsidies to campesinos. These goals become ambitions for both corporations and farmers because it provides a framework for rural development to take place. The question is always whether these are actually achieved and if they ultimately benefit the minorities inhabiting the investment zones.

To further strengthen the history of agrarian reforms in the country, each presidency proposes a National Development Plan in which several industries are addressed for further investmentDuring the presidency of Juan Manuel Santos (2010-2018), the mining sector has been at its peak of expansion because of the National Development Plan proposed for 2014-2018. It focused on the progress achieved and set goals by 2018 for more foreign investment, higher production, and higher royalty and taxation fees, which is based on the amount produced (Becerra, 2013). With the establishment of this plan, in May of 2018 Colombia was able to enter the Committee for Mineral Reserves International Reporting Standards (CRIRSCO). Alongside a few other countries, like Chile, Brazil, Indonesia, Kazakhstan, Mongolia, Russia, South Africa, USA, and Canada, Colombia has to keep up with other countries that have been long recognized as mining countries. According to the president of the National Mining Agency (Agencia Nacional de Mineria) there are a lot of 
[top] figure $\mathbf{0 8}$ the contracts for the mining operations in la Guajira and Cesar. Originally, these mines were run by Colombian companies like Carbocol and Ecocarbon. [bottom] figure 09 the role of the government is semi-transparent.

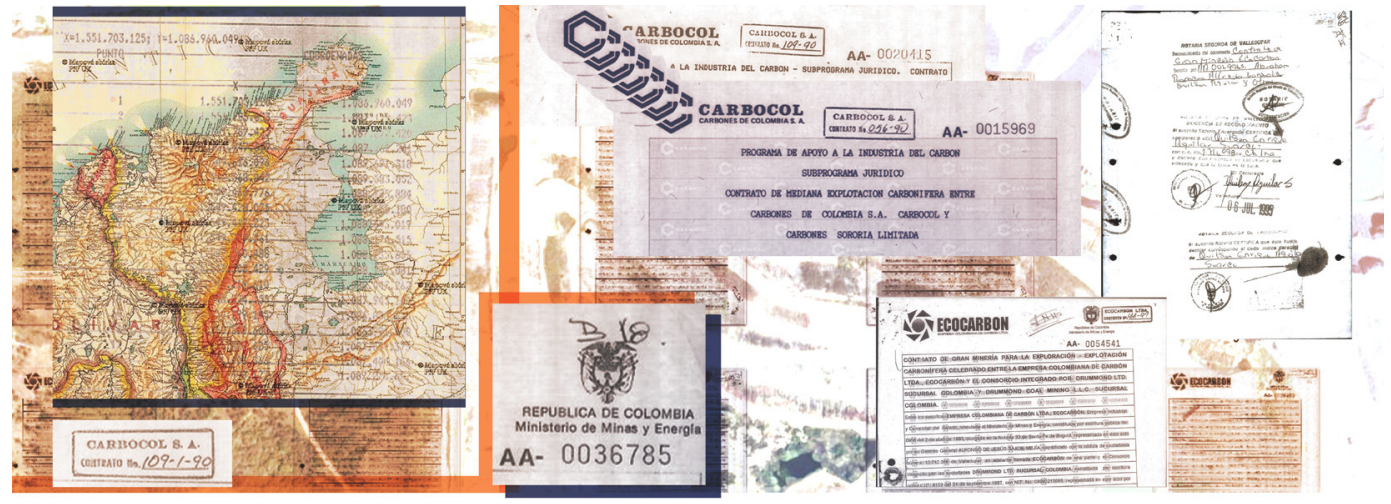

\section{PROGRAHA DE APOYO A LA INDUSTRIA DEL CARBON}
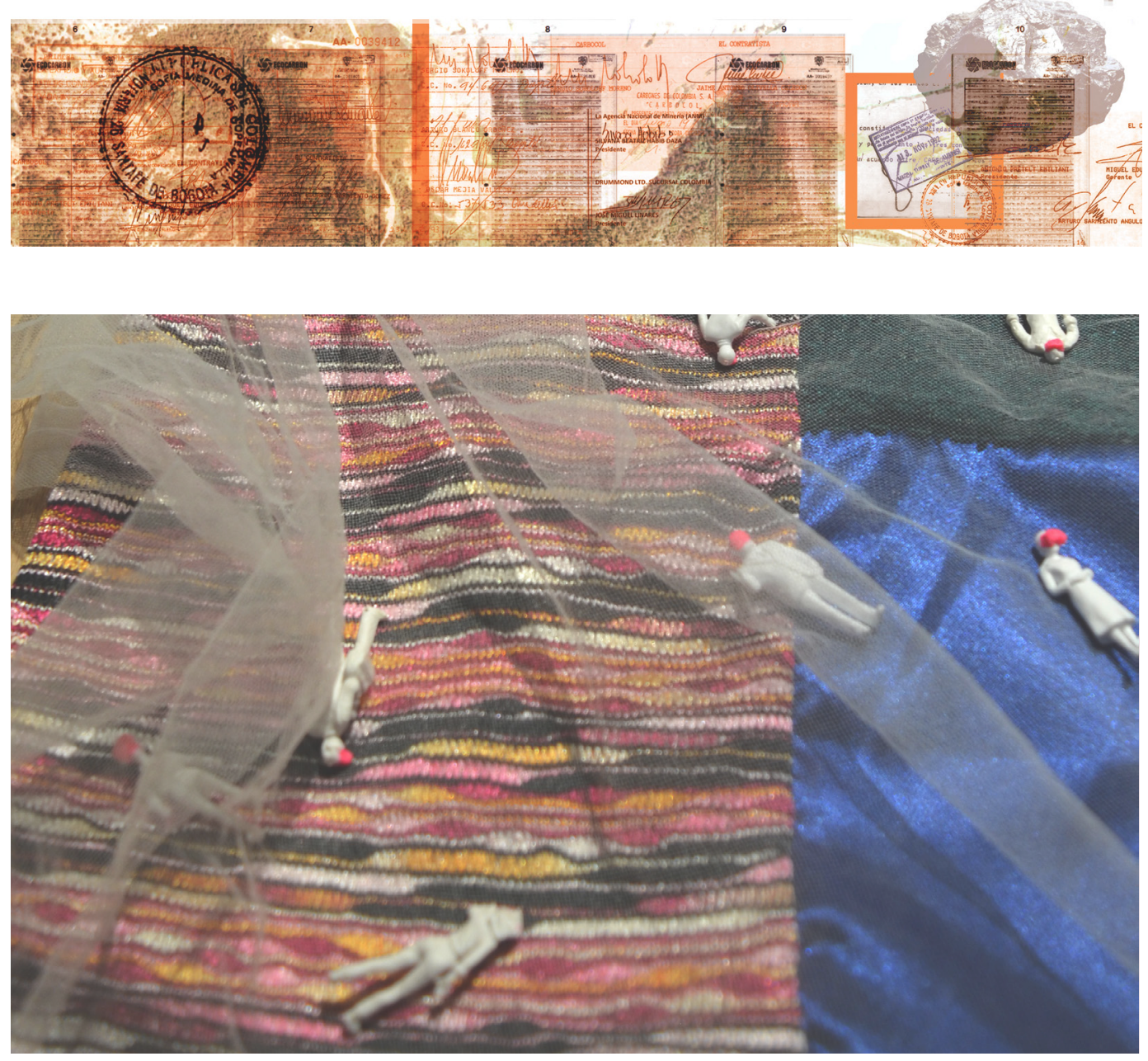
figure 10 monument to coal in Albania, La Guajira, Colombia.

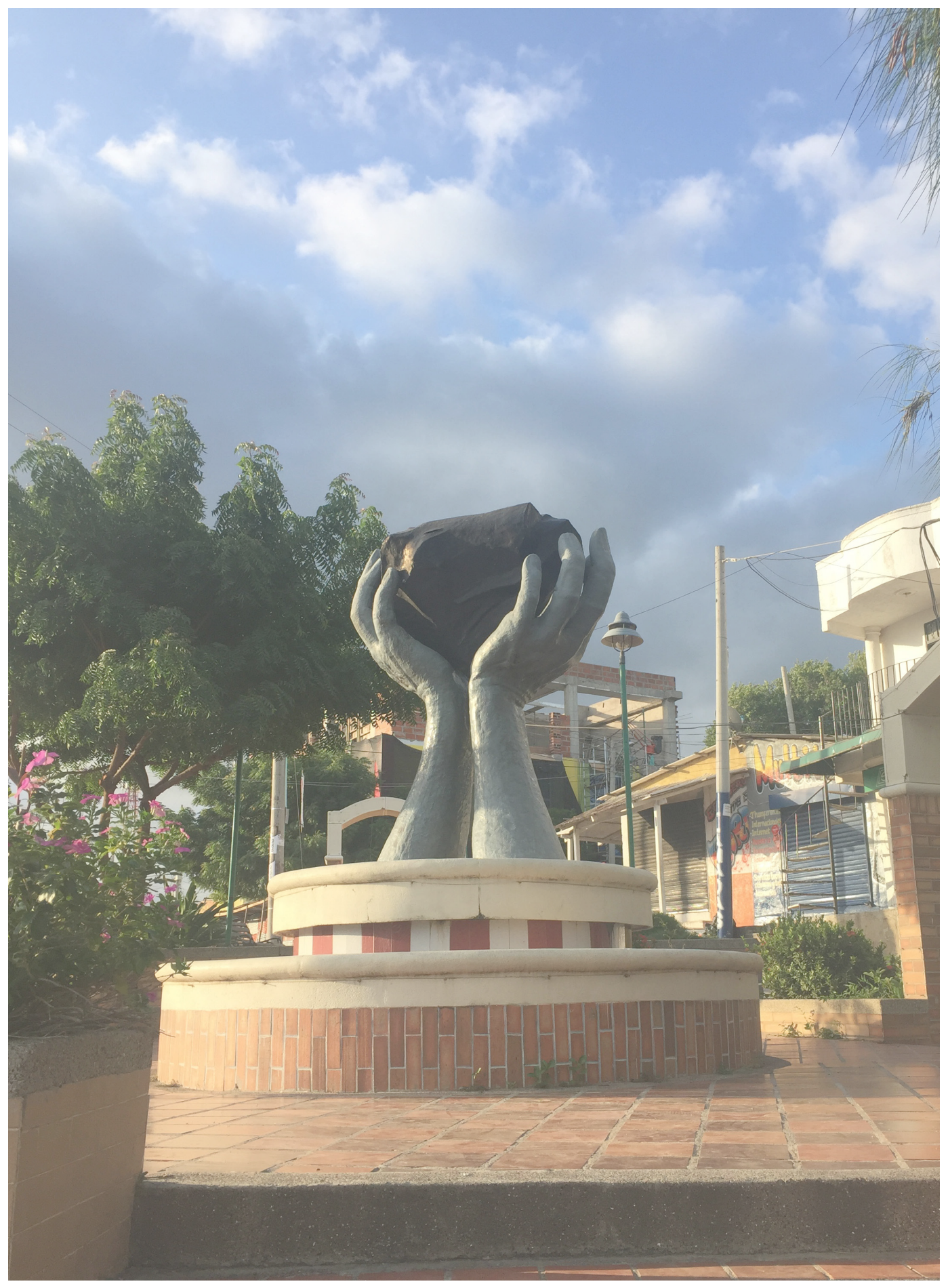


benefits to being part of this committee, such as "valuation of mining properties; competitiveness of concessionaires within the global mining industry; financial leverage and access to risk capital; value creation in the mining industry with social and environmental responsibility; planning of sustainable mining projects" (Colombia enters CRIRSCO , 2018). Although there are some regulatory procedures for mining and the Committee is designed to have more regulatory control over mining activities, it can be seen that the main goal of the State, under pressure from the implied global competition, is to maximize the capitalization of the soil.

In 1991, the State renewed the national constitution, which also brought changes to the mining industry. The most important change was the establishment of the State as the sole owner of the national sub-soil and non-renewable resources (Articulo 332). Any entity who was to exploit for such purposes is forced to pay a regalia, royalty to the government. According to Article 360, royalty is a fee for exploitation of a State-owned non-renewable resource. Before this, mining companies only had to pay taxation over the mineral price assigned by the Ministry of Mining. The royalty system has changed to equally benefit all the departments, by switching from National Royalty Fund (Fondo Nacional de Regalías - FNR), which royalties per department depended on whatever they produced, to General Royalty System (Sistema General de Regalías - SGR). This new system guarantees money to be spent on public projects like new roads, community centers, sporting centers, and any kind of space that would benefit the community in any of the 32 national Departments.

Due to the national interest in bringing international investors, the government has been able to improve and guarantee sustainable development in areas of interest, mostly in the countryside. There are entities that advocate for environmental protection such as ANLA - Autoridad Nacional de Licensias Ambientales - that have put pressure on mining areas. In a particular case, the Cesar mines have been the centre of several socio-environmental problems. According to an article by a local newspaper, ANLA fined four companies that operate the coal mines in the Department of Cesar, in the area of Jagua de Ibirico, because they failed to relicate communities affected by environmental pollution (Multa a minas de carbón del Cesar , 2018). The resettlement of such communities was required by the government, but the companies completely neglected to do it. According to the mining bill number 13 of 2000, it is mandatory for settlements and communities to be relocated if they are within the boundaries of a mining operation. The State provides a very defined area of concession, where the industry is allowed to operate during the time frame of the contract.

Although the government has been able to establish a set of institutions that help with the regulation of responsible mining and the compliance of socio-environmental development, there are many concerning challenges, like making sure companies actually follow the legal parameters. Adding to this, the main problem in the country is corruption and this impedes the appropriate control over mining activities and the full protection to inhabitants in areas where the operations occur. This is the particular case for the mines in Cesar, where the connection between the guerrilla groups, corporations, and even political leaders has led to massacres and the deaths of innocent people. 
Praise be to you, my Lord, through our Sister, Mother Earth, who sustains and governs us, and who produces various fruit with coloured flowers and herbs.

Pope Francis in Laudato Si

There are existing environmental and social crises, especially in Colombia, that rattle God's system. This disruption, as mentioned before, has been achieved by globalization and neo-colonialism, as embodied in mining. This industry's production has caused significant social and environmental consequences. The growing concern of climate change, the abuse of natural resources, and social degradation have been strong reasons for Pope Francis to issue an encyclical called Laudato Si, Latin for praise be to you. Influenced by the Canticle of the Creatures by Saint Francis of Assisi, the encyclical emphasizes, analyzes and discerns the relationship between the Bible, God and Nature, and all the current problems with the environment. The underlying themes are Integral Ecology, the interconnectedness of all elements on earth, and the Common Good, as "the sum of those conditions of social life which allow social groups and their individual members relatively thorough and ready access to their own fulfilment" (Francis, 2015). The Colombian landscape has suffered the degradation of an ecosystem formed by culture, traditions, and understanding between the land and the farmers.

The Roman Catholic church becomes an advocate for the people by clearly pointing out the impact of mining in society, as opposed to government policies, which prioritizes the industry and sells the minerals over the locals' needs. In 2013, the Vatican demanded for mining companies to look beyond the mineral and soil. Instead, they ought to look for "technical and social complexity, moral responsibility, solidarity...spiritual insight and discernment” (Cooney, 2017). Governments and corporations are aware of these problems, but instead of trying to mitigate them, they completely neglect them. According to a study conducted by Pew Research, at least $90 \%$ of Colombian population are Christians, of whom 79\% are Roman Catholics (Religion in Latin America Widespread Change in a Historically Catholic Region, 2014). This demonstrates that any advocacy from the Church, for a more regulated 'industrialization' process, becomes important for the locals' opinions and decisions. This might give them a sense of security and support that might not have been found from anywhere else.

The presence of churches is predetermined in each Colombian town, no matter how large or small. The archetype and tectonics of church facilities do vary from location to location. In the town centre, the churches tend to be big and elaborate. But in the outskirts, like villages or smaller municipalities, the churches are either improvised with scrap material, or use very simple construction techniques. What matters is that believers have a place of worship and the creation of communal space. Unfortunately, violence in the country has had such a strong presence in the rural landscape that these sacred spaces are not immune from any kind of aggression. For instance, the Massacre of Bojaya, in the Department of Choco, led to the death of 100 locals who were seeking refuge in a church; from a confrontation between paramilitaries (AUC) and the guerrillas (FARC) (Tragedia de Bojayá: perdonar o no perdonar, 2016). 


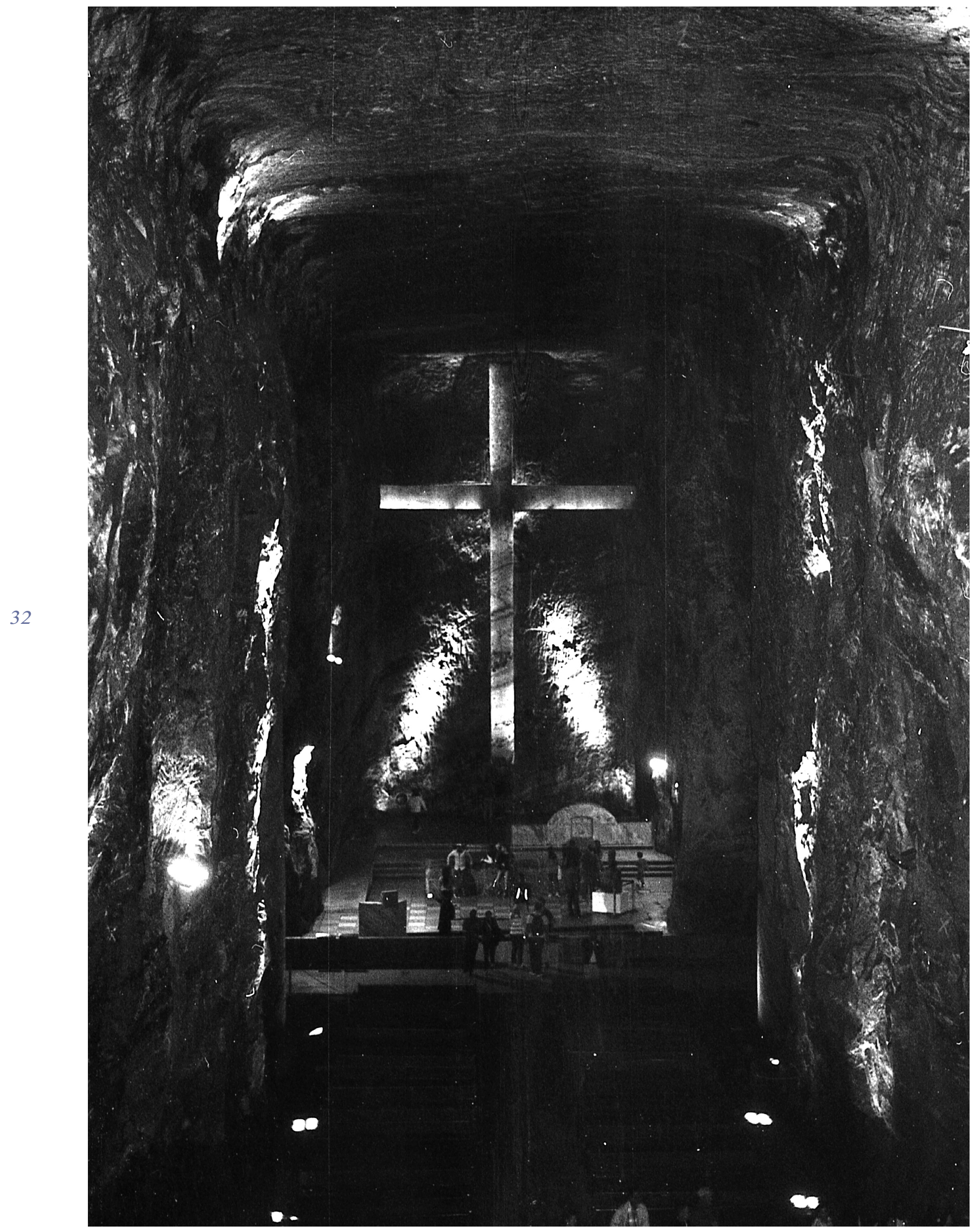


[opposite page] figure 11 salt mine in Zipaquira, Colombia. The salt mine is still operating, but a section has been turned into a pilgrimage site, where the stations of the cross lead to this sublime space underground.

[this page] figure 12 typology of churches (outside and inside) in various regions of the country. As it can be seen, it ranges from simple tectonics to extravagant.
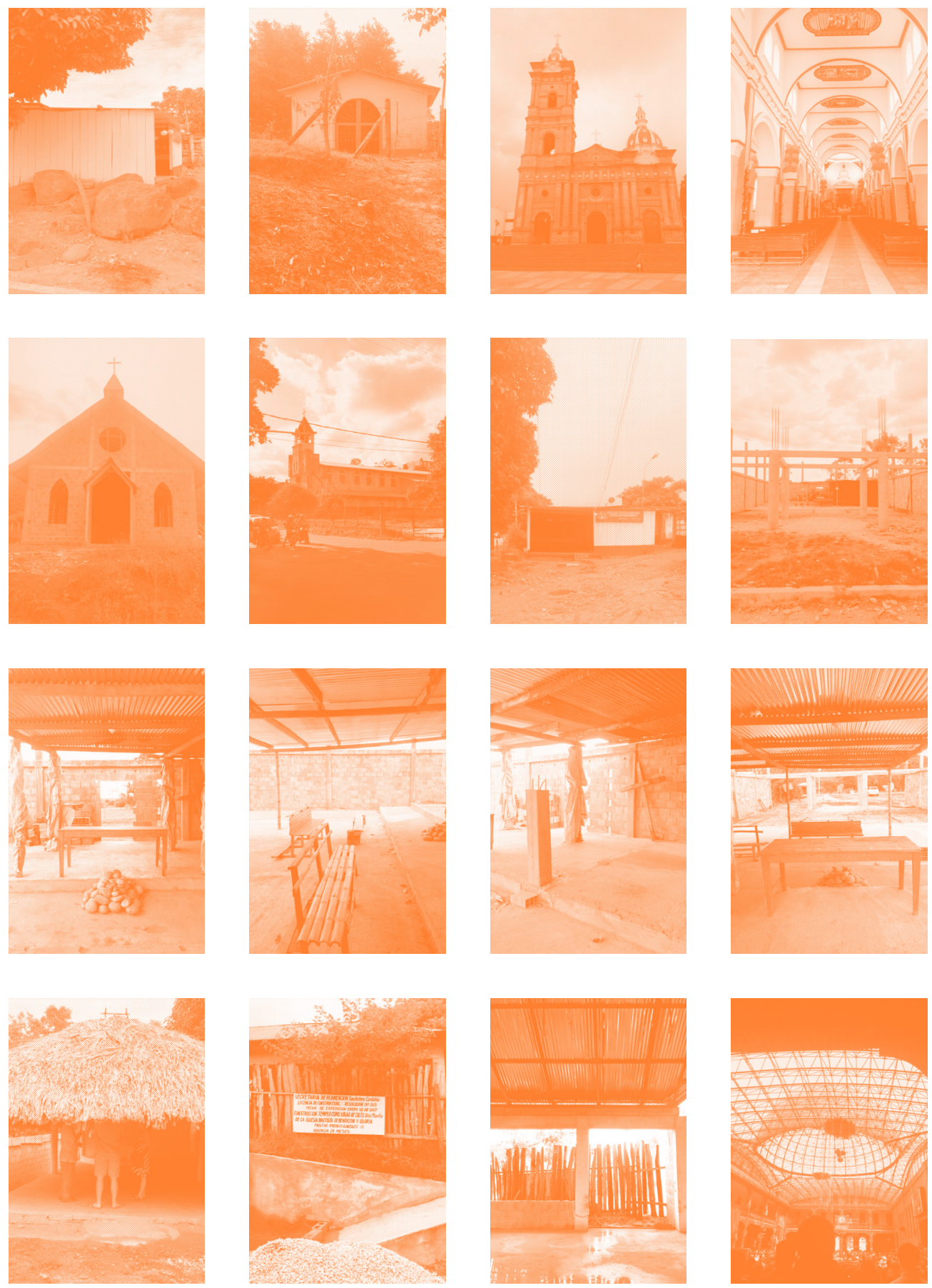
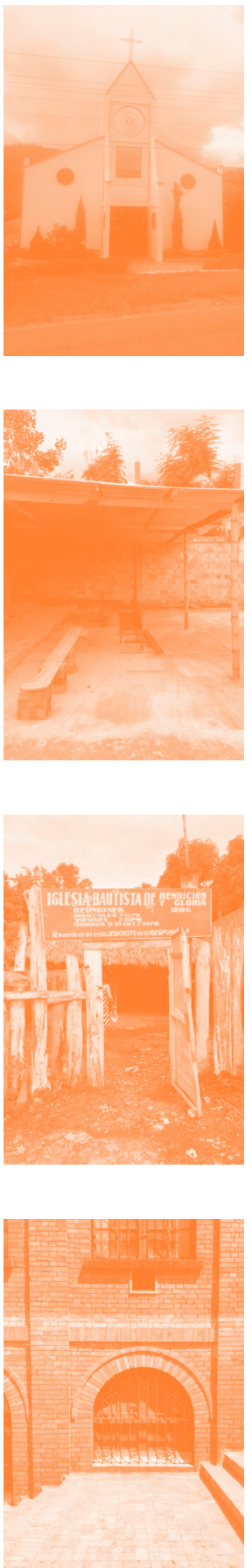


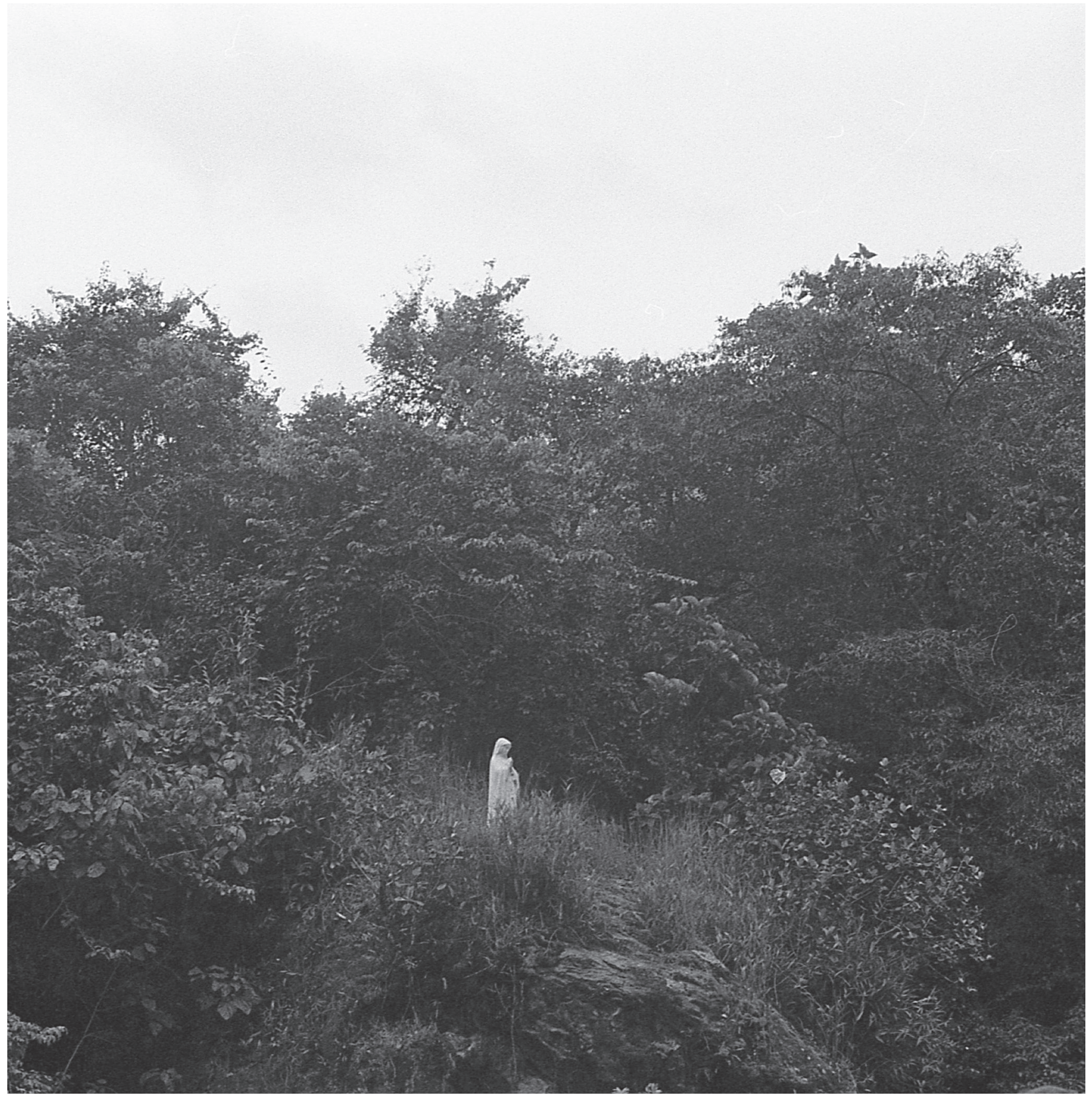

Virgin Mary at the River Magdalena Strait. River Magdalena is the main river in Colombia 


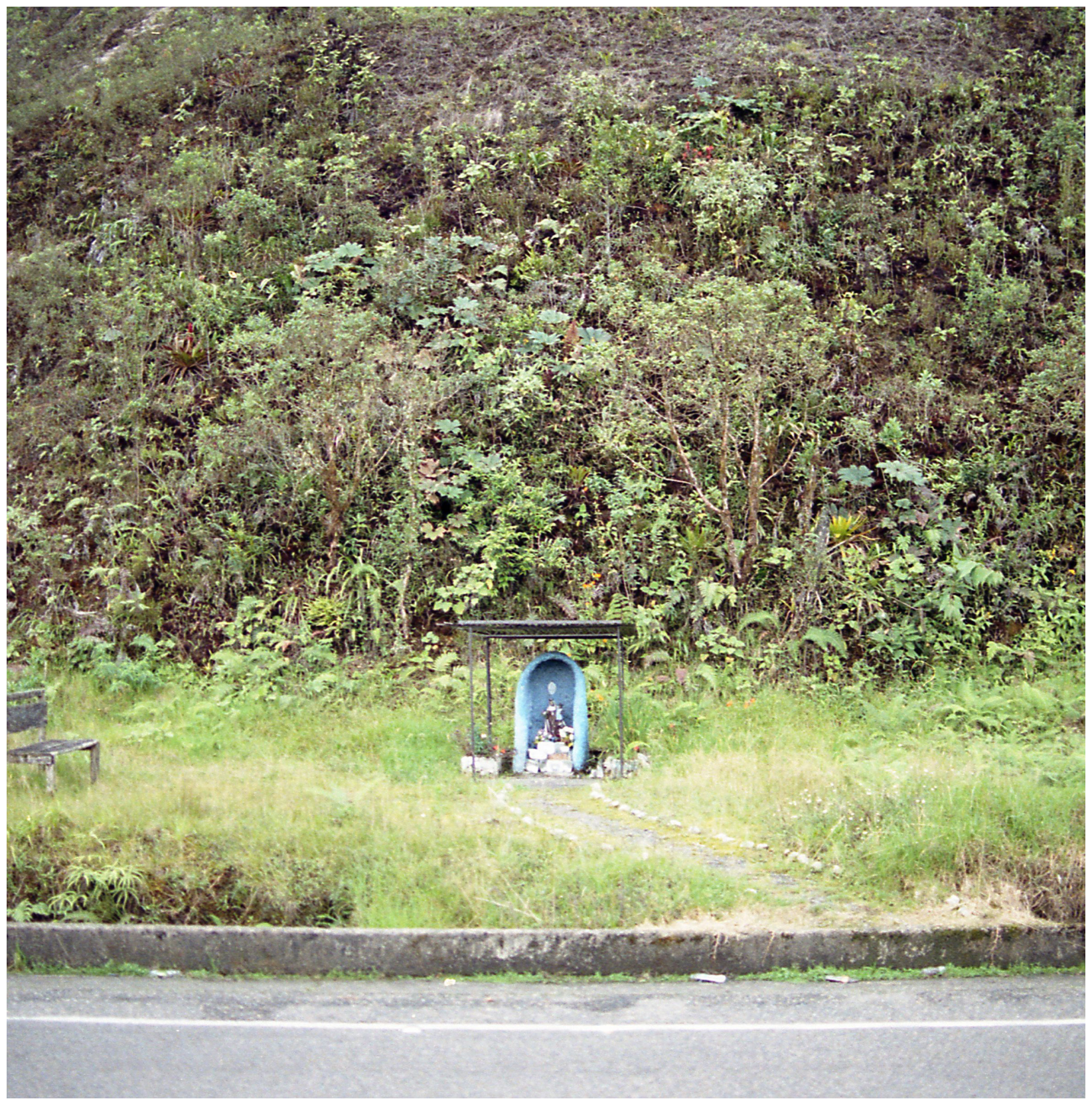

Praying site on the side of the road with a Virgin Mary and Baby Jesus.

These small shrines are often found in areas of high vehicular accidents. 


\section{Locals and Campesinos}

A very polarized landscape characterizes rural life in Colombia. The rural soil is either owned and worked by farmers who have a modest lifestyle, or latifundistas (landowners) with far greater economic advantages, who invest and develop the land with more technologies. In addition, the national territory is also a mixture of land uses, from local-owned crops to international owned, for small scale to large scale cattle raising, and more. However, campesinos and small to mid-scale agricultural areas have been the number one target for violence between the insurgents and the army. It is important to make note that Colombia's major economic force is from agriculture and having such problem leads to a decrease in the national economy. The violence also affects the rural population, which is approximately $11 \mathrm{M}, 23.29 \%$ of the national population. So, due to conflicts, lack of opportunities, and the overall deprivation and hardship in the countryside, campesinos, when challenged with forced displacement, end up migrating toward the urban areas. It is estimated that the urban population growth due to rural emigration is approximately $1.23 \%$ per year, where large cities like Bogota, Medellin and Cali become hubs for their relocation. However, these new settlement zones have many disadvantages and drawbacks as they are usually located on the outskirts of the cities, where mobility, access to good education and the health system are more limited than in the core of the city. However, it is still slightly better than the rural conditions. For instance, there have been cases in which children living in villages, or small towns in the countryside, only attend until elementary school because middle school facilities are not easily accessible. Taking into account the access to opportunities, living, and safety conditions of Colombian farmers, the Santos government has worked on setting up the Victims' Law and Reinstitution of Land (Ley de Victimas y Restitution de Tierras). This law, turned into a program, aims to help with the relocation of victims from forced displacement back to the countryside.

Within the mining programs and soil development, the government outlines in the National Plan of Mining Regulation (Plan Nacional de Ordenamiento Minero - PNOM) that 'natives' traditions and cultures ought to be prioritized, as it is a fundamental right (Plan Nacional de Ordenamiento Minero PNOM, 2014). The Mining Guide outlines the restriction of mining in areas where indigenous and afro-Colombian communities live. Although communities are forced to accept the exploitation of land, there have been cases where people successfully opposed. The most successful case is the open-pit gold mine of Colosa by AngloGold Ashanti (South Africa) in Cajamarca, Tolima. The population of 50,000 inhabitants summoned the government to a general vote in the municipality, asking the inhabitants in the area if AngloGold Ashanti should or should not start operations. Some of the concerns included the tailing storage facility, fee evasion for starting the mining operation, and the protection of natural reserves in the area. Even though the 
[this page] figure 15 the soil and the impact of water from mining.

[next pages] figure 16 relationship between the actors and the open-pit.

[following pages] figure 17 different interposition of the actors with the land.

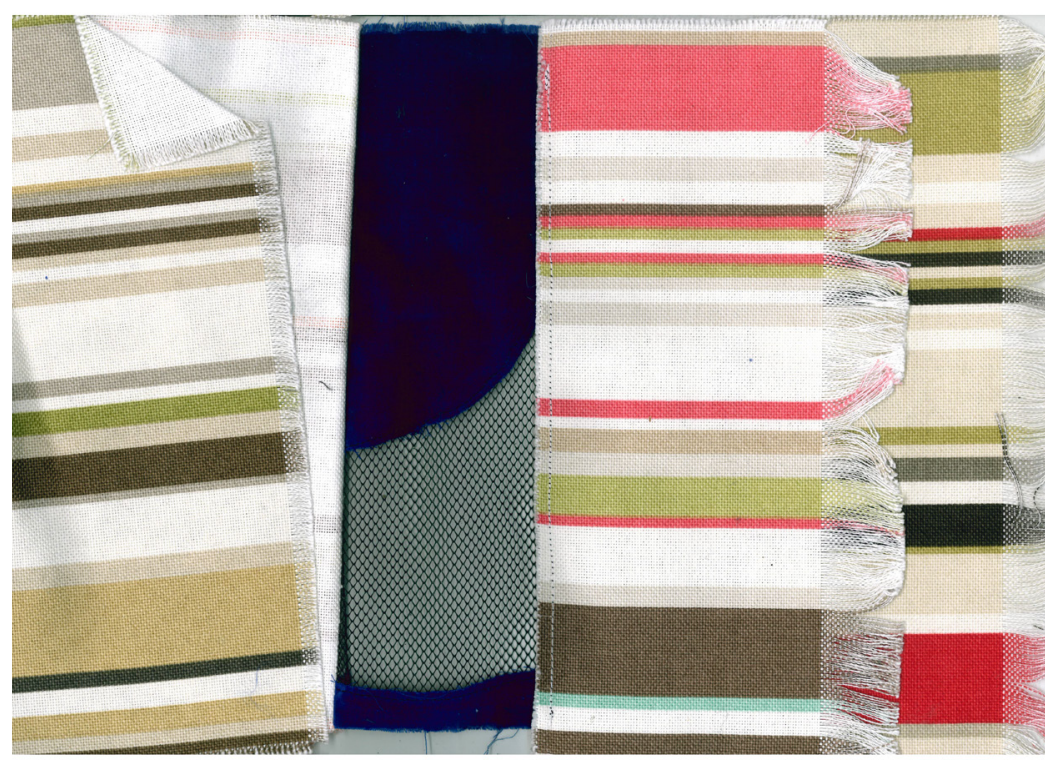

area of the Colosa has one of the largest gold deposits in the country, and the $10^{\text {th }}$ largest in the world, communities and campesinos were more concerned with the environmental impacts and the change of their surroundings (La mina "La Colosa", 2010) than becoming a 'competitive' mining area through the gold exploitation. Locals were aware of the negative impacts that the mine would generate at the immediate context and the whole nation. The process of defying the operations took about two years.

On the other hand, some departments have not been able to halt operations, and the inhabitants become the target between companies, rebellious groups and the government. Companies like Drummond and Prodeco had subsidized paramilitary groups for 'social cleansing' of guerillas, and even for financially assisting the killing of social advocates and trade unionists, who opposed Drummond (Moor \& Sandt, 2014). As a result, most communities ultimately seek a harmonious relationship between the State and the companies through a fair and socially responsible resettlement process, established by the companies, and overseen by the State; employment opportunities; community meetings between industry and nearby towns in order to solve any kind of changes of soil properties and uses, landscape alterations, and studies on the impacts on cultural patrimonies.

The goal for the progress of rural Colombia in inevitable; the wealth of natural resources, and the fertile soil are indispensable for the State's economic global position. The government's responsibility is to strategize how this development will take place and how its outcome will affect campesinos, indigenous communities and other minorities. They, unfortunately, are located in a very contested territory, where they have the least power. 
Left: Corporations

Right: Campesinos

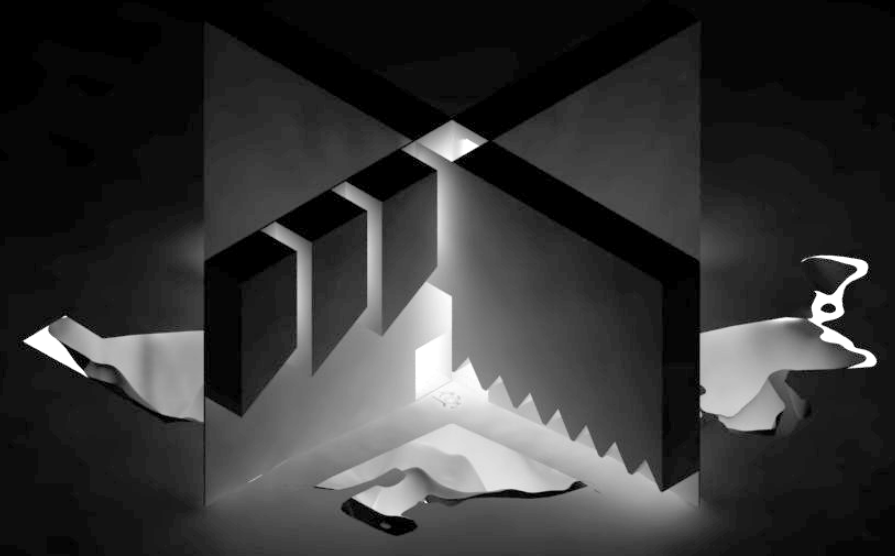

Left: Government

Right: Church

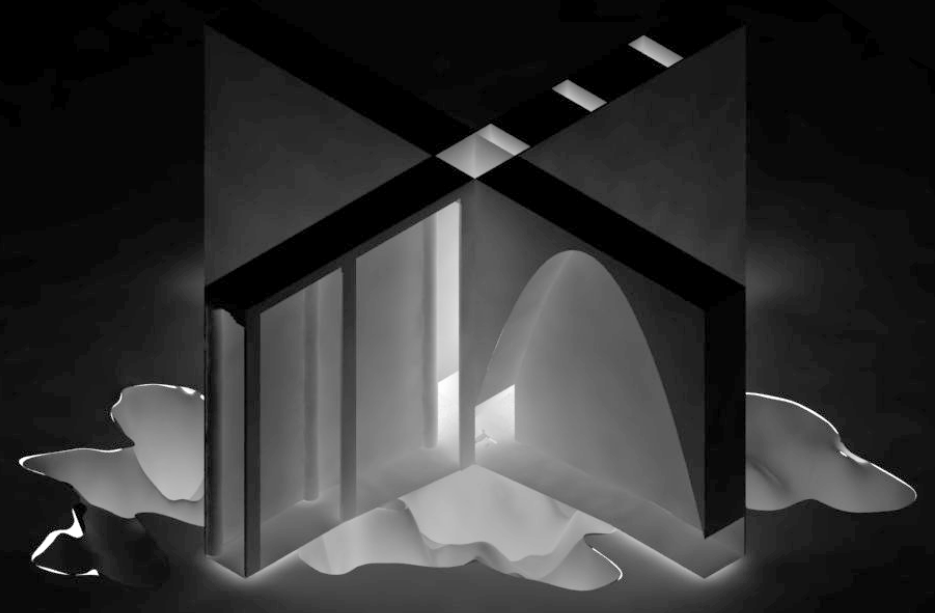


Left: Campesinos

Right: Government

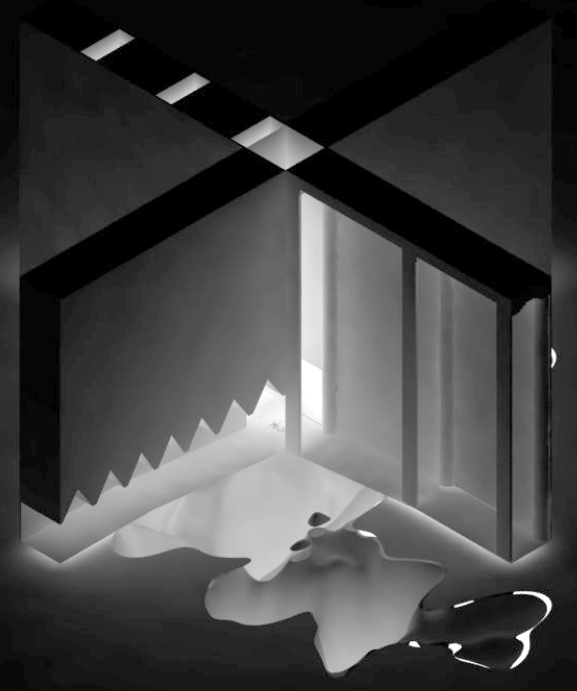

Left: Church

Right: Corporations

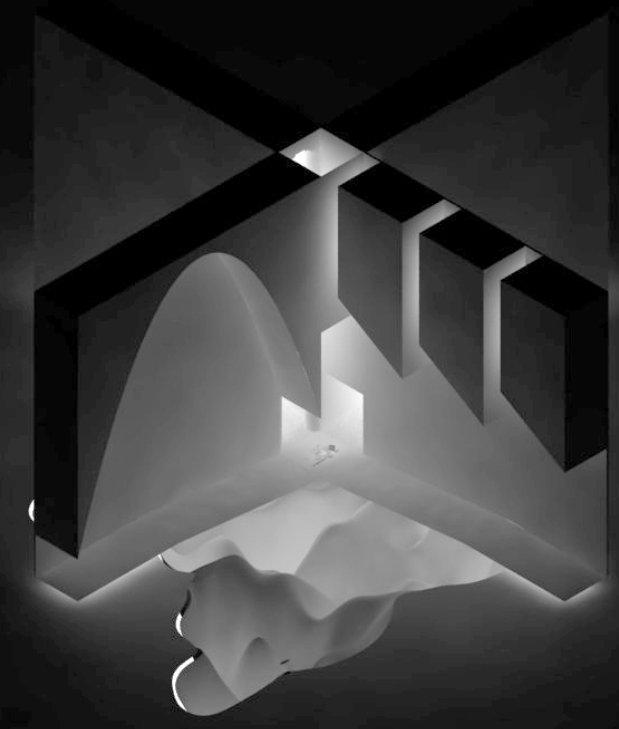




\section{Surficial}

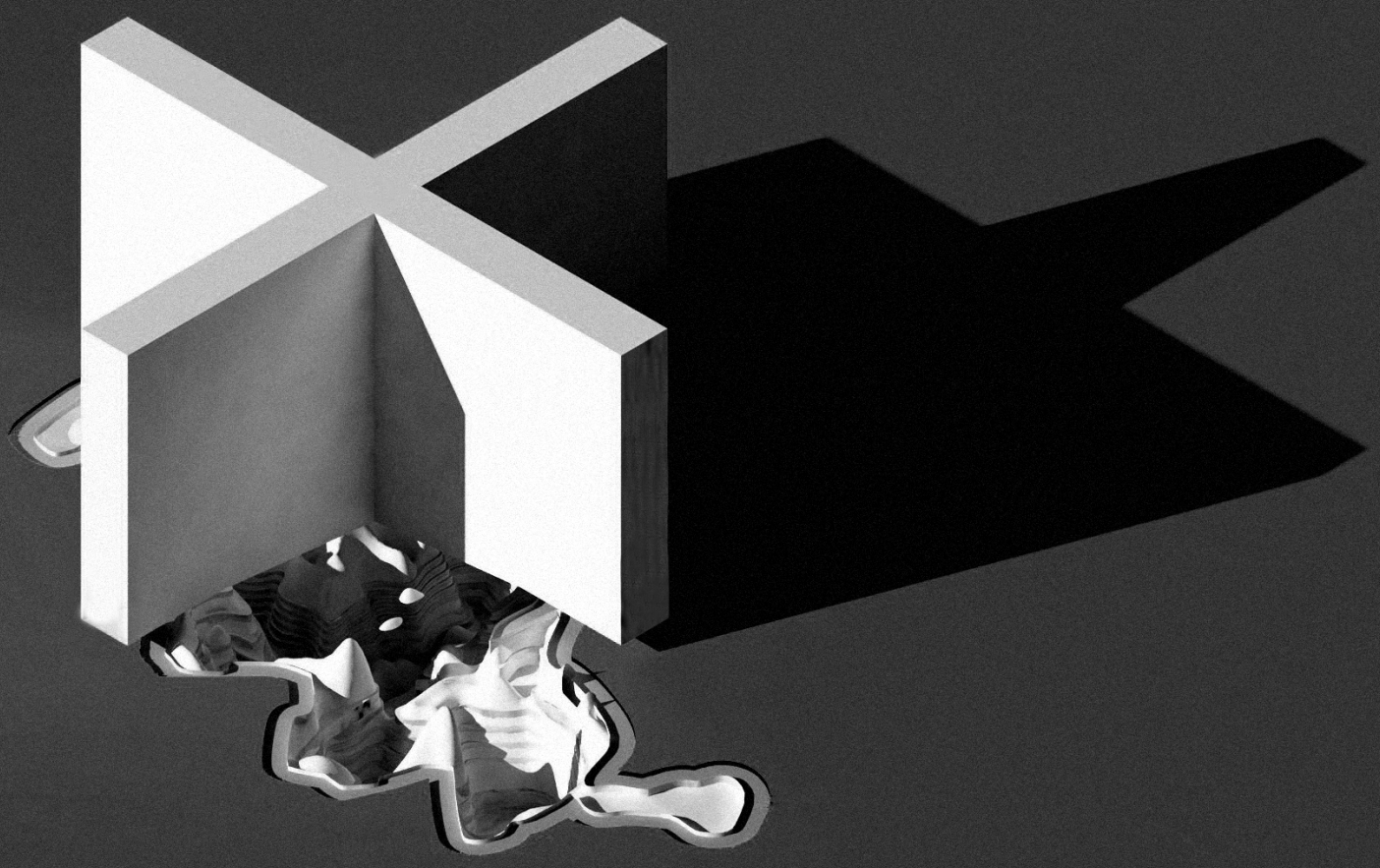

Surficial: The actors, although positioned partially on the land and on top of the open-pit, are interconnected but estranged from the context.

Superficially hostile: The position of the bars along the perimeter of the open-pit create an environment of alienation and estragement towards the open-pit. As if no actor would like to be responsible for the 'scar'.

Thorough: Each actor is placed according to its actions and interventions pre-, during, and postoperations. 


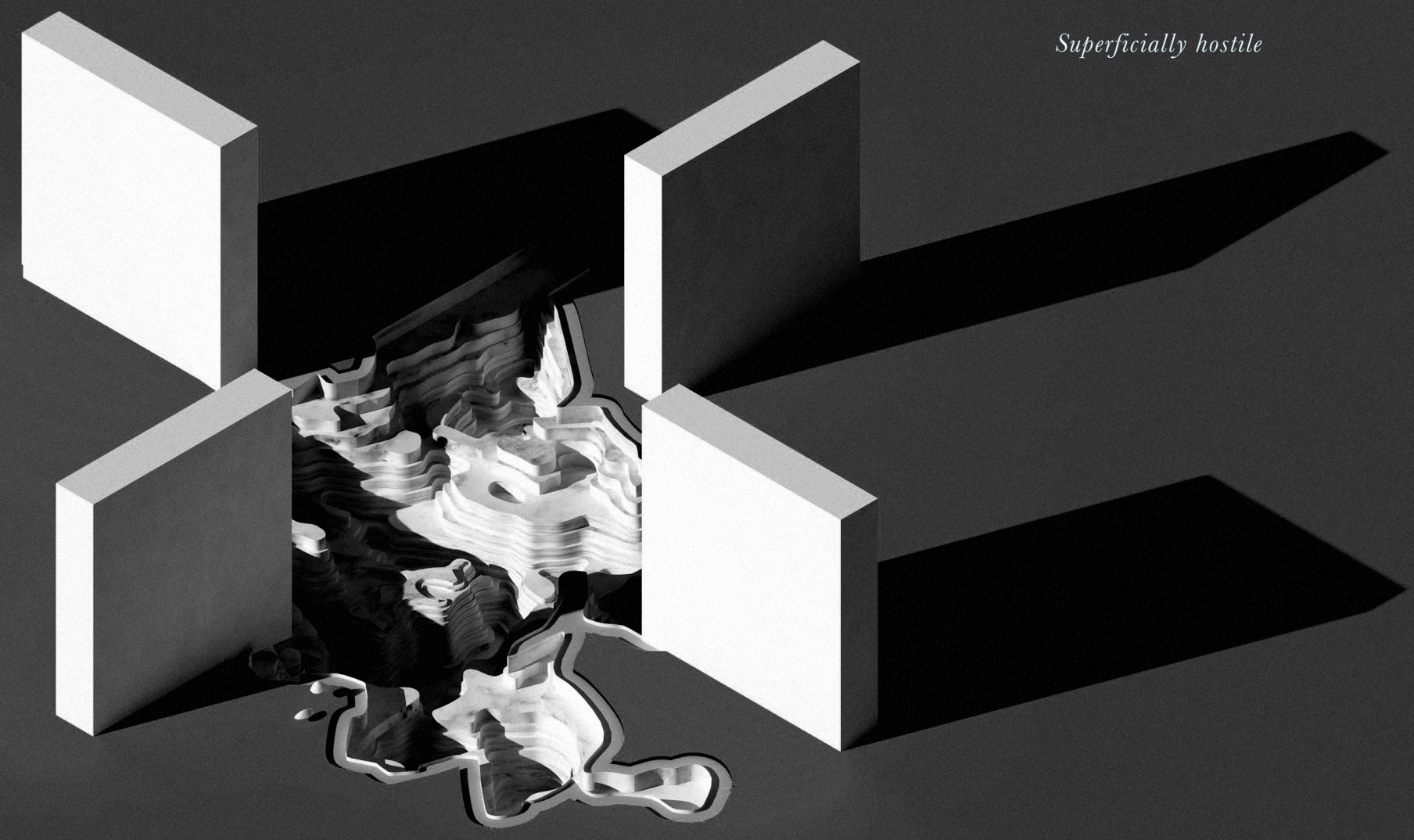

Thorough

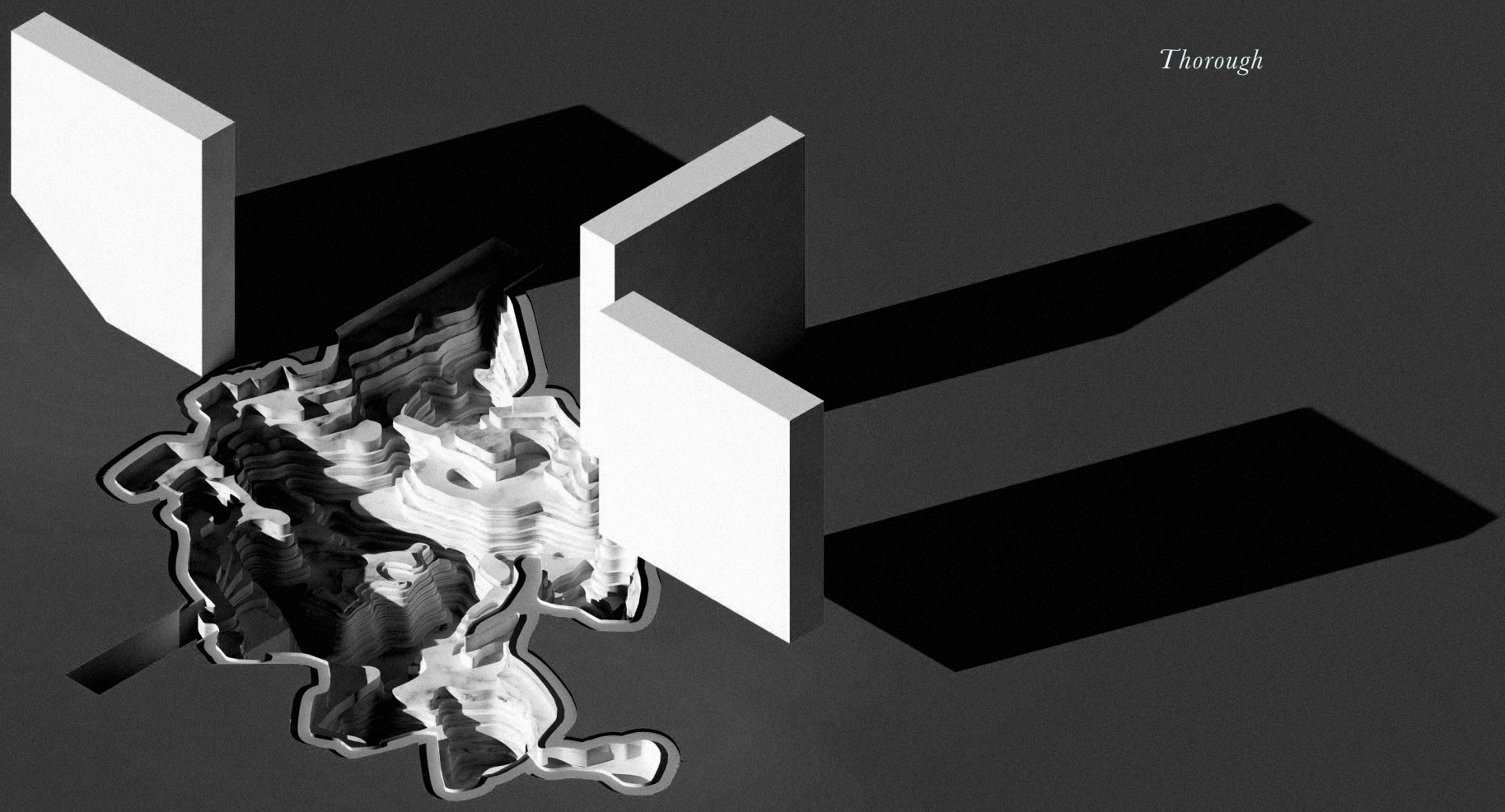




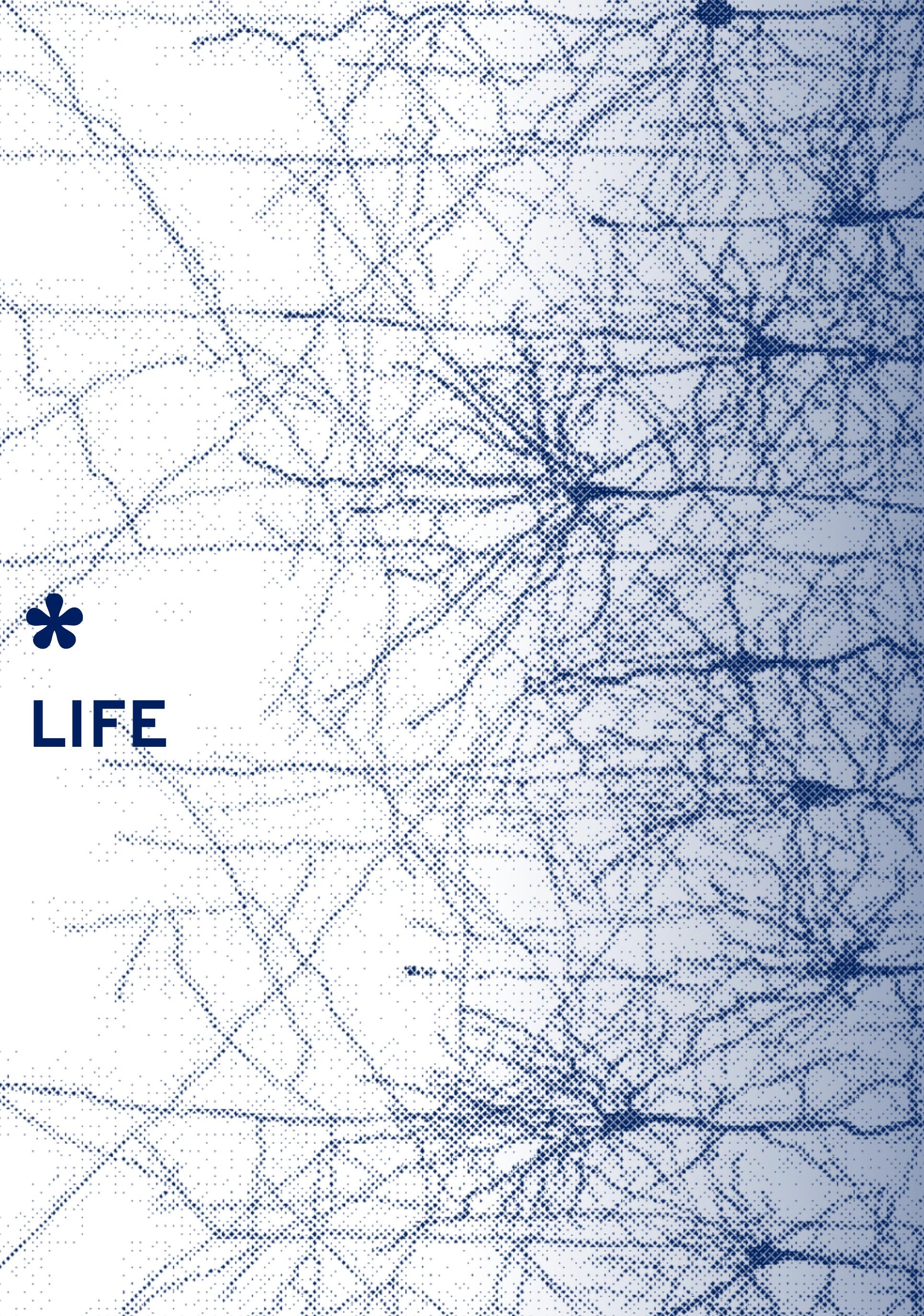




\section{Las Acacias by Silva y Villalba}


Defined as "the condition that distinguishes animals and plants from inorganic matter, including the capacity for growth, reproduction, functional activity, and continual change preceding death" (Oxford), the existence of humans is enriched and enhanced by their relationship to the surroundings (nature, buildings, neighbours, etc). However, architectural ideas like Superstudio's saw life as the "rediscovery of ourselves, through the elimination of all formal structures, and in general all that which exists apart from the individual" (Marchi). This concept of life was further explored in their project Life/Supersurface in 1972, in which they proposed a series of grids for a nomadic society. The benefit of the gridline is that creates equal spaces and access to resources. This project resonates with an ideal vision for rural Colombia, in which some kind of system ought to adapt to the nomadic and settled. As it has been mentioned before, campesinos and minorities are susceptible to unexpected changes that remove them from their personal belongings, traditions and familiar places, stripping them down to the mere basics. Part of the struggle of the rural population is that they are still seeking for such a 'grid' that would provide them with equality and equity regarding opportunities at a national scale.

Life is a synonym of motion, activities and development that our human existence resembles through the constant change in our bodies, activities and stages. Life is also defined as the synergy between human beings and their context. For Andrea Balestrero, an Italian architect, life is when "living organism ... draw energy from the environment in order to remain in a constant state of disequilibrium” (Balestrero, 2016). In a book commemorating Supertudio's stages of human existence, Balestrero writes about life and identifies some key points that make it the most relevant part of architecture. These points assist us in understanding how we become elements in an everchanging environment, how the individuals belong to a collective unit, the impact of the plasticity of contemporary architecture creating homogenization, and most importantly, the renewed experience with nature. But the Colombian context shows a concept of life that opposes these views, where the renewed experience with the environment is one of alienation and disconcertment, and where the homogenization of the landscape due to globalization is palpable. Although rural life has been largely subjected to violence and perpetual fear, the most passive attack (slow violence) has been the exploitation of natural resources, as well as being marked by poverty, to the point of misery. According to the National Planning Department, the Department of La Guajira has a Multidimensional Poverty Index (MPI) of 53.3\% and Cesar of 42.3\%, compared to the national of 26.9\% in 2015 (Pobreza Monetaria La Guajira Año 2017, 2018). The high levels of poverty is juxtaposed with the high value of the royalties left after coal exploitation. As mentioned before, these two Departments have the largest coal deposits in the nation. The MPI focuses on access to education, health, and living standards. There is a failure in achieving an appropriate standard living, accommodation, and recreational facilities from the corporations by the campesinos and other smaller communities. Livable and unlivable conditions, poverty, and lack of daily life things are ubiquitous in all rural zones.

Aside from the difficulty of carrying out a life in tranquillity in Colombia's countryside, the 
locals can undertake actions on their own. For example, one of the unique qualities of La Guajira is the form in which indigenous groups have organized themselves as Comunidades, composed of family members of the same clan and Rancherias grouping together a number of Comunidades. Women take an important role as being leaders of the clans. They also become the bearers of life, the embodiment of mother nature, and the intermediary between life and death, as they are in charge of burial processes. Part of the essence of life, it is the role of women in development, not only by giving birth to next generations, but through lessons, discipline, and experiences, they are discerning the meaning of life. With a particular attention to mined Colombia, women who belong to indigenous communities, see a big environmental challenge because they see the land, metaphorically and literally, as mother earth (Ulloa_Feminismos territoriales en América Latina. pdf). The mega-exploitation, alteration and removal of the soil make the landscape unrecognizable and, thus, impossible to bear the fruit of life. Spiritually, the fruit from the Tree of Life is unattainable for mortals, because it gives eternal life. Although the Tree symbolizes more than immortality (Alcorn, 2016), it becomes a representation for understanding the beginning of a new life, as it is portrayed in Genesis and Revelation, the renewal a loss and achieving social and spiritual harmony. This is further achieved through the use of water with the river that nourishes the tree of life. This artery reconnects human beings with God, as it is written in Revelation 22:2 "In the midst of the street of it, and on either side of the river, was there the tree of life, which bare twelve manner of fruits, and yielded her fruit every month: and the leaves of the tree were for the healing of the nations". Ever since Adam and Eve sinned by eating from the Tree of Good and Evil, the direct connection with the soil and other elements of paradise were transferred to a more direct intervention of humans and earth. One of the involvements is by returning to the earth as God commanded to Adam after having sinned "for dust you are and to dust you will return" (Genesis 3:19). It also opened up a new territory for exploration and beginning of a new life, and a new stage for a human relationship with the land. Compared to the urban life, rural life's hustle is about surviving and thriving by connecting the person to the land and the natural environment. 
figure 01 Sierra Nevada de Santa Marta aerial photograph 1938 - 1946.

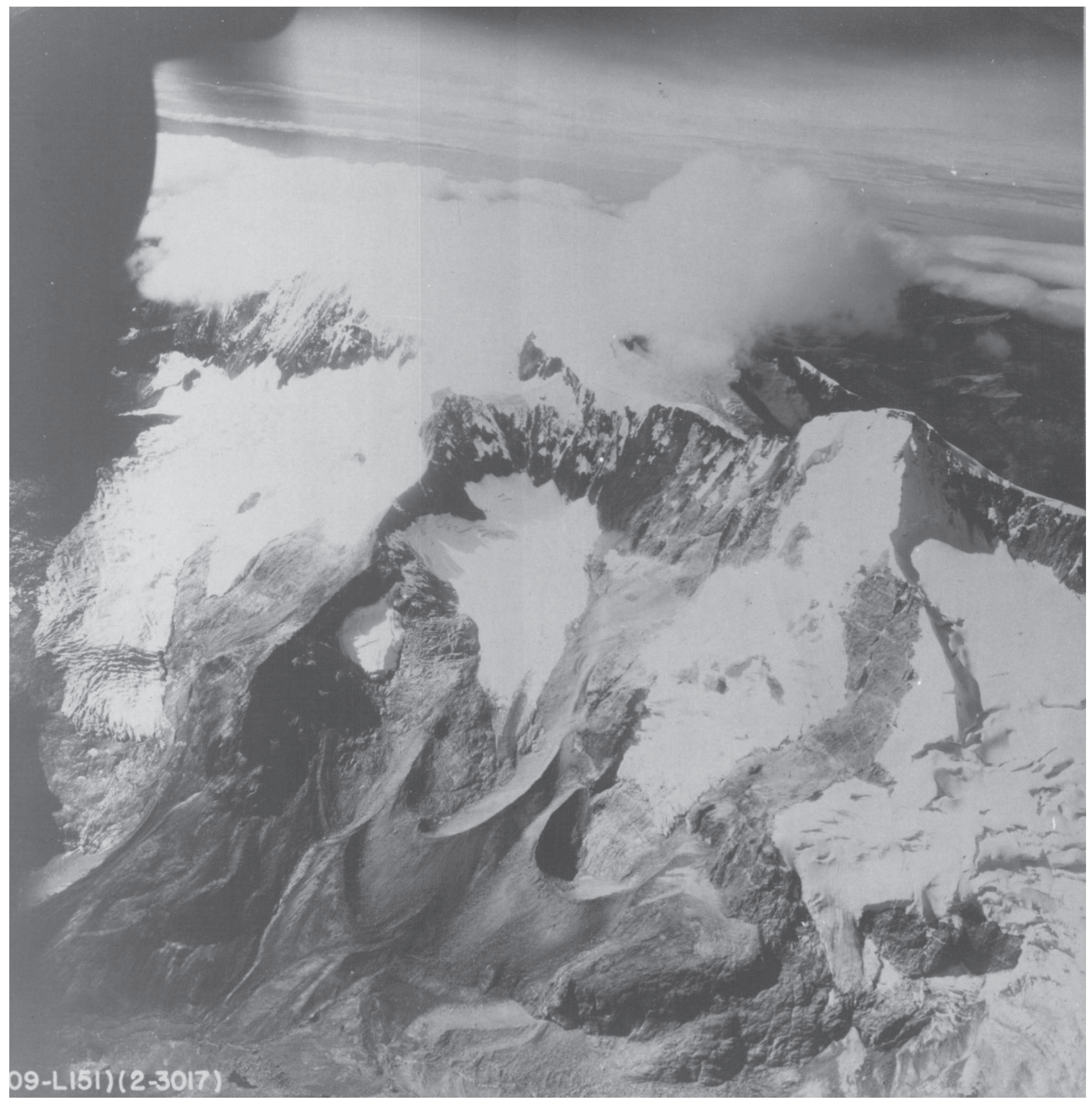

Rio Rancheria, one of the most important bodies of water in La Guajira, is born in Sierra Nevada (pictured above) 
figure 02 photograph taken 1938 - 1946

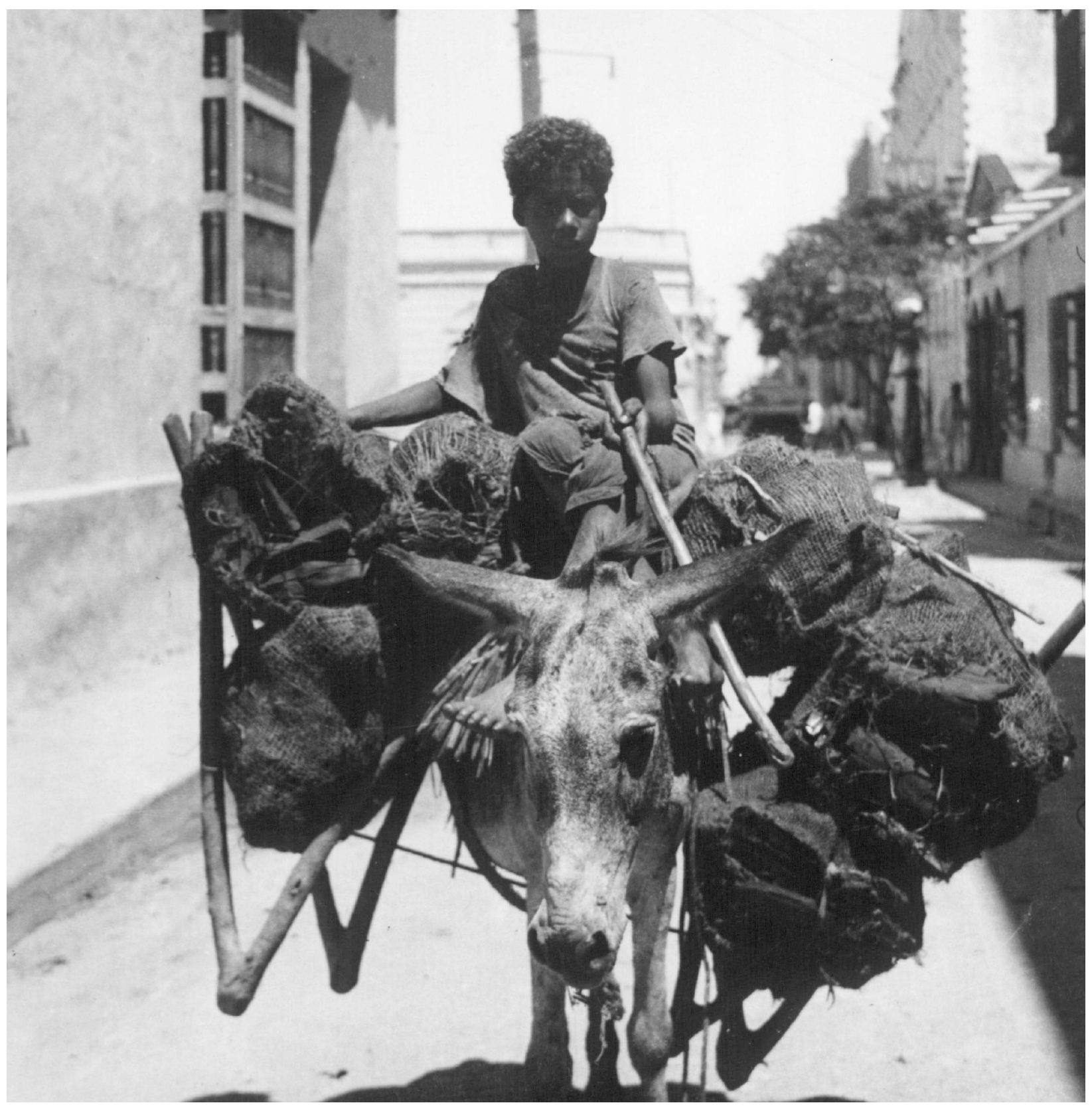

Labour in rural Colombia begins at a yougn age. Although parents often force children to attend school, sometimes the situation drifts away the possibility of finishing the educational level, and instead, they start working. 
figure 03

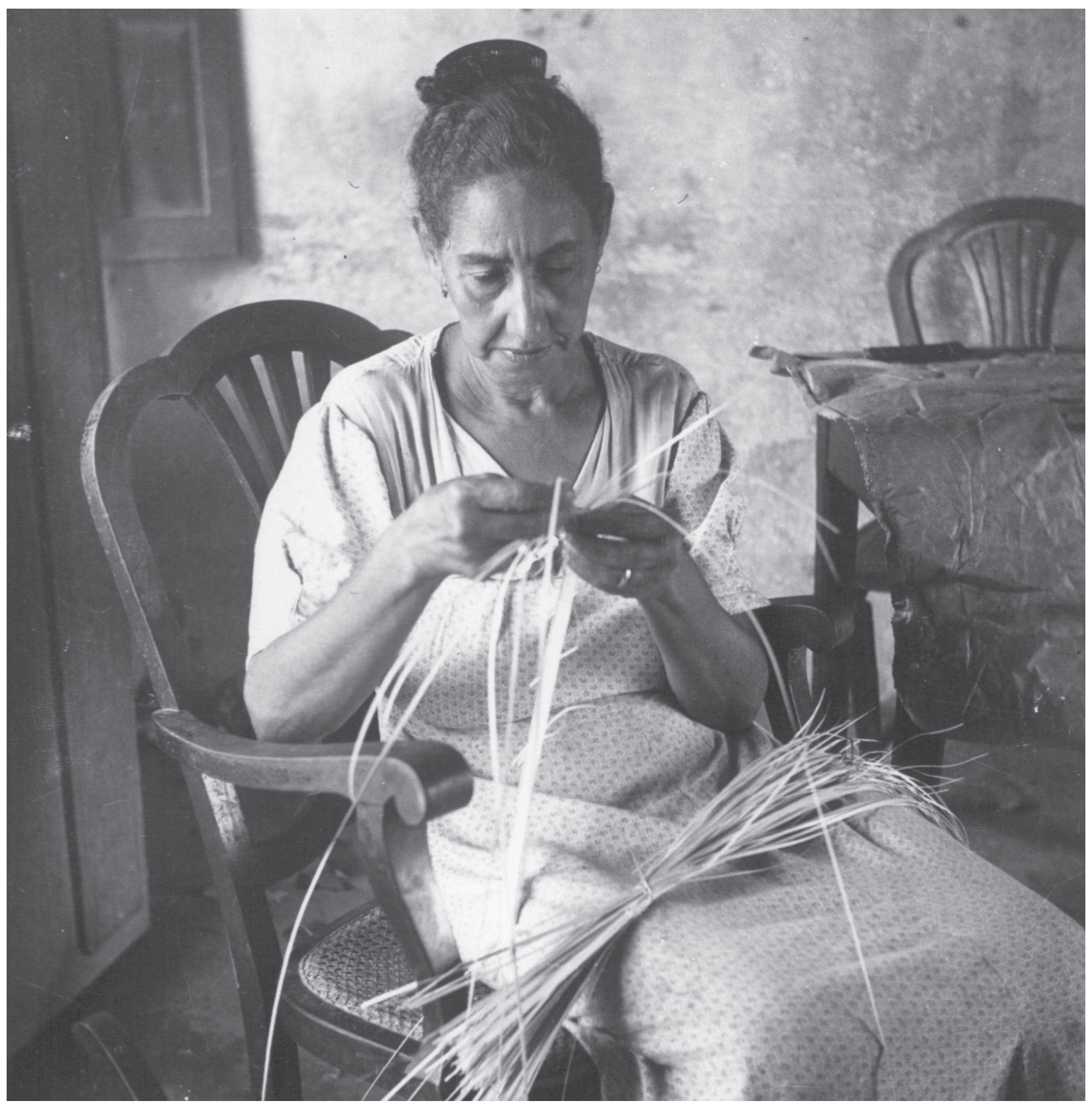

Local arts and crafts have always been a driver in Colombian homes; usually passed on generation to generation. 
figure 04

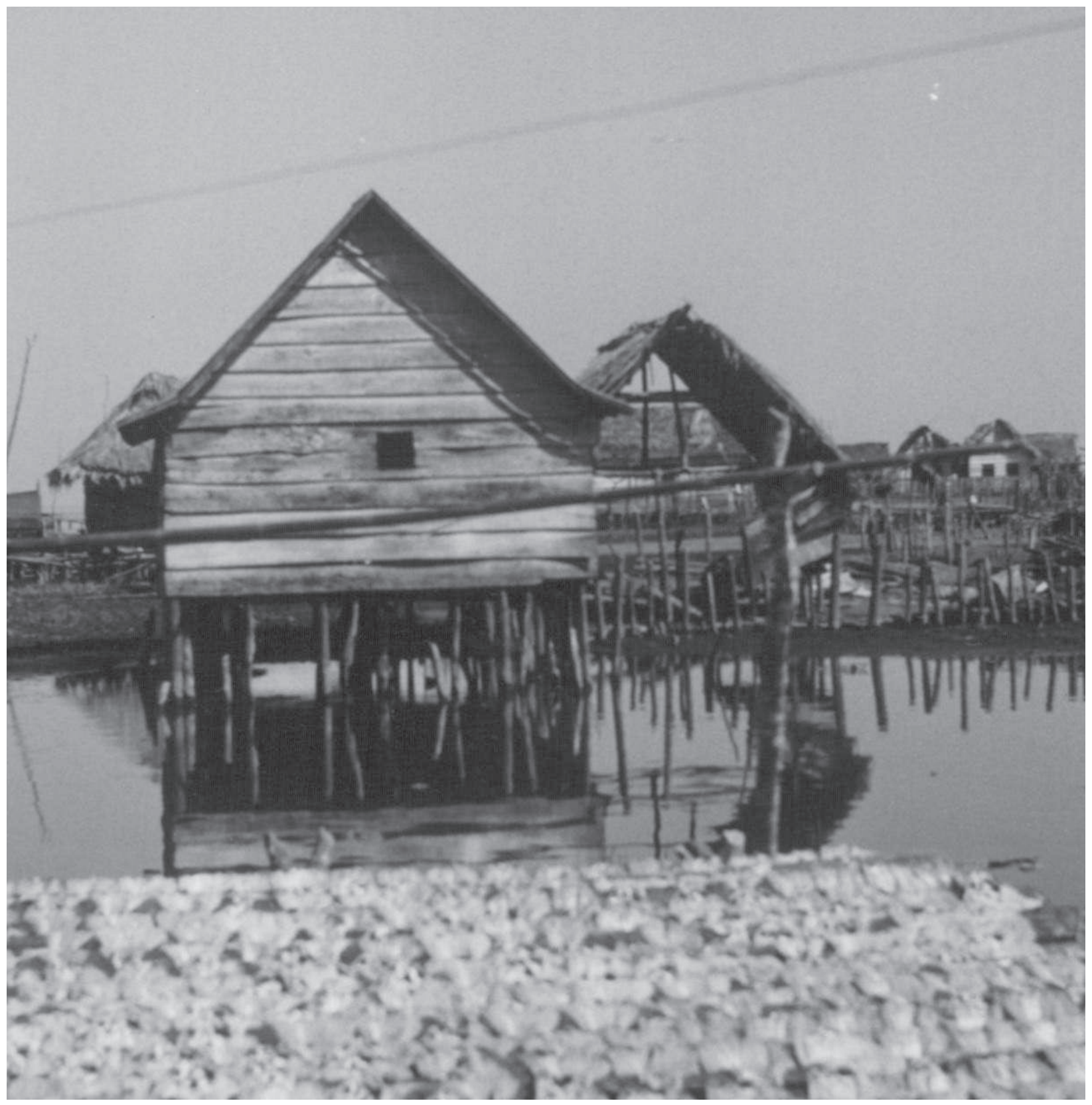




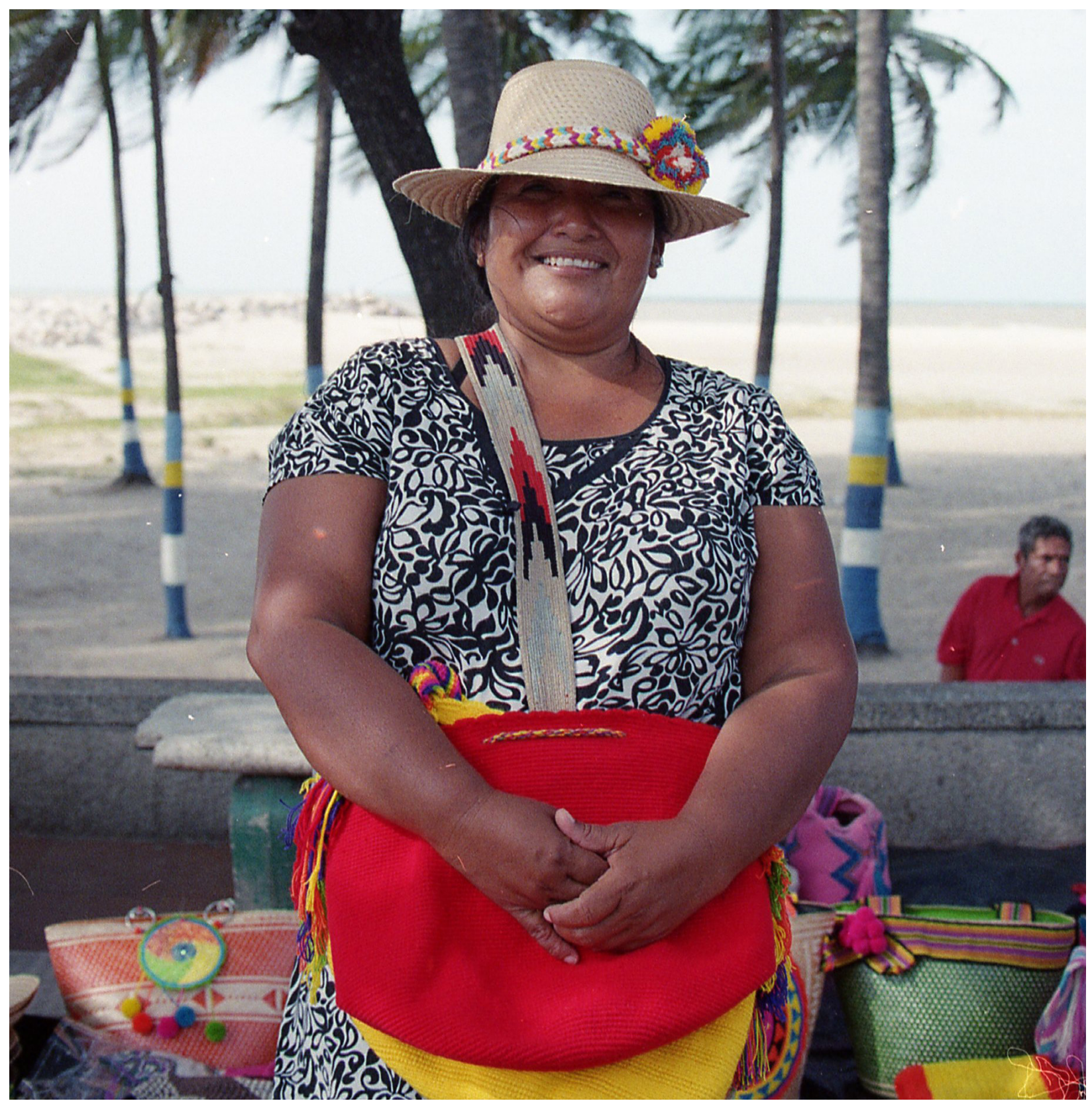

Wayuu woman holding traditional bags (Rioacha, La Guajira, Colombia) 
figure 06

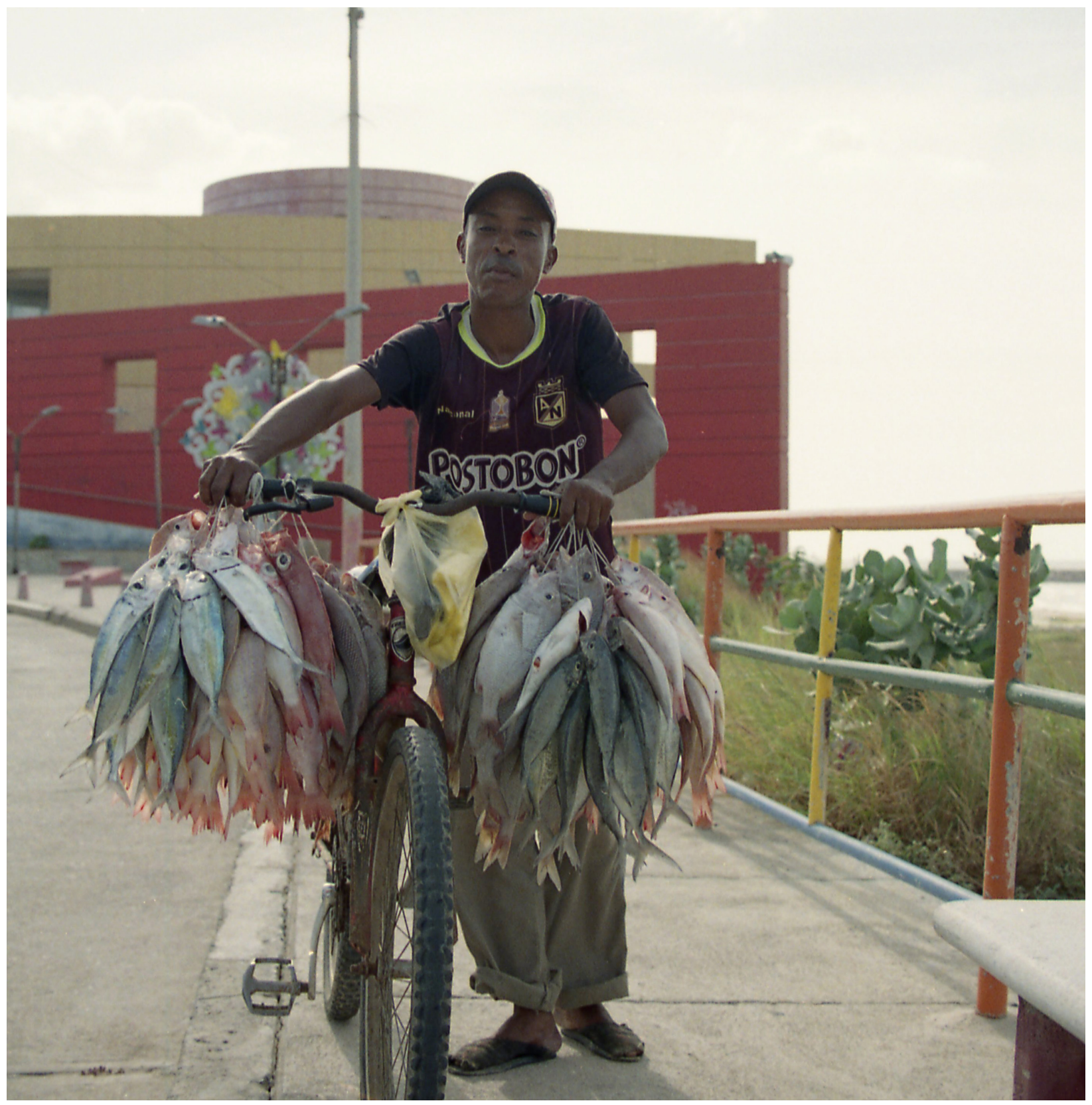

Fisherman with fish from the sea (Rioacha, La Guajira, Colombia) 


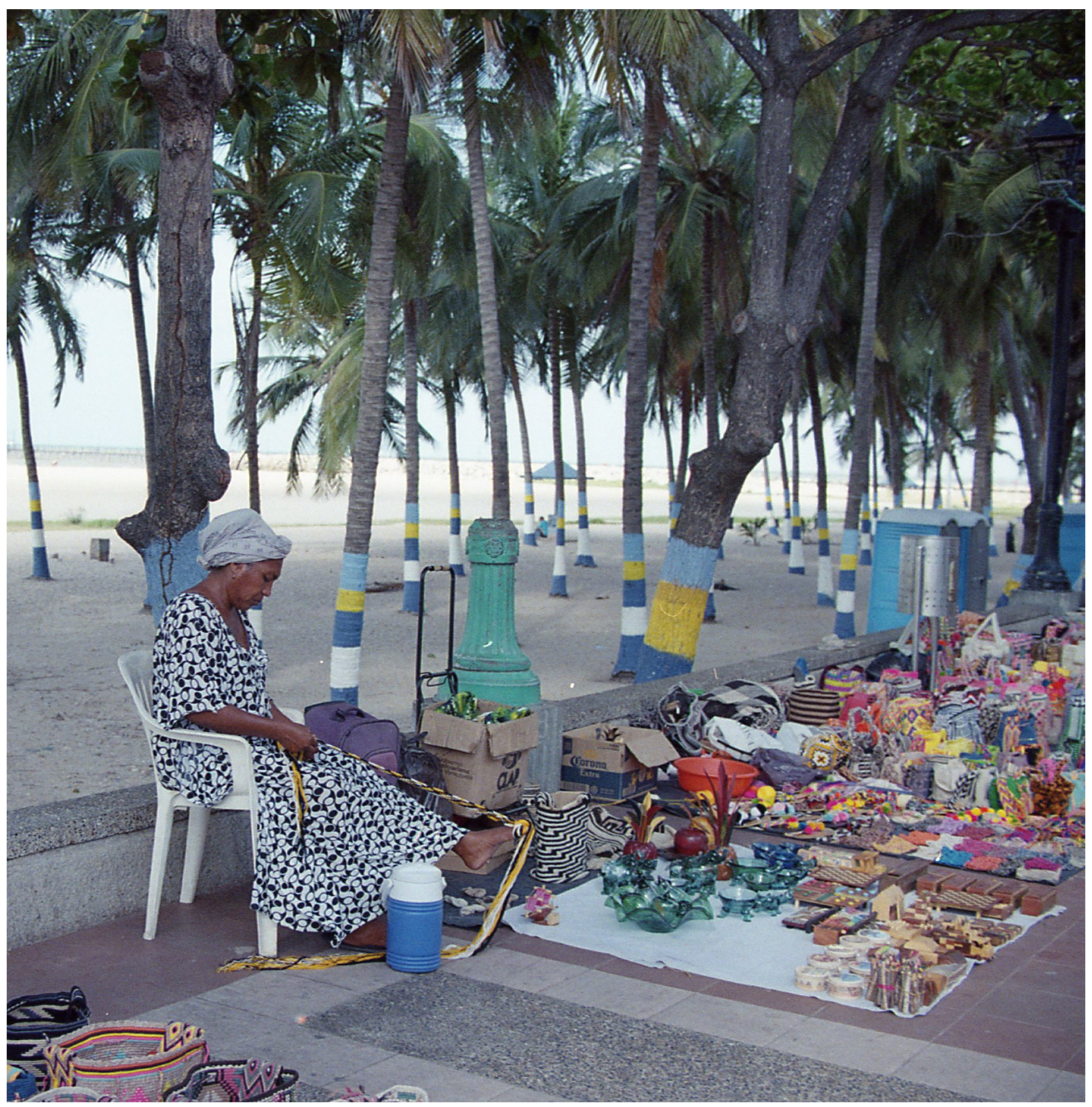

Wayuu woman weaving a strap for the traditional Wayuu bags in Rioacha, la Guajira, Colombia 
figure 08

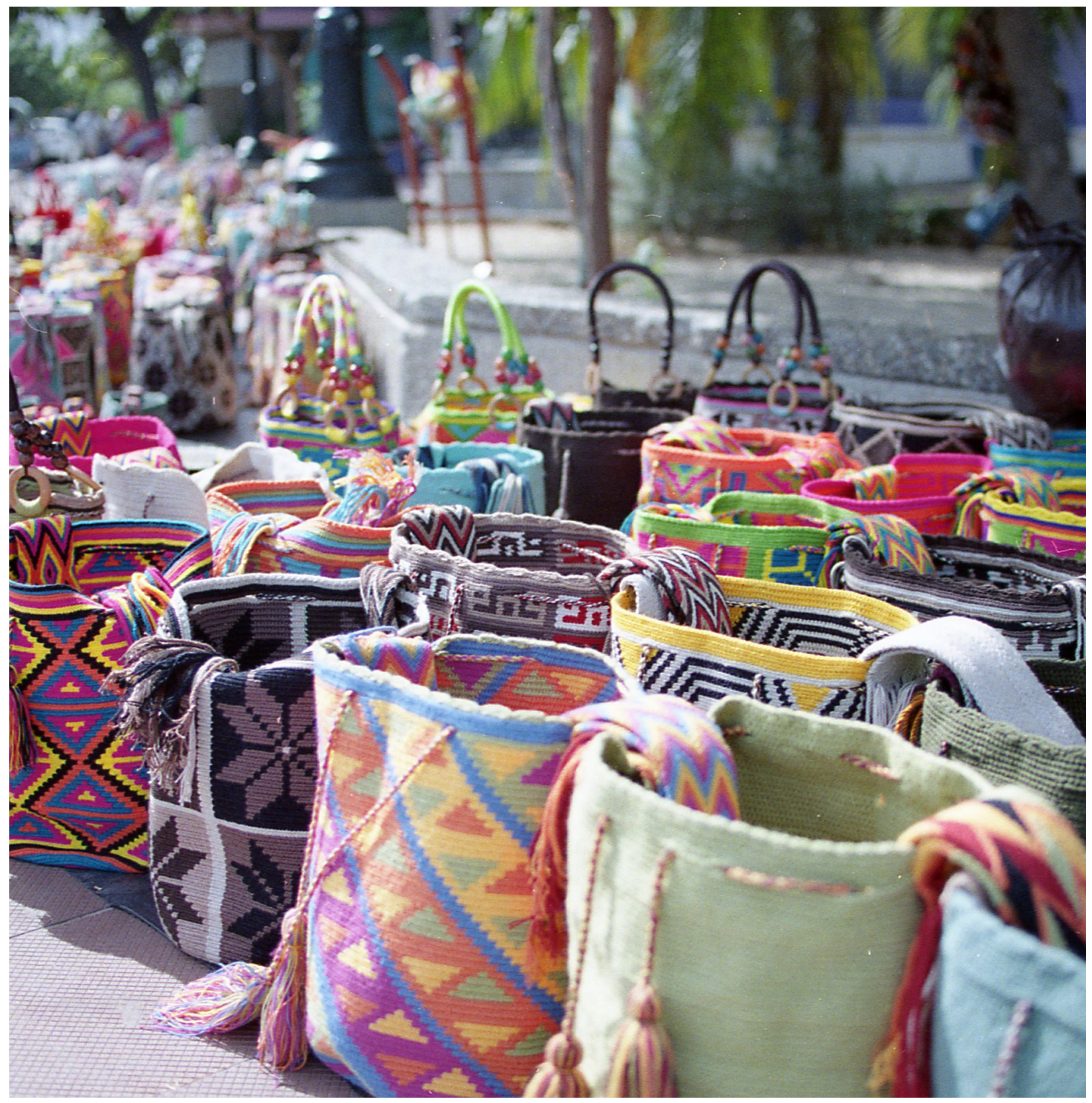

Traditional Wayuu bags in Rioacha, la Guajira, Colombia 
figure 09

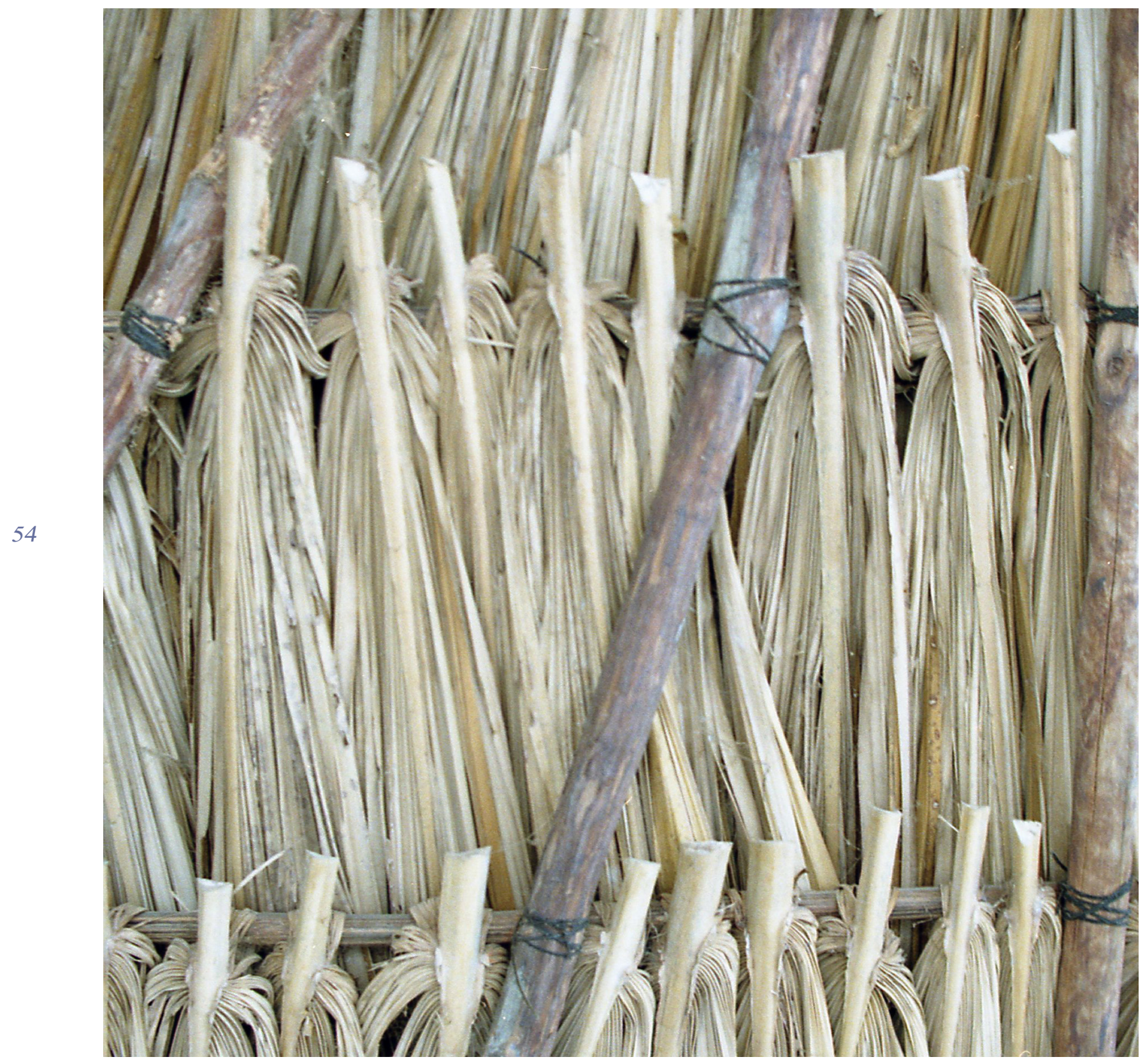

Palm leaves roof often found in regions where the weather is hot. This material proves to be flexible, inexpensive and durable (Monteria, Colombia) 
figure 10

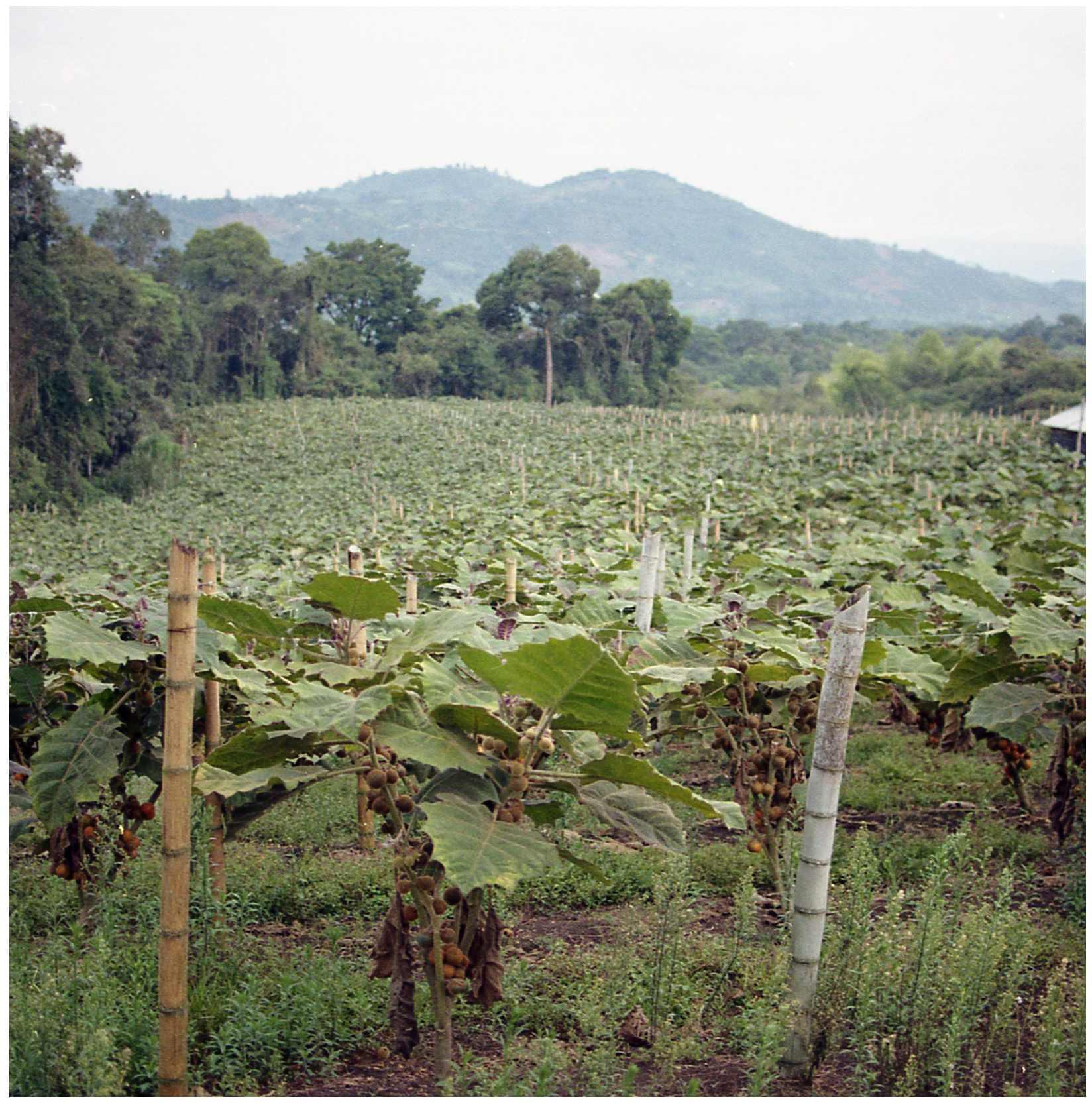

Plantation of tropical fruit lulo (Huila, Colombia) 


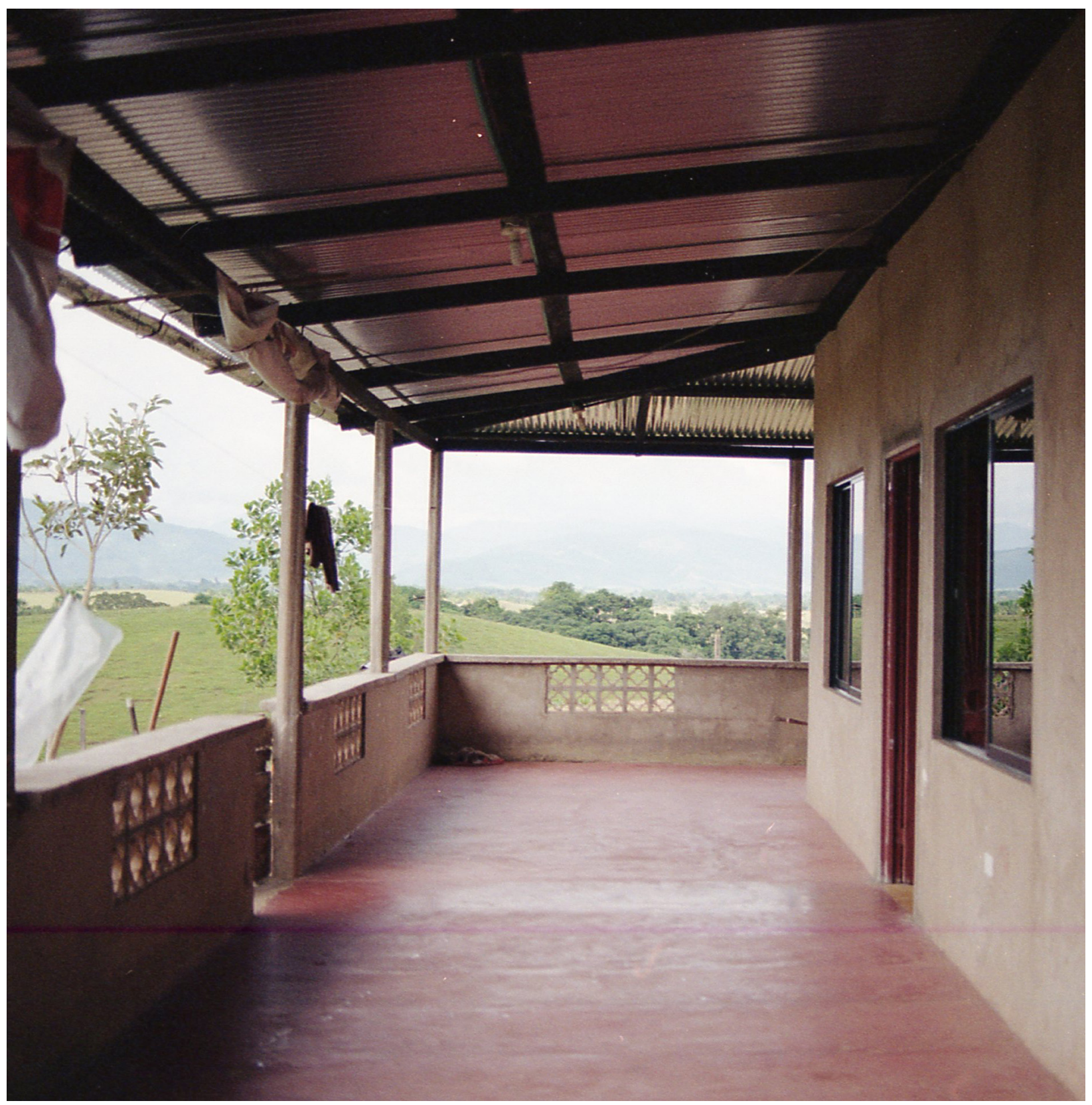

House in the tropical area of Caqueta, Colombia 
figure 12

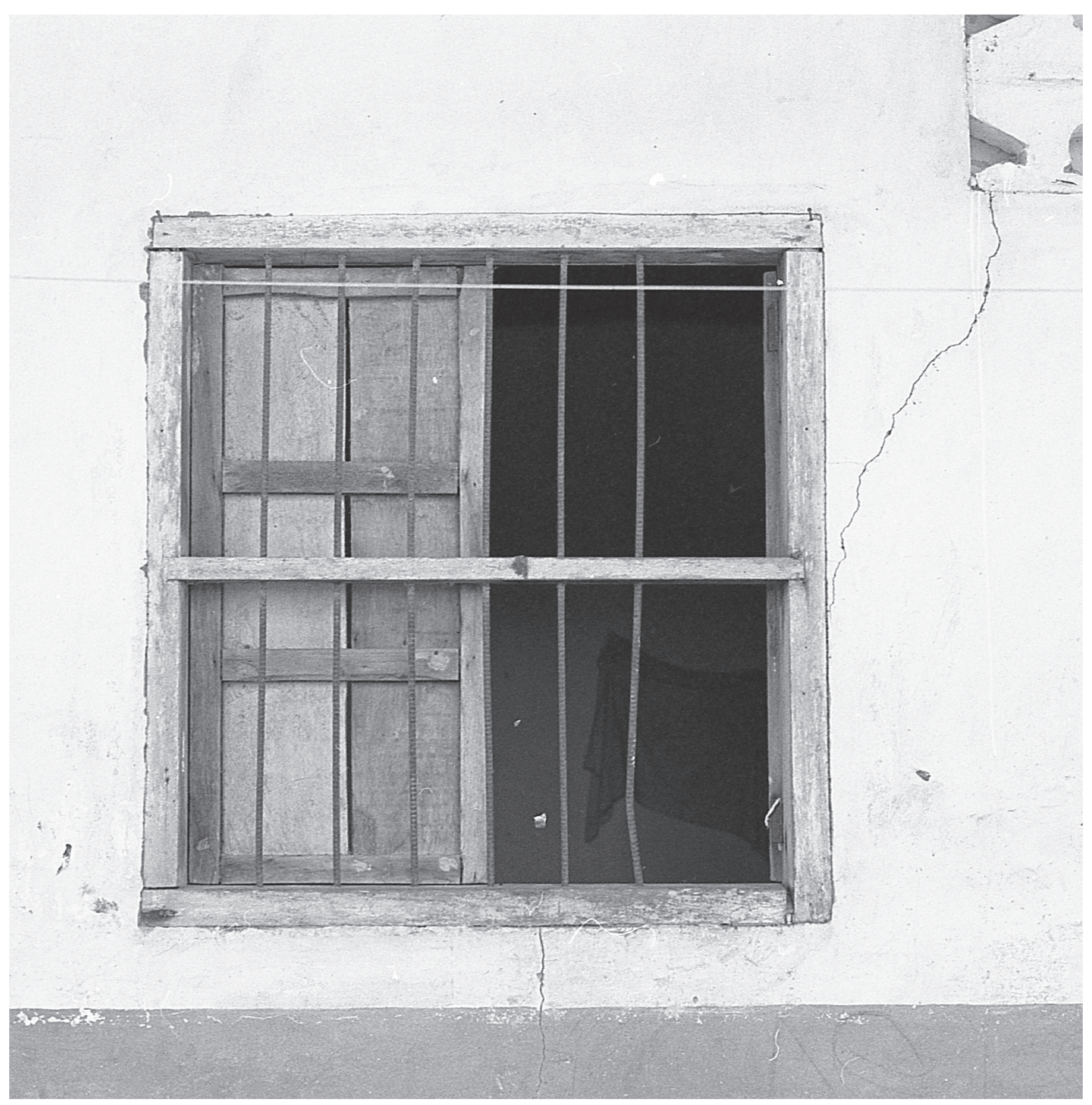


figure 13

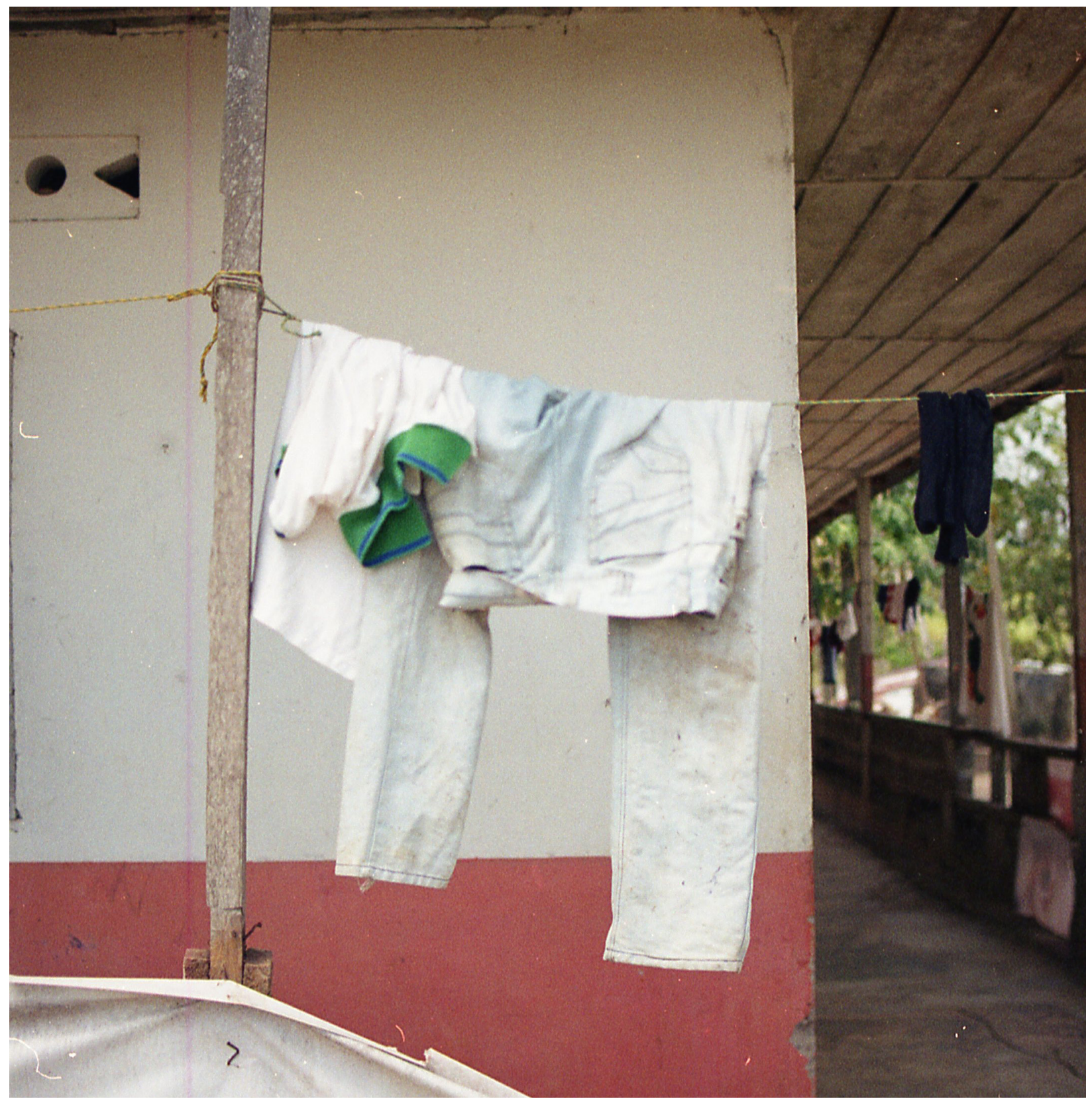

Signs of life and work at a rural home (Caqueta, Colombia) 
figure 14

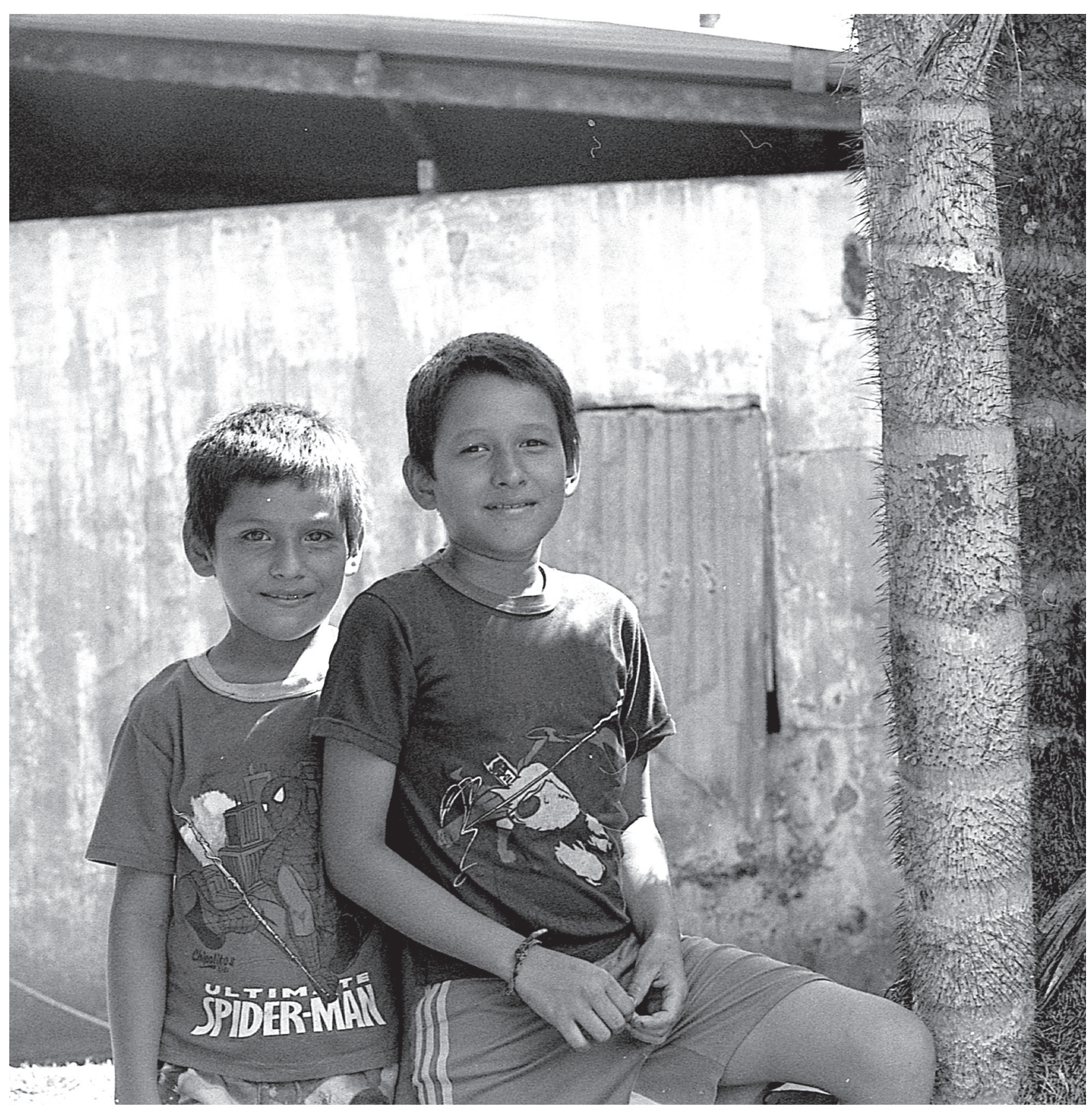




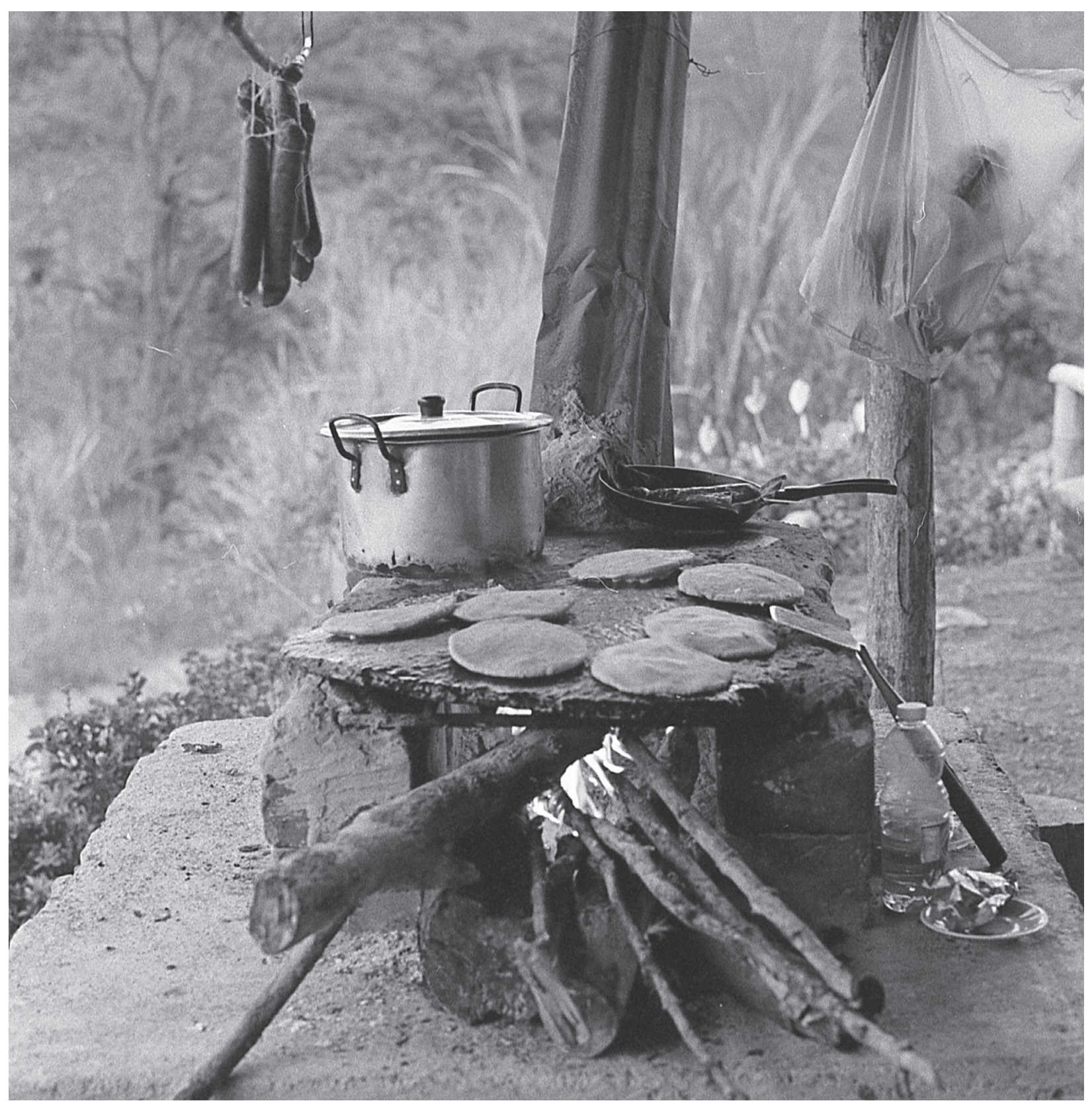

Traditional cooking method in rural areas of Colombia. (Huila, Colombia) 
figure 16

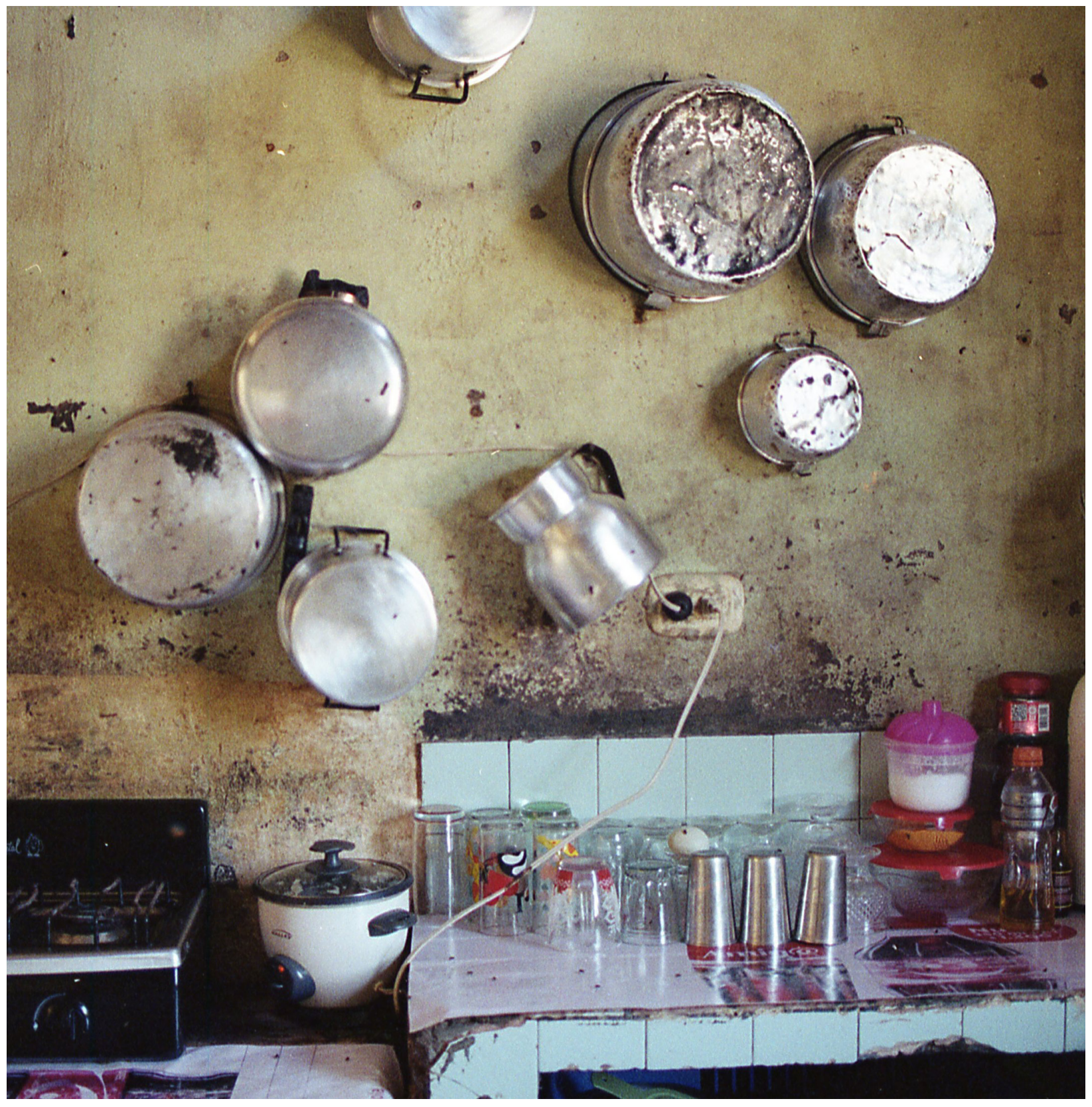

Signs of life at a rural home (Caqueta, Colombia) 


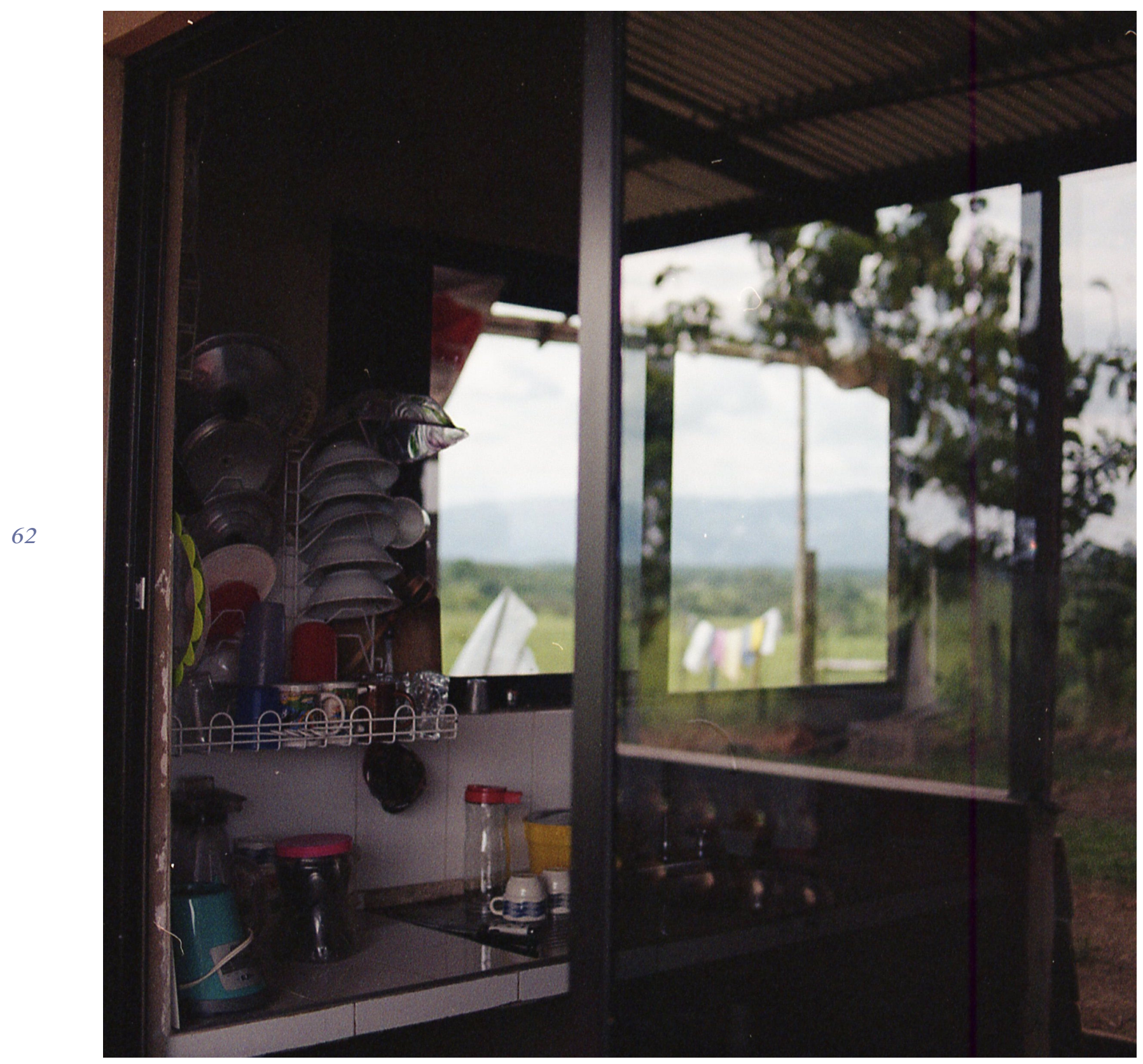

A kitchen. (Caqueta, Colombia) 
figure 18

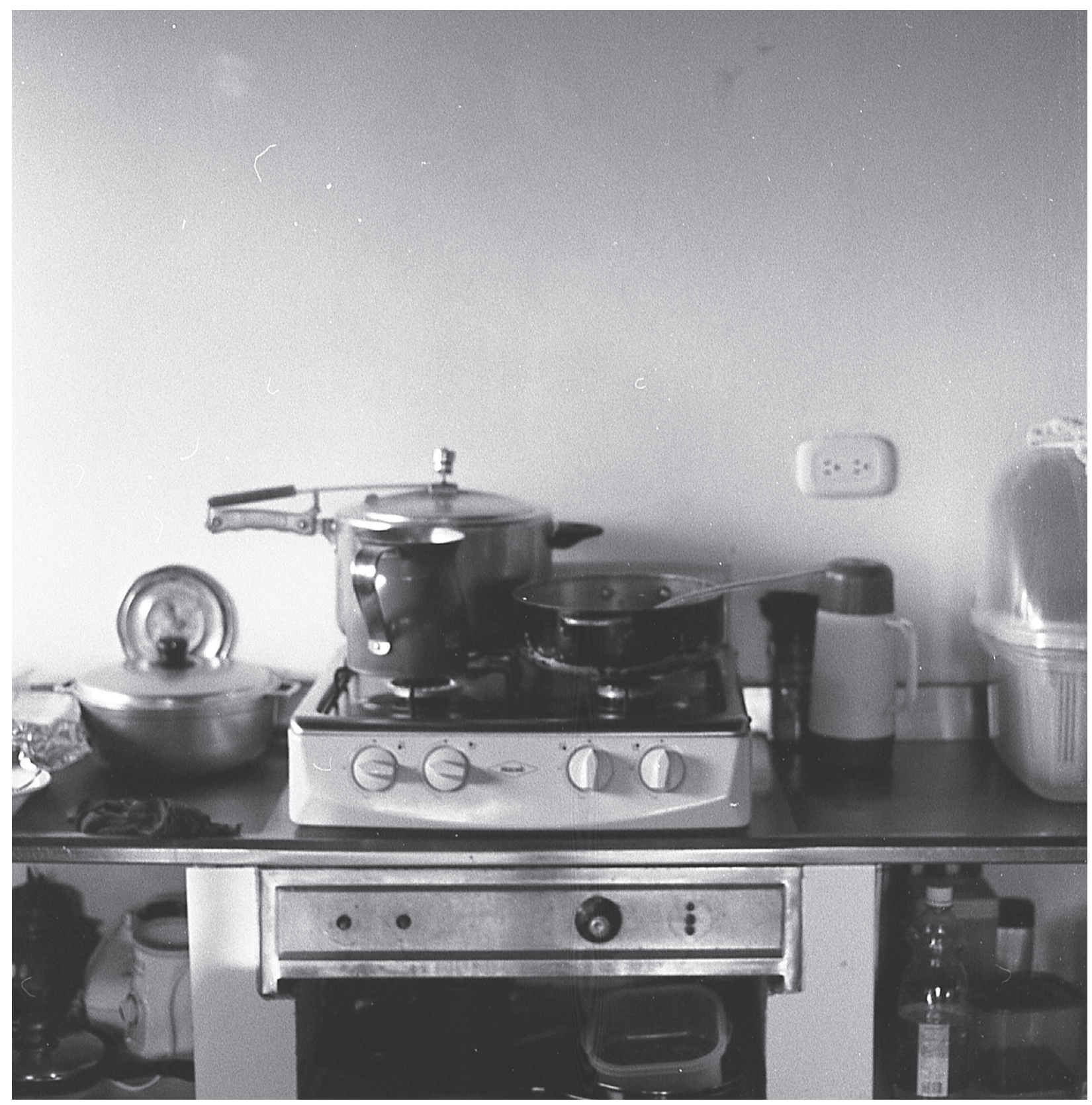


figure 19

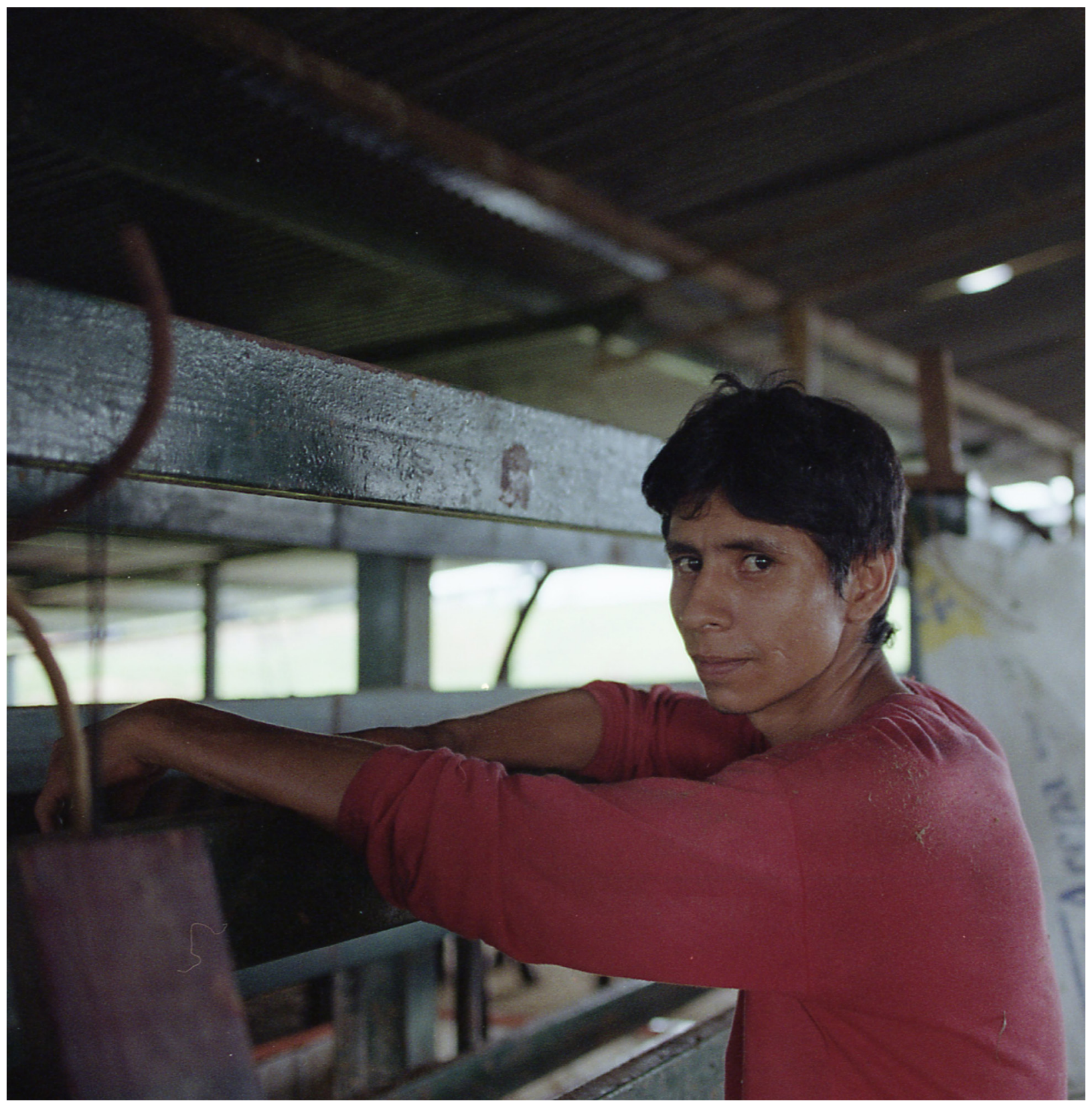

Worker at the Artemisa farm in Caqueta, Colombia 
figure 20

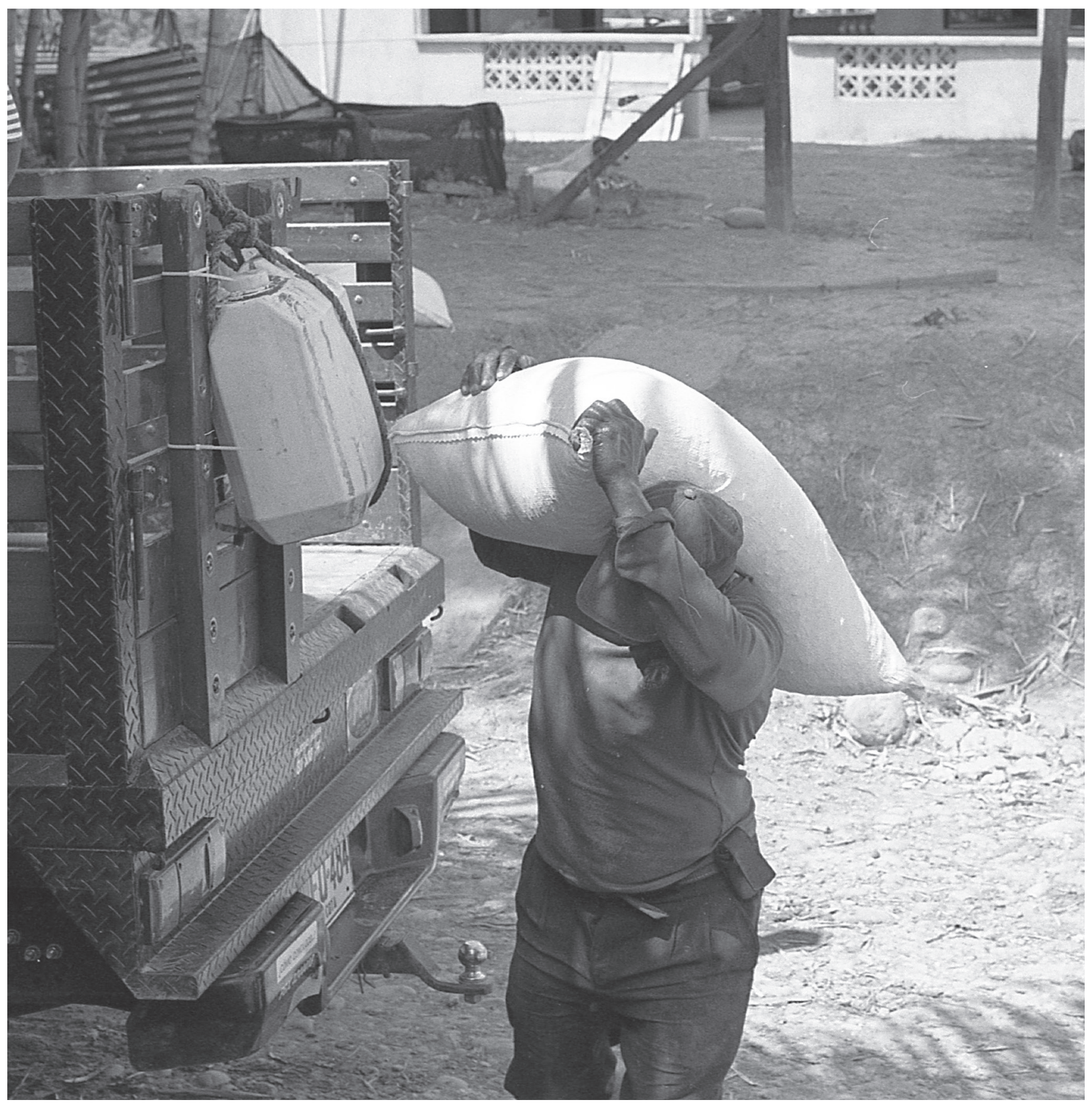




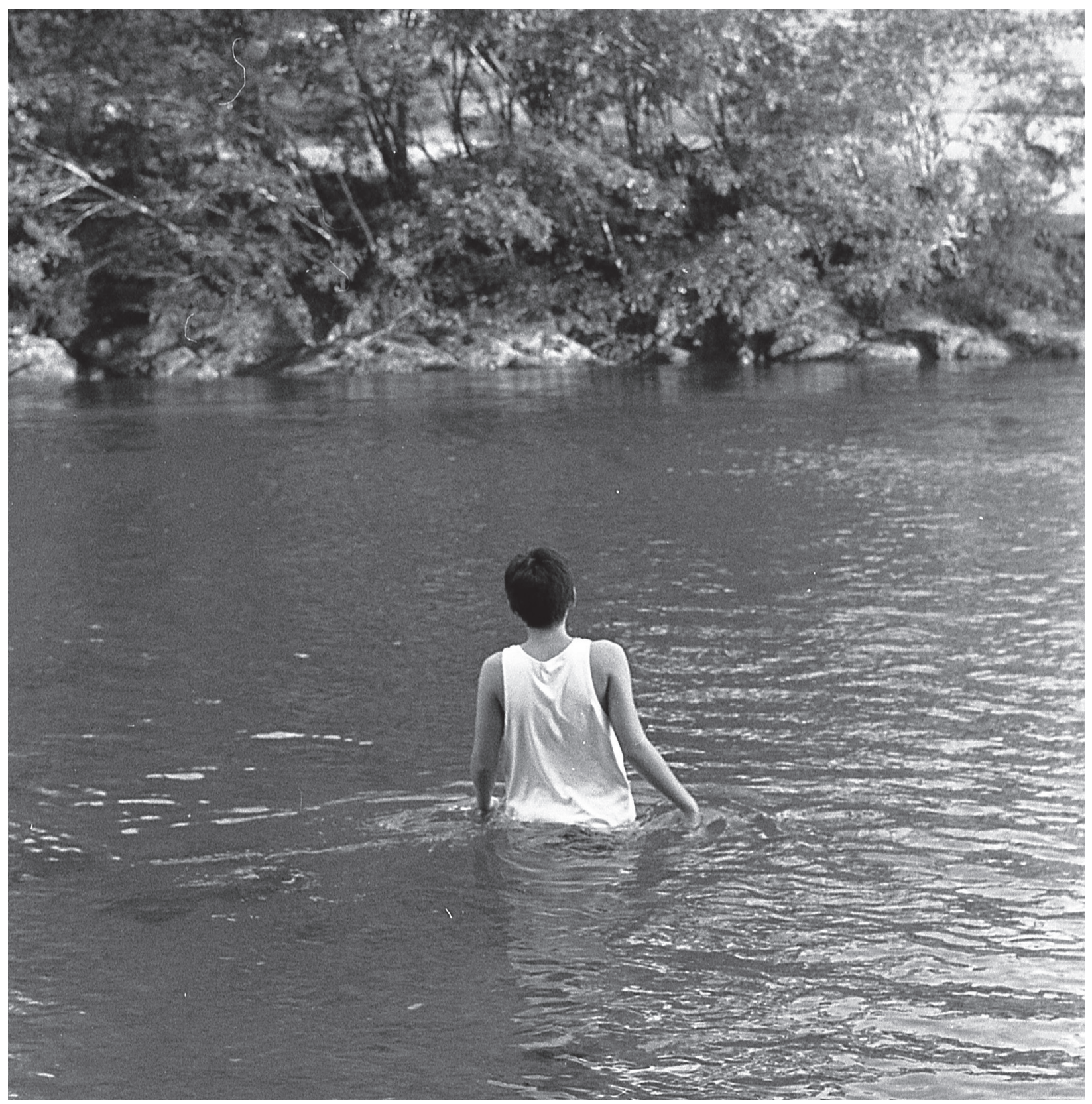


figure 22

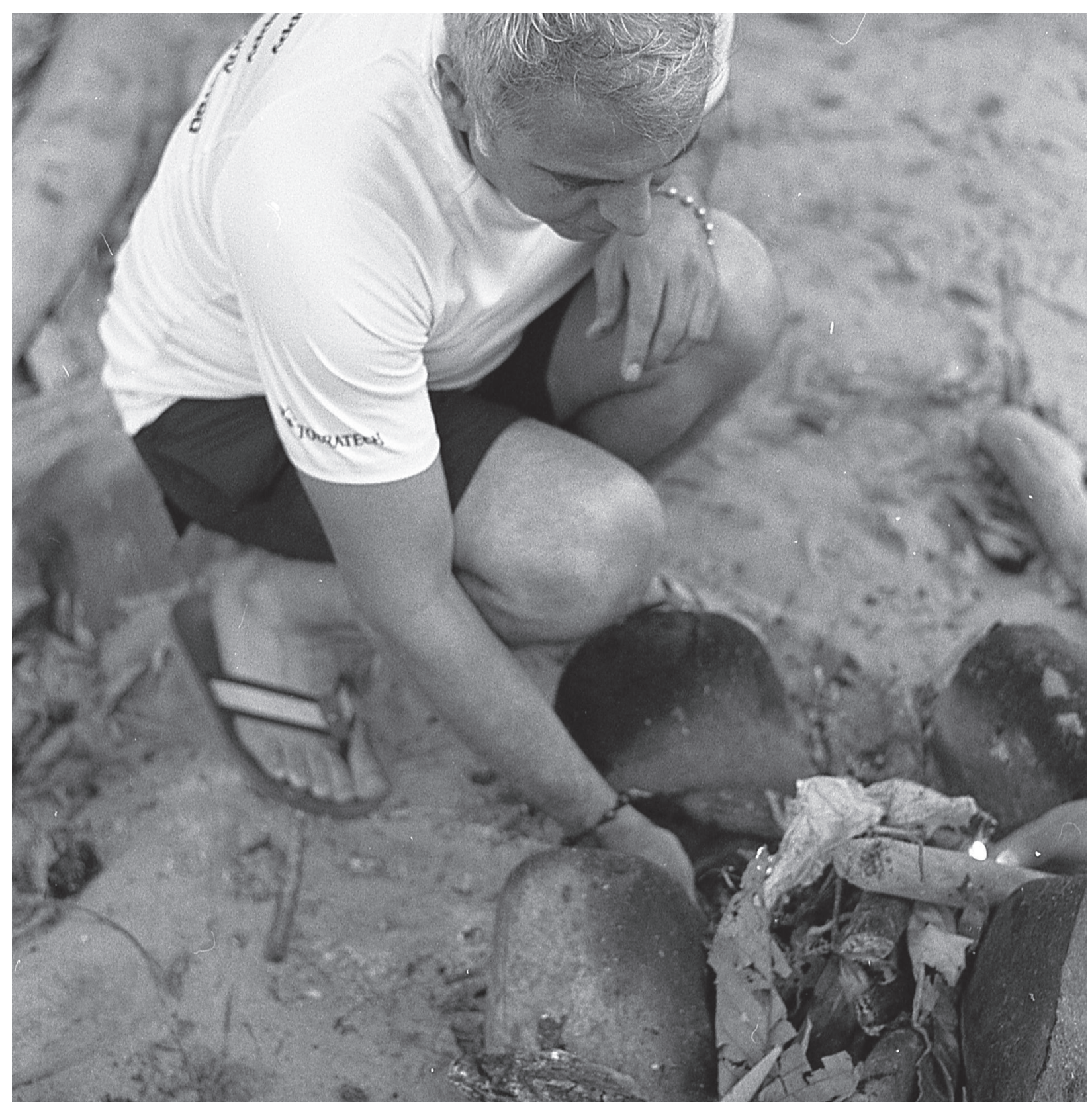




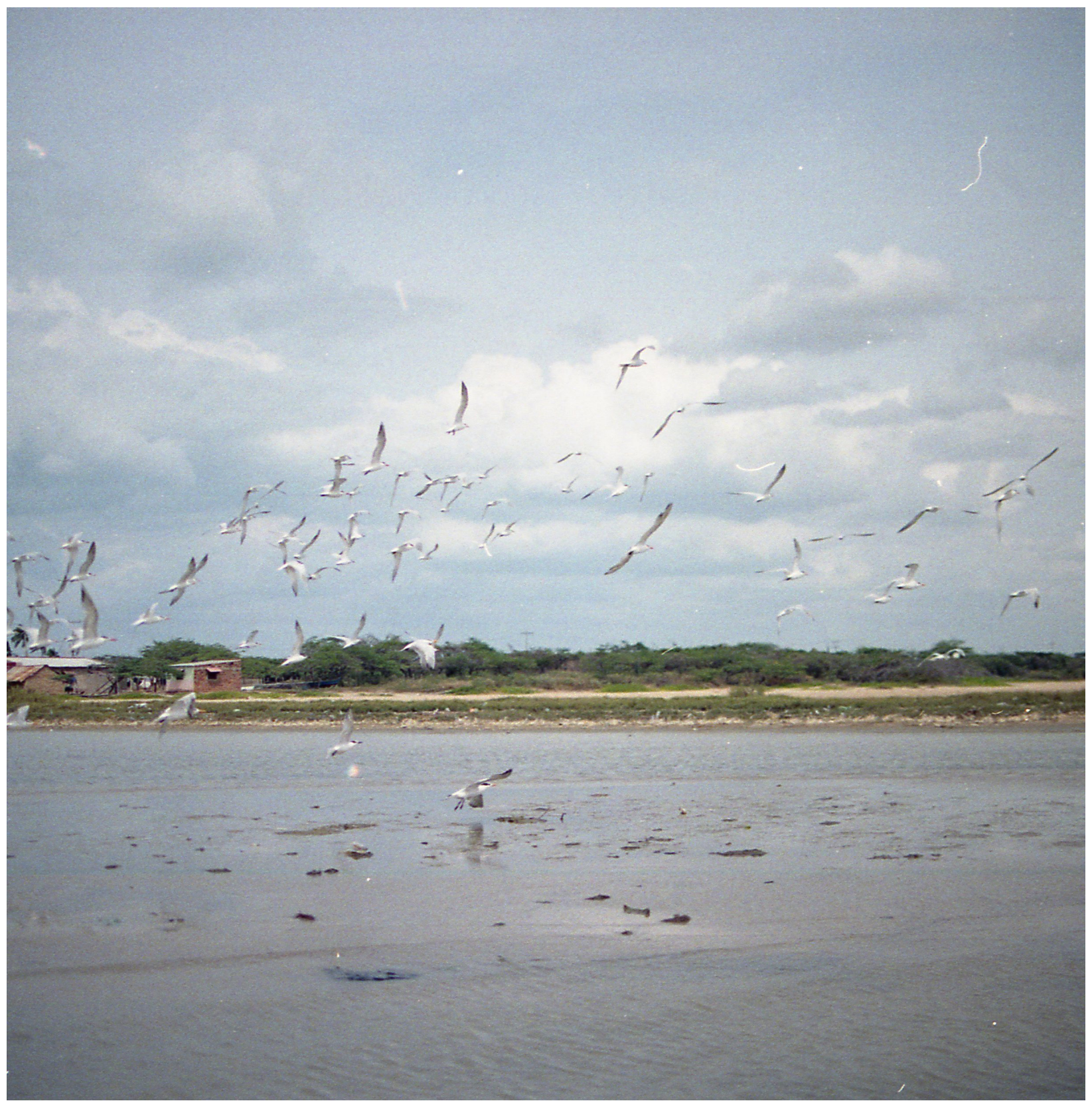

Birds flying over Laguna Grande at Sanctuary of flora and fauna the Flamencos, Rioacha, la Guajira, Colombia 
figure 24

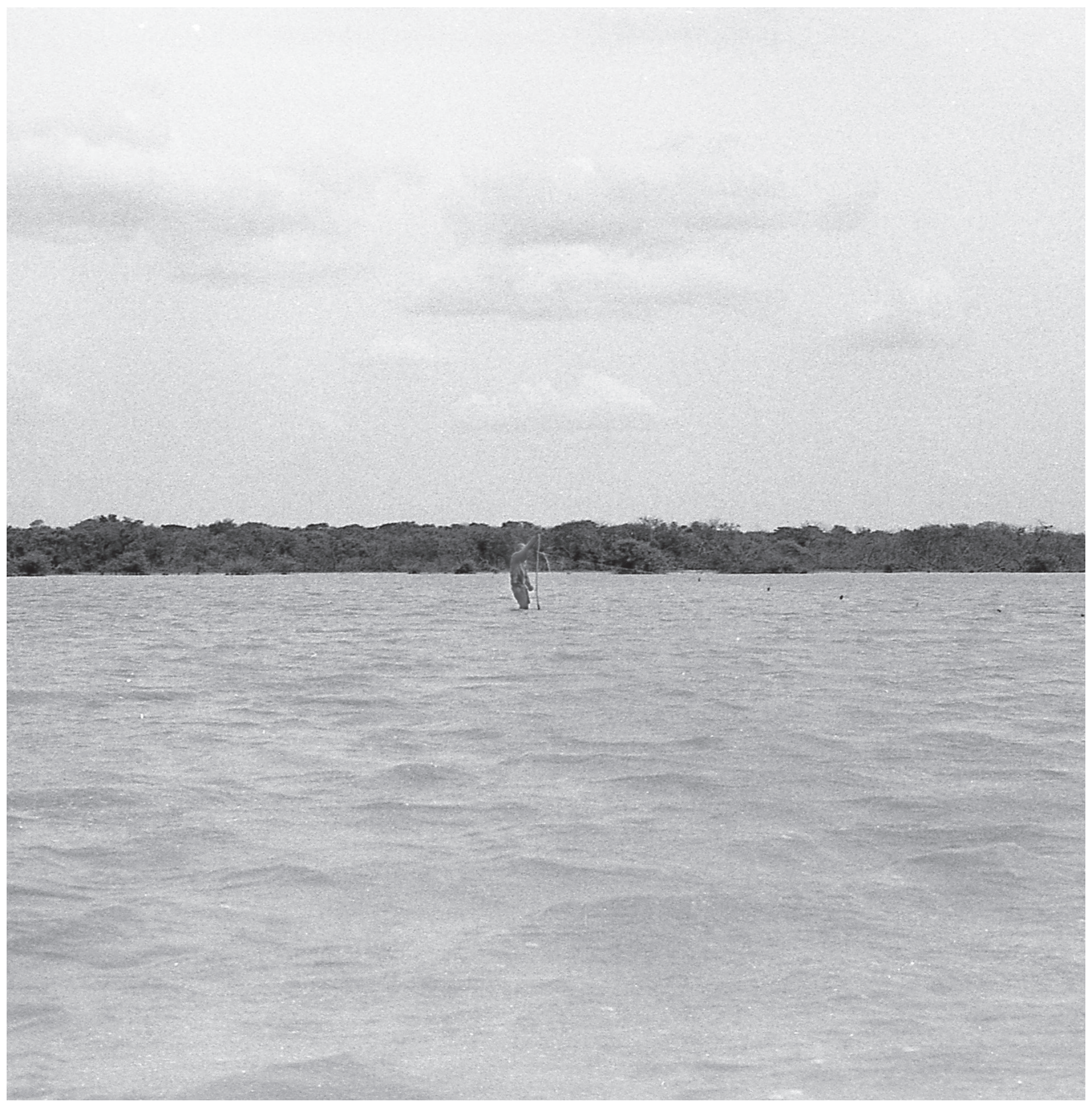

Man fishing in Laguna Grande at Sanctuary of flora and fauna the Flamencos, Rioacha, la Guajira, Colombia 
figure 25

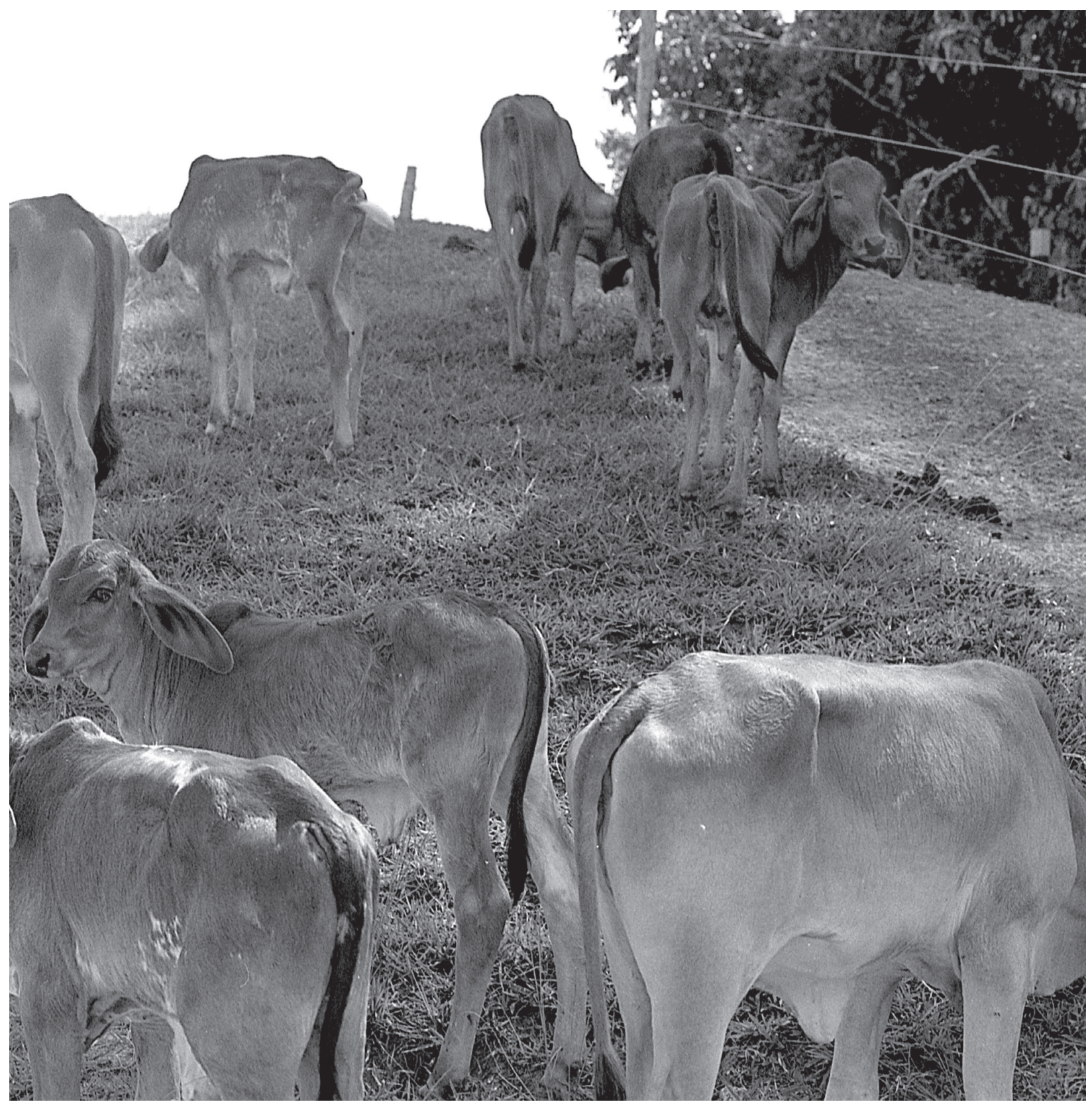

Cows at Horus farm, Caqueta, Colombia 
figure 26

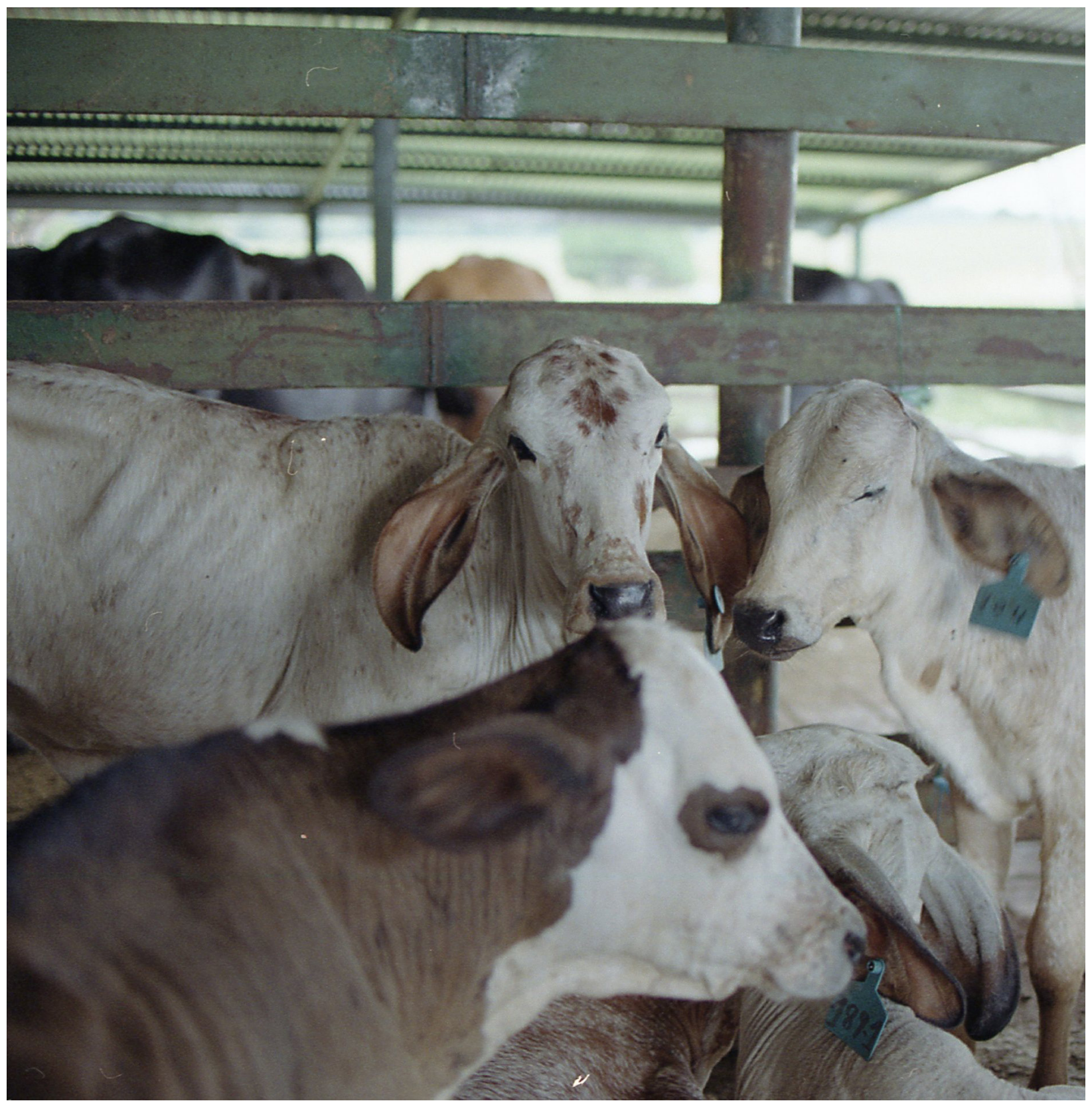




\section{Dwelling}

The house is

the junction of

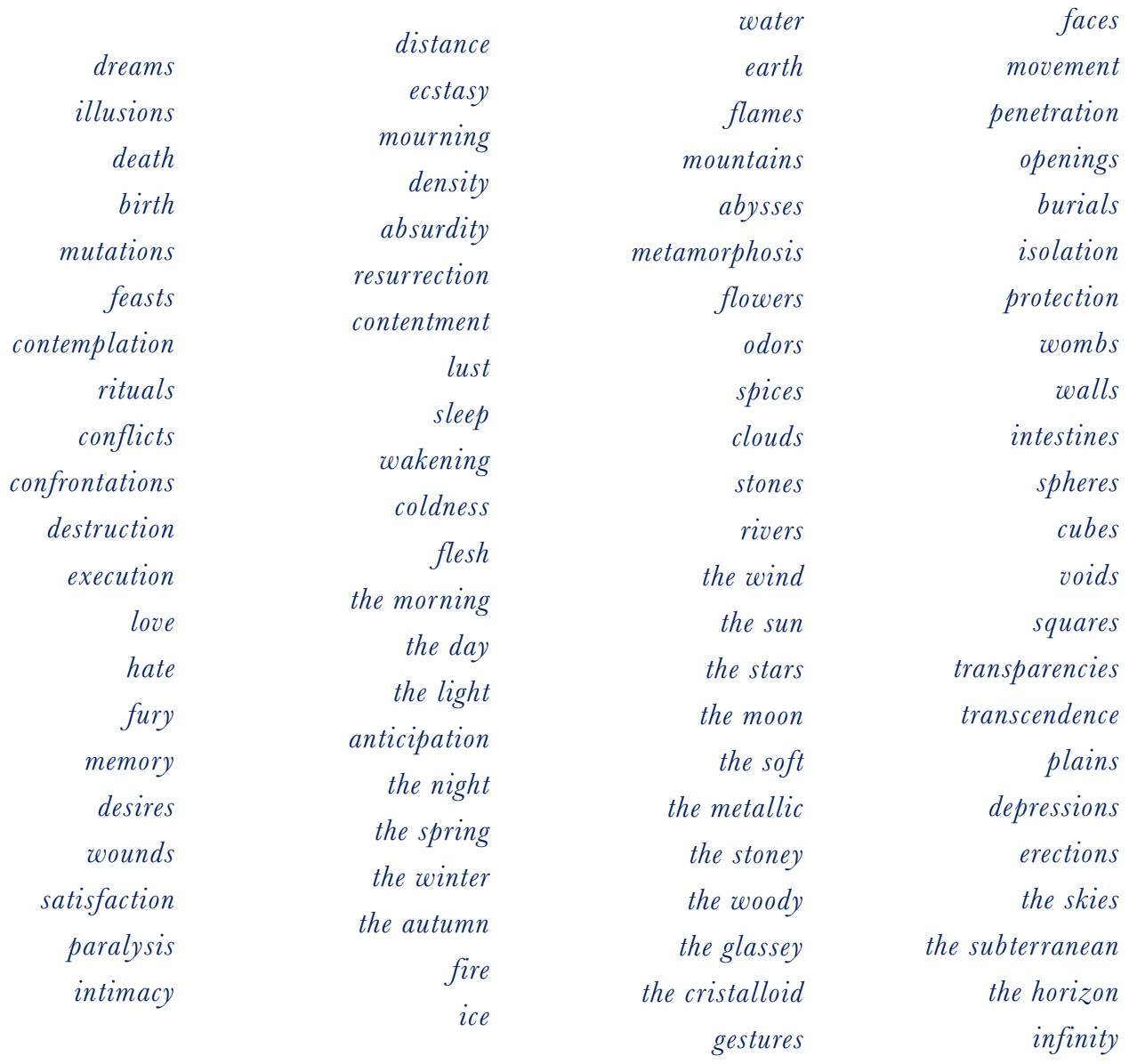


An area where we develop our own sense of place, space and habits is home. Our own dwellings become a medium for private/public, individual/collective and interior/exterior dichotomies. For Eliade, "houses are held to be at the centre of the world and, on the microcosmic scale, to reproduce the universe" (Eliade, 1983). Eliade refers to cosmos as a system that is perfectly synchronized (Eliade, 1983). Rural life is characterized by a stronger connection to the cosmos, since rural work depends predominantly on land, water, air and fire. Adding to this, Vitruvius also viewed the concept of house and home as having "the unique capacity...to realize and consider their place in the universe" (Barrie, House and Home: Cultural Contexts, Ontological Roles, 2017). This individual identity begins at home, in a personal space. However, the concept of home in rural Colombia is challenged, as some areas have a shortage of basic infrastructure to supply life. Mining towns are exposed to greater housing insufficiencies. For instance, in the area of Cesar, this deficit reached $95 \%$ near the mines, in contrast to $37 \%$ of non-mining municipalities. Regardless of these insufficiencies, the areas of Cesar and Guajira present a kind of vernacular dwelling, characterized by simple construction techniques. Paul Oliver writes about how "vernacular houses...were organized and materialized as means to harmoniously situate their collective culture in the world" (Barrie, House and Home: Cultural Contexts, Ontological Roles, 2017).

The Departments with the largest coal mines, Cesar and La Guajira, have focused on the economic programs for development for each department. Both areas have provided some kind of resettlements. But particular attention will be paid to La Guajira's Cerrejon in regards to housing. Being one of the longest operating mines, Cerrejon has a very organized structure and infrastructure for workers and locals living in the vicinity. The mining area also encompasses the concept of dwelling for visiting workers, specialized contractors, families and administrative staff. They provide a small citadel known as Mushaisa and it is located inside the premises of the mine. Outside the mine, the town of Albania, with 2,404 households and 8,641 people, lodges all the other workers and families. In this small town, the influence of the mine is very palpable because there are several monuments to the industry.

The company of Cerrejon has also been responsible for responding to the relocation of Comunidades in the areas of Las Casita, Roche, Patilla, Chancleta and Tamaquito. In an organized framework, they have established five steps for a sustainable resettlement process: first, a relationship is established with members of the community, and social capital is strengthened; then, along with the community, an action plan is developed following IFC (International Finance Corporation) guidelines; the third and fourth steps are the execution of resettlement process is then implemented with relocation to, and stabilization of the new site; and finally, closing the process (Reasentamiento integral responsable, n.d.). Adding to this, the company provides compensation of $150 \%$ of the land's value, payment of any damages and any dismantling cost as established by the government. 
The new houses, and new communities, cover some basic standards for living with an integrated sewer system and a layout that includes a toilet and a proper kitchen. The new housing communities cover an area of 300 ha, in which 100 ha are for housing, 100 ha for cattle, 70 ha for crops and 30 ha are natural reserves. The program developed by the company has helped reduce the MPI by providing better living conditions by legalizing land ownership. For instance, the average construction for houses is with wood sticks and mud (bahareque), and people do not have ownership over their land, which facilitates expropriation. Ultimately, these communities hope to symbiotically come to an agreement with the companies, by having an assurance that the relocation will improve their access to public services and the overall quality of life. Even though the new infrastructure can be better than the original place of living, Gaston Bachelard writes about this relationship of house and home, in modern cities, and how they are "far away, it is lost, we inhabit it no more; we are...certain of inhabiting it never again. It is, however, more than a memory. It is a house of dreams" (Vidler, The Architectural Uncanny, 1992). The relocated communities seek to find reconciliation with the social location by adapting from their memories to this new environment, the mining landscape and the new housing communities.

Speaking of dwelling does not necessarily mean a building. Heidegger explains this as "building, has ...dwelling ${ }^{1}$ as its goal" (Heidegger, 1993). The physical qualities of home - delineated in a house - are the framework for people to develop themselves. Superstudio's exploration, of the stages of life and the concept of dwelling/living, was analyzed in their 1973 video Ceremonia (Architecture, 2018). The video narrates how a community who lives underground show the way they live by focusing on what they do instead of showing the actual house and rooms. From the actors in the video, the viewer can imagine an 'invisible house' framing their actions. It is also explained that this new house is a memory of the old:

the house will be the projection and the dissolution of the submerged house. It will take from the submerged house only a flat surface, perhaps, or the axis the direction in which to grow. The new house will keep only a memory or the centre point of the old. If it's true that the ancient founders of the submerged house chose a site after having consulted the omens, then and also because we've lived there for a long time, the place is so sacred to us that we cannot abandon it

(Architecture, 2018).

In the quest for seeking reconciliation, the idea of having a structure and framework as parameters for something else to take place becomes essential to this process. The openness of Superstudio's house, their view of “architecture [as] a symbol of dominion, procreation and immortality" (Architecture, 2018), and the structured view of Heidegger become methods for 'deconstructing', and 're-constructing' the rural dwelling without losing the inherent values of home and house. In the case of Colombian mines, it is important to never neglect the dwelling of the rural population because its disappearance and fragmentation, due to violence and environmental conflicts, does not mean it is non-existent or irreparable.

In Heidegger's "Building, Dwelling, Thinking", dwelling is "the basic character of Being" 
figure 27 superstudio's ceremonia.
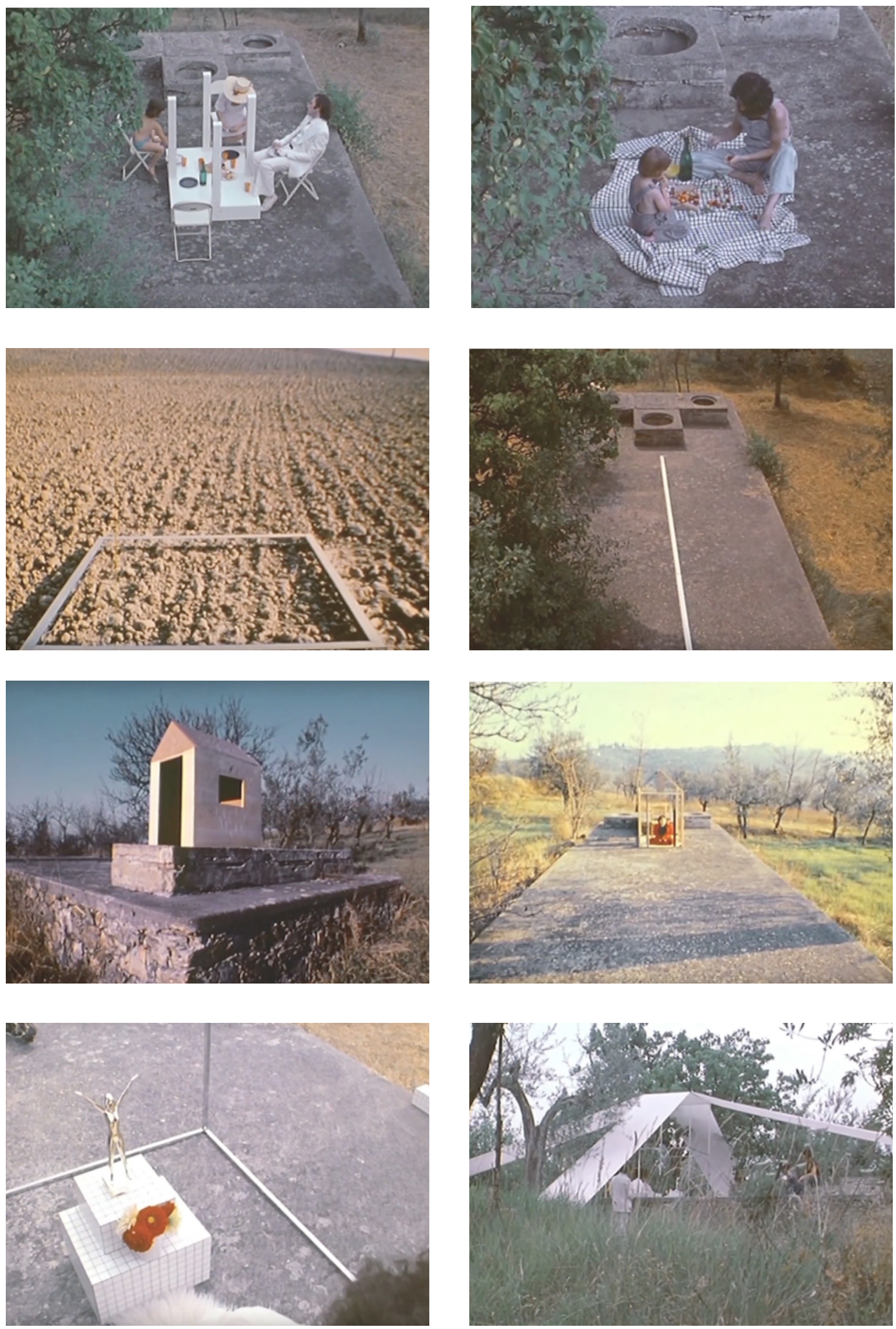

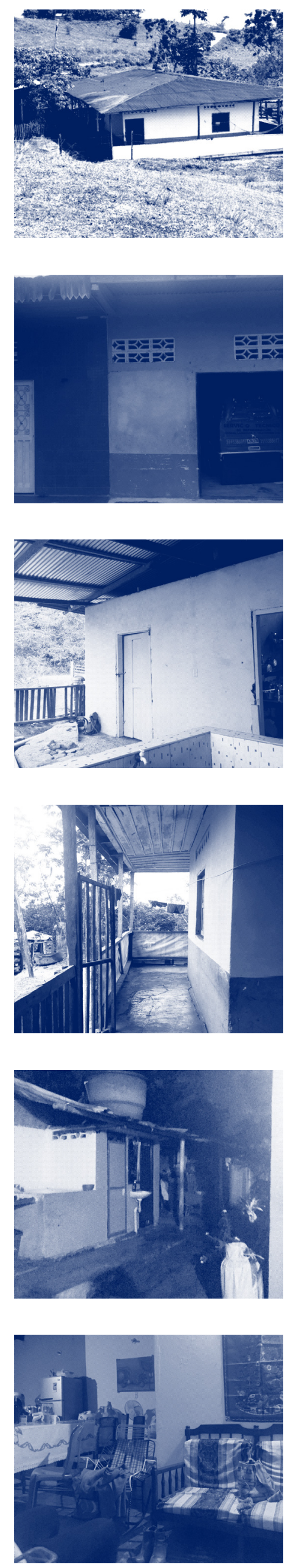
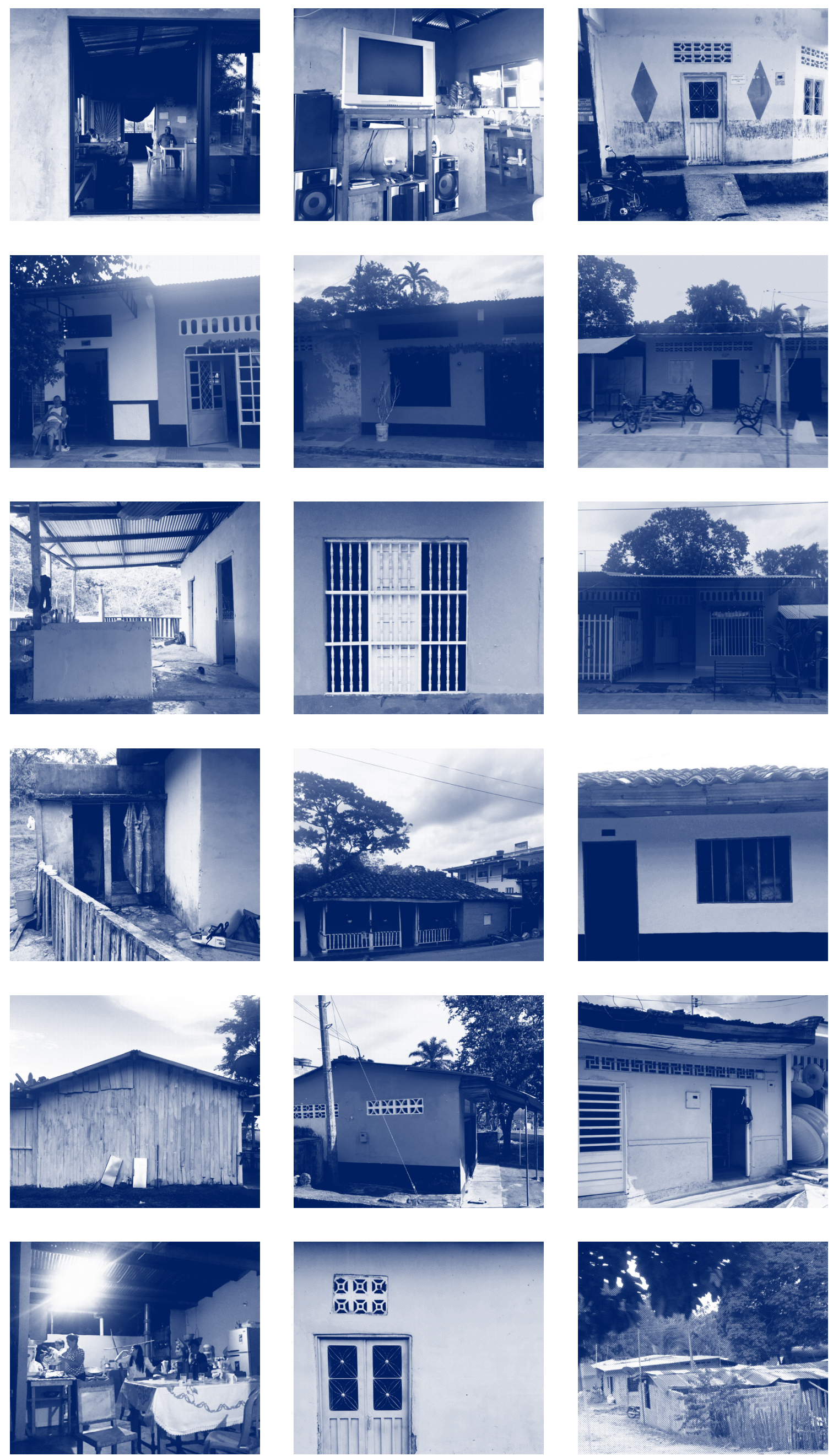
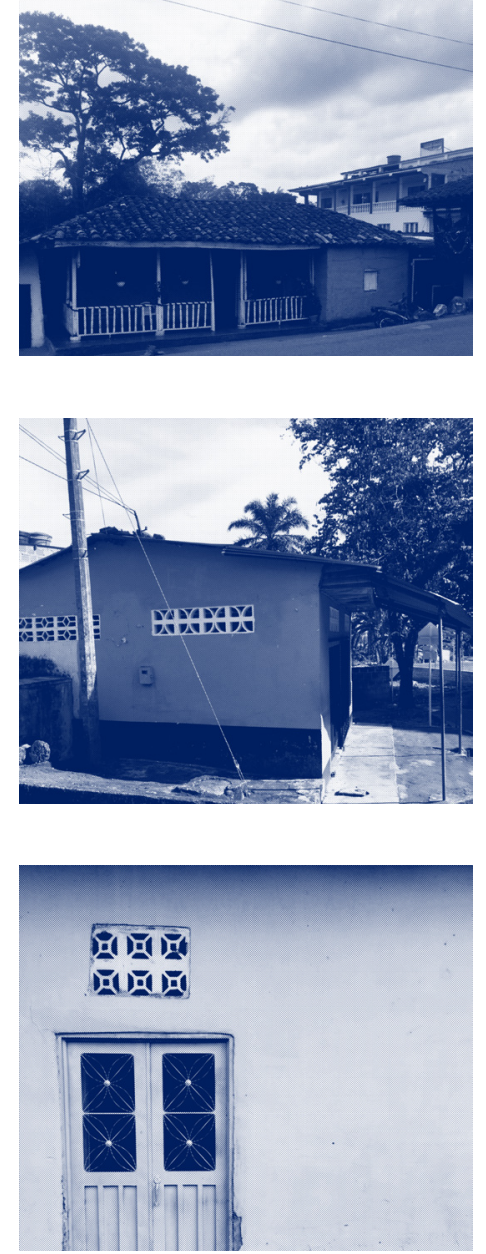
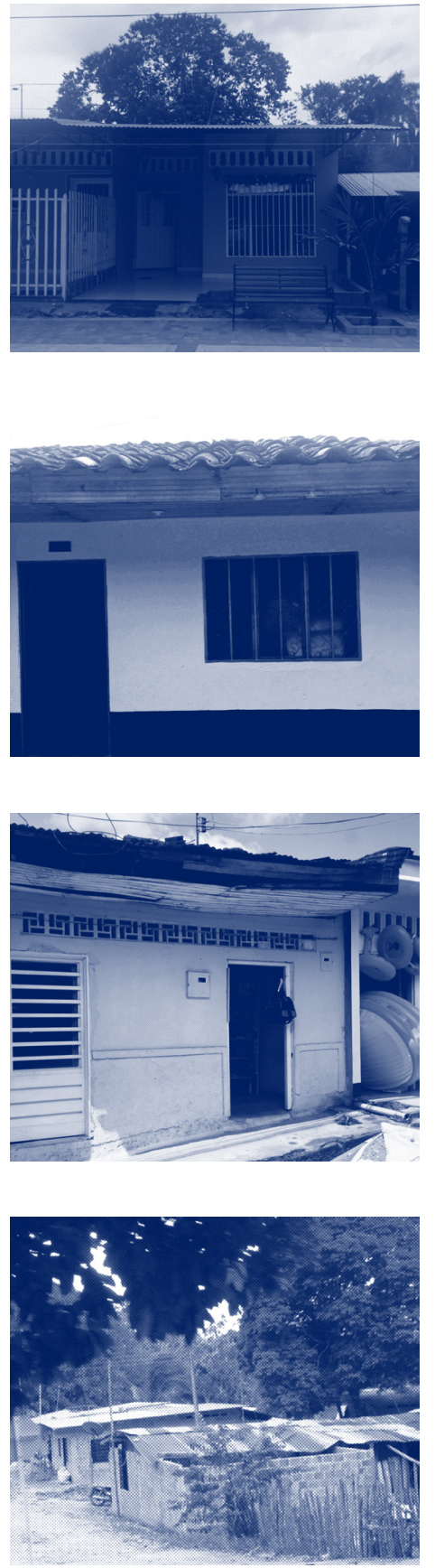

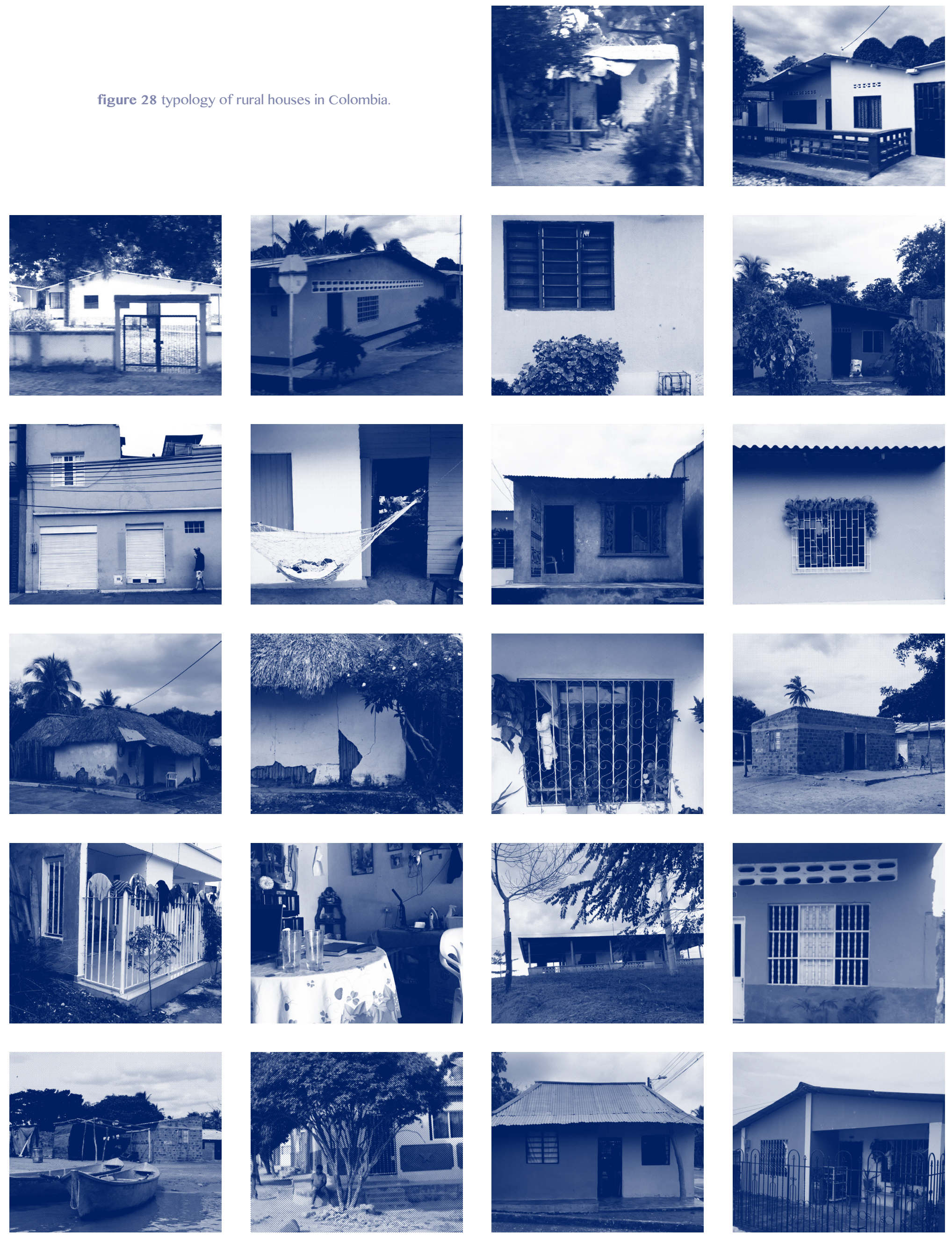
figure 29 four houses - these will be the centre of analysis because they have different interior spatial qualities, the interior/ exterior in some houses is ambiguous. These houses are located in San Antero, Monteria, Colombia and Caqueta, Colombia.

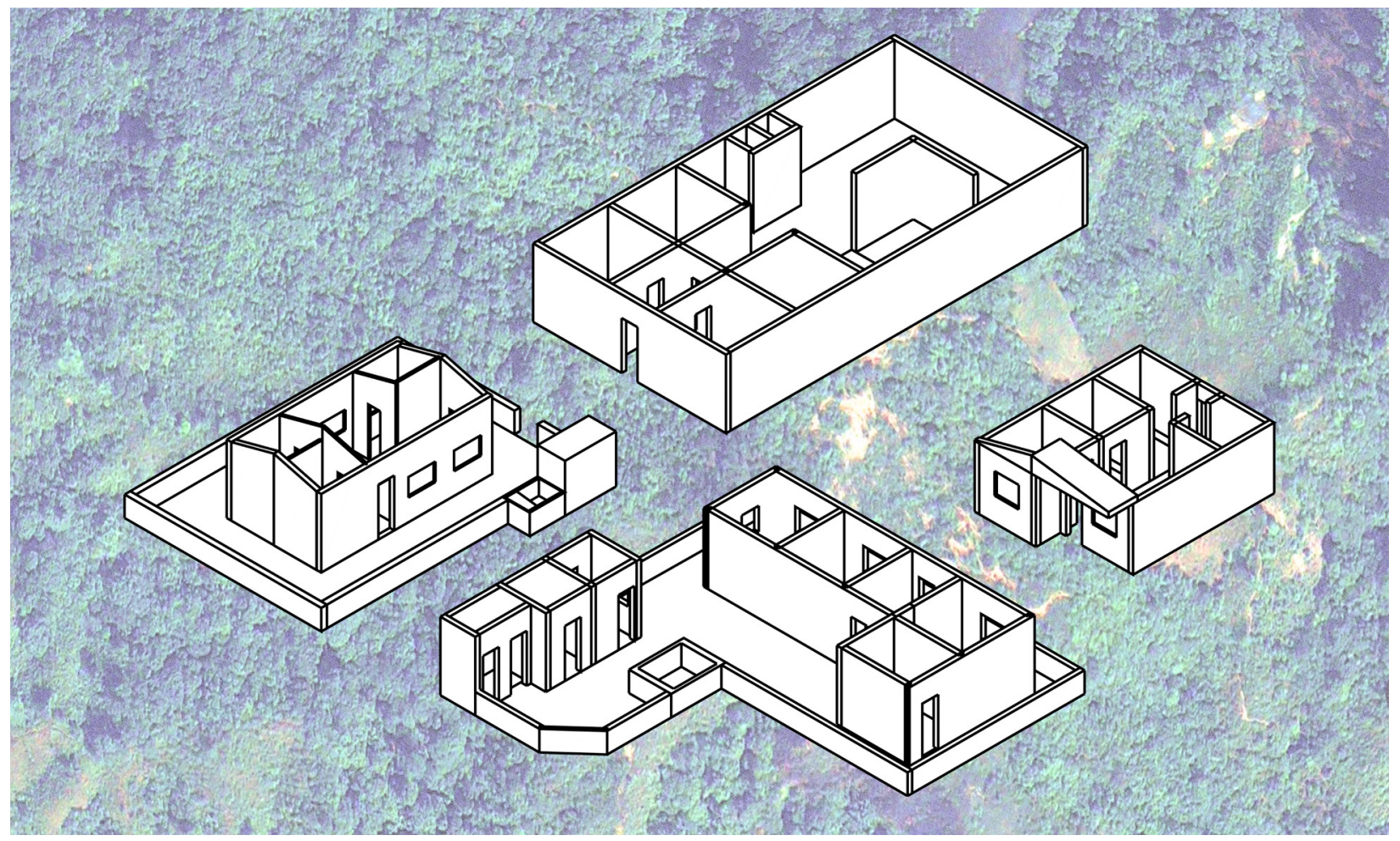


figure $\mathbf{3 0}$ one rural house

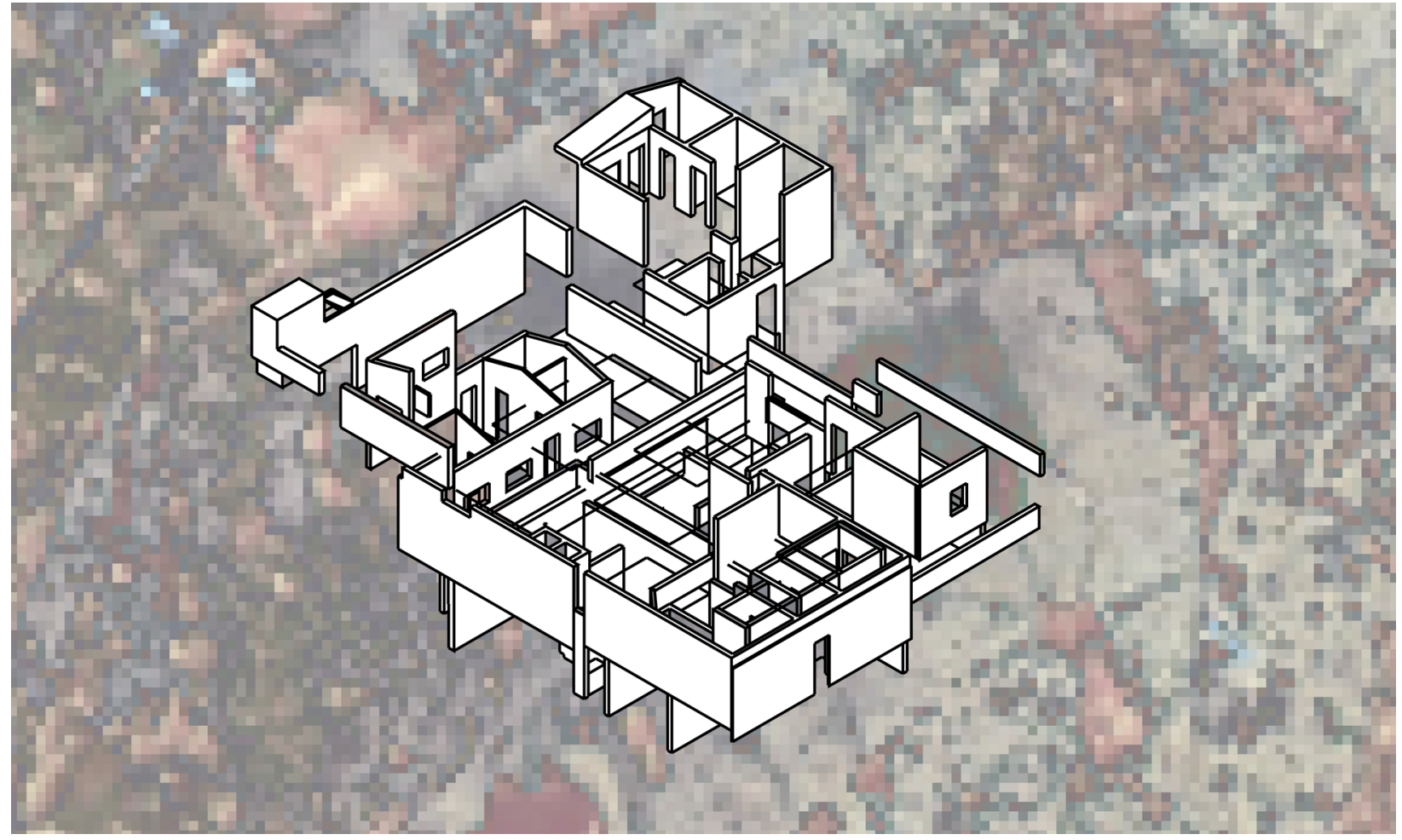




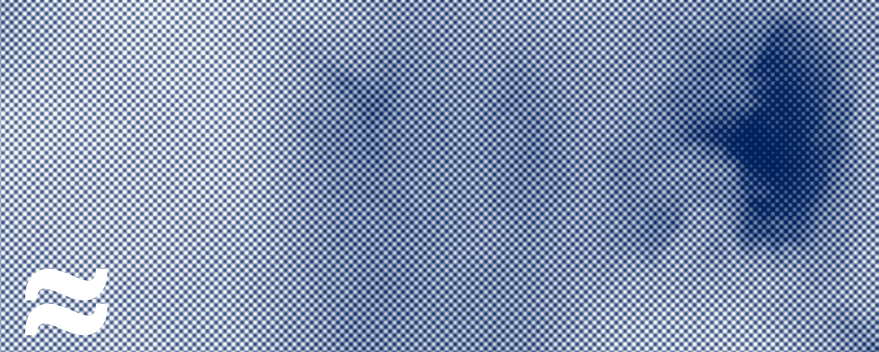

TRANCE

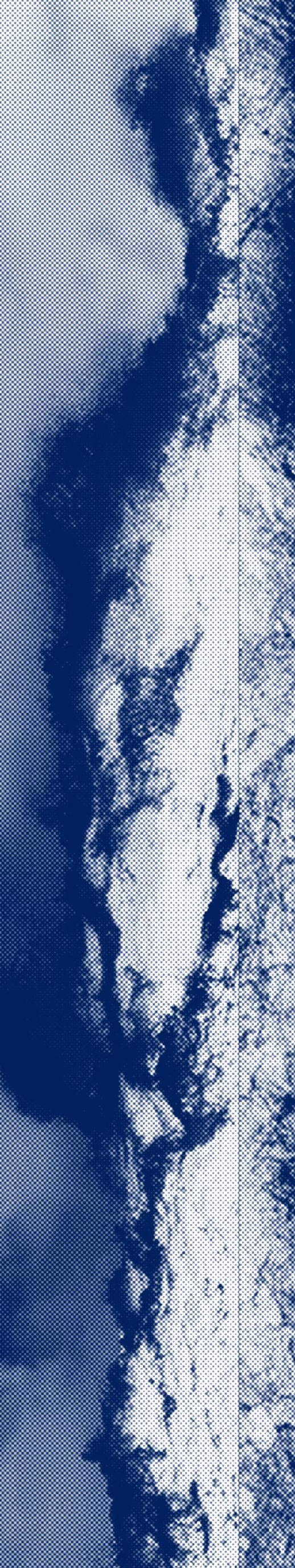




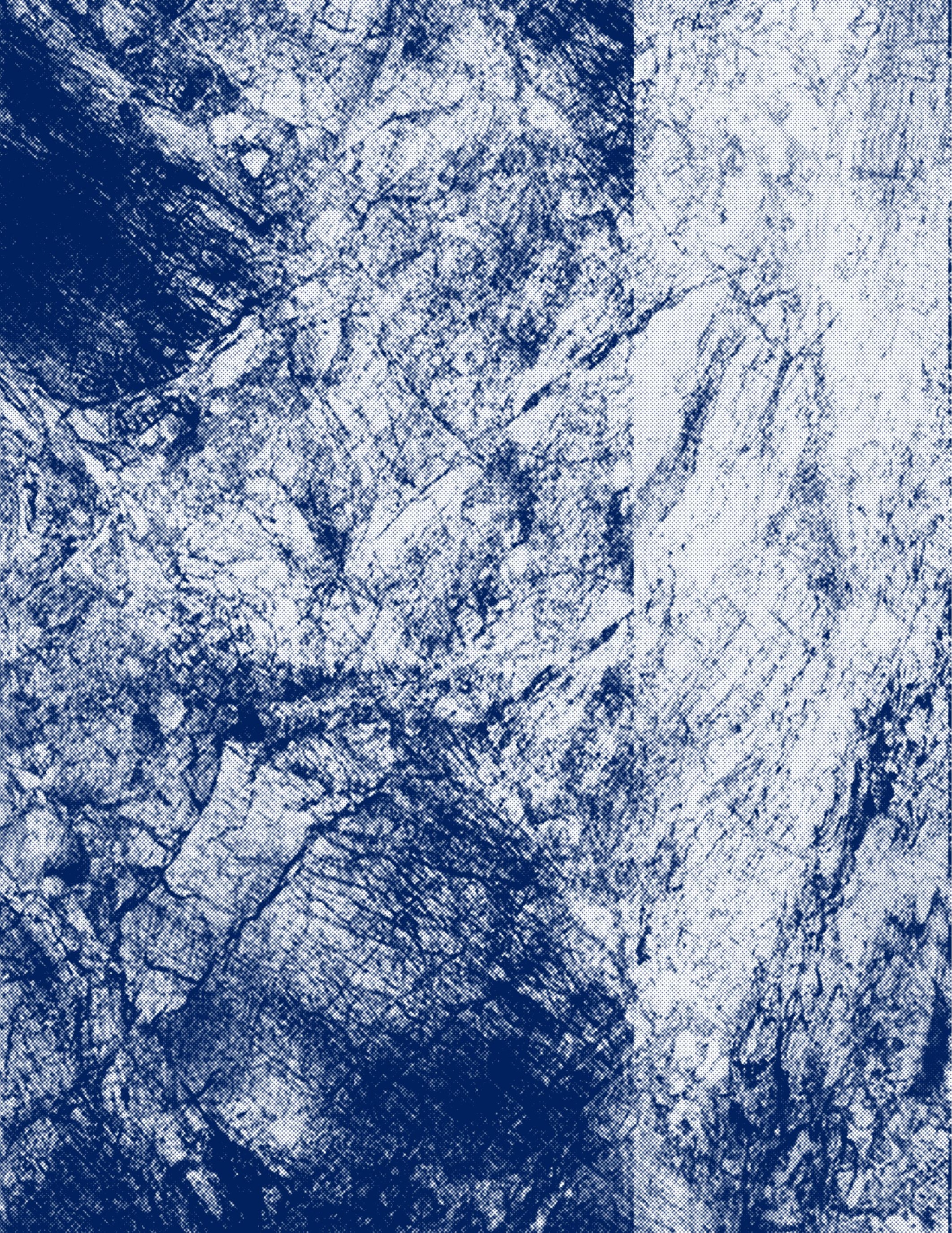




\section{SLOW VIOLENCE}

Any decisive moment, stage, phase, is characterized by a journey, a passage, or a transitional point that reaches to a final instant. Between the rural life and the death of the rural living, there is a condition of trance. From the Old French transe, it means the "passage from life to death" (Etymonline). Trance is also defined as "half-conscious state characterized by an absence of response to external stimuli, typically as induced by hypnosis or entered by a medium" (Oxford). The rural life is in a trance because during mining its inhabitants are in a constant battle of wanting to be settled in their own traditions, values to land and anything that composes life. But, they are also confronted with dispossession and forced displacement, loss of local and rural cultures and the moment of death of the genuine lifestyle. This difficulty is characterized by the dualities of investment and sustainable development and between global presence and local life, which lead to socio-cultural and socio-environmental harm. This harm is seen as slow violence ${ }^{1}$, because it is a kind of progressive violence that is far apart from the victims, yet close enough to cause problems, "a violence [of] delayed destruction that is dispersed across time and space" (Nixon, 2011). This kind of violence grows exponentially, and once it is visible, palpable, and/or known, the solutions become harder to find and accomplish and resolve.

Without being aware, the pressure put on ecosystems can carry severe consequences, sometimes visible or invisible, long-term or short-term. The mining industry exhibits both types of repercussions; the removal of soil (visible), the relocation of communities (visible/invisible), the relocation of rivers (visible/invisible) immediately affect organisms, plants and people, and the infrastructure for transportation (and exportation long-term) dividing and delimiting areas (short term). One of the increasingly long-term impacts, in both countryside and urban areas, is displacement. Although Colombia's main reason for the internally displaced results from conflict and violence, the mining industry has committed 'slow violence' by failing to appropriately relocate communities along the boundaries of the complete infrastructure that includes transportation (railway) and exportation (port). The rural areas where this network falls happen to be areas of need that lack a lot of basic housing infrastructure. Rob Nixon's Slow Violence also tackles an environmentalism of the poor that focuses on how traditional landscapes that are full of history, culture, traditions and legacy become the target for the neo-liberal development. Usually, these areas are inhabited by marginalized people who seek ways to improve their lives.

The dependency on non-sustainable industries, like mining, bond the people inhabiting the area of interest, the government with their legal framework, and the industries' objectives. 


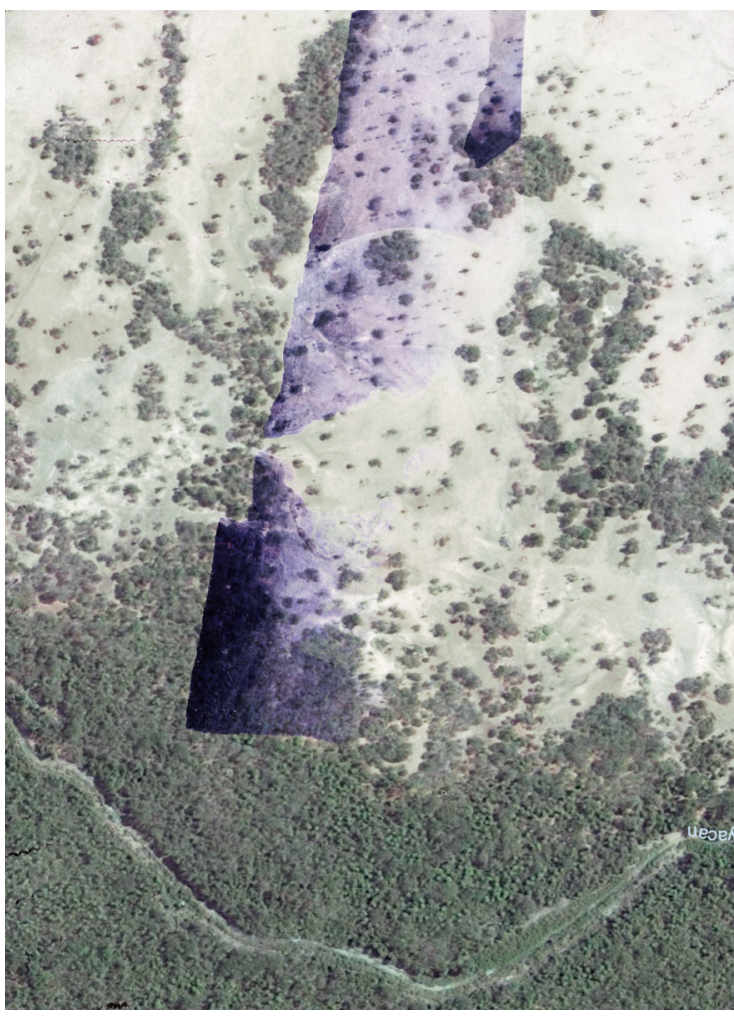

Regardless of the outcomes, each one has to live carrying the burden and benefits of mining. For instance, the long-term disadvantages of the mining industry are overshadowed by the financial gains from it. The coal industry in the Departments of La Guajira and Cesar accounts for 42.4\% (UPME_Informe departamental minero La Guajira.pdf) and 33.4\% (DANE_ICER_Cesar2015. pdf), respectively, of the departmental GDP. Both areas demonstrate that the presence of mining corporations completely dominates the economy of these two Departments. But once the operations are absent, the whole region will be affected because almost half of their income came from an industry that would no longer exist.

Slow violence and trance take place when people carry actions blindly, without considering the aftermath, usually resulting into drastic changes. Moreover, these alterations become hard to fix in such areas because it affects more than soil: the people with their beliefs and customs. 


\begin{abstract}
${ }^{9}$ And God said, "Let the water under the sky be gathered to one place, and let dry ground appear." And it was so. ${ }^{10}$ God called the dry ground "land," and the gathered waters he called "seas." And God saw that it was good.
\end{abstract}

Genesis 1:9

Waterbodies are characterized for creating union and separation, flooding and dryness, being large and small, still or transitory. From the different scales, rivers and creeks are the transitional elements that change from small streams on a mountain to lakes and/or seas. This change of scale shows the adaptability of water to its surroundings. Because waterbodies travel in different shapes and scales, any human activity will have an impact on them. In rural areas, the consumption and use of water go towards fishing, irrigation, and, more limited, for domestic use. They also become meeting points and communal spaces for leisure. However, the industries like mining bring environmental damages, through overuse of water, at least $17 \mathrm{M}$ per day, and the relocation of rivers, such as Rio Rancheria and Bruno Creek in La Guajira and Rio Calenturitas in Cesar. Rio Rancheria, 248 $\mathrm{km}$, begins at Sierra Nevada de Santa Marta's Mountain of Chirigua and ends in the Caribbean Sea. The river is used for agriculture (corn, rice, banana, palm oil and beans), cattle raising, and domestic used, benefiting 420,000 people. Between 2003-2012, the company of Cerrejon carried out a Consulta Previa, or prior consultation with the locals to address possible compensation for the relocation of a river. This tool was used to relocate the river $26 \mathrm{~km}$, which would progressively affect the municipalities of Barrancas, Albania, Hatonuevo, Maicao, Fonseca and Distraccion (Gacs, 2013). The company approached them with the benefits the locals could gain, like getting more cattle, construction of more schools, hospitals and community centres, and the overall improvement of life quality and more job opportunities. The response from the indigenous community was generally positive with 103 of 113 communities agreeing. As it is known, the area of La Guajira is one of the poorest of the country, and seeing such an opportunity gave them hope, regardless of the environmental damage. The company has also developed jagüeyes, a large pool of water, and wells in order to supply for the absence of water. But some communities have not been able to fully benefit from the company's decision. The relocated community of Tamaquito saw the limitations of living so close to the Cerrejon mine, by not being able to go fishing or hunting because the river was within the mining concession (Osorio, 2011).

From a religious perspective, water becomes an element of cleansing and reconciliation. In Christianity, there have been events that marked a transition for betterment and new beginning through water. In the old testament, Noah's ark and the flood was "God's reason...to destroy all the earth's wickedness" (Life Application Study Bible, 2015). The coverage of the whole surface of the 
[this page] figure $\mathbf{0 2}$ life and slow violence, in the form of the railway infrastructure.

[next page] figure $\mathbf{0 3}$ slow disappearance of some waterbodies in Cesar near the mines. Rio Calenturitas runs for $32 \mathrm{~km}$ and it is part of Rio Cesar flow. Its location falls within the mining regions of La Jagua de Ibirico (30\%), El Paso (6\%), and Becerril (64\%). From observing some terrain maps, it can be seen that disappearance of Rio Calenturitas, Arroyo San Antonio, Rio Tucuy, have been imminent due to mining.

[following page] figure $\mathbf{0 4}$ slow disappearance of some waterbodies in La Guajira near the mines. [page 90] figure $\mathbf{0 5}$ absortion of water into the soil as a result of the use of explosives for mining. [page 92-95] figure 06 hypothetical emergence of water inside the mine.

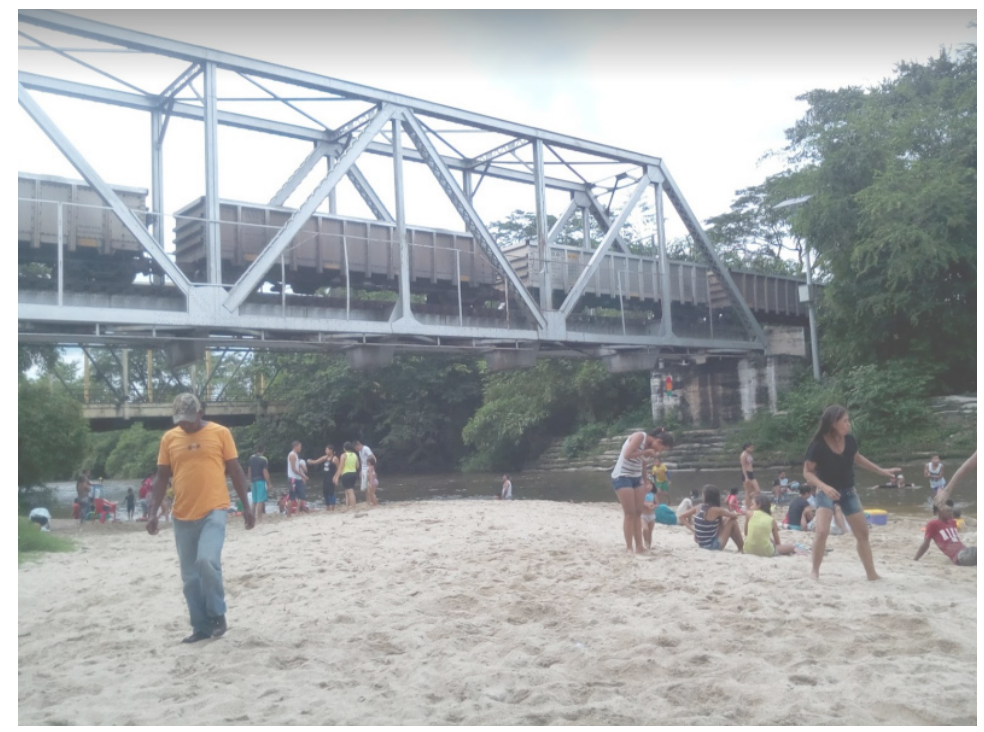

earth ended some of its inhabitants and all kinds of living organism. Another major event was the partition of the Red Sea as the gate towards exodus, which led to a journey of 40 years, detached from anything material, while seeking to settle on a new land. Jacob and Esau's long-time dispute was resolved through the presence of a well, which then became a symbol of reconciliation. As part of the Christian sacraments, the first one is baptism, which is about "washing with water to demonstrate cleansing from sin, linked with repentance and admission into the community of faith" (Life Application Study Bible, 2015). In the spiritual sense, water is the symbol of alliance with a community, and a tool for changing our mistakes, and starting again within the moral laws and spiritual beliefs of religion.

Water, as noun and verb, is the element that helps connect with $a$ something else: either another location or another spiritual level. There is a dichotomy of how overuse or underuse can have consequences: a flood hides the wanted, but a drought reveals the unwanted. Regardless of how water is used, water is life. 
1950

1960
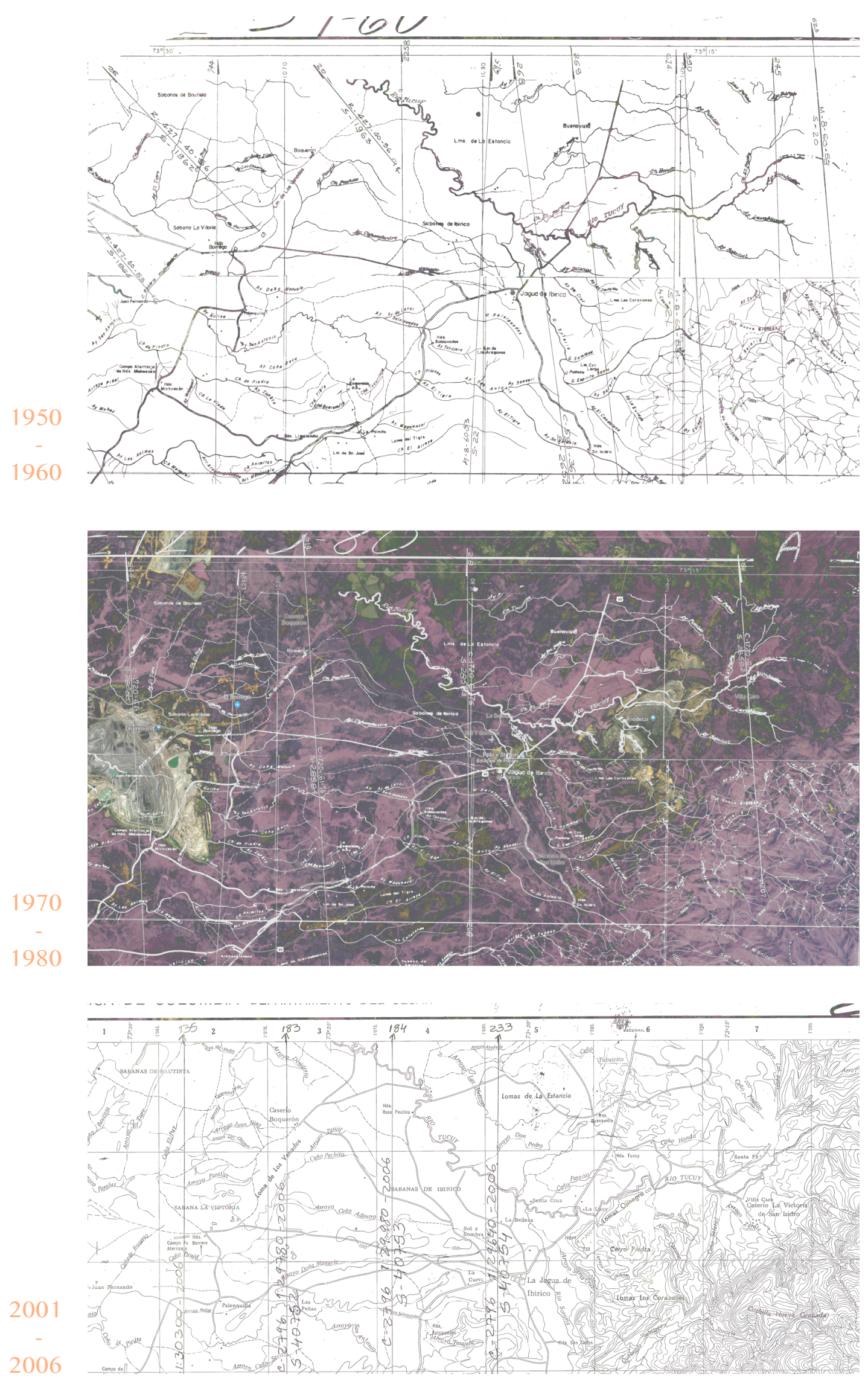

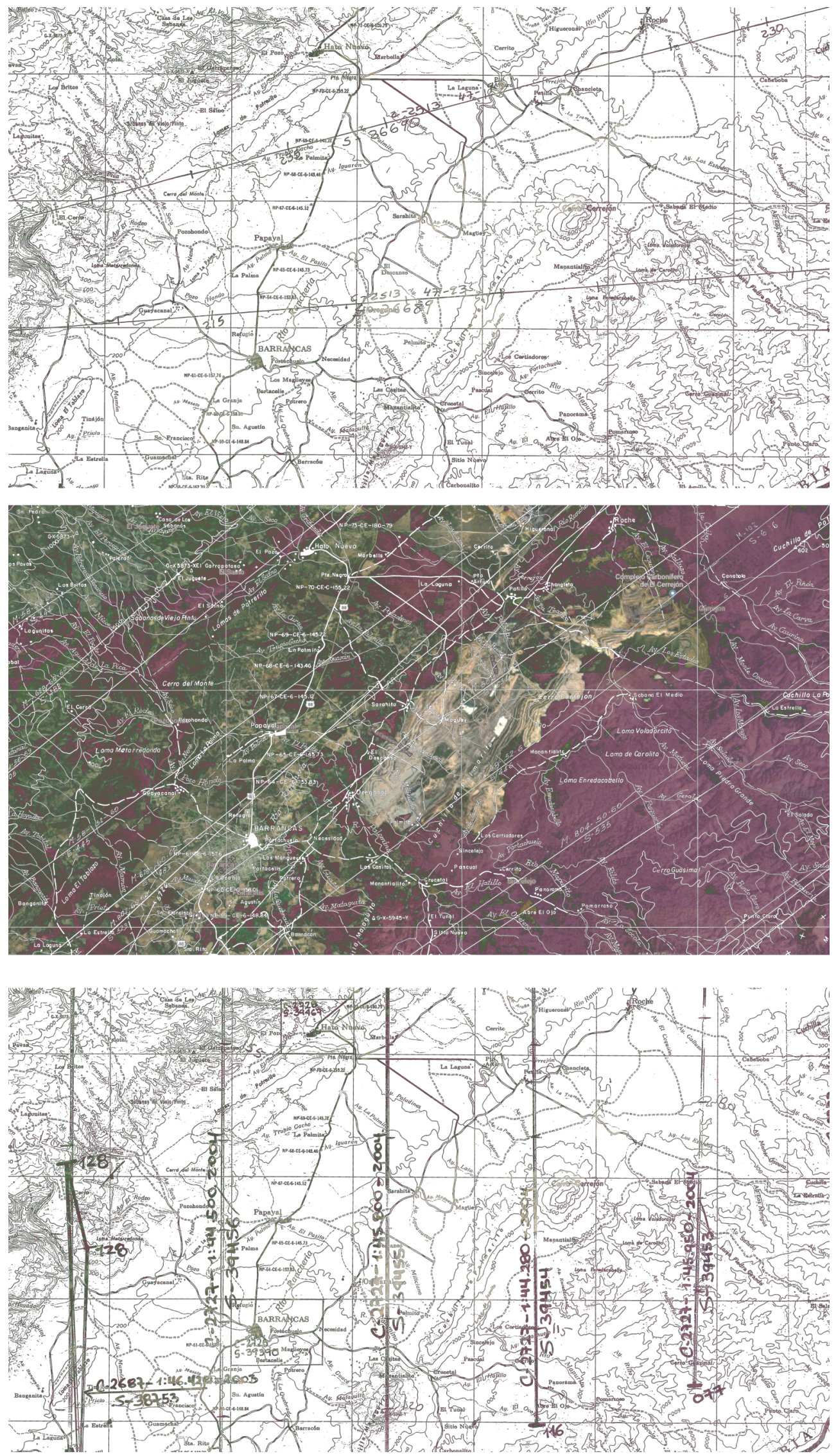


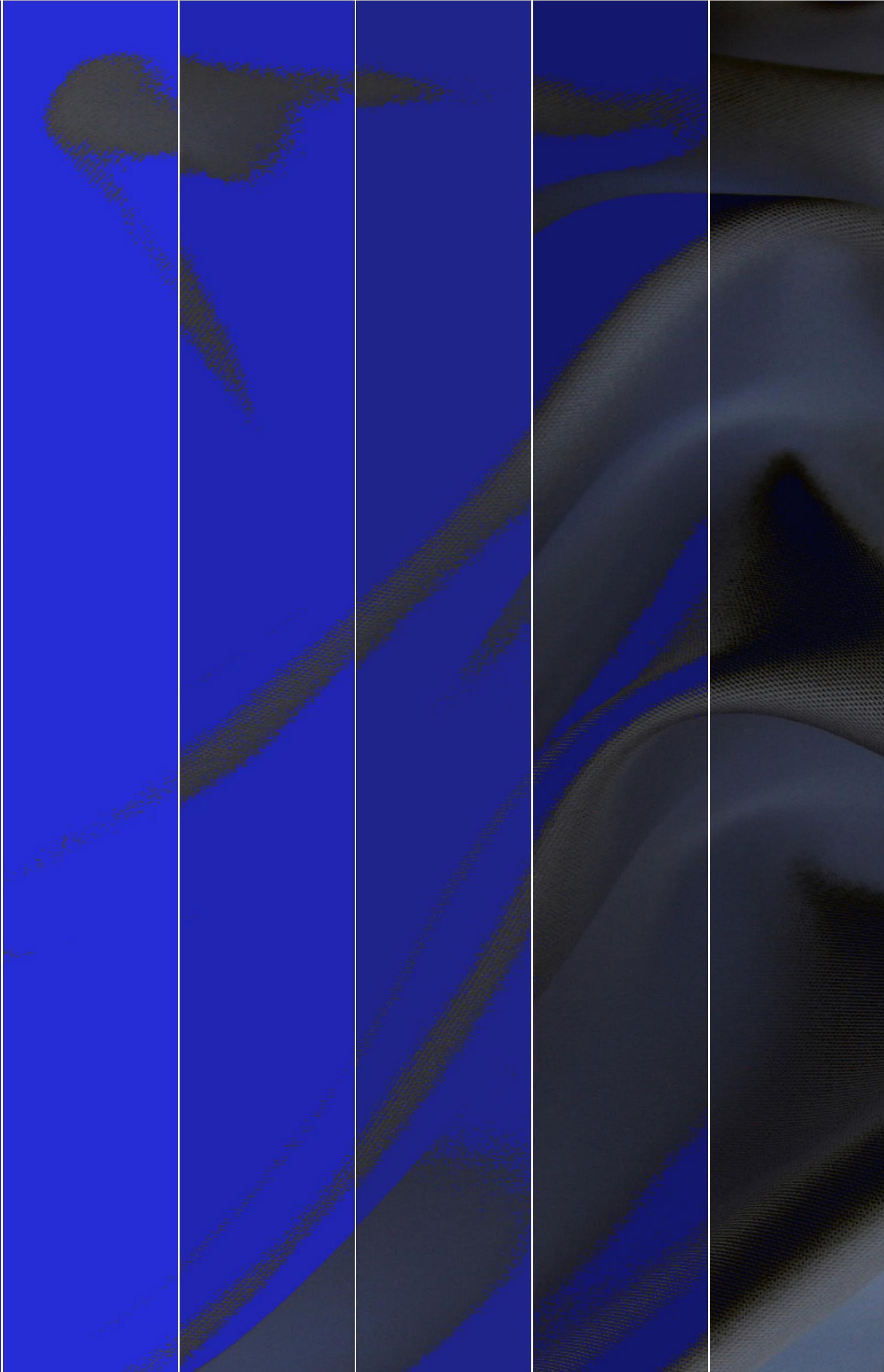





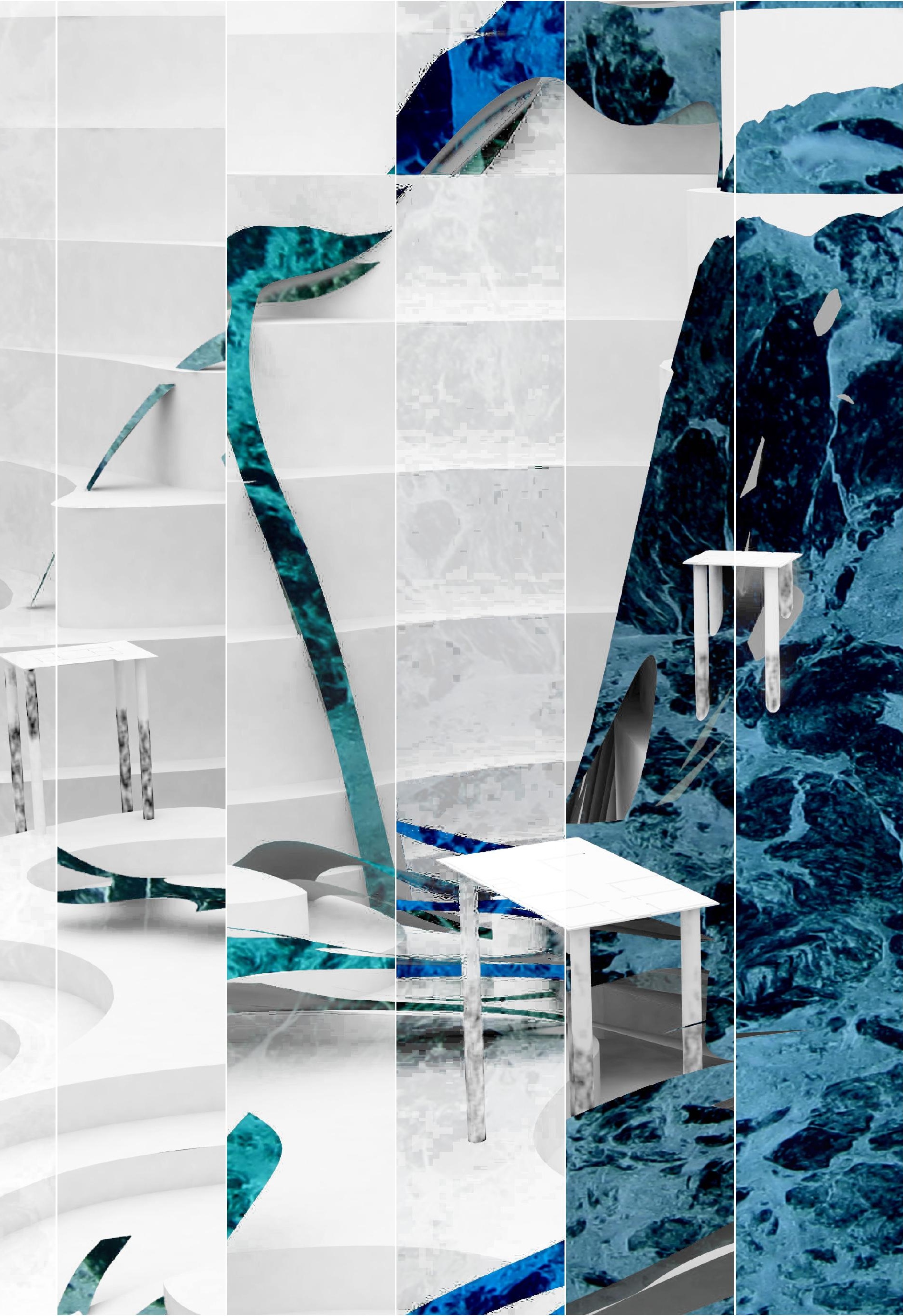




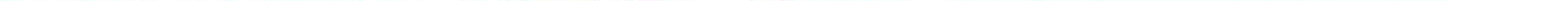




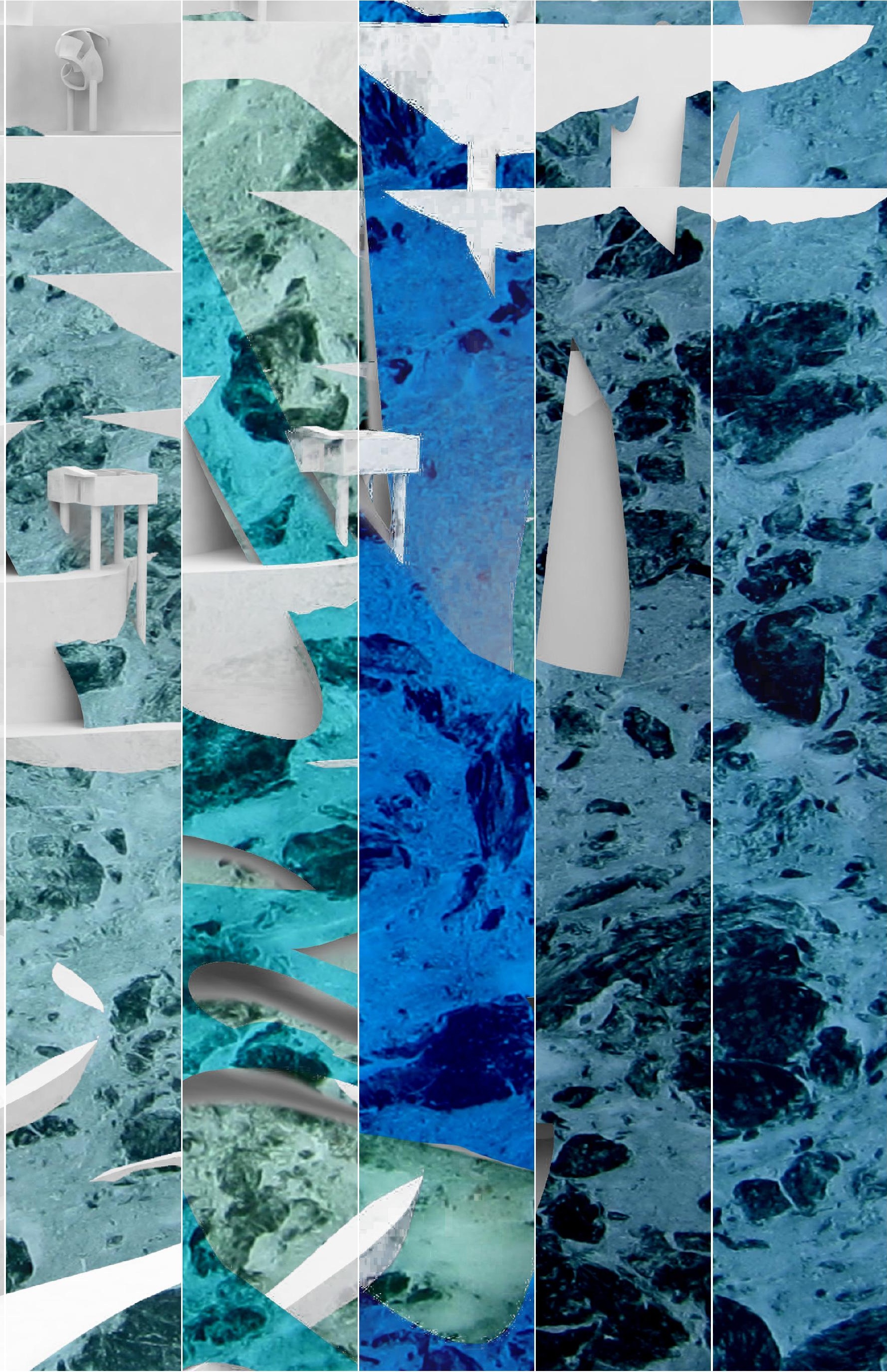




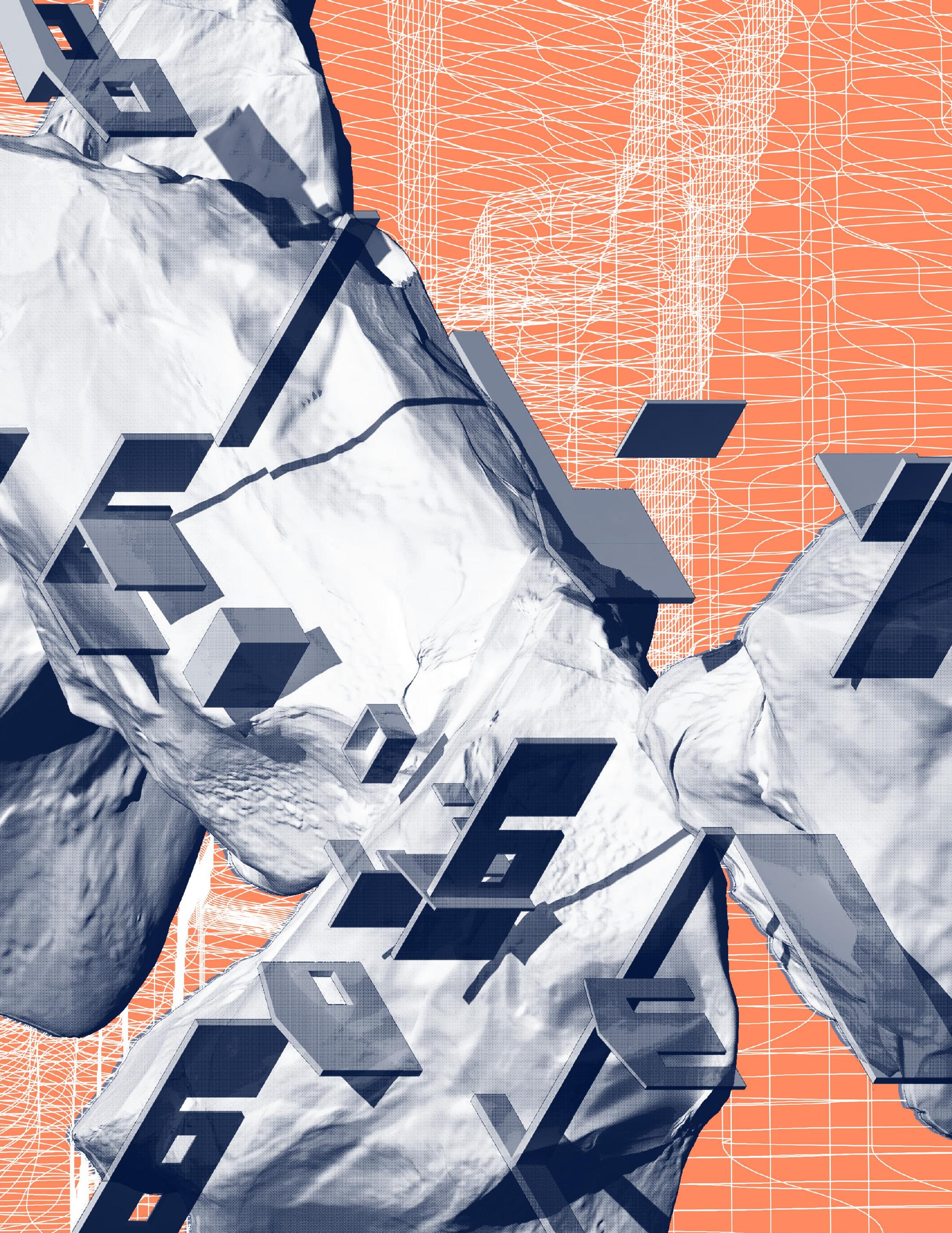


figure $\mathbf{0 1}$ the actions done over the land create a new paradigm; to bring opportunity and re-structure an existent culture, or leave the existing conditions and leave the terrain as it was? Either way, communities are always the target for negative repercussions.

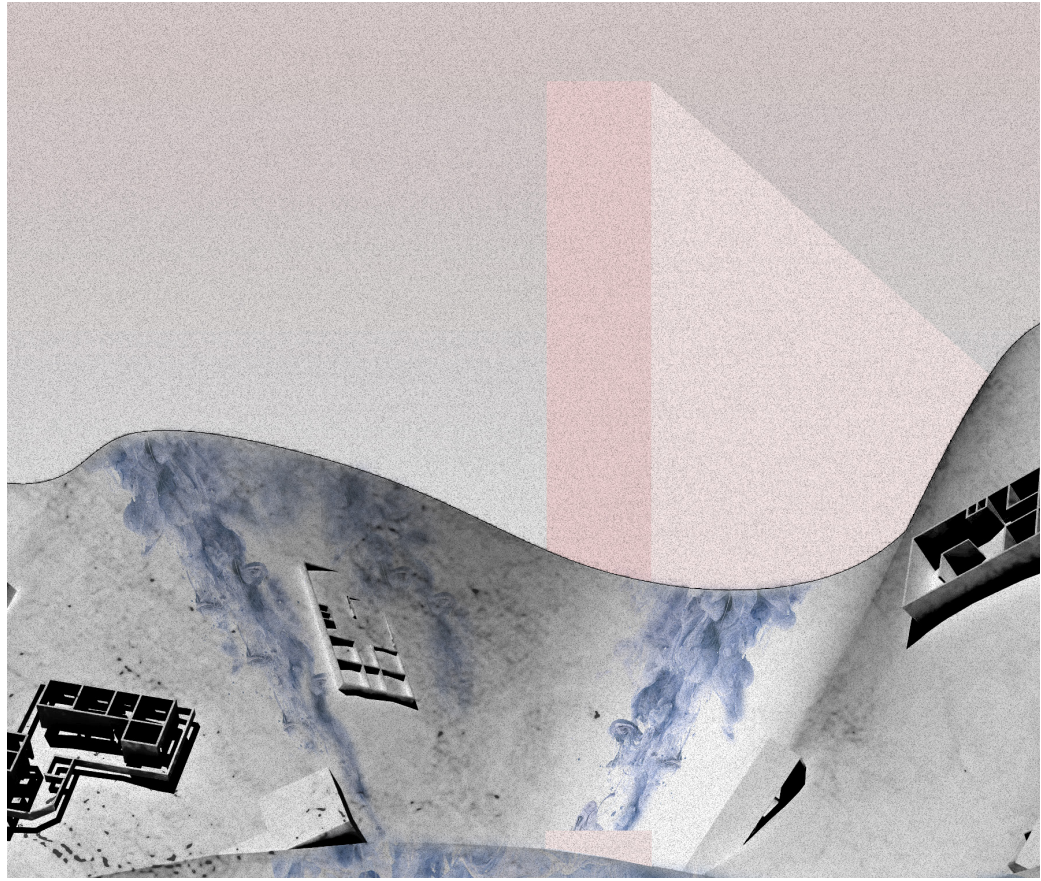

From a biblical perspective, Exodus meant the voluntary displacement, or escape, from oppression towards a promised land that would bring hope and re-birth of a new community - freed from slavery and domination. Its etymology comes from ex meaning "out" and hodos meaning "a path" (Etymonline), in which it was necessary to know a direction in order to leave. Rather than an exodus, which happens in an organized manner, rural Colombian locals face displacement, being characterized by dispersion, dispossession and disorientation of the people and their living conditions. The social consequences due to the lack of living alternatives once farmers leave their land, or flee the countryside have repercussions in how communities interact with one another, how families deal with loss, and most importantly, how house and home are reinterpreted as people are detached from it. With the Victims' Law and Reinstitution of Land (Ley de Victimas y Restitution de Tierras), the government has proposed a strategy to give back land to victims from the internal conflict, which opens up the possibility to bring back the agricultural condition in the country. However, any action taken will always be followed by a spectre, or what Derrida would define, as Hauntology, of both mining and internal conflict. Furthermore, the exodus becomes a spatial estrangement, the consequence of a force that generates an evacuation, or a void in the land resulting from mining. 


\title{
DISPLACEMENT AND RETURN
}

\author{
Return poses both a challenge and a promise that are far in excess of the \\ mere reversal [of] time. It is the most necessary move in the implementation \\ of decolonization because the notion of returns demands the complete \\ reorganization of modes of property ownership and the relation between \\ multiple polities and territory. \\ Eyal Weizman
}

The life and environment of rural areas, particularly in Colombia, are always contested by governments or by insurgents, leaving campesinos and minorities as victims of forced displacement and dispossession. However, the abrupt departure from the rural routine brings challenges. For instance, the arrival to new environments - specifically to the city - is presented with lifestyle changes, new customs and a sense of loss and nostalgia for the rural home. Heidegger writes about "homelessness, rootlessness, a failure to connect, was becoming humans' destiny" (Vidler, The Architectural Uncanny, 1992). Although he writes within the context of a post-WWII European society, where the impacts of political division and a destructive war impacted cultures and societies, this can still be perceived in today's context. The Colombian scene has been seen through the lenses of economic pursuit, socio-political differences, and social problematics, where war and violence have become the vehicles for producing power, fear and tenure. The impact of these are shown in the constant decrease of the rural population, from $50 \%$ in the late 1960 s, to less than $25 \%$, in 2016 , (Colombia - Rural population, n.d.). One of the most predominant reasons for such rapid decrease is the 50-year-long internal conflict. While the main purpose of the internal conflict is seeking tenure and ownership of fertile lands, it has actually led to mass displacement of farmers and peasants.

The economic interest in the land is to maximize profit over natural resources. The neoliberal approach to such practices guarantees neo-colonialism, where a superpower overtakes a developing country. In a country like Colombia, where there is instability in the social fabric and an existing war going on, the areas of economic activity, like mining, are also subjected to social violence. At least $80 \%$ of human rights violations through violence is higher in areas where mining occurs. The main victims are union leaders, indigenous people and afro-Colombian communities. These industrial areas also account for $87 \%$ of forced displacement (Valencia, 2013). The link between mining and the internal conflict seems to be inseparable, and the displacement of cultures becomes unavoidable. The neo-colonization of the rural Colombian landscape is filled with homelessness and rootlessness due to the loss of cultures caused by the disputes over the soil.

Inherently, the term displacement implies a transition or translation in space and time, from one point to another. Although not always the case, there should always be a possibility of return. Eyal Weizman's Decolonizing Architecture Art Residency (DAAR), who studies Israeli- 
Palestinian relationships, proposes return and returns as concepts for understanding decolonization of land. DAAR defines returns as the right of return in daily material practices. Return is understood as "coming back to one's places of origin and one's property" (Petti, Hilal, \& Weizman, 2013). Although DAAR writes from the perspective of the Israeli-Palestinian geographical division, his analysis can equally be applied to rural Colombia, where it also faces division and social polarization between different cultures and groups. The Colombian returns will be characterized by the ability to return to intangible qualities of the daily life in a new landscape shaped by mining. This new site will drastically change the relationship between the land and its people, striving to regain the soil as home, to gather communities again, to re-establish one's life and activities, cultures and traditions, to break the barrier of neo-colonization, and live in a post-colonial setting. For return, it is the physical transition back from the city, while seeking back domestic life in semi-industrial spaces within the newly created countryside. The challenges arise with both kinds of return(s)as the locals are repeatedly changing where they live, from rural to urban, making it difficult for them to fully grasp, adapt and develop stable ideas of life, dwelling, new and old traditions. 
figure $\mathbf{0 2}$ return and returns

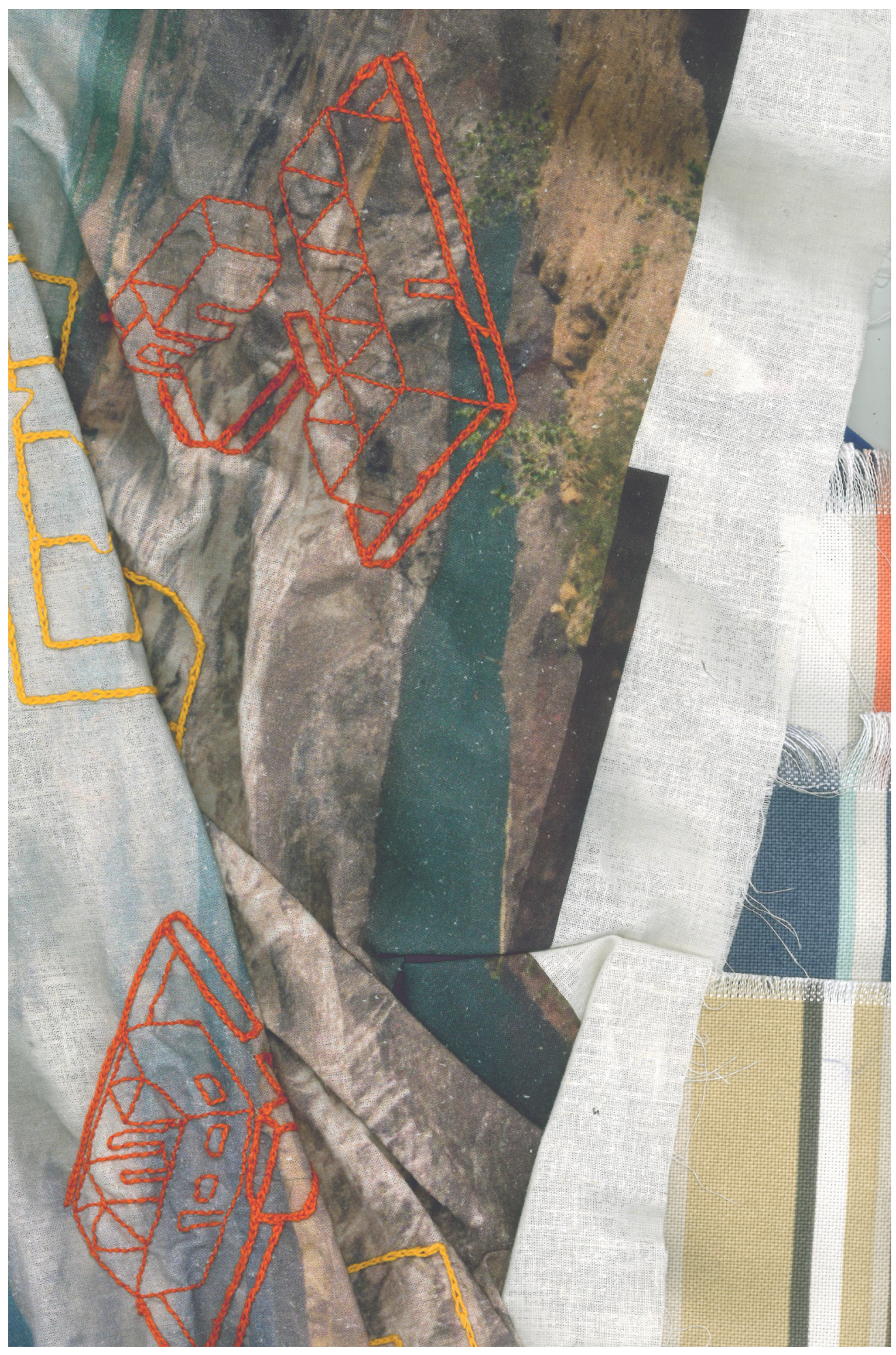


Hauntology

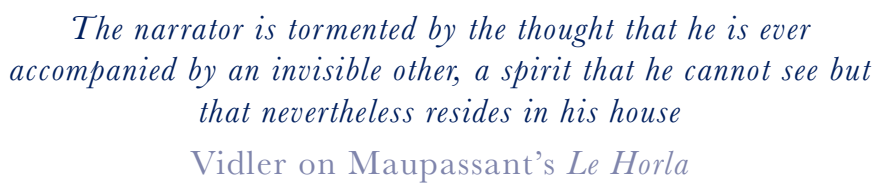

The exodus and displacement as a result of neo-colonial domination leave a trace, or as Derrida would define, a setting indirectly dictated by hauntology. This term is derived from the idea of haunting ${ }^{l}$ of being and ontology of haunting. Haunting of being means "presence is shadowed by un-acknowledgement of histories and suppressed relationships that disturb the present's complete severance from the past" (Demos, 2013). Some examples of hose this manifested in Colombia is through the reforestation of open-pit mines, the regulations and policies of the government aimed towards the improvement of rural life, the housing projects for displaced campesinos and any program for socio-environmental and socio-cultural rehabilitation. All these aspects, which at first glance look positive, are hiding the past and the realities of neo-colonization. For ontology of haunting, Derrida defines it as "the being, effects, and affects of possession" (Demos, 2013). In other words, it is the repercussions on rural Colombia, its inhabitants, and the idea of dwelling, caused by neo-colonization through globalization and neo-liberalism. The Colombian hauntology is a method for seeking transparency on a neo-colonized and mined territory, by exposing the real elements and artifacts that make up the site and attempting to avoide the complete eradication of the past.

Part of the etymological root of 'haunt' juxtaposes the idea of home (the living) and ghosts (the non-living). This dichotomy is omnipresent in mined rural Colombia from the lens of its inhabitants because of their loss of house and home; displaced populations long for their return to their 'original' home but are encountered with only traces of it. Hauntology is also defined as "a restatement of the key deconstructive claim that being is not equivalent to presence. Since there is no point of pure origin, only the time of the always-already, then haunting is the state proper to being as such" (Fisher, 2013). Colombia's hauntology is about finding the essence of home in the context of an absent home, because home does not necessarily have to be tangible. Moreover, because of the long history of traditions and cultural values developed over time and generations, it is undesirable to restart a new set of views. Instead, the return towards the haunted site will develop a hybrid culture between the 'urbanized' farmers and the manufactured landscape with the inherent legacy of the previous cultures. Taking this situation into account, it becomes important to acknowledge

${ }^{1}$ ts early etymological root defines it as "to frequent, visit regularly; have to do with, be familiar with; indulge in, cultivate". An alternative, from the proto-Germanic root, meant "to go or bring home" or it was also implemented in terms of "a spirit or ghost returning to the house where it had lived...but if so it was lost or buried" (etymonline). To haunt is also "to visit or inhabit as a ghost."

${ }^{2}$ Study of being. 
[next page-top] figure $\mathbf{0 3}$ the Colombian terrain hideas a secret.

[next page-bottom] figure $\mathbf{0 4}$ the secret is revealed, yet it is not clear of what it is.

[following page] figure $\mathbf{0 5}$ some geometries appear, or disappear, to the ground.

how "transgenerational communication, particularly the way in which the undisclosed traumas of previous generations might disturb the lives of their descendants even and especially if they know nothing about their distant causes" (Davis, 2005). The layering of rural ideas will be shaped by the perpetual fear that has both affected and ruined, the authentic life of campesinos and indigenous groups.

Similarly, Derrida focuses on the non-existent, yet present (like a ghost), "the virtual space of spectrality ${ }^{3} . .$. sharper distinction between the real and the unreal, the actual and the inactual, the living and the non-living, being and non-being" (Demos, 2013). These spectres are ambiguous because it becomes something unspeakable and indescribable, but perceivable. Although this environment creates anxiety, Colombia needs to take a position of objectively, choosing what to show and what to hide from the period of neo-colonization through mining, to the imaginative postcolonial landscape. This semi-transparency becomes key for the development of an architecture of reconciliation because the socio-cultural, and environmental scars become its framework. During this process, it is important to move away from the idea of nostalgia. Fredric Jameson's nostalgia mode "is not defined by a yearning of the past... [but] is better understood in terms of a formal attachment to the techniques and formulas of the past, a consequence of a retreat from the modernist challenge of innovating cultural forms adequate to contemporary experience" (Fisher, 2013). So, this nostalgia mode is how the present, in the quest of defining new cultures, shapes its contemporary view by using tools from the past. Inevitably, the globalized world brings eradication, but also births hybridization of cultures. In the particular rural Colombian lens, these new cultures ought to become aware of how and what a vernacular and genuine society was, and how a new upgraded culture could be born. Architecture enters this discourse as an agency that can manipulate the present to shape the past, and analyze the past to provide the space for this new society to develop.

An architecture of hauntology, in the context of mined Colombia, is one that does not inhibit the past in order to be present. But on the contrary, makes the past more palpable, even to the point of creating a silent discomfort between the victims and victimizer, the subjugated and the subjugator.

${ }^{3}$ From specters, its etymological root is both "an image, figure, ghost" and "appearance, vision, apparition" (Etymonline) 

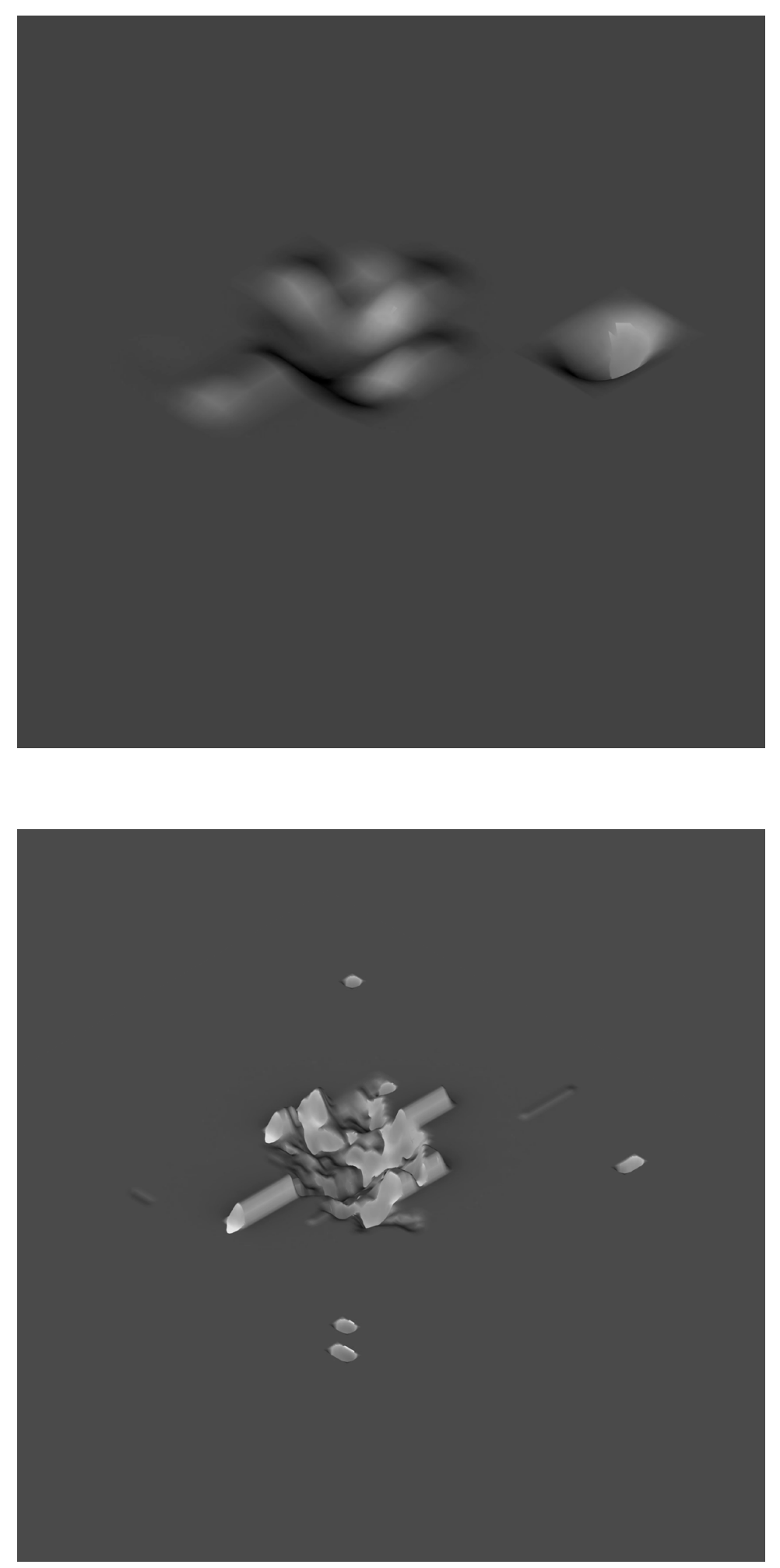


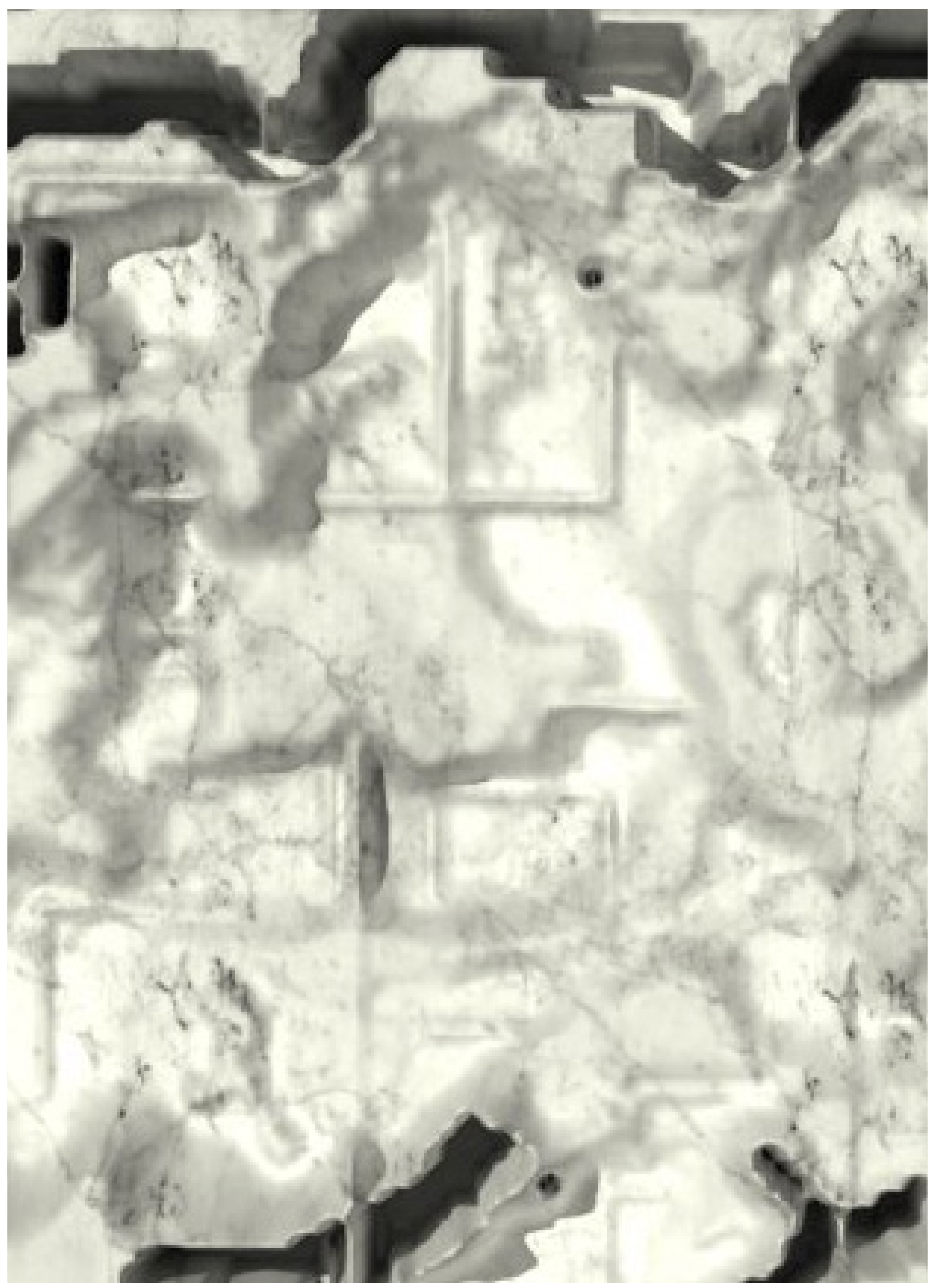




\title{
THE VOID IN THE LAND, ALIENATION \& SPATIAL ESTRANGEMENT
}

\author{
Estrangement and unhomeliness have emerged as the intellectual \\ watchwords of our century, given periodic material and political \\ force by the resurgence of homelessness itself, a homelessness \\ generated sometimes by war, sometimes by the unequal \\ distribution of wealth. \\ Anthony Vidler in The Architectural Uncanny
}

Global competition among nations applies pressure at a local scale. Developing countries are forced to work with wealthier countries in order to progress. However, this does not account for some of the consequences such as "alienation, social and individual estrangement, exile and homelessness (Obert, 2016). All these characteristics are palpable in the rural landscape of Colombia, especially alienation and estrangement. As it has been mentioned earlier, the motivations, or causes, for such inequality have been the misuse of land for its industrialization and for illegal activities. When the displaced people are exiled to the city, they are alienated from their customs, environment and even community. Adding to these social conditions, an ongoing transformation happens in the rural area that they used to inhabit. Looking through the mining industry, coal extraction, especially open-pit, becomes environmentally violent because it empties, cleanses, alters and, most importantly, it leaves a void in the land. This absence becomes difficult for the re-establishment of cultures because there is, literally, no ground, and figuratively, because there is no history to rely on. Even though it takes years to bring the land back to an almost original state, the perpetual scar will always be present in one way or another: either by long-time remediation programs and processes or by the dissolution of the socio-cultural traditions that once occupied the territory.

The ideas of alienation ${ }^{1}$ etäusserung, and estrangement ${ }^{2}$ entfremdung are associated to Marx's of class struggle (Vidler, The Architectural Uncanny, 1992), and are associated with a "psychological and a spatial condition" (Vidler, Agoraphobia: Spatial Estrangement in Georg Simmel and Siegfried Kracauer, 1991). Although the words are interchangeable, they carry different meanings. For alienation, its etymological root includes "renunciation, parting with, relinquishment, externalization, divestiture, surrender" (Arthur, n.d.). Hegel and Marx used it in terms of externalization ${ }^{3}$, which strongly connects to the Colombian condition. The land, that once was the bearer of rural life, is now undergoing the process of rejection of that same culture, by not providing a space to continue traditions. Hegel and Marx proposed a solution for environmental alienation "by thoroughly humanizing the natural world, transforming it by our labour so that it entirely reflects the human self” (Stone, 2014).

${ }^{1}$ (in Marxist theory) a condition of workers in a capitalist economy, resulting from a lack of identity with the products of their labour and a sense of being controlled or exploited (OXFORD).

${ }^{2}$ The fact of no longer being on friendly terms or part of a social group (OXFORD).

${ }^{3}$ Give external existence or form to (OXFORD). C.J. Arthur's analysis on Hegelian text "means manifestation... establishment of or entry into a new state or relinquishment of an old state... thus...the sense is that something is manifested in such a way as to change its state" 
Vidler writes about the manifestation of estrangement "of the inhabitant of a city too rapidly changing and enlarging to comprehend in traditional terms; the estrangement of classes from each other, of individual from individual, of individual from self, of workers from work" (Vidler, Agoraphobia: Spatial Estrangement in Georg Simmel and Siegfried Kracauer, 1991). Although this is a metropolitan critique, the rural areas are going through a similar process; the development of the land, the disengagement from anything and everything that once belonged to the people, rural inhabitants encountering a city's culture, social classes, and ways of living, far away from their customs. But overall, they are marginalized, in the rural context, from all kinds of aspects; from decision-making, to working opportunities, education, health, technologies, and living opportunities. Moreover, the apparition of corporations and the alliances with the government become vehicles for the construction of a new spatial form. This includes the overall mining infrastructure, from the railway system to ports and warehouses, the resettlement of communities in the outskirts of the project, and ultimately the extraction of the soil leaving an open-pit. These spaces are distinguished because "these spaces haunt...as symbolizing every aspect of the nomadism ... and displaced individualism of modern life" (Vidler, Agoraphobia: Spatial Estrangement in Georg Simmel and Siegfried Kracauer, 1991). They are transitory spaces that disconnect people from everything in their context. The spatial estrangement is understood once the interdependency of all the elements of such landscape is disrupted.

Although spatial estrangement deals with the detachment and absence of home, there remains a constant longing for one. György Lukács coins the term transcendental homelessness to describe "a spiritual and emotional home no longer available in a world without a deity" (Moir). For him, the concept of transcendental takes place in terms of site, as loci, and psychology. As loci, it is when "nature and consequences can be described ... but for which it will ...be impossible to find a psychology, whether of empathy or of mere understanding" (Lukács, 1971). It is like facing a sublime landscape that is described as scary but admirable at the same time. The mining voids clearly generate a whole range of impacts, from flora and fauna to socio-cultural areas. But it is challenging to know the limits and challenges of the creation of a new place that transforms the relationships with nature. For transcendental psychology "there is no qualitative differences which are insurmountable...between transcendental loci among themselves" (Lukács, 1971). This optimistic approach helps to see that the voids are something attainable, maybe not at a human-physical scale, but certainly at a spiritual one.

Just as the displaced people are faced with urbanization, they seek for a place to belong, similar to the place they once belonged. A transcendental architecture could be a heterotopia, as finding the sacred within the profane, thus isolating and juxtaposing the new and the old, the urban and rural. As a sacred space, it works for the people because it is already isolating the user from the reality, the profane. This sacred space does not necessarily need to be a church, or any kind of religious space. It can be related to what Le Corbusier compared to 'huts' (Barrie, House and Home: Cultural Contexts, Ontological Roles, 2017). These structures are synonyms of home and being at home means the "passively visionary acceptance of ready-made, ever-present meaning. The world of meaning can be grasped, it can be taken in at a glance; all that is necessary is to find the locus that has been predestined for each individual" (Lukács, 1971). The new generations of rural people will re-interpret the meaning of place, as it has been transformed due to globalization and mining. 


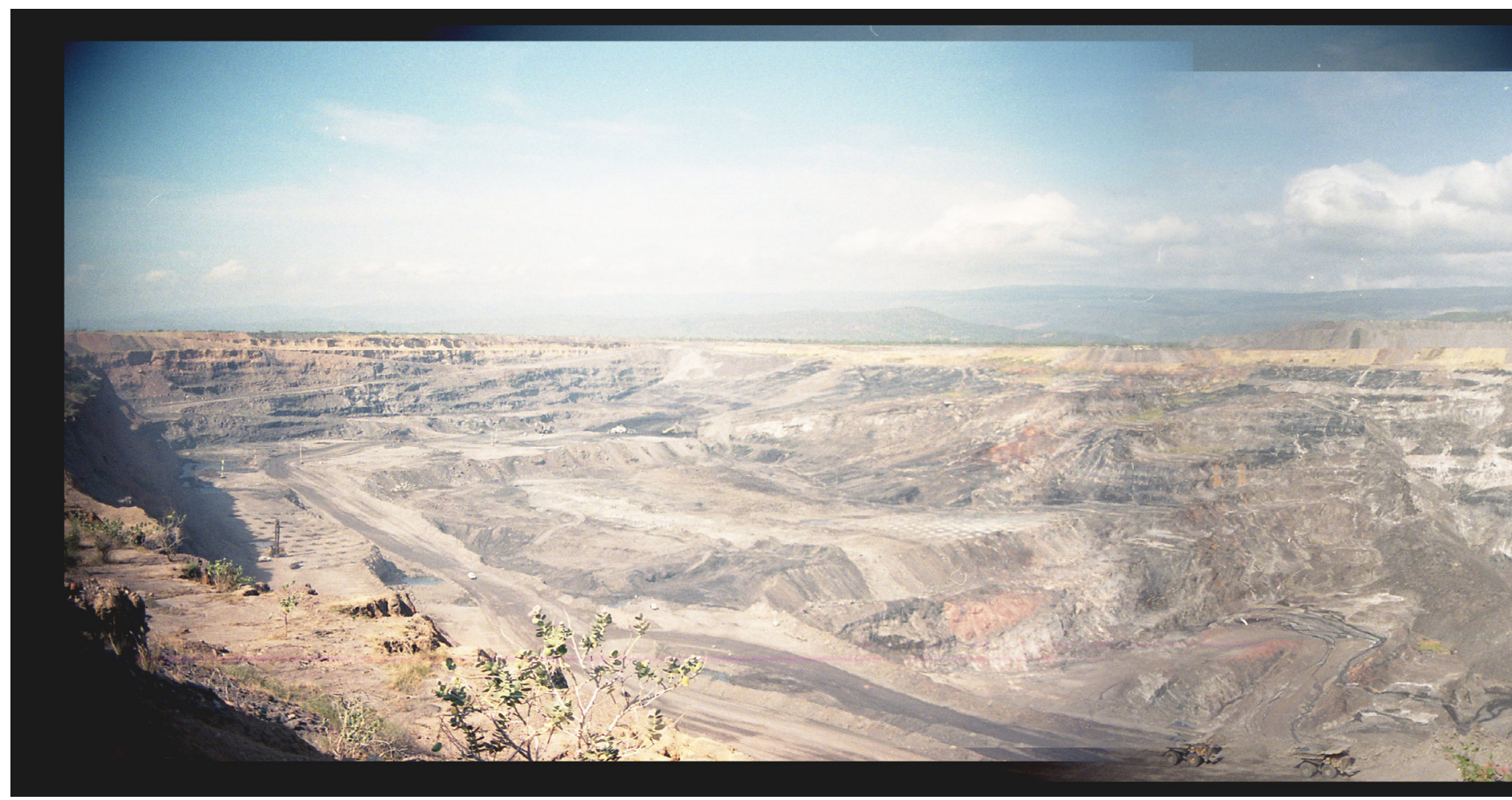


[this page] figure $\mathbf{0 6}$ view of one of the pits at Cerrejon, La Guajira, Colombia. Although this void looks massive, it was one of the smaller ones.

[next spread] figure $\mathbf{0 7}$ plan view of the mines in Cesar and Colombia. This represents less than 1\% of the national territory, but its impact is like $99 \%$.

[following spread] figure $\mathbf{0 8}$ plan view of the mines in la Guajira and Colombia. This represents less than $1 \%$ of the national territory, but its impact is like $99 \%$.

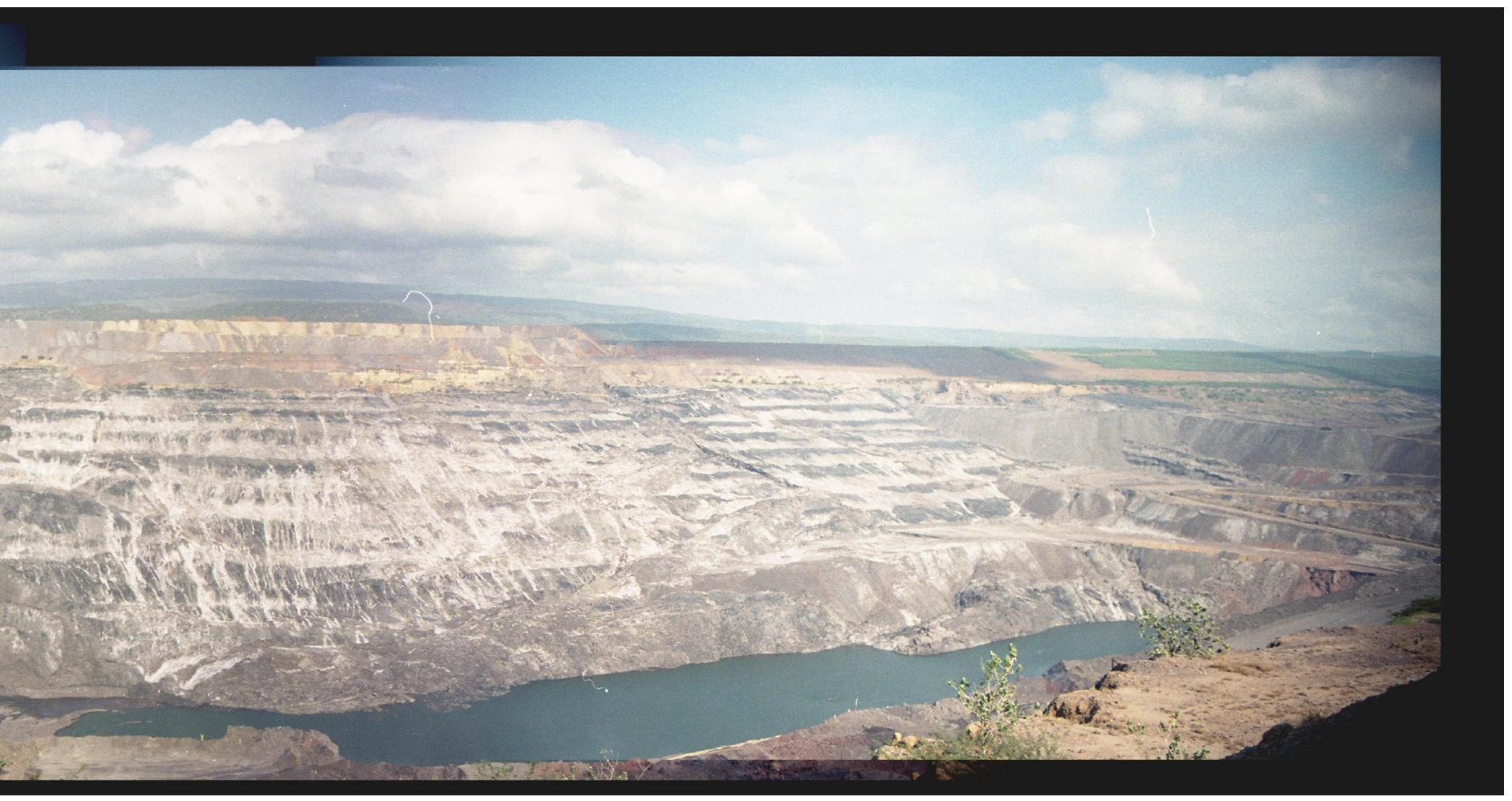




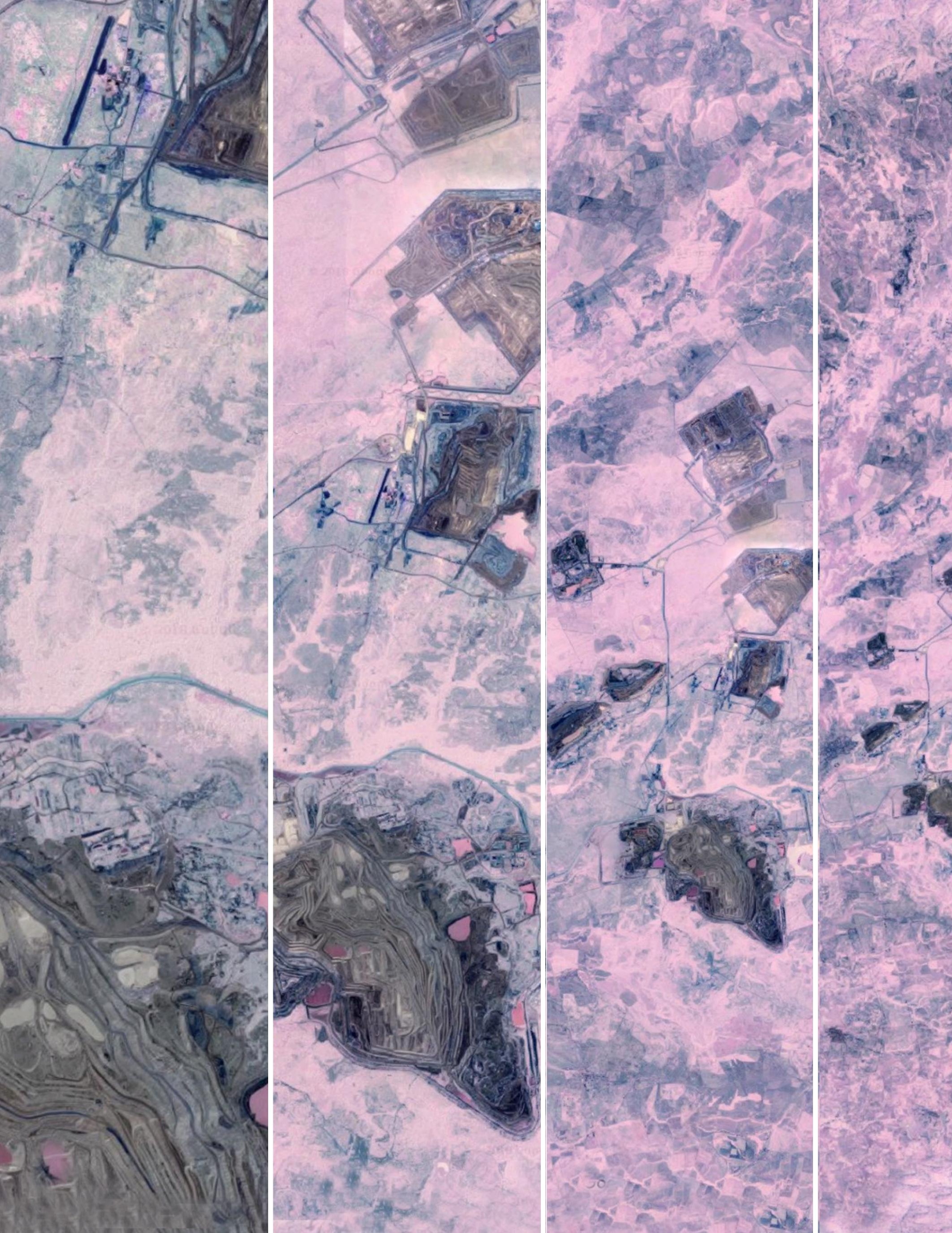




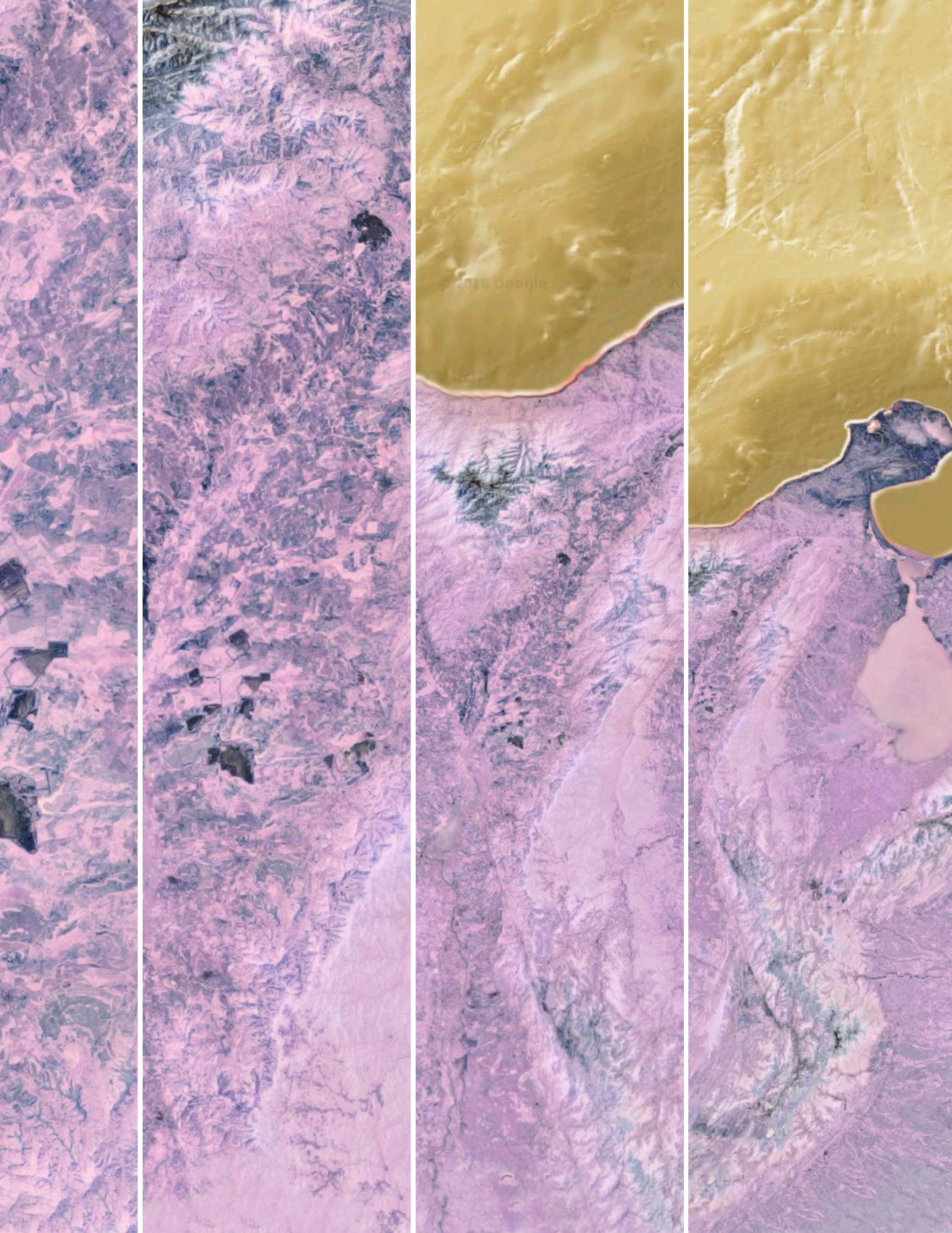




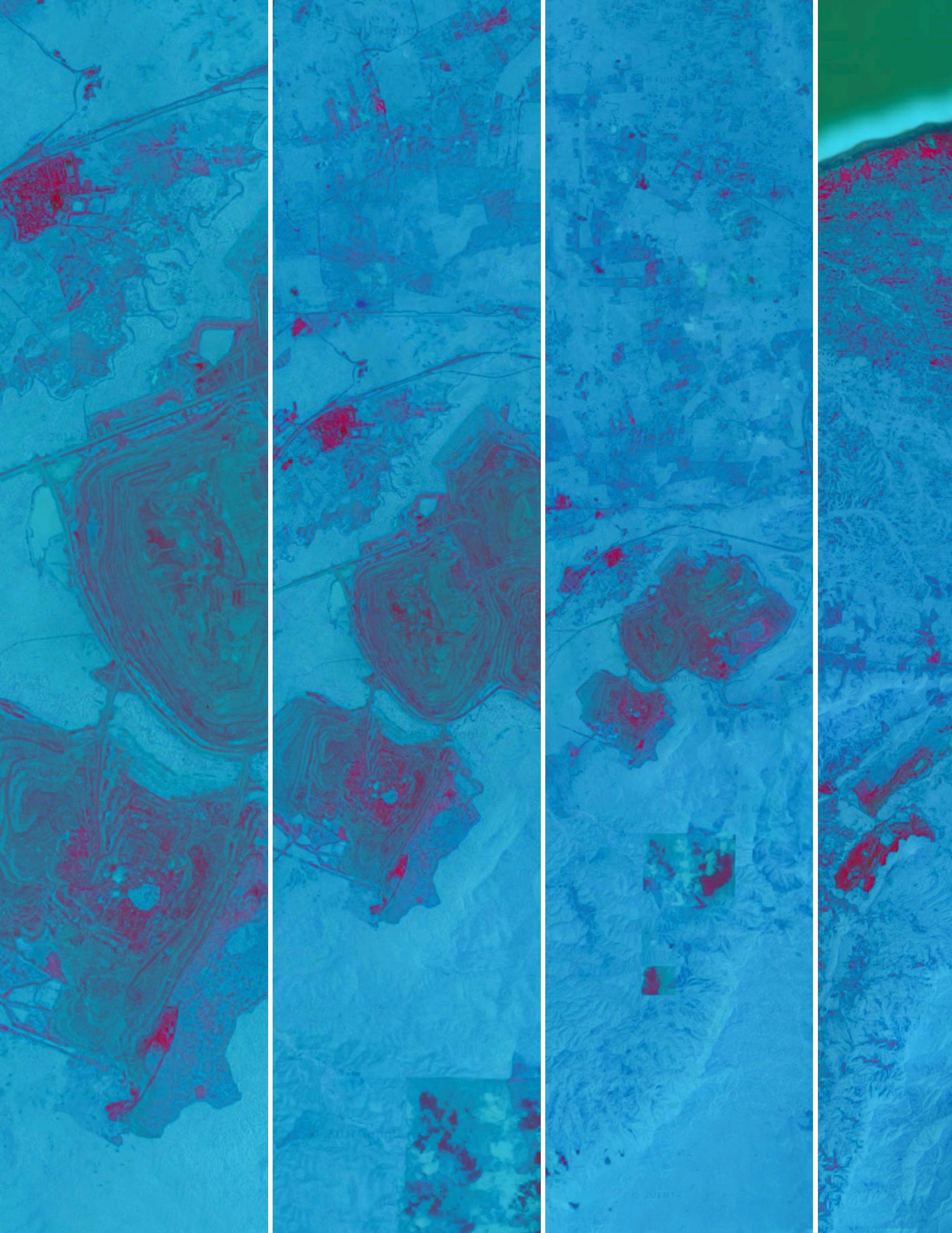



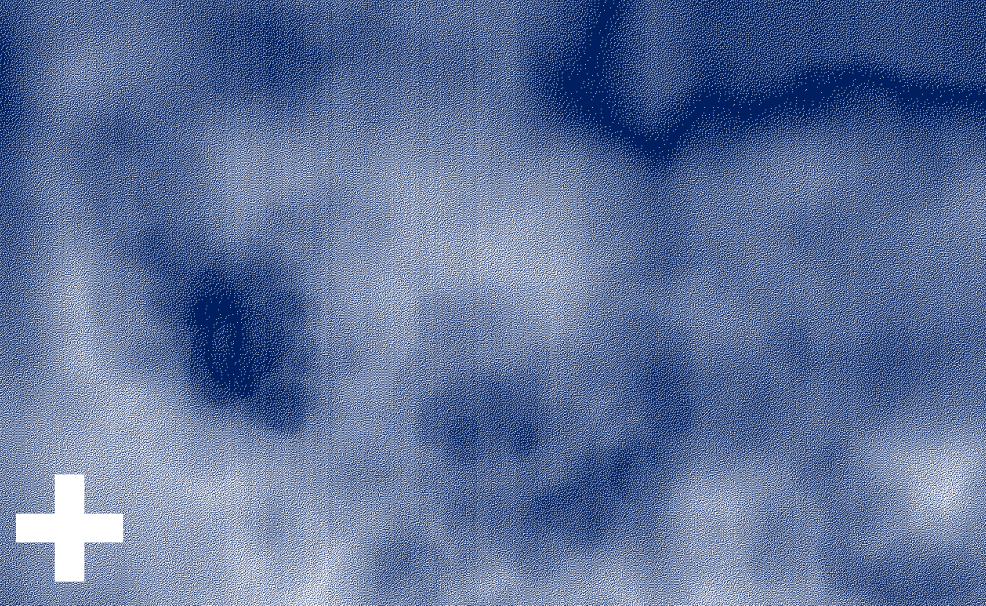

DEATH
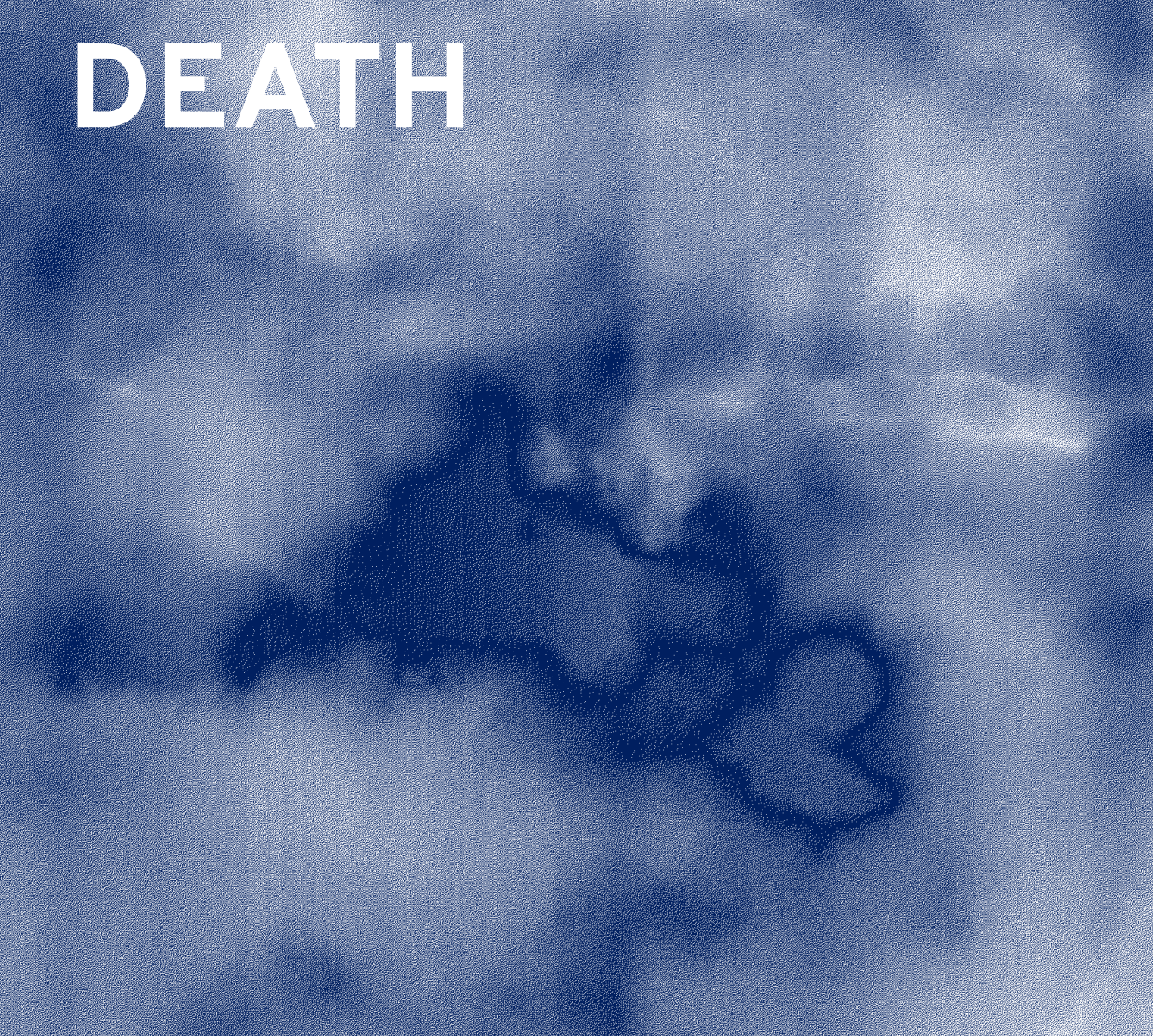


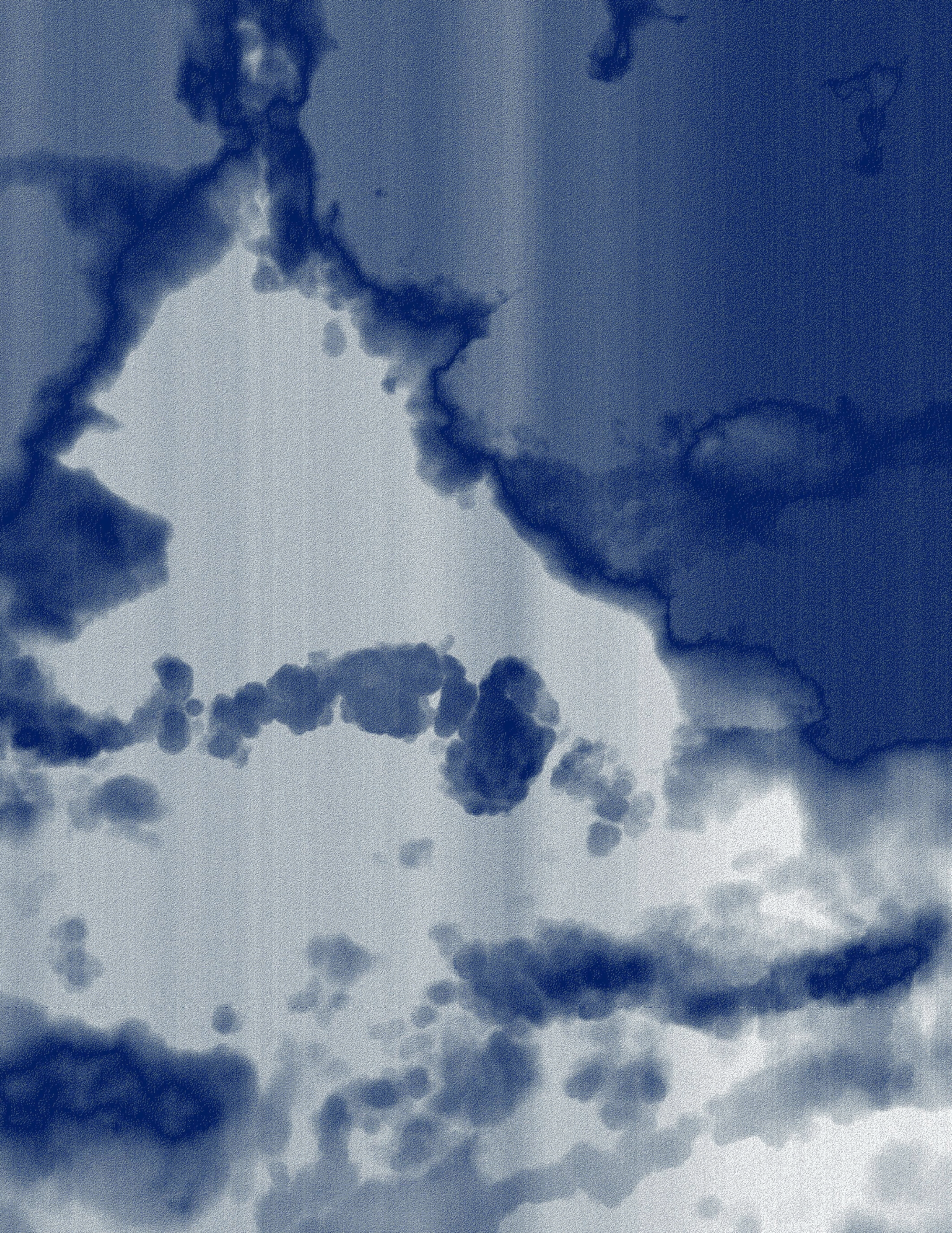


The living Laudonia has to seek in the Laudonia of the dead the explanation of itself, even at the risk of finding more there, or less.

Italo Calvino

Human existence is composed and celebrated by life, love, education, and death. These phases, which define and shape us as individuals, are intertwined, making it difficult to draw a boundary and know when one starts and ends. Aware of our ephemerality on earth by the natural arrival of Death, we inherently hope for continuation through remembrance and renewal, rather than halting forever. Part of dealing with death is relying on memories and images because the visualization deceased temporarily alleviates the loss. It helps for the transition from the end of one phase, to the re-birth of another one. Design and architecture are mainly preoccupied with the daily life environment: the quality of spaces, the urban infrastructure, parks, dwellings, and all those moments that can alter and change our existence. However, these moments are only marked as transitory memories. Boullee's Temple of Death becomes "a monument to death that represented an ambiguous moment, somewhere between life and death, or rather, a shadow of the living dead" (Vidler, The Architectural Uncanny, 1992). If our human existence is made up by the overlap of states (living - dead, love - living, love - dead, etc), the cultural values and traditions towards death through ceremonies. For instance, Qingming in China, or the Day of the Dead in Mexico, show a vibrant dichotomy between the optimistic meaning of death, as the beginning of a new afterlife, and the pessimistic view of halting to exist. These rituals demonstrate how the spaces for the deadcemeteries - can bring life and be active. Another dichotomy in relation to death is the role of Wayuu Women in Colombia. As they are seen as the bearers of life, they are also in charge of the burial process (pueblo_way_u.pdf). Traditional Wayuu cemeteries are located in the communities where women are leaders. These places became the linkage between newer generations and ancestors. However, when it comes to the burial, the living family members of the deceased are kept away because it would interfere with their lives (Plan salvaguarda Wayuu - Zona sur de la Guajira , 2014)

In a landscape that is already dead, such as open-pit mining, where its lifespan has reached its limits and a new territory is created, people feel the disconnection between the religious idea of being directly born out from the ground and returning to it as "for dust you are and to dust you will return" (Genesis 3:19). The obsolescence of the soil will not respond to the needs of the buried. The rural landscape of Colombia is subjected to a recognizable state of oblivion, where common graves, violence and neglect are the constant environments of the living. Adding to this, the deforestation rates in the mining areas are higher than the rest of the country. For instance, Cesar region lost 46 ha 
figure $\mathbf{0 1}$ the void in the land represents a new territory for life. The question is, how will the scars of the soil heal through life?

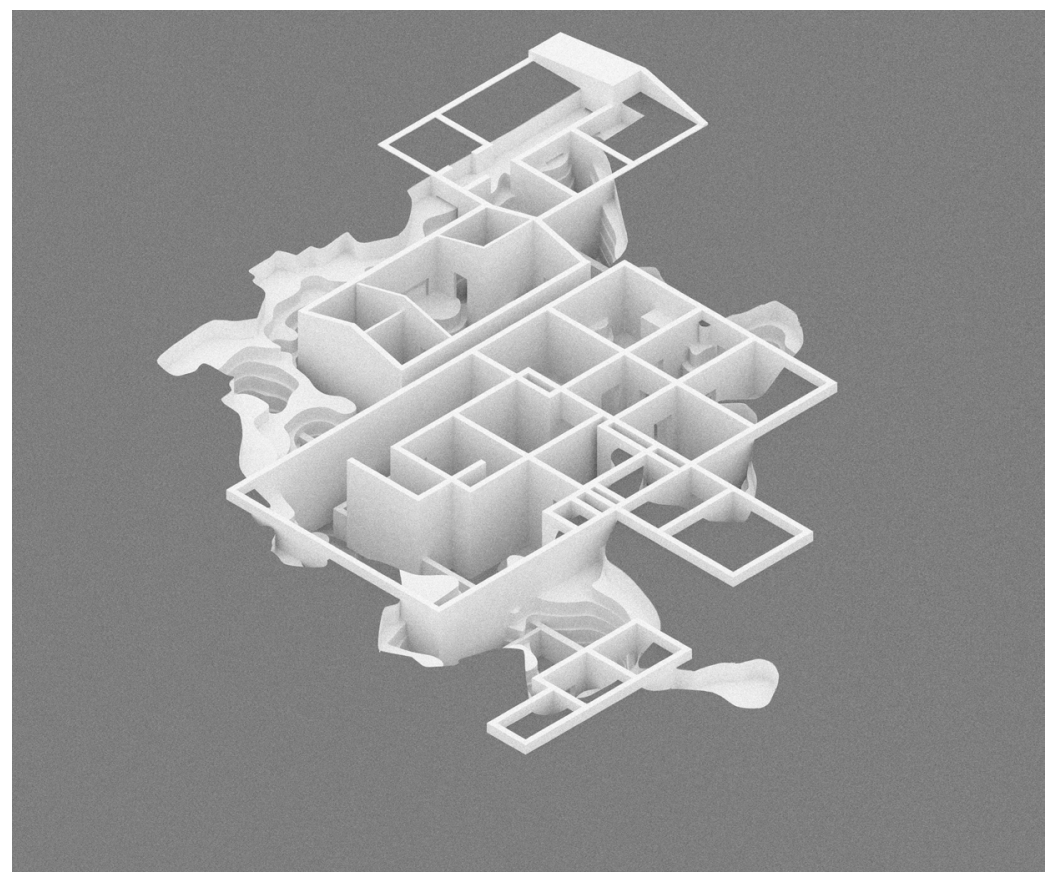

per 1000 ha, compared to the national rate of 27 ha per 1000 ha (GARAY). It becomes burdensome observing a land that once provided life is now pushing away the stay of households, dwellings and homes.

Any intervention upon the mined artifact revives and presents a new beginning, a new interpretation of life and death. 


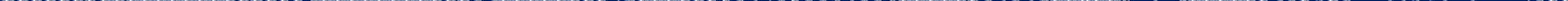




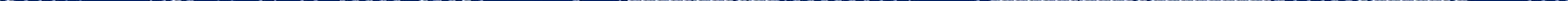


figure 01 table study. From left to right, top to bottom: align, bend, blueprints, carve, difference, extrude, illusion, intersect, multiply, remove, rotating, scale, split, stretch, shear, taper, twist, union, table.
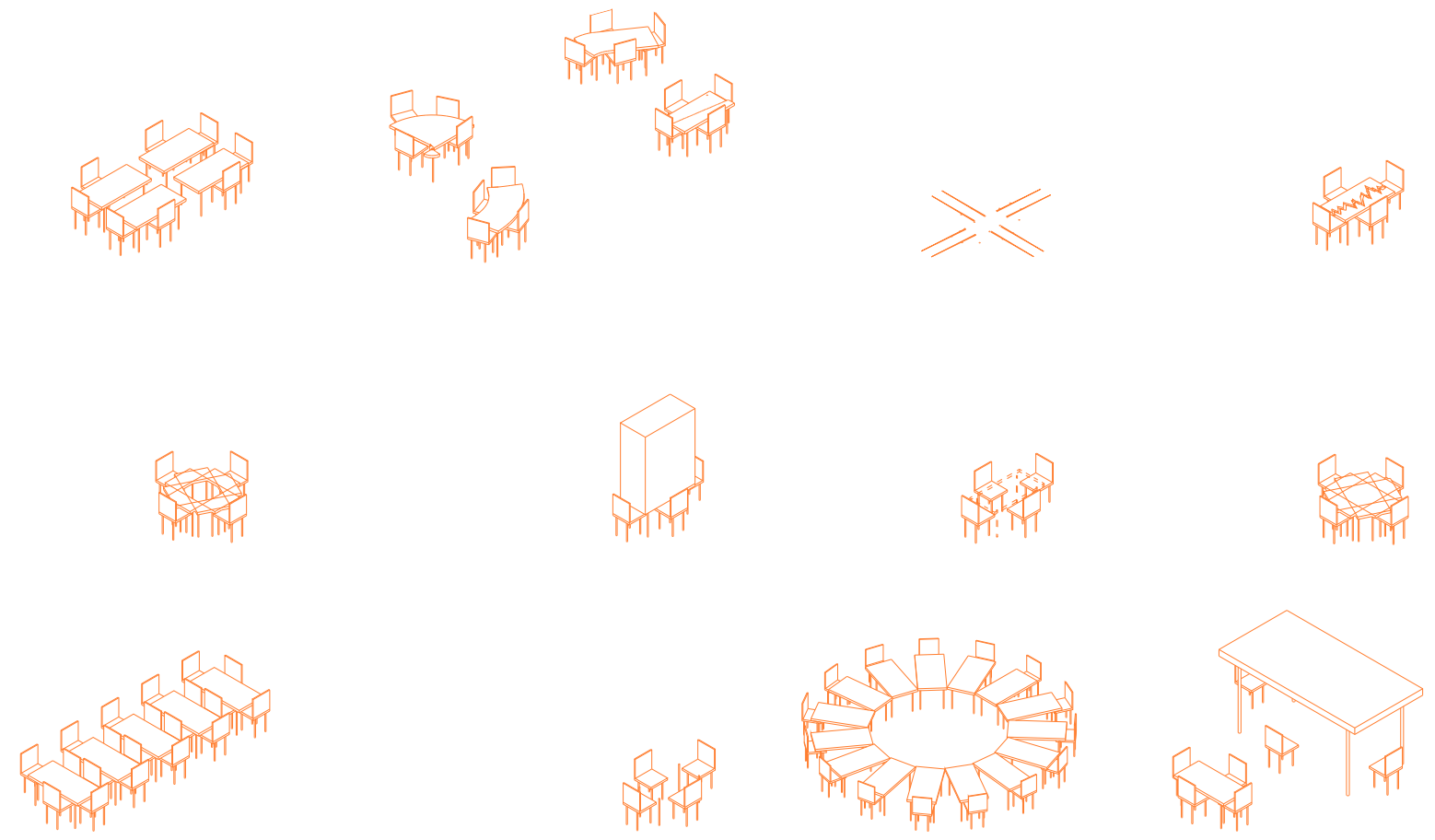

118
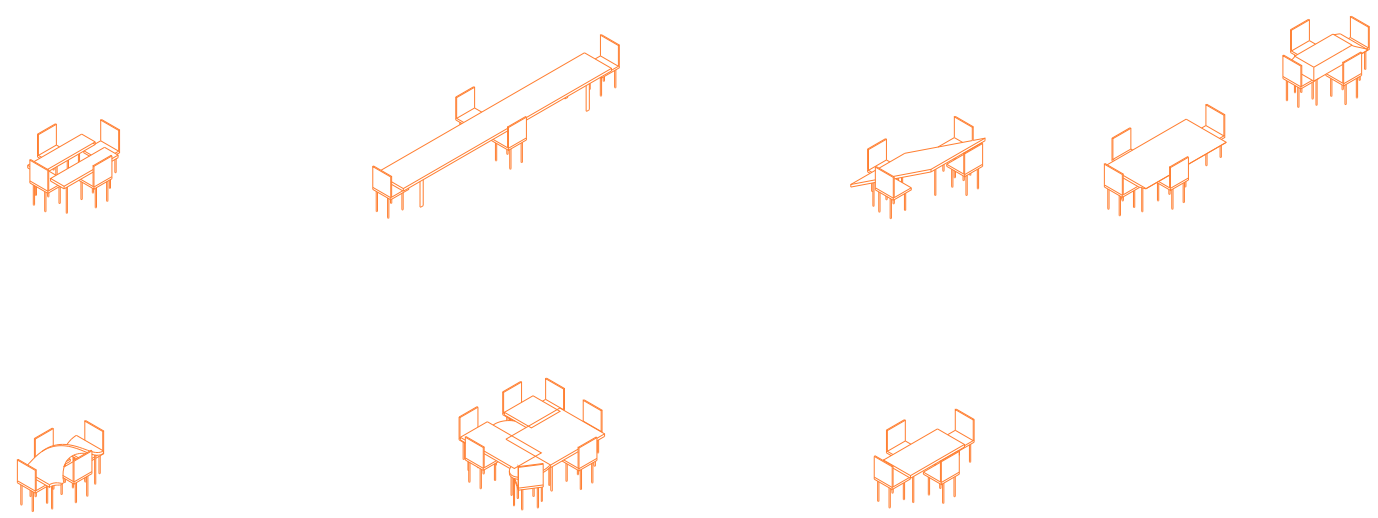

A table is an element that is always present in architecture. Presented as a surface, it has the potential to be used for different things: eating, talking, drinking, playing, working, etc. Having a space dedicated for discussion will finally open up a space for all the actors to come together and seek balance, a win-win for everyone.

What happens if the flat surface is altered?

Will all the actors have a fair participation?

Will the table work as an element of reconciliation? Or will it turn into an element of deceit? Will it be a 'smokescreen' for dominance? For violence? Will the interaction have a long term effect? Will the table become a translation of the expectations to reality?

Who will appropriate the table?

Will it become a camouflage for decoying? 
Reconciliation does not cause this postcolonial difference, but is ... an effect of a causal disposition towards forms of society

that respect the principles of self-determination and peaceful

co-existence, and that this causal disposition is a permanent

virtuality, immanent to the historical process.

Simone Bignall in Postcolonial Agency

The history of Colombia's urban and rural population has been marked by hardship in finding security, safety, equality and respect. The minorities and lower socio-economic classes inevitably become oppressed, with everything to lose but nothing to be left with. The social agitation is tangible in both the countryside and the city and it is largely attributed to the war against drugs, environmental catastrophes, and the aggressive possession of land from leftist and right-wing groups. After years of long conversation between the government and these groups, the government is finally closer to undertake reconciliation and peace processes in the country. As all the attention has been centred towards the war against drugs, little has been done to achieve reconciliation within the mining industry. This reconciliation does not only take place within the social and economic realm, but also environmentally and culturally. With a particular attention to indigenous tribes and farmers, a new reconciliation is sought in order to bring balance in the re-structured rural landscape, through the active participation of everyone involved in the circumstances that created the need for reconciliation. For Hegel and Marx, reconciliation is "the state of being 'at-home-with-oneself-inthe-world"“ (Stone, 2014).

Within the neo-colonial context, the need for reconciliation has an extra layer of difficulty, as the economic factor plays an important role in decision making. Moreover, the dominance over weak local governments on the decision making by superpowers overlooks the socio-economic realities of the minorities and marginalized communities. The idea of a newer colonization prevents the desire to reach a level of reconciliation between all the parties because unacknowledged individual interests are still present. For instance, developing countries, which are rich in natural resources, will always have the attention of developed countries for exploration and exploitation. The first step towards reconciliation is to shift from neo-colonial to a post-colonial mindset. This post-colonial phase implies that the concept of colonization, or domination, is finally understood and recognized, and the new context asks for the revitalization of the colonial era. Within this framework, Chief Dr. Robert Joseph, a first nation ambassador for the process of reconciliation in Canada states that "when we are reconciled, justice and equality will prevail" (Joseph, 2016). But this can only be achieved in a post-colonial setting, where corporate and even political interests understand that they do not have responsibility only on natural resources, but also on the rehabilitation of the social fabric.

Achieving reconciliation is a long term process that involves the active participation of everyone involved. It is conditional, non-linear, bilateral and its outcomes are not immediately seen, and there are phases that aid for the structuring and realization of it. Generally conducted under a spiritual framework, reconciliation is preceded by redemption, renewal, conviction, confession, repentance and reinstitution. These stages are arbitrarily achieved and they ultimately depend on 
the needs of each of the different actors (in this case locals, government, church and the mining industry). Reconciliation is bilateral because the actors and their actions are further reduced to the forgiver and the forgiven. But these roles are not entitled to one specific actor: for a particular condition, the forgiven might be the forgiver, but for another, it could be the other way around.

Reconciliation is a synonym of re-establishing relationships. The active process of talking and doing, accelerates the healing process of socio-environmental damages. Hegel's concept of reciprocal recognition plays an important role in the steps towards reconciliation. This kind of recognition is formed from a "response to the problems of subordination, exclusion, and marginalization in diverse communities" (Farneth, 2017). These characteristics are commonly found in the polarized social fabric of Colombia, where a large percentage of the rural population has faced the economic and social hardships of living on rich soil. In the case of mining in the country, particularly in El Cesar and La Guajira, subordination is palpable in two forms: the first one is through the land being slowly taken away due to the value in it (minerals), but not on it (the life of the farmers and indigenous tribes). The second method is through the economic thrust and trusts the companies provide to each region and its locals, thus making each region largely dependent on the mining industry. For instance, in the case of el Cerrejon, the power the company has over La Guajira is so large, to the point that they can influence politics through votes and elections, and socio-economic, becoming the hub of job opportunities in the area. Furthermore, the mining industry gives the impression of being socially, and even, sustainably responsible through programs of housing, job opportunities and reforestation, and even by allowing tourist visits to the mine. However, the truth is that there is a sense of social and political exclusion. The social exclusion is demonstrated by the little to no decision-making the locals have when it comes to the exploitation of natural resources. For instance, the relocation of the rivers, which affect the people, can be hardly opposed, and even the government lacks participation in preventing such actions. Politically, the only participation conducted by the government is through the collection of royalties. But they are aware that opposing any large intervention will put a lot at stake. This politico-economic fear leads to a self-marginalization from the reality of the industry and control through policies. The social marginalization is seen in the disruption of the social fabric and local traditions. According to Kojève, this polarized relationship is further built on "the life-and-death struggle ... desire for recognition 'creates, realizes, and reveals' the human being” (Farneth, 2017).

In Hegel's Phenomenology of Spirit, the underlying theme is the balance between the bondsman and the lord, whose relationship "is characterized by domination. The lord exercises power over the bondsman but denies accountability. The bondsman is accountable to the lord but has no independent authority" (Farneth, 2017). Although in the context of Colombia, there are more than two actors - locals, industry, government and church - they basically fall within these two categories of bondsman and lord, dominator and dominated. However, the characterization of bondsman is applied to locals, as they are subjugated: economically by the industrial exploitation, socio-politically by the government through the lack of democratic choices, and spiritually by the 
[next page] figure $\mathbf{0 2}$ reforested pit that 'hides' the reality of the image on the right.

[following page] figure $\mathbf{0 3}$ another pit during operations. The expectation is to bring it to look like the image on the left. [page 128] figure 04 the relationship between 'table' and house for understanding reconciliation.

church. Hegel's definition of reconciliation is that it is both "universal and particular" (Shikiar), or more specifically "socio-cultural and individual" (Shikiar). In other words, each member of a community needs to acknowledge the present condition, in the case of mining and Colombia, the fact that the soil has changed. Once they are each aware of their new context, inhabitants of these areas will collectively seek reconciliation with the other actors.

The concept of reconciliation is intangible, but its outcomes are tangible. Architecture, being an art and science that shapes and delineates, has the role of becoming both the vehicle and agent of reconciliation. Having a defined space allows for the action to take place. However, reconciliatory spaces are usually represented in spiritual, sacred spaces like churches, or rooms in churches.A space with such a specific program, within a church building, would not be neutral, as faith plays an important role in the Colombian culture. Reconciliation is a communal action that results from the synergy of all the actors seeking it. A neutral space that offers the flexibility for everyone involved to express themselves without a label, while it shows the pre-existing condition. Moreover, the act of reconciliation cannot be bound to time and a fixed condition. The arbitrariness of time allows for freedom while being presented with challenges. Reconciliation is dynamic and arbitrary but it still needs a framework, some parameters and guidelines, so that there are both understanding and clarity among the different parties. Just like with mining, reconciliation has to break the boundaries of the 'norm' in order to seek, explore and aim for a goal. Reconciliation cannot be achieved by just standing still; the people have to move and adapt. Environmentally, it takes the form of reforestation, and yet, this is not an authentic exhibition of it because it conceals the loss of soil properties. For instance, one of the Cerrejon open-pits that operated from the early 1980s to late 1990s has been reforested, and 17 years later, the land looks like a normal forest that at first glance does not show any signs of exploitation. 


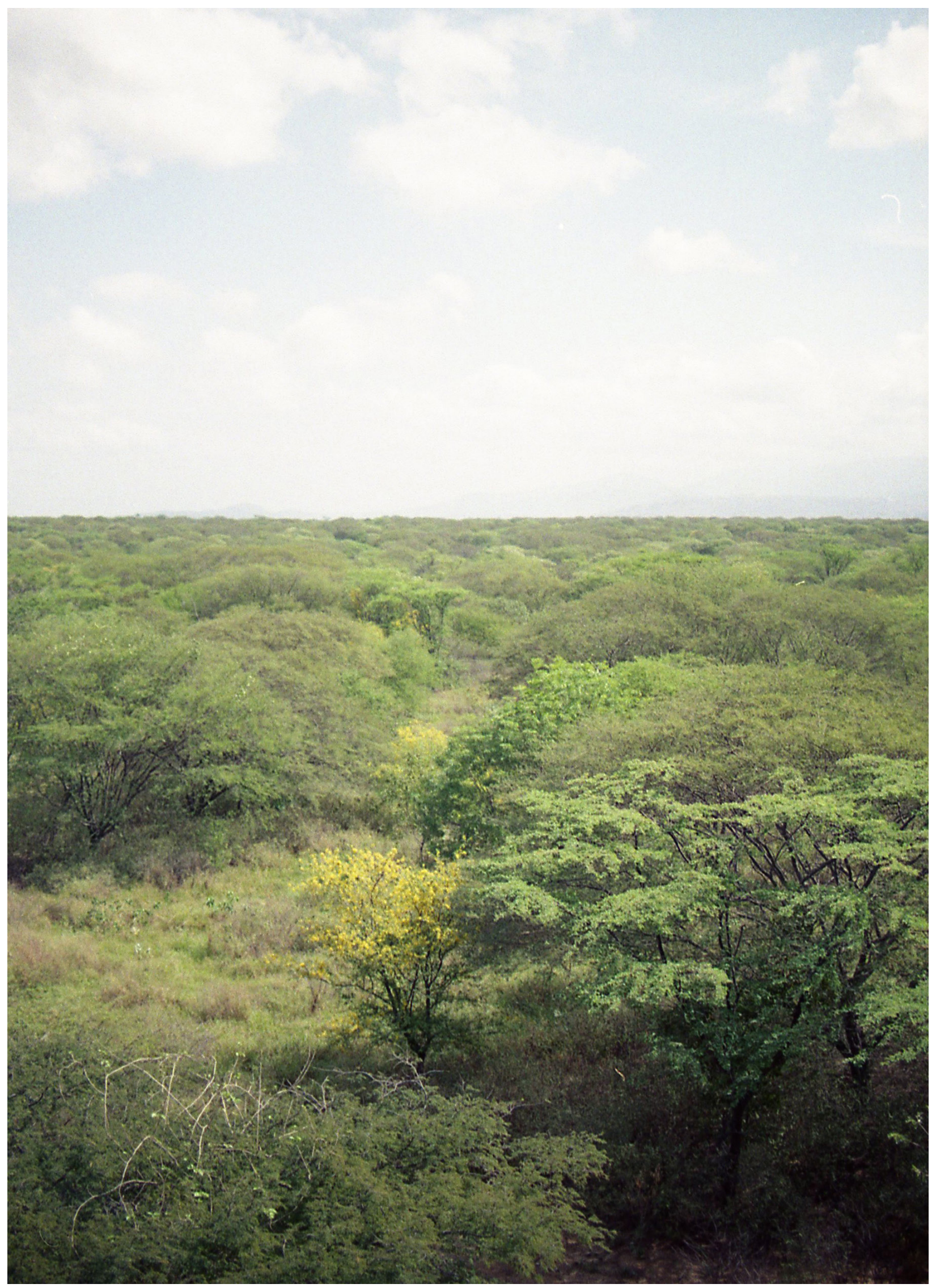




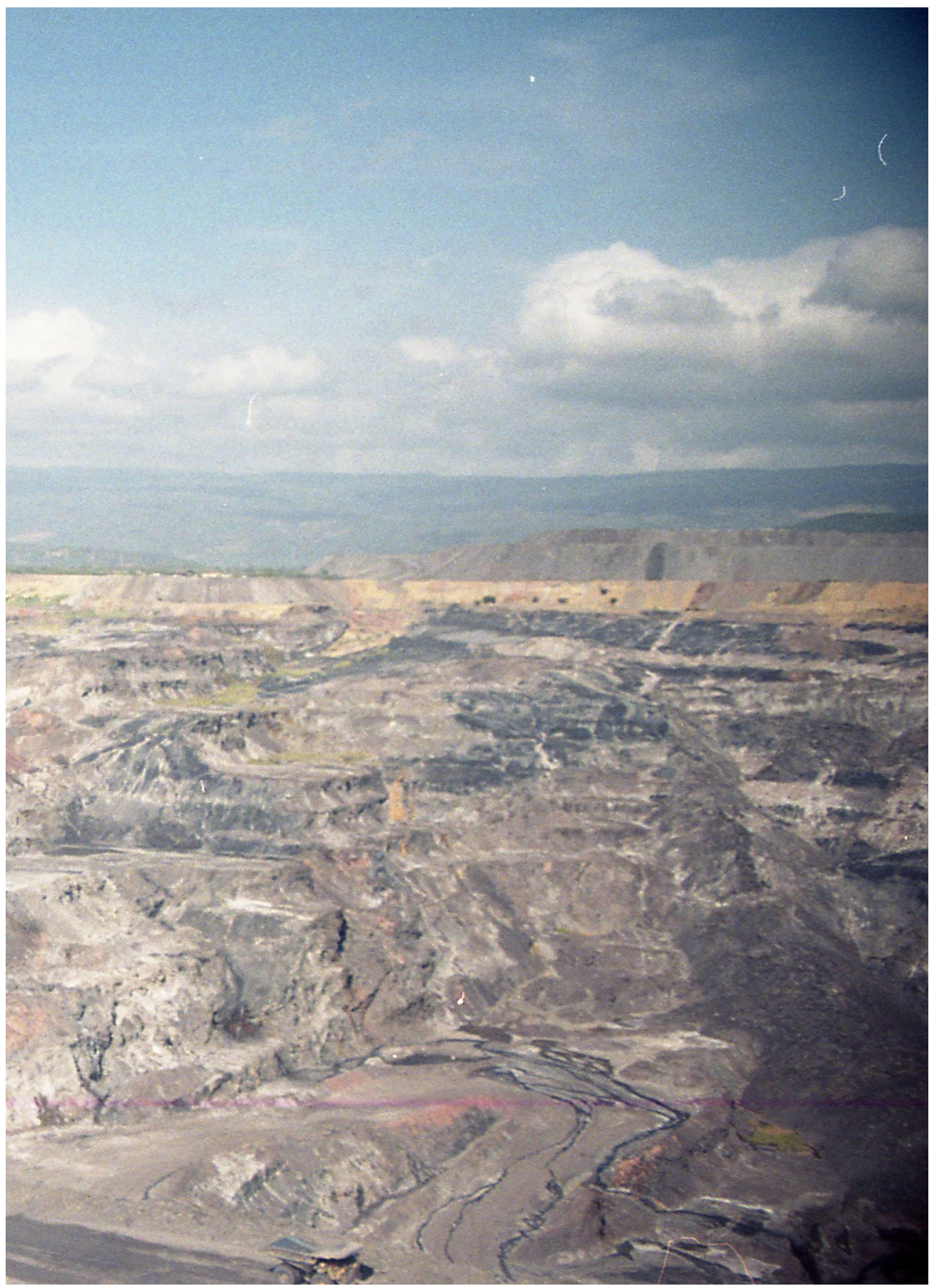




\section{Truth \& Acknowledgement}

Before the need for reconciliation is acknowledged and sought, there must be an awareness of the existing conditions. This prepares and balances out the differences between all the actors involved, and begins a path towards renewal and reconciliation. For instance, the long history of eradications, suppression and (almost) abolition of traditional first nation cultures and identities in Canada, especially in forcing western-style education, has only recently started a dialogue with the government known as Truth and Reconciliation. According to the Commission of Canada, a socially stronger future has to acknowledge and be transparent about the past. If decisions and actions are done at an early stage, or when the problem is still present, it will avoid resentment among the parties and the development of a long term resistance. Moreover, prevention and regulation would also avoid the disappearance of social and natural environments. In the case of Canada, during the more than 100 years that the boarding schools were present, there were at least 150,000 affected people, thus leading to social tension between the first nations and the government (Truth and Reconciliation Commission of Canada: Calls to Action, 2015)social tension between the first nations and the government. Although for Colombia, where mining is still active and will continue for future decades, acting now will prevent, but not fully avoid an environmental and "cultural genocide" (Truth and Reconciliation Commission of Canada: Calls to Action, 2015). It must be pointed out that the mining industry is a generator of opportunities but at the same time presents a lot of challenges and damages. In the 40 years that the industry has been active in the country, campesinos have seen the drawbacks through displacement, missed opportunities and, drastic changes in their lifestyles. 


\section{Tabula Rasa}

Architecture as building delineates a place, enclosing space to provide users with a program. Within the context of reconciliation, architecture-building becomes only a framework, but what constitutes the task of reconciling are the elements, particularly a table. A table, defined as a flat surface, is both a noun and a verb. This grammatical duality carries possible contradictions, between good and bad, individual and collective, subject and action. Table, seen from a noun perspective - i.e an object, piece of furniture - possesses the qualities of being multifunctional and collective. Presented as a surface, it has the potential to be used for different things: eating, talking, drinking, playing, working, etc. As a verb, table imposes positioning, location and action, through creating space ready for discussion. Having a space dedicated for discussion will finally open up a space for all the actors to come together and seek balance, a communal benefit for everyone. In both cases, however, table is a concept that is always present in architecture, tangibly through elements, the use of tables for different activities or intangibly through actions within an architecture, for instance, squares are spaces dedicated for public gatherings. The Colombian rural soil, where mining has taken place, becomes an analogy for a table, where collective actions take place, different activities inform the use of such landscapes.

Aside from the grammatical definitions of table, its Latin etymology is tabula, or a plank piece. After new forms of neo-colonialism have created newly manufactured landscapes, the table becomes a tabula rasa for the landscape, the culture and for the people. The landscape as tabula rasa, or "An absence of preconceived ideas or predetermined goals; a clean slate" (Oxford), provides the opportunity for architecture to re-shape the context as social and environmental mistakes seek a space for renewal through reconciliation. The destruction of a previous colonized and dominated territory allows for a clear new beginning, but it also hides its past. There must be present the idea of "opened ways to negotiate, inhabit, and thus transform the colonial structures that have generated deep deformations of space and geography. Colonial remnants and ruins are not only the dead matter of past power, but could be thought of as material for re-appropriations and strategic activation within the politics of the present" (Petti, Hilal, \& Weizman, 2013). Hiding anything that brought changes, terror, fear and anxiety will not take away the fact that colonization happened. Instead, it can set a new socio-political and socio-cultural agenda aimed towards negotiation, conversation and ultimately, reconciliation. 


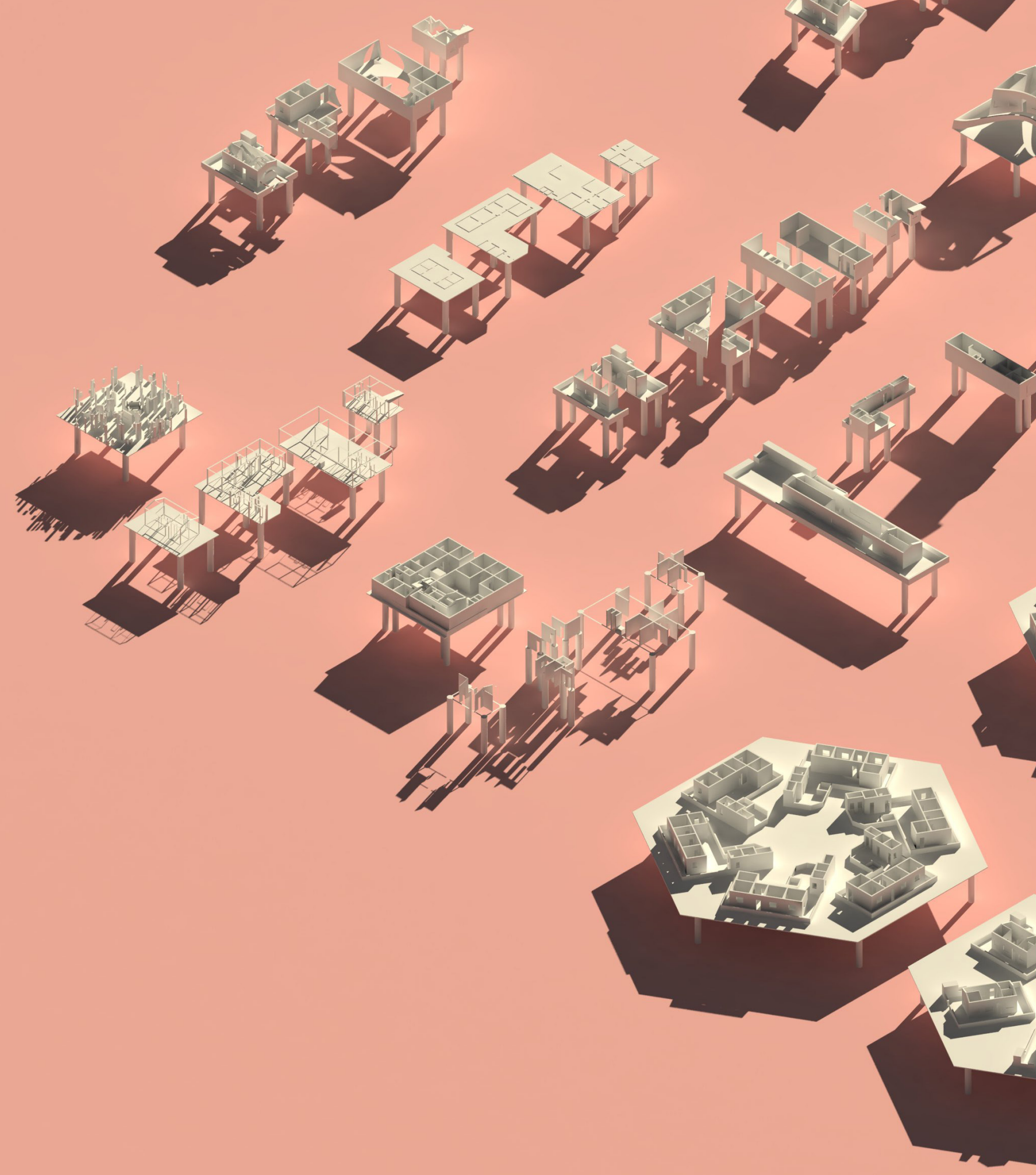




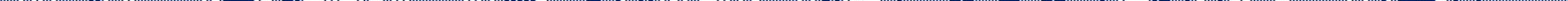


After the rupture of land and communities due to the profanity of globalization, the sacred is needed back. Globalization is analyzed as profane because it utilizes the natural resources that are so valuable and sacred in the Biblical and religious perspective, which is even reinforced in Pope's Francis Laudato Si. The moment a disruption takes place, there is the hope and need to sense a "manifestation of the sacred" (Eliade, 1983). Eliade would also define it as a hierophany, as being shapeless. For instance, Eliade writes about sacred being amorphous as when God appears to Moses. The site already becomes altered by the holy appearance. But this manifestation of the sacred is also represented in physical form, most commonly associated with sacred buildings like churches or even tectonically with craftsmanship and pure geometry. In architecture, Le Corbusier defined sacred through the ineffable, the things that cannot be seen but only felt; or Pallasmaa through the phenomenology of space. In contrast to these techniques, Frank Lloyd Wright focused on craftsmanship and tectonics (Barrie \& Bermudez, Architecture, Culture, and Spirituality, 2016). Even though sacredness does not inherently mean religious spaces, it is still important to be aware of how sacredness is applied within religion. For instance, the Hebrew Tabernacle, "a portable shrine or tent designated for the worship of God; metaphor for God dwelling among his people" (Life Application Study Bible, 2015) physically divides and organizes the profane, the sacred, the holy, and the Holy of the Holies. A simple fence demarcates the spiritual and physical boundary between these two worlds, while creating a journey through third spaces and rituals before reaching the physical manifestation of God on earth, or the Ark of Covenant.

${ }^{2}$ shall erect the tabernacle of the tent of meeting. ${ }^{3}$ And you shall put in it the ark of the testimony, and you shall screen the ark with the veil. ${ }^{4}$ And you shall bring in the table and arrange it, and you shall bring in the lampstand and set up its lamps. ${ }^{5}$ And you shall put the golden altar for incense before the ark of the testimony, and set up the screen for the door of the tabernacle. ${ }^{6}$ You shall set the altar of burnt offering before the door of the tabernacle of the tent of meeting, ${ }^{7}$ and place the basin between the tent of meeting and the altar, and put water in it. ${ }^{8}$ And you shall set up the court all around, and hang up the screen for the gate of the court

(Exodus 40: 2-8)

There is an ambiguity between sacred and profane, and how one can borrow elements and qualities of the other. Guarding the Holy of the Holies, the structure divides and subdivides the mundane/profane from a more sacred space, and ultimately separating the most sacred space. It is through a fence that the first division occurs, then it is a tent, and finally, it is a veil. The mundane and the profane is the environment that we constantly see and live. Within sacred becomes the moment that is marked by something different that can only be perceived as being present at a place. In a similar way, open-pit mines have this gradual transition from one condition to another; the overall rural landscape becomes the scenario where all kinds of activities happen and people are constantly surrounded by the essence of rural life. But then, the pit becomes a disruption in the uniform landscape. It gives sacred a new meaning because it is a new overall environment, the 
figure 01 The sacred and profane of mining. The Tabernacle is considered the Holy of the Holiest. The temporal structure consisted of a fence and an inner structure, in which the main material used was animal hides.

Raimund Abraham's House with Curtains that has a permanent frame, juxtaposed by the light and unrestrained curtain along the perimeter.

These two precendents are essential for understanding the relationship between inside and outside, private and public, and sacred and profane.

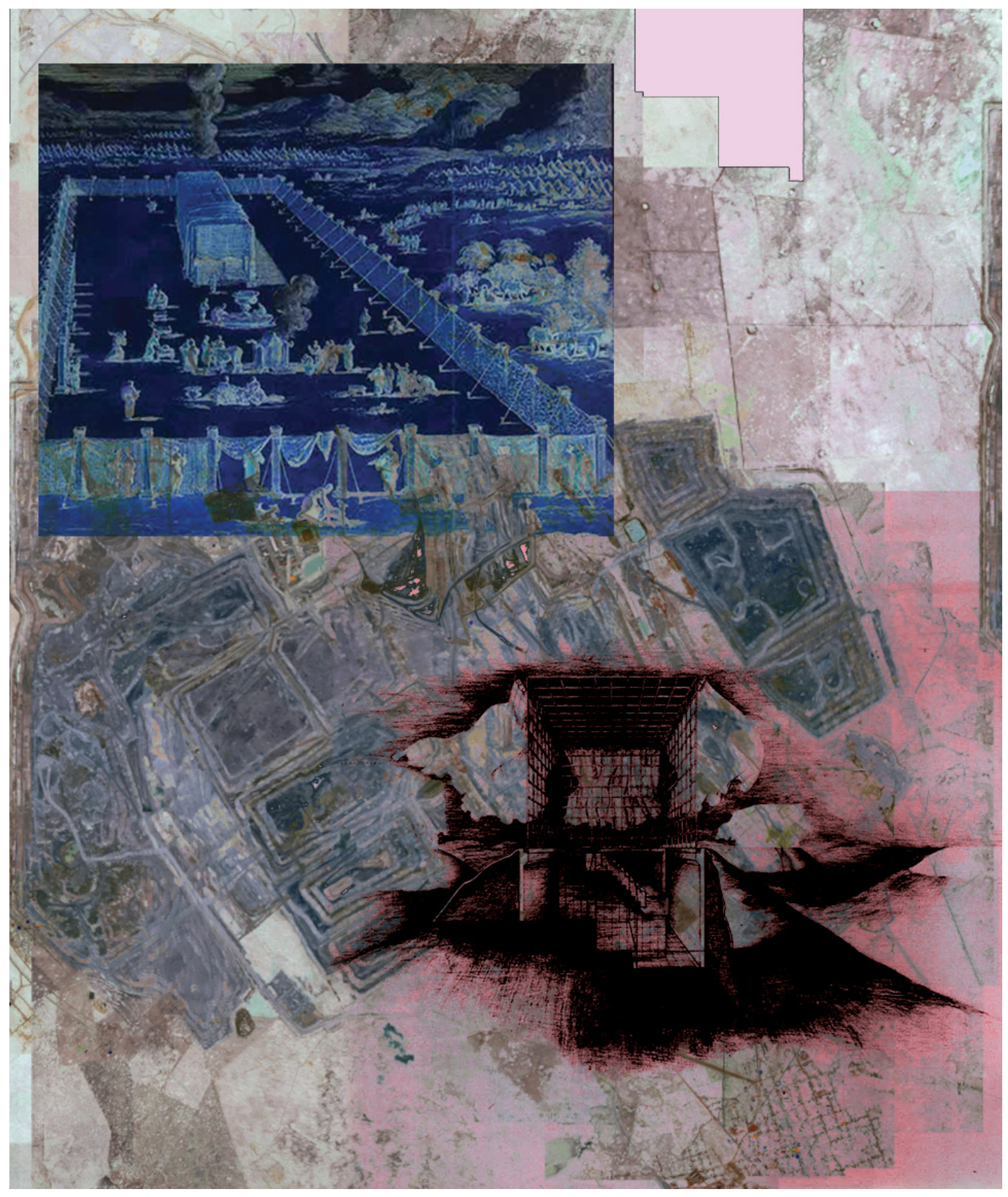


combination of the tangible and intangible, the real and the surreal, the spiritual and the physical, the past and the future. It is "all that goes beyond man's natural experience" (Eliade, 1983). Mining exceeds human beings' natural abilities, experiences and opens the door to experience the sublime in an alternative sacred world, mixed within the profane. Sacredness is organized through systems - spatial, temporal, natural, and collective - that is subjected to change when mining occupies those territories. Diana Agrest defines system architecturally as "both by what it includes and what it excludes, or represses" (Nesbitt, 1996).

Mining alternates between the definitions of what is sacred and profane: in a similar way as the Tabernacle, the edge of the pit becomes the boundary between two worlds: the sacred, communities and the spiritual and natural value of the soil; the profane of the hole in the ground; and the most profane the social discord caused by the industry. Before our secular approach to architecture, sacred took "the idea of religion ... inseparable from the idea of a church, it conveys the notion that religions must be an eminently collective thing" (Durkheim). A sacred space takes shape, not in the sense of spiritual sacredness but more in the sense of protected, immune, inviolable, shielded from the profane, but yet, aware of its presence. According to Giorgio Agamben, "through profanation it is possible to restore things to their common use" (Petti, Hilal, \& Weizman, 2013). The idea of not knowing what you have until it's gone relates to sacred: as soon as there are signs of danger, or challenges, we become more aware of the need for the sacred and the existence of the two polarities of sacred and profane.

The polarity between these two terms is further understood in four themes: as space, composed with two kinds of mundi; as time and the repetitiveness of rituals; as nature's symbolism and analogies through natural elements; and lastly, the self. The correlation of these four themes demonstrate that sacredness and profanity are non-geo-specific, but rather conducted by individuals using physical elements to achieve a collective environment. This environment belongs to a space, which could be tangible or intangible, broad or precise. Just as ambiguous as the perception of sacredness within an environment could be, space is either a noun, adjective or verb; it is dimensional or a defined area, it could refer to the cosmos, and/or it is simply a separation or gap. Eliade uses imago mundi and axis mundi as collectively and individually representing space in its three states. The former is the multiplicity of individual and subjective tangible spaces. But the attention will be placed on axis mundi because it is a more general concept of sacred. This mundi bridges three cosmic levels: earth, heaven and underworld, or the 'system of the world' (Eliade, 1983). Eliade defines this system as follows:

(a) a sacred space constitutes a break in the homogeneity of space; (b) this break is symbolized by an opening by which passage from one cosmic region to another is made possible... (c) communication with heaven is expressed by one or another of certain images... which refer to the axis mundi: pillar, mountain, tree, vine; (d) around this cosmic axis lies the world (our world), hence the axis is located 'in the middle' at the 'navel of the earth' (Eliade, 1983) 


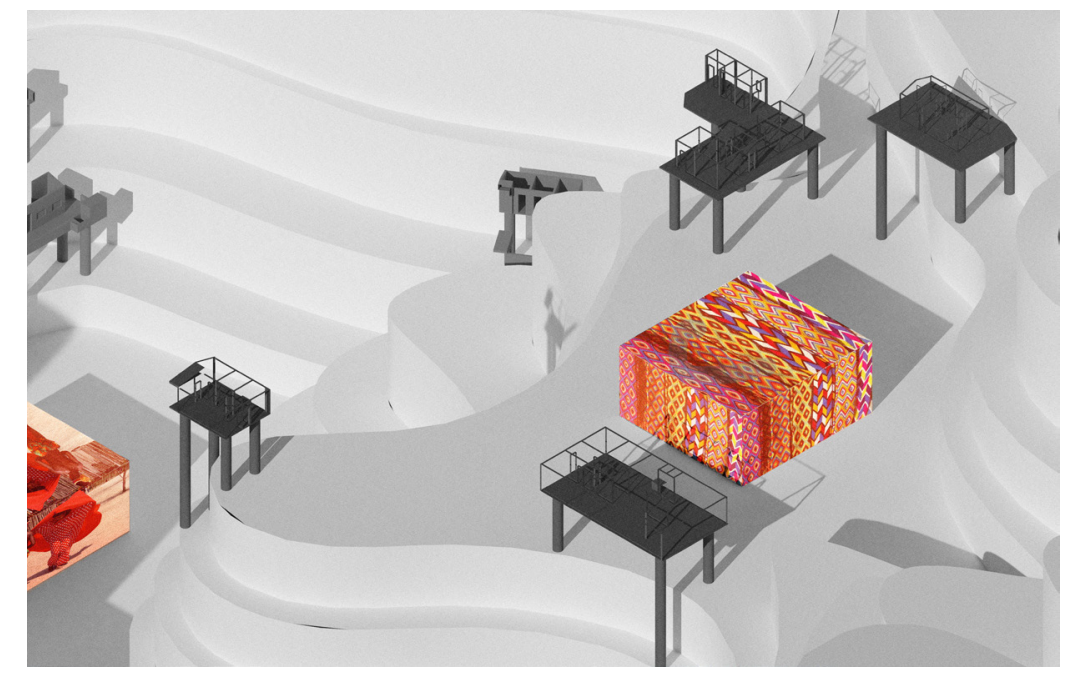

A site such as the open-pit mines presents challenges, contradictions and alternatives to the definition of sacred within the system of the world. The profane act of violating the soil and creating a void becomes a generator of space, as a noun and as a verb, within the homogeneity, yet individuality of rural communities in Colombia. This homogenization is seen in the abandonment of the rural landscape for the exploitation of the land and the mobilization of campesinos and minorities to new living areas, and cities. This new communal environment detaches everyone from their own traditions. Eliade writes about the disruption in uniformity as a relationship between us and the cosmic levels. But mines literally demonstrate this representation, through the strata of the soil being exposed to the heavens, to bring light to the hidden - to the underworld - to have space (verb) within the horizontal plane of the soil. This communication between the three cosmic levels is achieved by the alteration of Eliade's axis mundi, because a universal pillar is not required to join the levels, but there is still a need to make the connection tangible and experiential. A new world, a new system is set up in, on, at and around the open-pit mines, as the reinterpretation of the axis mundi, being inverted and becoming a symbol of the neo-colonial era.

Spaces that are contested for different interests and investments become the transition between the two states of sacred and profane, which is carried through rituals and beliefs. These vehicles correspond to sacred time, which Eliade defines as "reversible in the sense that, properly speaking, it is a primordial mythical time made present...every religious festival...represents the reactualization of a sacred event that took place in a ... past... sacred time is indefinitely recoverable" (Eliade, 1983). Similar to sacred time, and its cyclical manifestation through rituals, Freud writes 
figure 03 the overall relationship between sacred and profane in terms of reconciliation. Mimicking the void of mining, the sacred is at the centre, the hearth for, and of, reconciliation .

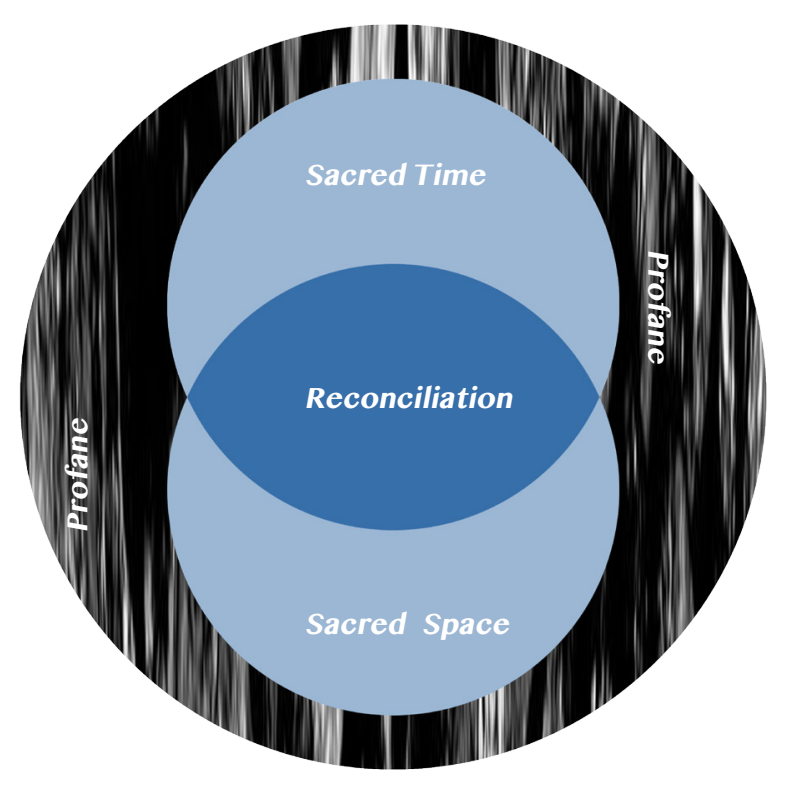

in The Future of an Illusion, "that unsettling interplay of suppression and memory that arises from living subject to fears and anxieties in an unpredictable world ... how uncanny encounters within religious rituals can help participants come to terms with fears and anxieties, transforming inchoate emotions stemming from trauma or dislocation". This specific time adapts and responds to the zeitgeist, becoming a fusion between its inception's time to the present, waiting to be even further modified and adapted for the future. As part of adapting to the present, the new urbanized rural Colombia has to find alternatives to use the real sacred-space with the ideal sacred-time to the socio-environmental changes. The mining industry utilizes and exhausts natural resources for the exploitation of another natural resource. From a religious perspective, all natural elements are sacred. However, water has a more important value as it "existed before the earth (as in Genesis, 1, 2, 'Darkness was upon the face of the deep. And the Spirit of God moved upon the face of the waters')" (Eliade, 1983). 
figure 04 nature becomes essential in the process of recuperation and reconciliation between sacred and profane. It has the ability to emerge and grow regardless of its circumstances, context or condition.

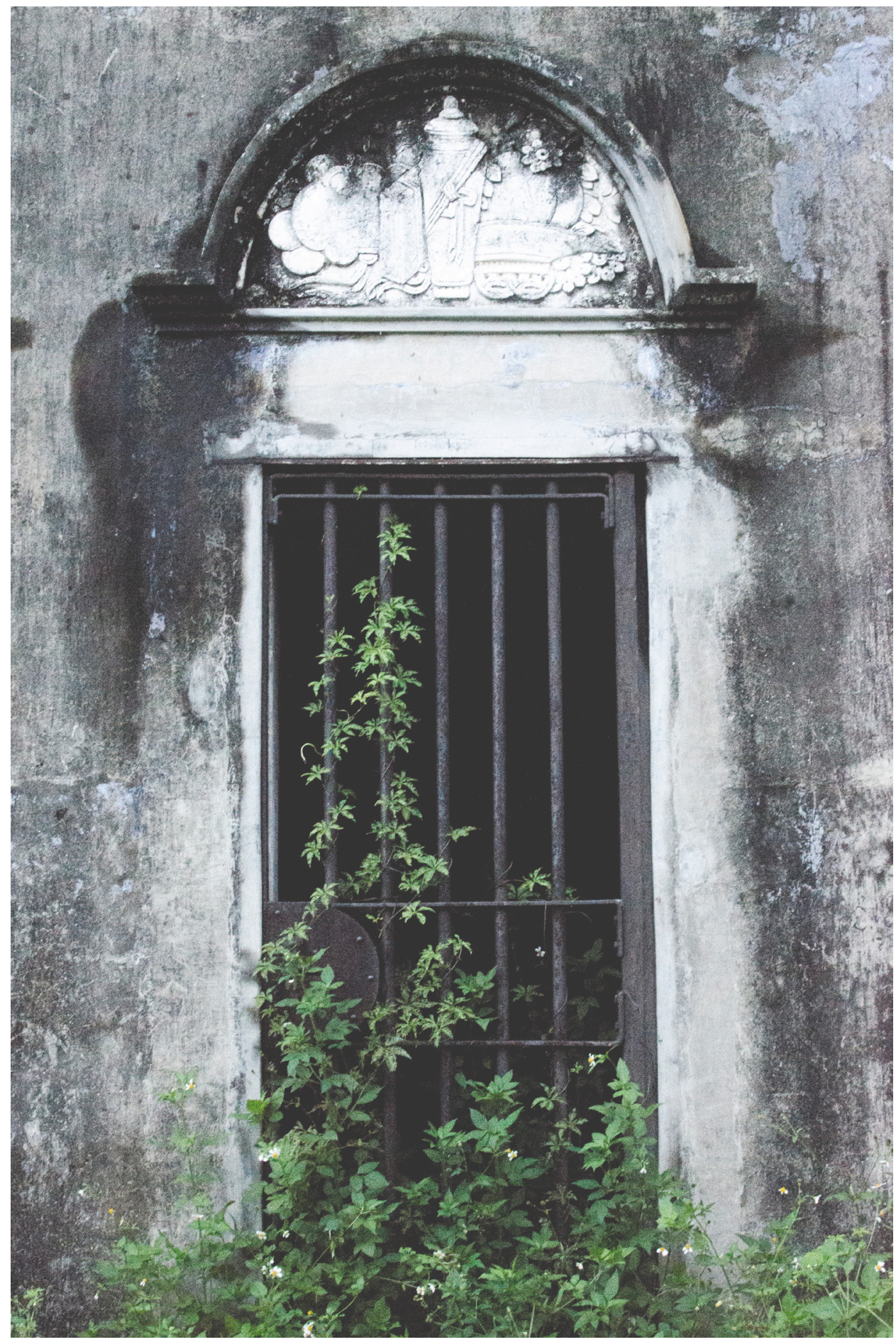




\title{
MAGIC REALISM AND NEW OBJECTIVITY
}

\author{
La primera condición del realismo mágico, como su nombre lo \\ indica, es que sea un hecho rigurosamente cierto que, sin embargo, \\ parece fantástico. \\ Gabriel García Márquez
}

The reality seen in the every-day is always altered, manipulated and disguised. After World War I, Germany sought facts, sachlichkeit, or matter-of-factness. Known as New Objectivity, it criticized the non-realism of the art produced, depicting an emotional and abstract reality. German Art Critic Franz Roh defined this new depiction Magic Realism as the "accurate detail, a smooth photograph-like clarity of picture and the representation of the mystical non-material aspects of reality" (Bowers, 2004). Seeking the genuine representation of the context, either ugly or pretty, good or bad, this new objectivity will then become part of magic realism. The concept itself presents an ambiguity and juxtaposition of two opposing ideas, that together, work towards the understanding of the world: Real, as an undeniable truth, and Magic, as the fabrication and alteration of something. It might be arguable that a magic reality is distrusted because it becomes fantasy. But, on the contrary, it gives a new spectrum of perceptions towards "an attempt to find a new way of expressing a deeper understanding of reality" (Bowers, 2004). Irene Guenther summarizes this contradiction in terms of the unheimlichkeit (uncanniness) (Bowers, 2004).

When it comes to mining, companies and governments address the exploitation of the land as a win-win situation for everyone: social sustainability through consulta previa (prior consultation, environmental assessment by providing documentation of all kinds of impacts pre, during and post operations, economic royalties paid, and under the control of governmental laws. But all these reasons are romanticized in a way because nothing ends up being what it actually is or what is promised. These policies turn from objective to subjective, which really affects the progress of rural life. The hope that is told, and sold, to campesinos becomes a new reality. In a post-operation scenario, being able to perceive what was done to the land becomes a lesson for future generations as an alternative meaning for sustainable society ${ }^{1}$. Part of the acceptance of the industrialization of the landscape relies on having access to the site in an almost bona fide state.

Aldo Rossi's view towards the city can be applied to the revival of the countryside, as long as it follows "conceptual experience, resonant with memories" (Tafuri, 1998). After this has been considered, "the reference points of the existing city, placing them on a vast, illuminated surface: and thereby let architecture participate, little by little, in the creation of new events" (Tafuri, 1998). A new culture can emerge from this new landscape, with new traditions, values and views towards

${ }^{1}$ Sustainable society is defined as "one that can continue indefinitely. Its level of consumption should reflect environmental and resource balance. It should assure its citizens equality, freedom and a healthy standard of living"'

(What is a Sustainable Society?, n.d.) 
figure $\mathbf{0 5}$ the new objectivy in Colombia is the rupture of an ecosystem (people, nature, traditions, etc). Because sacred and profane are not two different entities, their synergy will be the creation of a new reality.
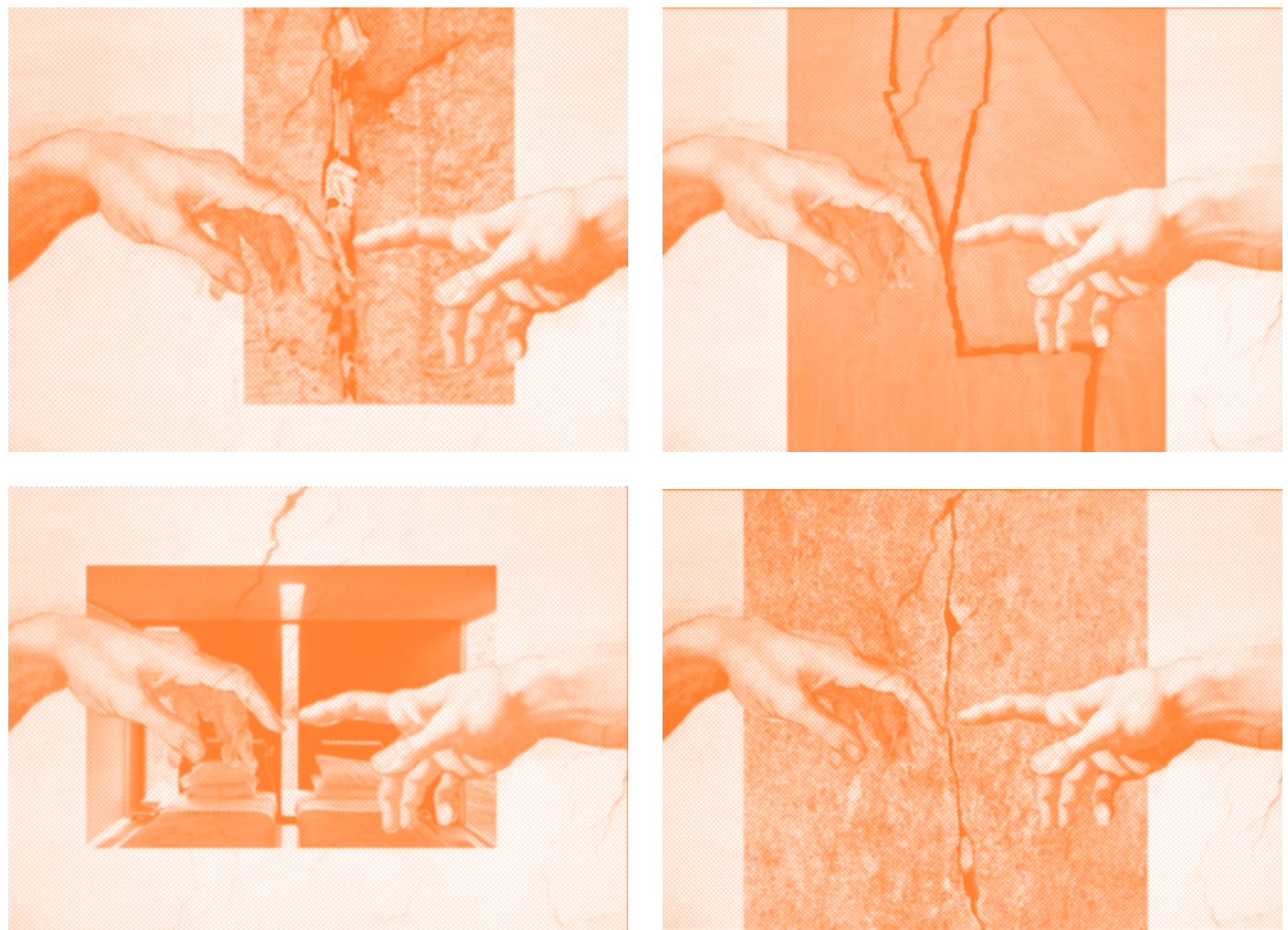

the 80\%. Alejo Carpentier coined the term Real Maravilloso (Marvellous Real), to denote cultural traditions that extend to another reality which only locals can comprehend. To external eyes, anyone outside the cultural cocoon, the traditional reality becomes 'different', 'alternative', 'weird' but also 'intriguing' and 'wonderful' (Bowers, 2004). In traditional cultures, the view towards reality and life experiences has been transcribed to generational myths and legends.

Regardless of the terminology, new-objectivity, realism (pure truth), magic realism (alternative or alternate reality), surrealism (subconscious reality), or real maravilloso (vernacular reality), there is the constant search for stating a matter-of-factness, a factual reality that has been omitted or suppressed, just like Colombian rural life. The countryside has undergone different periods of violence, marginalization, exclusion, and it's been targeted for its natural resources. Magic Realism becomes a key technique for the acknowledgement and reconciliation between locals, corporations, governments and church because it "is characterized by its visualizing capacity, that is, by its capacity to create (magical) meaning by seeing ordinary things in extraordinary ways" (Zamora). It becomes a coping mechanism for advancing towards the new vernacular landscape. 


\section{The Promised Land}

Colombia's main mining sites, in the departments of La Guajira and Cesar, have drastically transformed and fabricated a new infrastructure and landscape. The people who first used the land for other purposes are challenged to adapt to a new set of conditions. The method deployed in this thesis for analyzing the ubiquity of mining is by combining and overlaying aerial views (formal expression) of numerous open-pit mines. If only one particular mining site in the country when chosen, the 'architecture of reconciliation' would respond to that site only. But the consolidation of the mines of the northern region of the country abstracts the discourse, allowing for access to a more powerful representation of the impacts on the used land - which makes up about $2 \%$ of Colombia's national territory - and to understand the relationships between the actors corporations, governments, churches, campesinos and minorities - regardless of the specific issues on conditions on any particular site. This non-existent site represents the post-colonization of mining because it conquers a new land away from the industrial activities and equalizes everything that once was fragmented.

This new site clashes the real and the unreal, the present and the absent and the local

and global. This non-existent site is characterized by a lack of real communities, does not have coordinates for finding it, nor can it be visited. But because all the conditions prescribed for this new site are from real problems shaping rural Colombia, it becomes a real. The benefits of creating a non-existent site are that real elements can be added and manipulated to enhance its reality. And finally, the local imaginary site becomes a sample of the global industry of mining. The whole constitution of this ambiguous abstract site is that it borrows elements from the real, the surreal, the magical real, and real maravilloso: the reality of mining through the scarring on the land and the voids creating new landscapes, the sublime surreal resulting from the inhabitants' repression by the real mines and producing an alternative view of standard elements, context, and history of the original site, the magical reality of looking at the non-existent site as if it were real because of all of its qualities and characteristics, as well as looking at the existing site.

The open-pits are empty containers that wait for being repurposed. Legally, corporations re-fill and reforest the voids to bring back nature, culture and people. This superficial strategy can become the foundation for a new architecture. But the mined site offers a more challenging, yet rewarding conditions because "the intervention and transformation of a site is the true beginning of architecture" (Abraham, 1983) Although the violent manipulation of the land led to the disappearance of architecture (as in demolished houses), there will be a birth of a new kind of architecture coming from the need to seek reconciliation between the actors. Although the existing, real site has displaced people and removed them from their home and dwelling, by translating that space into the non-existent, imaginary site, the space becomes something attached to the people because it "is not something that faces man...it is not that there are men, and over and above them space" (Heidegger, 1993). 
[this page] figure $\mathbf{0 6}$ the promised land is born from the fragmented landscape generated by mining. [next page] figure $\mathbf{0 7}$ the promised land is the creation of a new culture.

[page 144] figure 08 the promised land is a combination of all the largest mines in the northern region of Colombia.

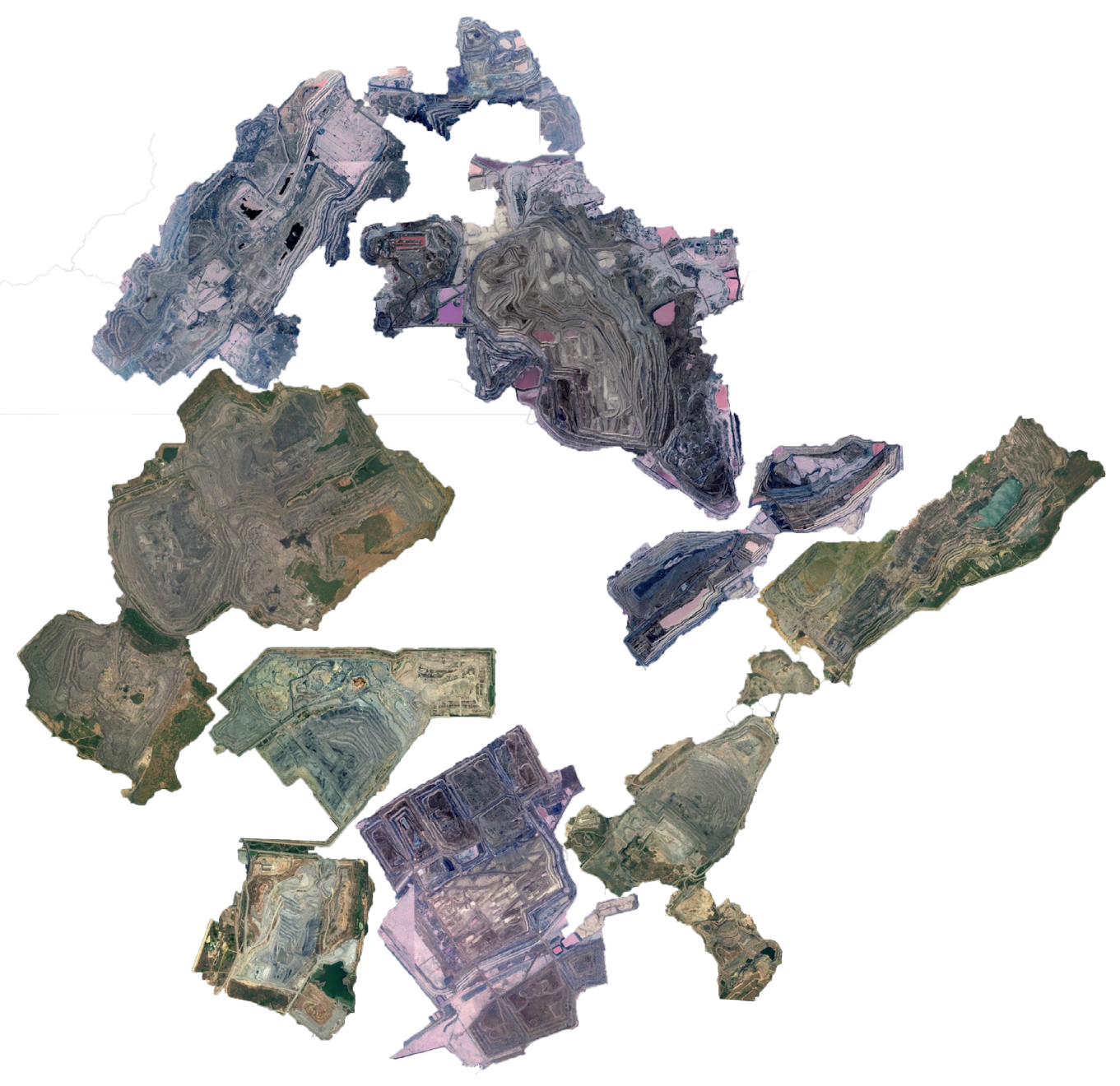




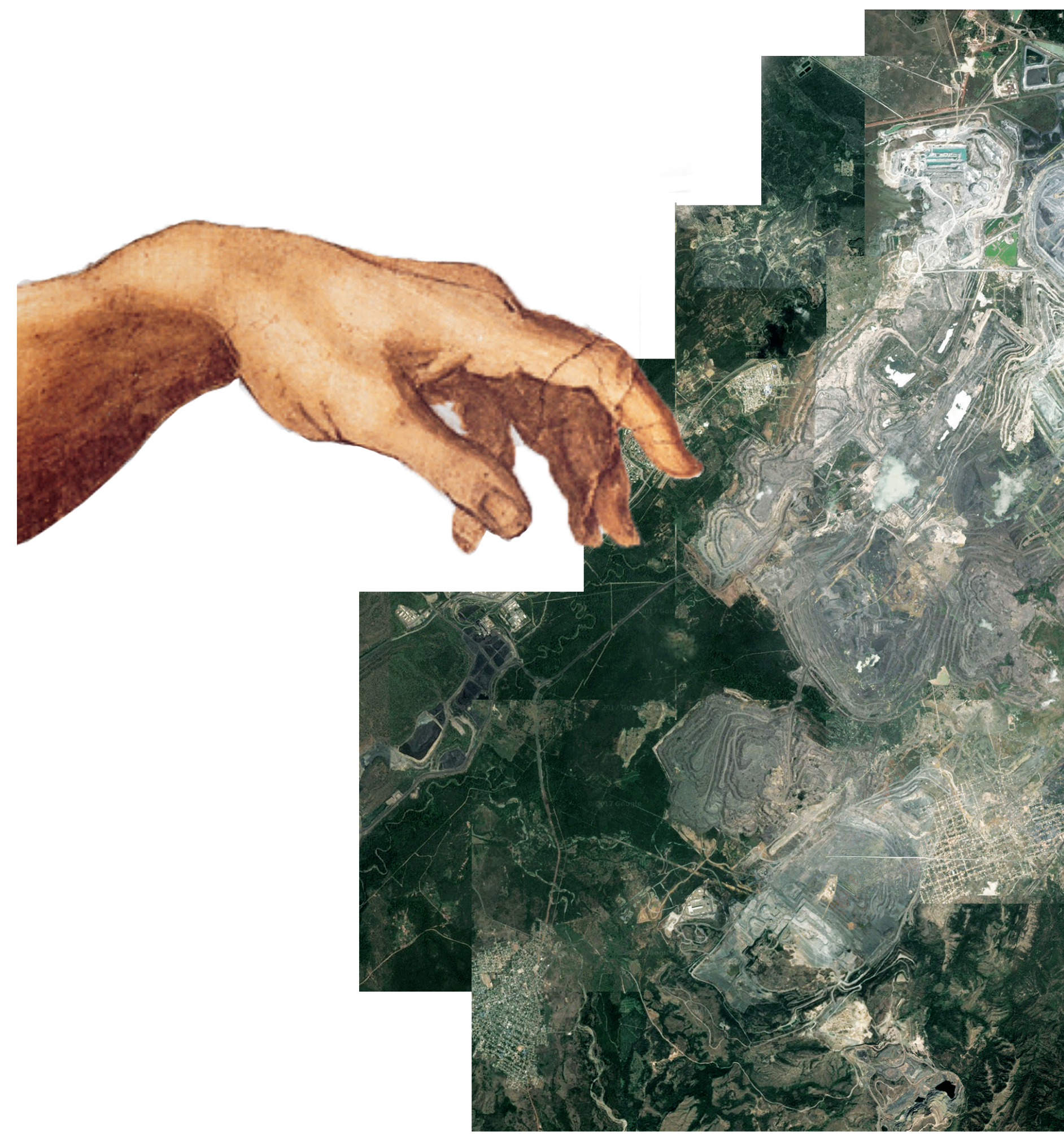




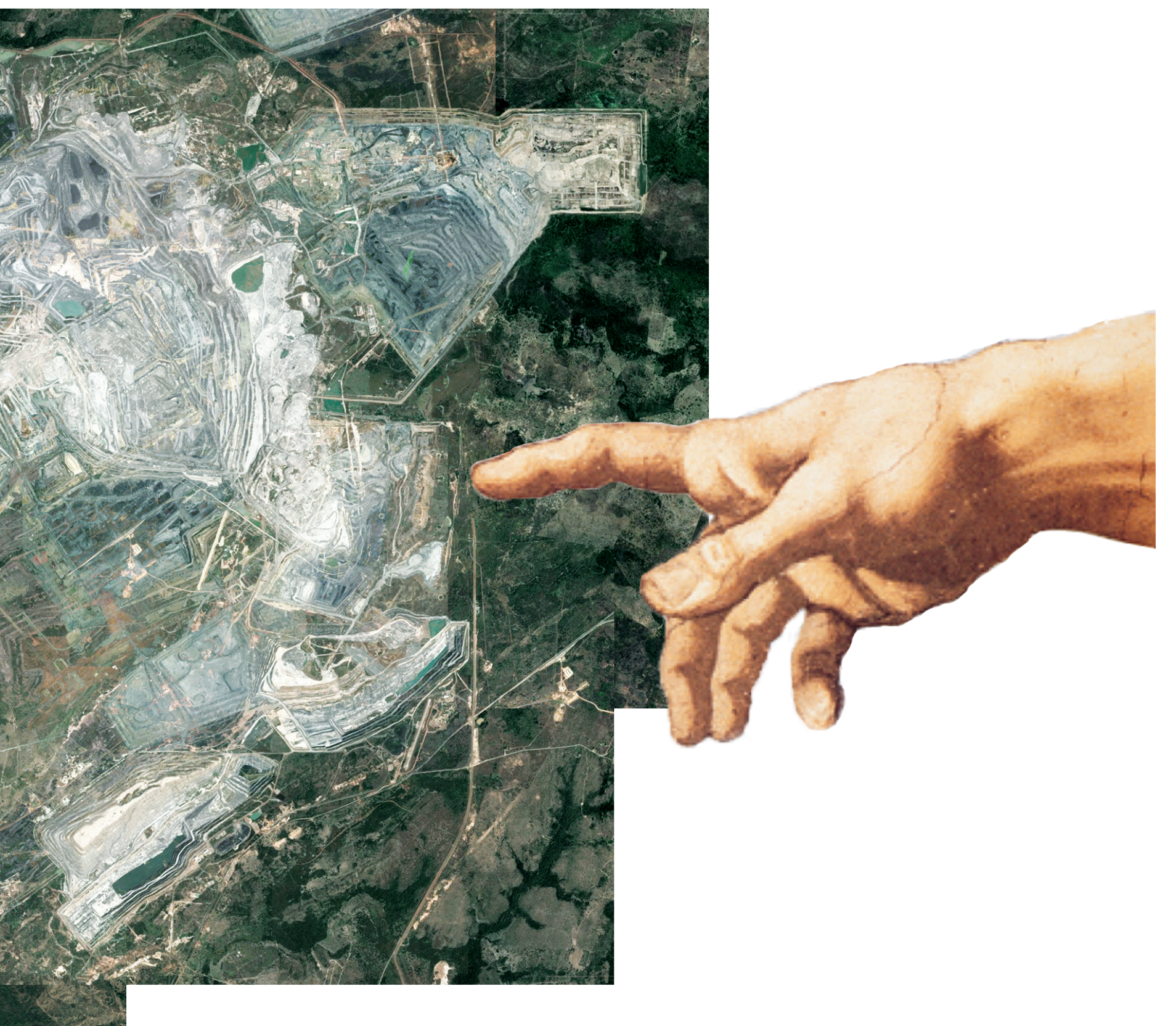





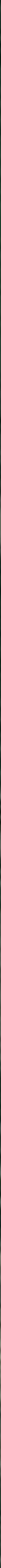

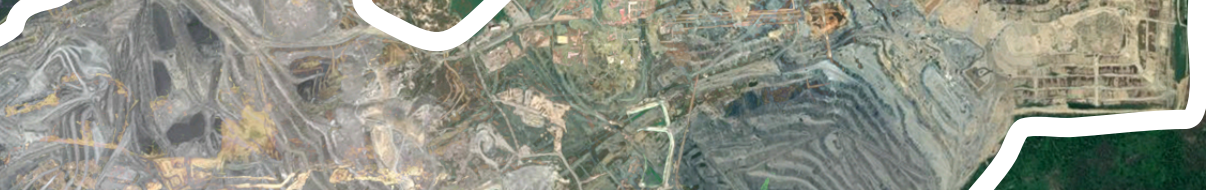

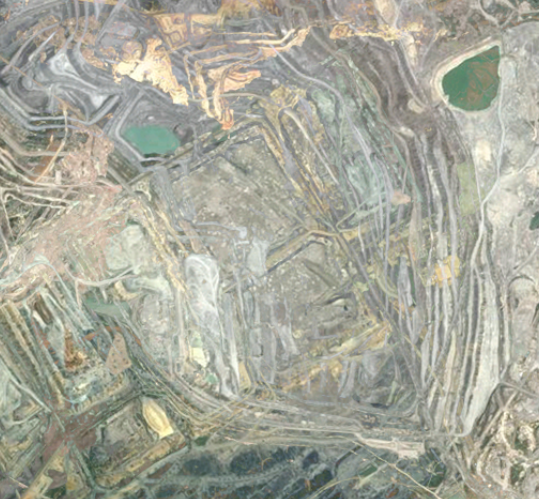




\title{
AMBIGUITY
}

\author{
Despina can be reached in two ways: by ship or by camel. The \\ city displays one face to the traveler arriving overland and a \\ different one to him who arrives by sea. \\ Italo Calvino
}

Ambiguity allows for a spectrum of definitions to act upon a single element, without having to be certain if it's right or wrong. A way to understand how an object can have one single meaning is through binaries. Aldo Van Eyck developed this concept in terms of architecture, so that "the significance of binary qualities for spatial action is that their qualities are inherently double and thus interpretative. Moreover, their complementary values mutually strengthen the appeal of each other" (Plummer, 2016). Binaries do not isolate antonyms, but use them as a tool to understand the strengths and weaknesses of a condition, an object and an environment, in which the victimizer and victimized, solid and void, dead and alive, positive and negative, become tools for developing an architecture of ambiguity. To exemplify this, the mining landscape in Colombia embodies these binaries, depending from where the scarring is looked from and who looks it at it. The rural landscape is ambiguous because it is fundamental to acknowledge that the mining intervention has brought both benefits and drawbacks.

In a more radical view, Venturi approaches ambiguity in architecture through complexity and contradiction. Venturi's basis for ambiguous architecture is through order and orderliness. He comes to conclude that "when circumstances defy order, order should bend or break: anomalies and uncertainties give validity to architecture" (Venturi, 1992). This is the particular case of rural Colombia as it has been subjected to several forms of alterations; social through displacement, environmental through mining, cultural through reframing traditions and values. But an architecture of reconciliation becomes a vehicle for conflict resolution, because "there have to be maximally satisfying, though conflicting, resolutions of the indecision concerning the denotation of the building which assign different denotations to the building" (Baumberger, 2009) 


\section{THE IN-BETWEEN AND THIRDSPACE}

The presence of an in-between means a transition and change between two spaces. Within the realm of sacred and profane, this area becomes the collision between two worlds. Herman Hertzberg defines this space as "the threshold provides the key to the transition and connection between areas with divergent territorial claims and, as a place in its own right, it constitutes, essentially, the spatial condition for the meeting and dialogue between areas of different orders" (Barrie, The Sacred In-Between: the Meditating Roles of Architecture, 2010). This can take place at different scales, from a hallway in a house, to plazas in cities, to mountains and forests between the city and the countryside, as seen in the Colombian regions. Regardless of the scale and location, thirdspaces become containers between elements (natural or man-made), intended to connect two separated spaces.

Similarly, as the in-between, thirdspaces represent more than the physical context, without being geo-specific. They synthesize all the factors that influence a space. Different thinkers have proposed their views of the in-between, like Edward Soja, who relates it to mixing different cultures to Homi Bhabha's post-colonial setting and Ray Oldenburg's physical space. The first space is symbolized through the home, the cultural home, which extends beyond the physicality of dwelling because it is 'embedded' with its user (Morgan, 2013). In contrast, the second space is the imposition of post-colonial structure. Anything that disrupts the vernacular landscape and creates a new landscape is called second-space. A combination between first and second space results in different theories for a third space, the people from the first space interacting in the second space, seeking a new identity developed through interaction (Morgan, 2013). The hybridization of culture in the first space becomes a tool to articulate their identity and be able to function within the second space. In the neo-liberal framework, it can be speculated that the true rural landscape, which is less than $25 \%$, is the first space, whereas, the city and urbanized rural landscape, more than the $75 \%$, are the second spaces. Coming from there, a thirdspace responds to Edward Soja's concept that is constantly growing to include an-Other thus enabling the re-negotiation of boundaries and cultural identities, which then leads to a process of hybridity. This combination results in a new culture and new structure that challenges the concept of urban and rural. Homi Bhabha's cultural thirdspace comes from a post-colonial mindset, resulting from the limitations of the colonized structure where there are pre-existing cultural identities. The thirdspace becomes a hybrid culture and it is nongeographically specific. In contrast to Bhabha's theory, Edward Soja's is geographically specific (Morgan, Third Space Part 2, 2013). Soja's thidspace takes into account the social and historical aspects of such space. Lastly, another thirdspace arises as a point-zero, neutral ground. For Ray Oldenburg, this physical space has no label, where people occupy it voluntarily (Morgan, Third Space Theory Part 3, 2013).

Thirdspaces are the results of combinations of tangible and intangible aspects that are inherently correlated. This is further explained by Aldo Van Eyck's twin phenomena, which takes into account the relationship between opposites so that their meaning is understood in a new way. It is a broader extension of the part-part-whole concept, where the understanding of the whole cannot be 
[this page] figure 09 thirdspaces as hybridity, history and equality. [next page] figure $\mathbf{1 0}$ thirdspaces as hybridity. [following page] figure $\mathbf{1 1}$ thirdspaces as history . [page 150] figure 12 thirdspaces as equalitarian.

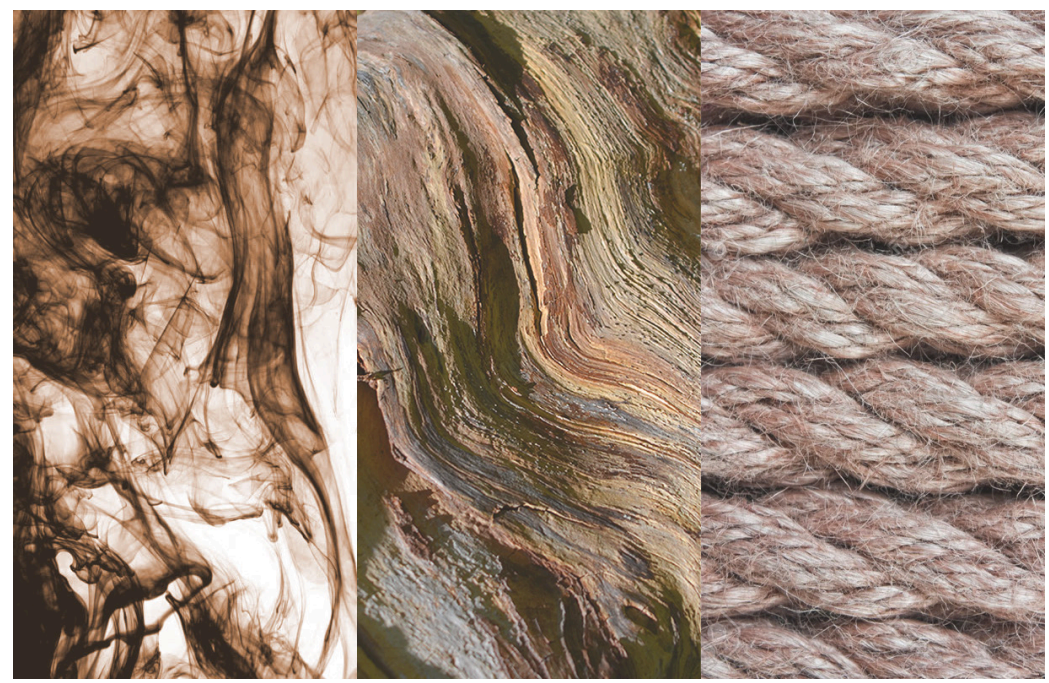

separated from the components that make it. The fragmentation of rural Colombia and campesinos blurs the possibility of seeing a complete panorama. The search for this outlook has to rely on finding the role of each actor and the causes that led to that rupture. Twin phenomena can be achieved through four dimensions: "space, time, environment and human" (Nam, 2009). The perception of time for campesinos is tedious and eternal because of the socio-environmental challenges (natural, cultural, social and economic). Adding to this struggle, the invasion of their territory and lack of their own space make the twin phenomena impossible to be studied in the rural landscape.

The dynamism of time can either enhance or undermine the quality of spaces where human activities take place. Norberg-Schulz divides space into two: perceptual and existential, where the former is the one essential for self-identity and the latter is to "belong to a social and cultural totality" (Chang, 2015). The spatial condition of campesinos is a battle between the perceptual and the existential because their personal traditions, which developed in the rural site, are contested once the new industrialized landscape is created, the urban becomes their new home, and the local becomes global. 


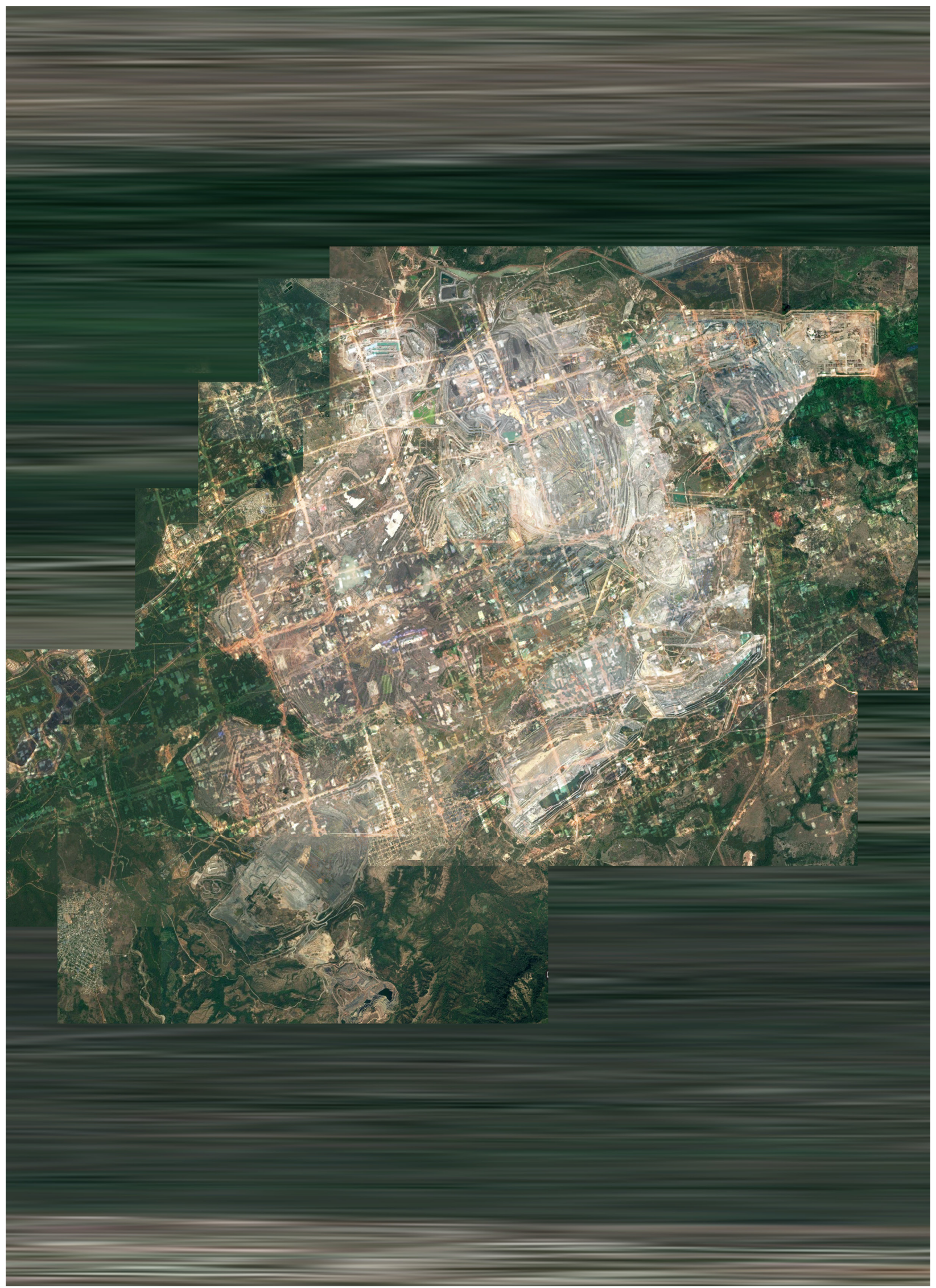




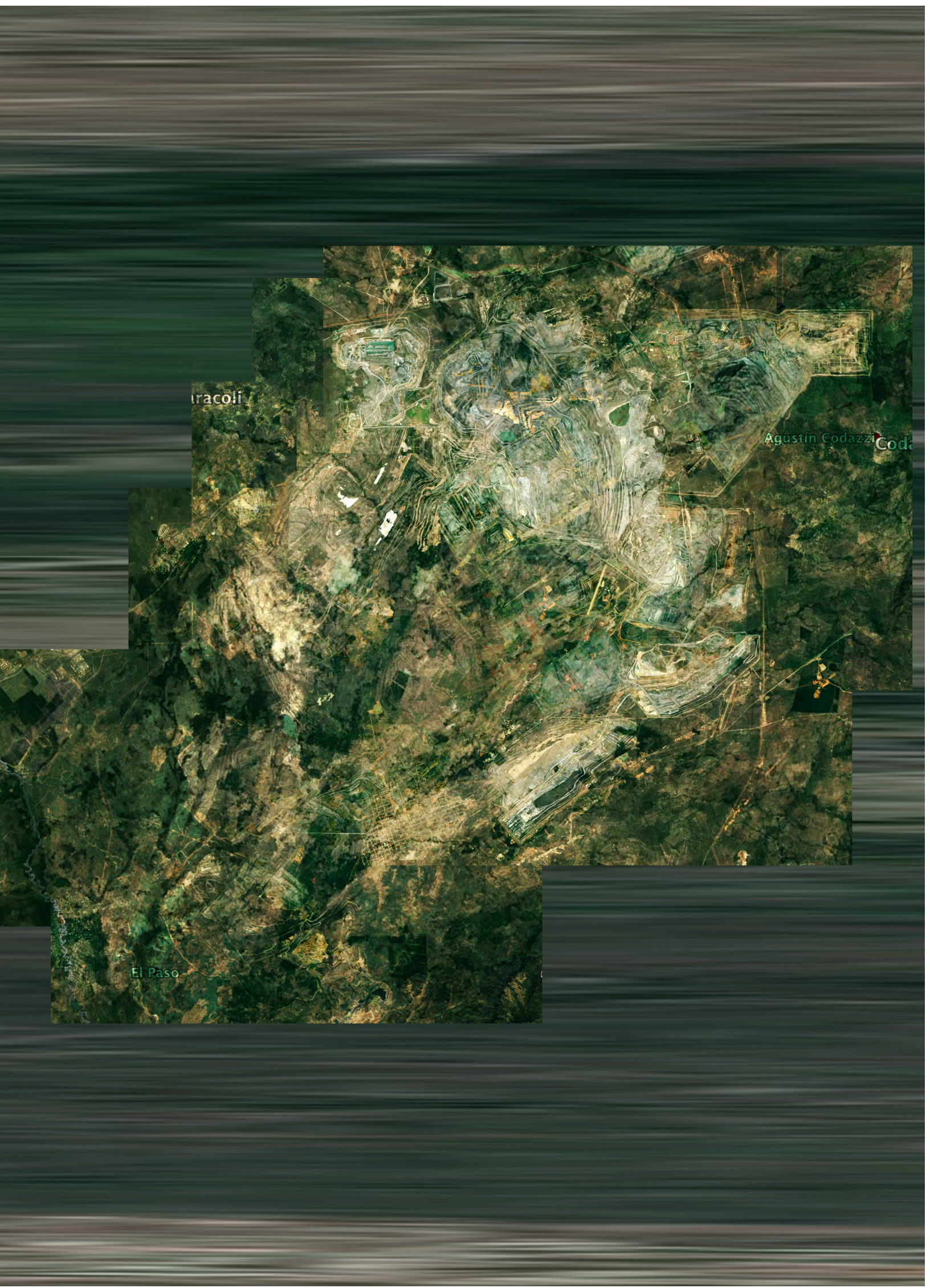




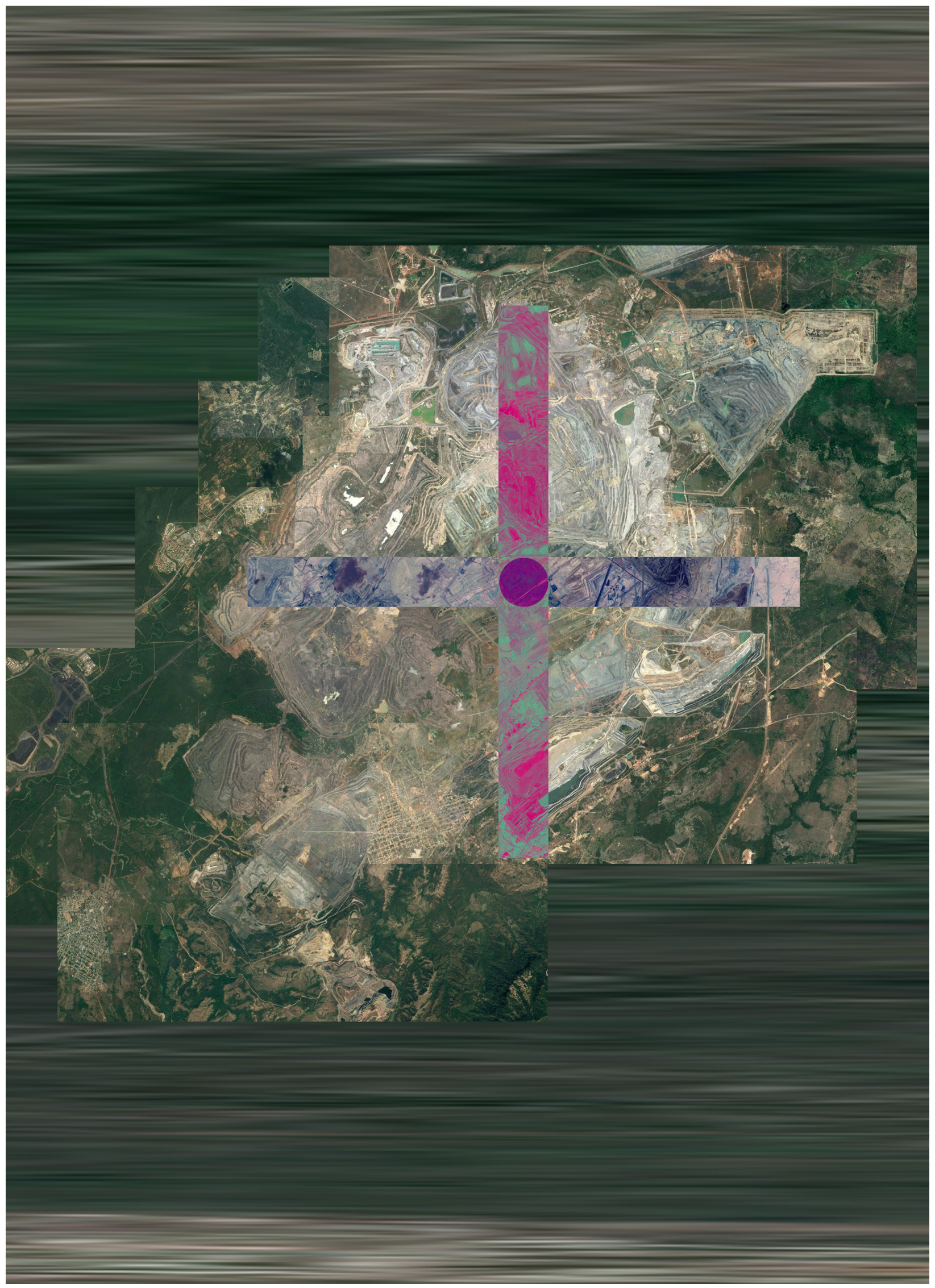




\section{UNCANNY}

The rural condition and the passive conflict between rural communities, the government and the mining industry is revealed as a scary feeling. The newly manufactured landscape becomes their new environment, a new condition that people have to adapt to. This psychological and physical sensation is known as uncanny. Anthony Vidler further studies the term that Freud coined within the architectural realm and defines uncanny as highlighting "the crossings and fissures within spatial and conceptual oppositions such as exposure and concealment, home and homelessness ... the 'shock of the modern' arising from the social traumas of the 20th century" (Morgain, 2012)

Along with Vidler's opinion on the reaction to the zeitgeist, Ernst Jentsch's definition of uncanny is being alienated from home, not being comfortable and "lack of orientation" (Jentsch, 1997). This disorientation is similar to what one experiences after being shaken, being dazed; our body is still there, but our mind and senses are altered by an external force. A place could still be the same but all directions overlap and there is no clarity and consciousness of site, because all that was familiar, has been removed. Furthermore, uncanny is the "involuntary recurrence of the old and familiar" (Homi K. Bhabha). This recurrence provides a sense of orientation because it refers to the repetition of something known. In a similar way to a phénakisticope $e^{1}$, where the fixed point of the slit and the eye, and the continuous movement of the images, allows the person to construct a visual journey with the reminiscences of a site. However, the concept of orientation is challenged at the open pit mines, where the familiar (the land and culture) is removed, displaced and relocated, the new landscape is far disconnected from the people, and the fragmentation between all the elements in the mining land worsens. Jentsch's uncanny is based on disorientation; besides being non-geographical specific, it becomes a 'layering' of blank canvases that once used to be occupied, like a palimpsest that does not keep the layers of the past, but rather eradicates it. In this context, orientation is completely arbitrary or convenient depending on the actor. Bhabha's uncanny is also challenged because a 'repetition' will be based on foreignness. Open-pit mines, where the large volume of absence dominates the landscape, is challenged by a severe case of uncanniness, while at the same seek and demand for bonding between the old and the new, the obsolete and the existent.

The modern condition that Vidler describes is a response to the globalization and neocolonial conditions shaping developing countries, a kind of "psychoanalytical and esthetic response to the real shock of the modern" (Vidler, The Architectural Uncanny, 1992). This clearly shows the worst that can be done to earth and cultures, and as a solution, the responsible entities immediately seek to hide the 'real conditions' of the grotesque, the harshness of reality, and the uncanny. Peter Eisenman argues that the "beauty in architecture is always trying to repress the grotesque". Architecture is a counter-reaction to the uncanny by becoming a spectacle between the real and the

${ }^{1}$ phénakisticope is a toy consisting of a disc or drum with figures representing a moving object in successive positions arranged radially on it, to be viewed in such a way (e.g., through a fixed slit) that the persistence of the successive visual images produces the impression of actual motion when the disc or drum is rapidly rotated. (OXFORD). This creates a dichotomy between movement and stillness. 


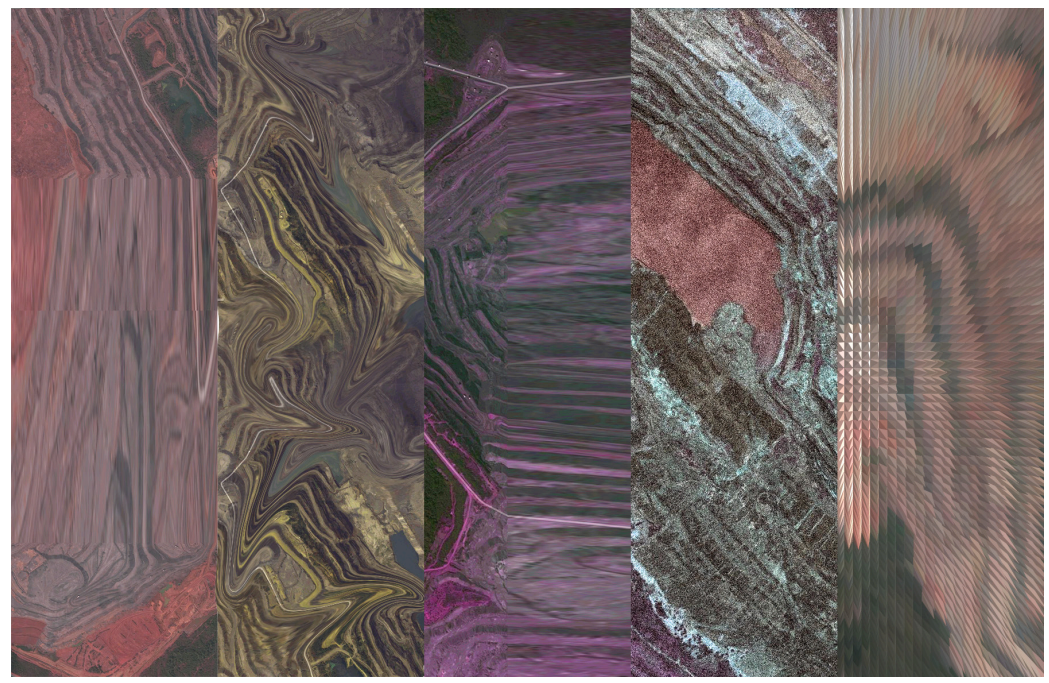

ideal, the ugly and the beautiful. However, architects like Etienne-Louis Boullee gave a new meaning to the connotation of ugliness. He was a prominent employer of absolute light, giving an alternative meaning to absolute darkness, which defines sublime as "the master category of aspiration, nostalgia, and the unattainable" (Vidler, Anthony; The Architectural Uncanny, 1992). The hole in the ground is sublime because it complies with three qualities. First, there is the immediate aspiration to return; secondly, the social, environmental and cultural contexts are shaped by nostalgia of the past and future of culture and traditions, but with a sense of hopelessness; and lastly, the unachievable goal of returning to the land the locals used to know. Adding onto that, Eisenman's sublime is another twist to the meaning of beauty and how open pit mines can be perceived as "the sublime deals with qualities of the airy, qualities which resist physical occupation, the grotesque deals with the real substance, with the manifestation of the uncertain in the physical... the grotesque is characterized by the uncertain, the unspeakable, and the unphysical" (Nesbitt, 1996).

The transition between the grotesque and the sublime is compared to the movement between the self and the natural, the internal and the external, the intangible and the tangible. These two concepts, sublime and grotesque, address the physical scar of mining, our perception of it, and how it can be approached. Although dichotomies might have a hierarchy, Eisenman's twoness "suggest a condition where there is no dominance or original value rather a structure of equivalences, where there is uncertainty instead of hierarchy" (Nesbitt, 1996). There is a contradictory emotion when being at the mine; the idea of the destruction of the land is supplemented by objects within nature, and how two natural elements (human beings and natural resources) are turned into artifacts. Similarly, as Eliade's imago mundi, the personal sacred space represented by home, is threatened by 
[this page] figure 14 Peter Eisenman's Fin d'ou T Hou $S$ mimics a house inside an open-pit. [next page] figure 15 the domestication of space.

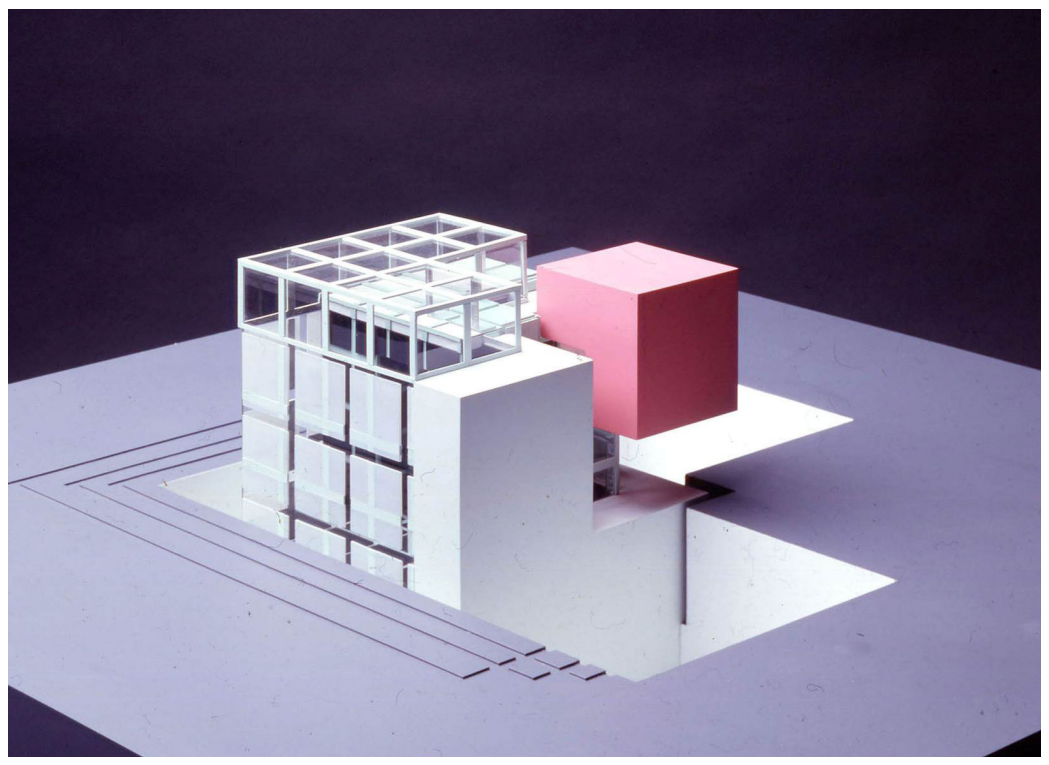

the profane, the external, non-sacred agents that seek to remove us from our comfort zone. Uncanny can even be considered a form of slow violence, in which the negative pressure on one's personal environment is manifested when there is no point to return.

Vidler further discusses the architectural uncanny by analyzing the elements that makeu architecture and the experience within and around it, especially in the context of dwelling and the meaning of house. His analyses on homesickness, buried alive and shifting ground attempt to address the consequences of being transferred, arbitrarily or planned, from the familiar and the comfortable (represented in the house, home, and living) to the unknown. At mining sites, the dwelling and houses are drastically changed, and the uncanny becomes more palpable. The new layer of landscape over an existent one questions what's real and what's not, what's truthful to the locals and what's deceitful. Eisenman's houses are the critique of how structure, elements and program can be altered, thus challenging our perception of space and understanding of architecture. For instance, his houses Fin d'ou T Hou S and House El even Odd sought to "destabilize their apparent object ... by attacking all of its elements of structure and signification systematically" (Vidler, The Architectural Uncanny, 1992). Eisenman's juxtaposes the synonym and antonym of living by playing with the structure and the standard configuration of rooms, and goes onto say that an abandoned house is simply a tomb, and then a monument (Vidler, The Architectural Uncanny, 1992). 


\section{Homely - Unhomely}

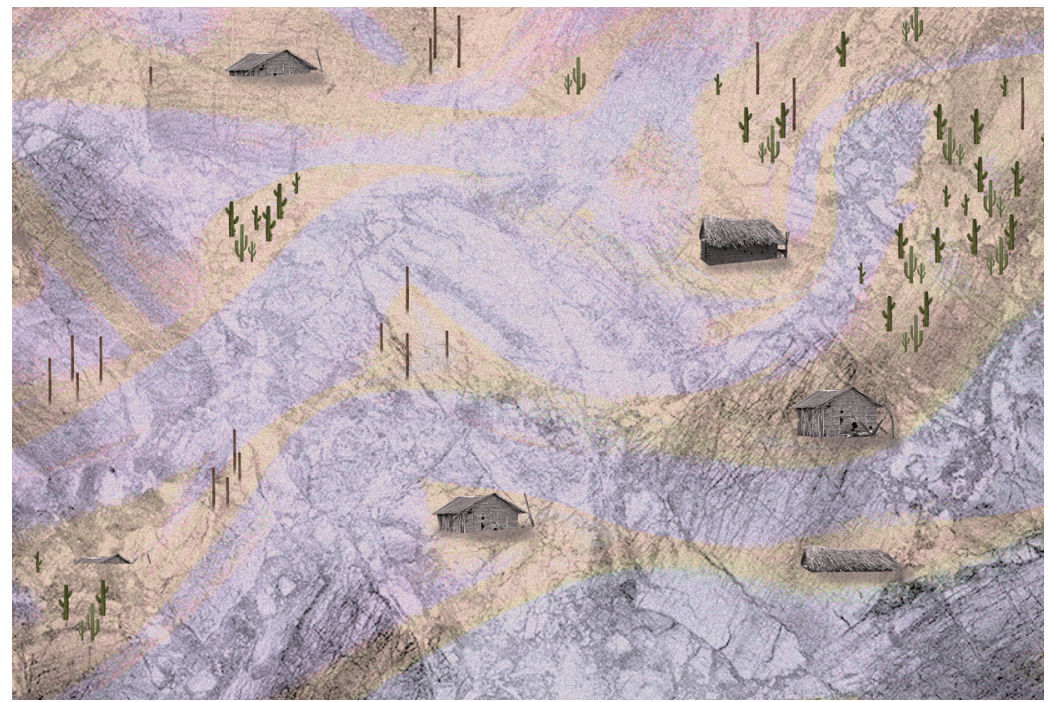

Uncanny is a "metaphor for a fundamentally unlivable modern condition", which comes from the German umheimliche, or unhomely. The concepts of homely and unhomely have a kind of ambiguity because of its multiple meanings: "lack of intimacy or warmth" (unhomeliness) and to the opposite of "lacking in physical attractiveness" (homely) or its etymological roots "of or belonging to home or household, domestic" (etymonline). In other words, unhomely is about finding appealing something that should not, and homely is about apathy, indifference and privacy. However, both concepts are derived from the idea of revealing and hiding. Unhomeliness or unheimlich is the name for everything that ought to have remained ... secret and hidden but has come to light' (Freud 1976: 623). Similarly, heimlich is a "secret and even dangerous, evoking what lies hidden behind closed doors" (Morgain, 2012). For the former, the secret is exposed, whereas in the latter, it has not been revealed yet, but there are hints that there is a secret. These dichotomies between hiding and revealing are subjective because each actor wants to keep a secret, and also partially show something: corporations, reveal the physical layer of the land with the voids, but hide the overall impacts of these; governments, especially local, expose the benefits of exploitation but neglect the fact that they are part of the neo-colonial mindset affecting thousands of communities; the church, as a spiritual path, shows the conscious way of achieving things but suppresses the realities of people's desire outside this path; and for the rural inhabitants, they become the living proof of everyone's secret.

Colombia's mining scene becomes a celebration of unhomely and the re-interpretation of homely. Upon returning to the land, the open-pits are the result of revealing what should have been kept hidden, or away. And once the place is re-visited, a new set of secrets are still present but not visible yet. Moreover, the new site also embodies the unfamiliar as the new environment, as campesinos had been estranged from the landscape, and are now coming to the new official landscape. The surfaces of the pit become an enclosed space that brings a new kind of intimacy with the enemy and offers to the unattractiveness of the site, the domestication of the space. 


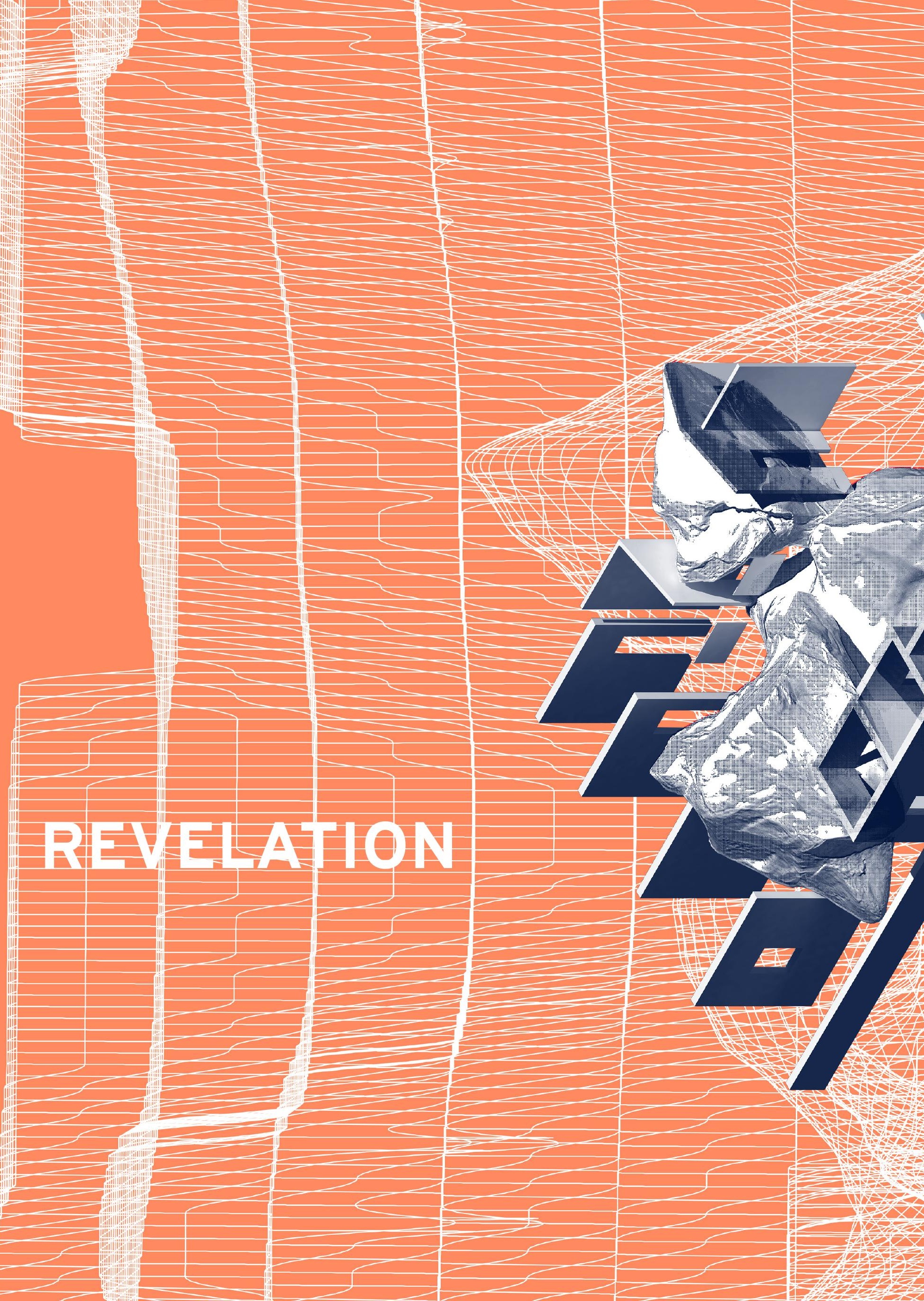



Colombia's rural landscape has shown to be overshadowed by more powerful external forces, through globalization and neo-liberal policies, which campesinos, locals and minorities might have zero control. The presence of such economic strategies is a revelation, in both the secular and spiritual sense. From the spiritual sense, Revelation, as the last book of the Bible, has a lot of layers of meanings and information. For one, it presents the re-apparition of the Messiah, for punishment and reward, with the ultimate goal to bring hope for a new beginning. It is also seen as the Apocalypse, defined as "an event involving destruction or damage on a catastrophic scale" (Oxford) but biblically meaning "uncovered, unveiled, revealed" (Life Application Study Bible, 2015). It is also apocalyptic for the use of "symbolic imagery to communicate hope...to those in the midst of persecution" (Life Application Study Bible, 2015). The persecution lived in Colombia is not someone literally following minorities and campesinos, but it's the slow violence of the abused landscape that haunts. Amidst this psychological conflict, the apocalyptic revelation is intended to bring hope, through architecture. Architecture is a canvas, and vehicle, able to adapt and capture the surroundings, in order to uncover the hidden.

The design response to mining and the rural changes is an alternative view of 'another' rural Colombia. This new space will define a new genius loci, or transcendental loci ${ }^{1}$, for future generations. In a similar way as Eyal Weizman's Decolonizing Architecture Art Residency sought architectural intervention through a symbiosis with the opposition, this project is aimed to give new meanings to what was considered profane, and/or sacred, to find the balance between two oppositions, that at the same time could be synonyms or dichotomies of the other. This project is based on giving "an instant perspective of the oppressor" (Petti, Hilal, \& Weizman, 2013). By positioning the users, victims, into the space that caused division and 'estrangement', architecture develops a connection and synergy between the fragments of the rural context. Moreover, facilitating access to the open pit mine will similarly engage reconciliation into the process of acknowledgement, remediation and awareness of the human greed that created a new rural Colombia. In the same manner as mining is done, reconciliation will follow a similar process. The extractive process is organized by the action of breaking, disrupting the standard - social and environmental - in order to seek a mineral (gemstones, coal, oil). Reconciliation, then, has to break the boundaries between the actors and all the neo-liberal factors that have created this new condition.

Michel Foucault writes about space as a "fundamental in any form of communal life, the space must also be 'fundamental in any exercise of power' and that 'whole history remains to be written of spaces - which would at the same time be a history of powers" (Harvey, 2007). Seeing the space as a canvas of what an architecture of reconciliation does is turning space ${ }^{2}$ into a place ${ }^{3}$ of life. The importance of space is how its elements and qualities form a place that embodies and captures everything existing and anything new. Foucault writes about space beings the means for power. This power does not mean in the sense of political power, but a more social power, where the social fabric is sown back together. Just as Foucault's heterotopias create a new space, a new -topia will emerge from the rupture of the veil between the social, political and economic, and even spiritual properties of rural Colombia.

'Referring to the term coined by Georgi Lukács that means "nature and consequences can be described".

2 Space: a continuous area or expanse that is free, available, or unoccupied.

${ }^{3}$ Place: a particular position or point in space. 


\section{DECOLONIZATION}

The rot that remains when the men are gone

Derek Walcott in Ruins of a Great House

Decolonization implies that a state of oppression has been finally released and freed. But in contested areas that carry some benefits, the process of decolonization results challenging, particularly in areas of Colombia, where mining has created such a dependency for the locals and even the country. In a way, this process might occur once operations stop, but the presence of a colonized land would still be palpable through the scarring of the open-pits. Eyal Weizman's writings are the result of the long and violent outcomes from the Israeli-Palestine war. But his analyses have common grounds with the Colombian rural condition of displacement and relocation generated by internal conflict and extractive activities. Locals, in both locations, are subjected to extraterritoriality, or “an extended 'temporary' condition of precarity, marginalization, and exclusion” (DAAR, 39), and return that "demands the complete reorganization of modes of property ownership and the relationship between multiple polities and territory" (Petti, Hilal, \& Weizman, 2013). The right of return "challenges the structure of property rights and means that new forms of cohabitations will need to be developed" (Petti, Hilal, \& Weizman, 2013)

One of the methods Weizman conducts is by studying the artifacts of the land that once where used for dominance and terror. For instance, one of his interventions was the restoration of the watchtowers in Oush Grabs, as a method for achieving decolonization. By doing so, people would regain access to something that was excluded from them, but yet, its presence was palpable. This reprogramming would accommodate new views and goals. This study of object-turned-intoartifact deconstructs the way violence, colonization and globalization pierced the social fabric.

Neglecting and forgetting, tend to mitigate the impact of the actions done towards the victims, but it does not solve nor bring to an acknowledgement the errors committed. The ultimate goal is to "seek to unleash a process of open-ended transformations toward visions of equality and justice" (Petti, Hilal, \& Weizman, 2013). A more sustainable environment and society is searched through equality, by switching the hierarchies of power and the positioning of campesinos that once were polarized during colonization. Undertaking this change will lead to social and environmental justice, which has been desperately sought by locals. Equality and justice become synonyms of reconciliation. 


\section{A FOURTH TYPOLOGY}

The use of typologies in architecture become "an agent of regeneration in an era of dispirited functionalism" (Hays, 1998). For this reason, the need of this fourth typology is to regenerate, renew, remediate, and finally reconcile, areas where landscape and locals have been seen as mere vehicles for ambition and control. Previous to the emergence of a fourth typology, each typology presented a new critical approach for architecture to respond to the external pressures that shape it. The first typology was born from an epoch of high ornamentation and appearances. Abbe Laugier presents a critique of this era with his primitive hut, as the quintessential physical architecture, primarily composed of columns, beams and pediment. Other elements beyond thatwalls, ceilings, stairs - are an interplay, juxtaposition and alteration of those three essential elements. The second typology by Le Corbusier, comes from a period of Fordism, where production processes influenced the final object and context, seeing architecture "as simply a matter of technique" (Vidler, The Third Typology, 1998). A third typology, developed by Anthony Vidler from the ideas about the city by Aldo Rossi, studies the larger perspective of a context to its components and parts. In contrast to previous typologies that reviewed the part-part-whole relationship, Vidler studied the city as "the site of a new typology ... born of a desire to stress the continuity of form and history against the fragmentation produced by the elemental, institutional, and mechanistic typologies of the recent past" (Vidler, The Third Typology, 1998). Vidler calls this typology an ontology of the city, where the city and the theory are only able to reassert "the restoration of a critical role to an architecture otherwise assassinated by the apparently endless cycle of production and consumption" (Vidler, The Third Typology, 1998)

A proposed fourth typology will be an analogy of the rural, as a case study for the new human condition, like an ontology of the rural. This new typology is formed, defined and developed, by the life from the city to the rural, from the secularization and profanation of the landscape as a vehicle for globalization, social polarization and fragmentation. Just as the previous typologies responded to the pressures of their contexts, today's concerns deal with the continuation of abuse and power in neo-colonial settings, the sustainability of earth's resources and the widening gap between rich and poor, in terms of education, money and opportunities. The urbanization and high densification of cities go hand in hand with the use of land for resources in the countryside: as one densifies, the spatial qualities of the other one amplifies. This careless approach to the rural landscape is turning it into an obsolete artifact. This condition will not mean that it stops, but a wave of consequences will have an impact in other areas. In a similar way to what Vidler proposed with his typology as a method for reintroducing the value of architecture into the city, this fourth typology will be analyzed for how architecture responds to the harsh demands in a fragile context. However, 
Vidler sees a way for architecture being "de-composed into fragments" (Vidler, The Third Typology, 1998), organized in three levels of meaning. The first one is the particular history that drives meaning toward a something; second, it is about taking particular elements and characteristics. Lastly, it deals with the application of those fragments, elements and parts in new ways. For a fourth-typology, the idea is to know how to re-construct - an architecture - from the fragments of the context; the void in the land, the dissolution of communities, the disagreement between all the actors, and the decentralization of life. Fragmentation comes from the "privation of the integrated body" (Nesbitt, 1996), through "psyche and dwelling, body and house, individual and metropolis" (Nesbitt, 1996).

The current landscape is a result of centuries of colonization and dominance. But through the application of this fourth typology, "colonial remnants and ruins are not only the dead matter of past power, but could be thought of as material for re-appropriations and strategic activation within the politics of the present. The question is how people might live with and in ruins, or "within the house of the enemy" (Petti, Hilal, \& Weizman, 2013). This typology focuses on "reason, classification, and a sense of the public in architecture" (Vidler, The Third Typology, 1998). These categories are the elements for satisfying a complete rural architecture in Colombia, in which reason opens up a dialogue towards reconciliation, the structuring of a newly born rural life is achieved through classification, and the presence of a new voice of architecture in relation to nature and land. 

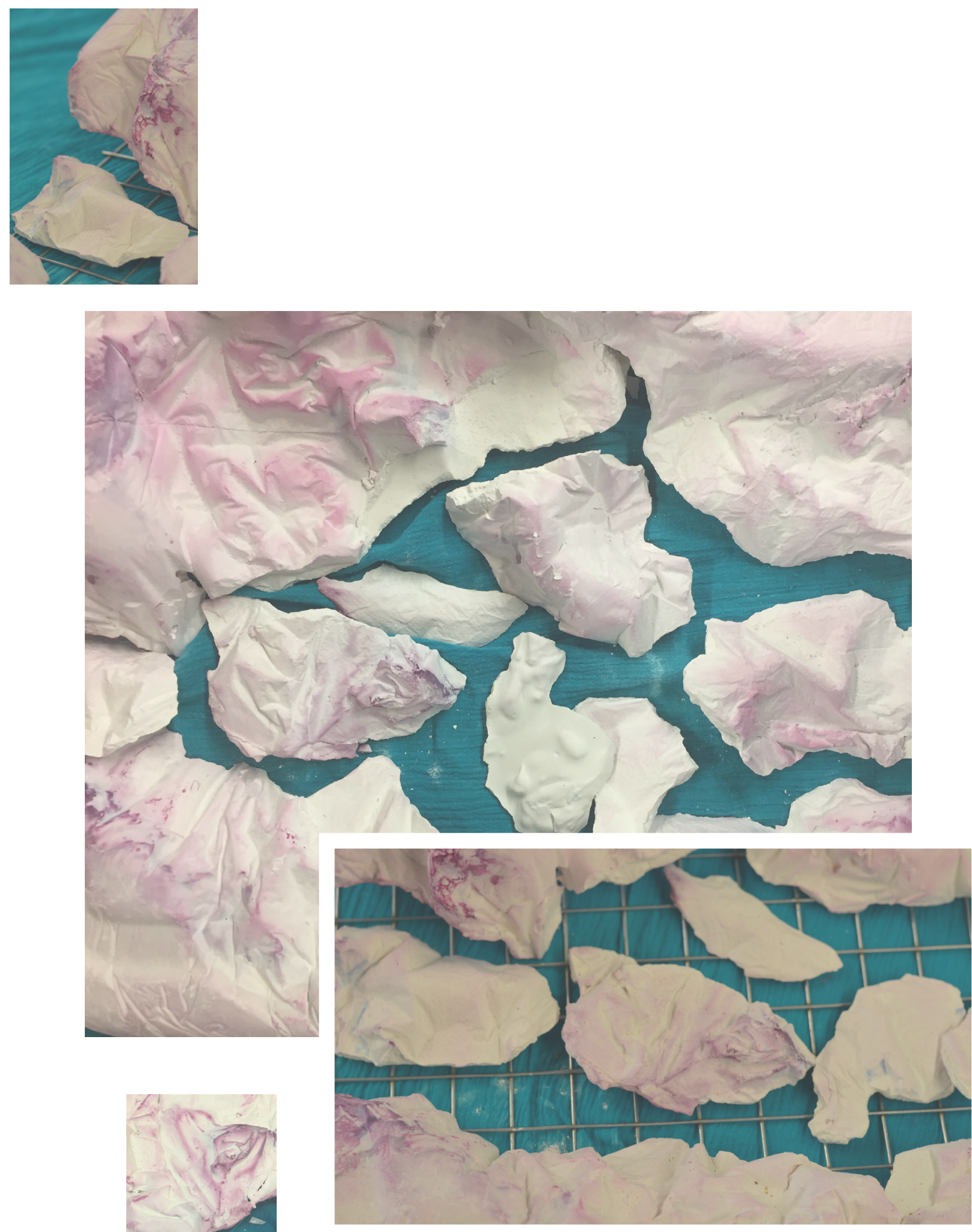


\section{HYBRITOPIA}

The realities of Colombia are proven to be a dichotomy between utopia and dystopia, in which the desire for an economically better Colombia is the priority, but all that can be foreseen is a socially and environmentally disrupted country. However, the people involved in a conflict of interest will seek for a demarcation of their own space, an in-between the positive and negative, the real and the unreal, the subjective and objective, the urban and the rural, the global and the local. Foucault addresses the demarcation of space through heterotopias, which are "real sites ... that can be found within the culture, ... simultaneously represented, contested, and inverted. Spaces of this kind are outside of all places, even though it may be possible to indicate their location in reality ... these places are absolutely different from all the sites that they reflect and speak about" (Foucault, 1984). Heterotopias are essentially people-driven idealistic communities, where rules, norms, ways of living have come about through years of understanding the individual and collective needs and demands. For instance, Wayuu tribes are part of rural Colombia, but within the arid and already marginalized area of La Guajira, they have created their own Comunidades, where members of the same family live. They have kept their traditional values, like their views towards the cosmos and their language, but have adapted to some extent to the non-traditional, like learning Spanish.

Heterotopias exist to prevent intruders. If they decided to enter those spaces, intruders will need to adapt to a new setting. In a similar way that a fence works, to set a barrier or to simply demarcate a space, heterotopias comply with both characteristics: it is a social and physical obstruction within the context that establishes a new program and community. In contrast, Vittorio Gregotti defines atopia as "the condition of non-places", which he studied to be "neglected corners or liminal places in the physical world, which exist between the dominant cores" (Huang, 2012). Heterotopias are more inclusive, re-asserting and re-defining a genius loci. In Of Other Spaces, Foucault establishes six principles for heterotopias to exist; first, they are innate in any culture and evolved from heterotopias of crisis to heterotopias of deviation; site, context and history are factors for how a heterotopia develops; heterotopias are able to synchronize and synergize contradiction in the real world; they respond and evolve over time; they are neither private nor public, free nor compulsory; and lastly, heterotopias are never apart from reality making them real in all aspects.

Previous - topias have dealt with removing the imaginative conceptual space from its context, or in other words from the reality that caused the -topia to be created: utopia is the idealistic view of the world, dystopia is pessimistic. In a way, it allows people to imagine themselves in a parallel world, for understanding how elements in our environment had shaped us for better or for worse. However, this new -topia, highly influenced by Foucault's, will not be about forgetting a particular place, but about considering the importance of the past, the traces that it left in order to create a new society. This new -topia is born out of the need to accommodate a palimpsest of realities of lives and deaths. It will not let 'death' die, but lets it live. Death does not mean halting; it means a new-birth. 


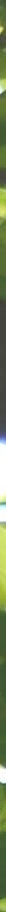

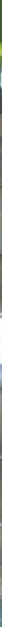
$z_{i=1} i_{n}$

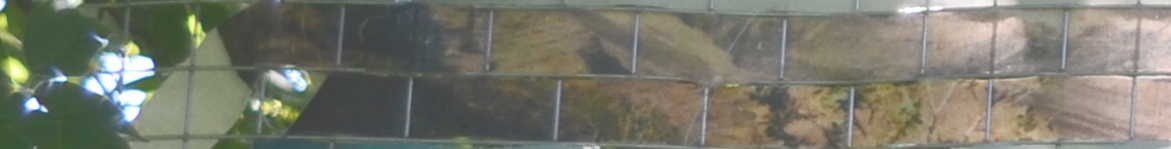

$x$

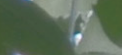

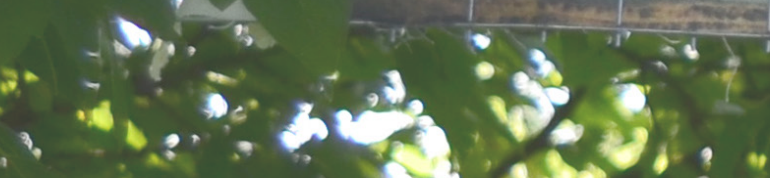

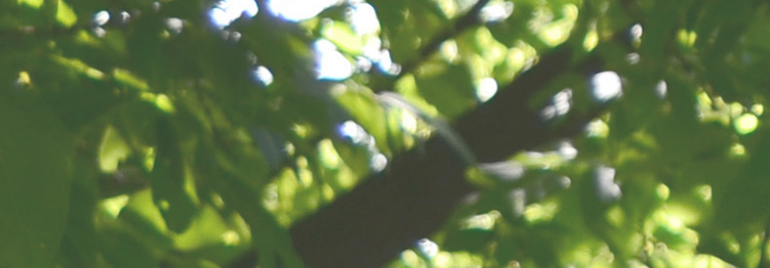

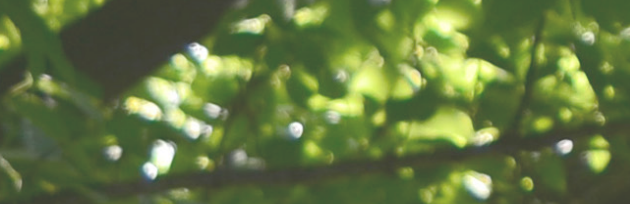

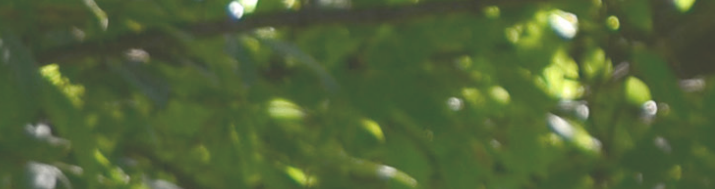

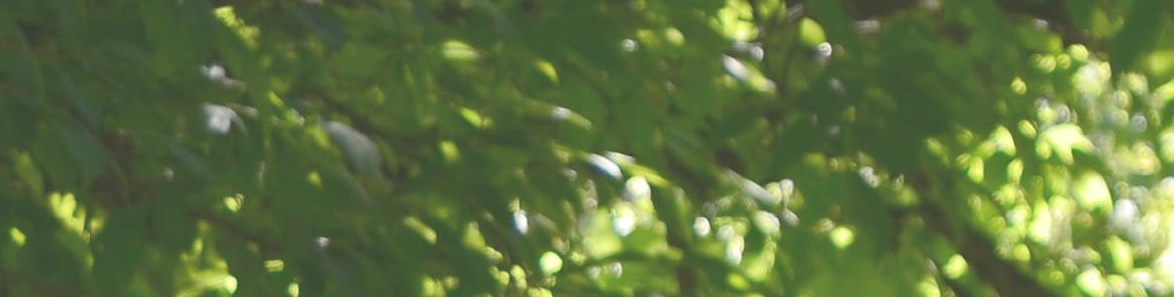

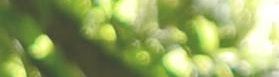

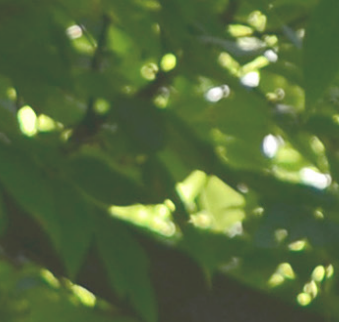




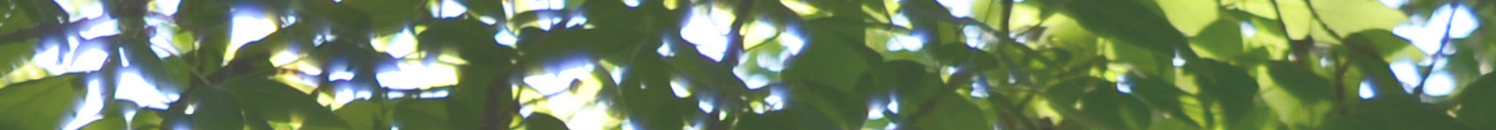

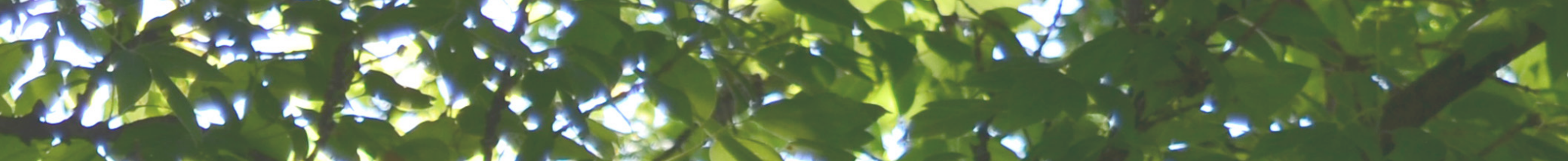

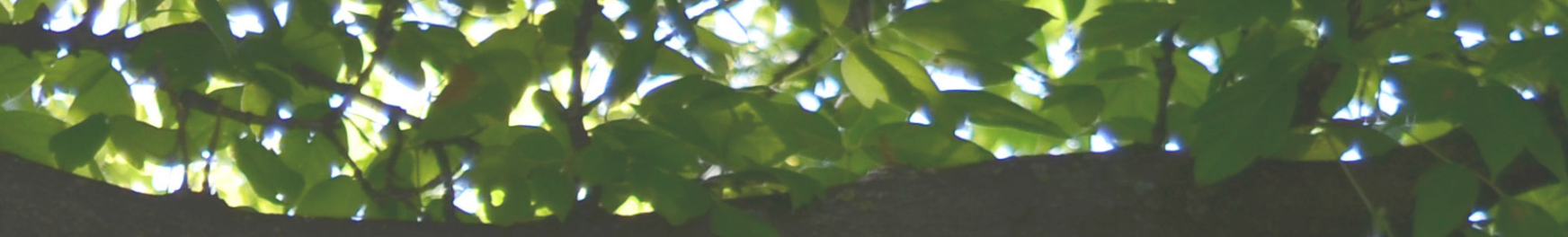

2.

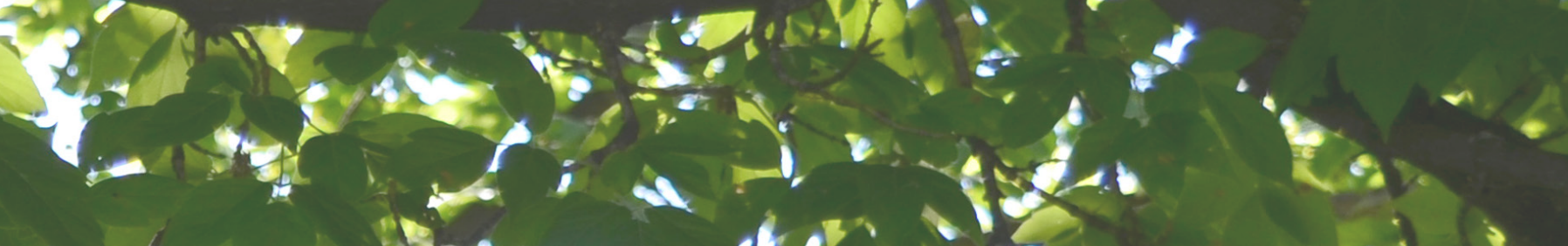

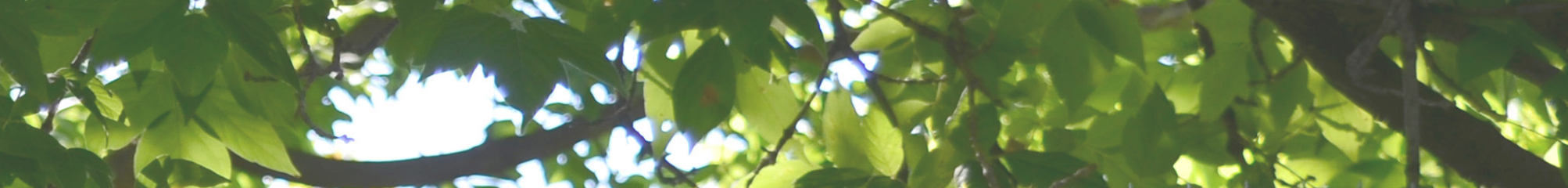

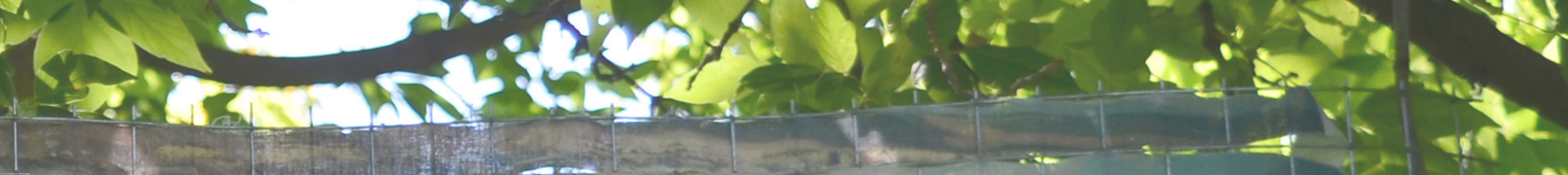

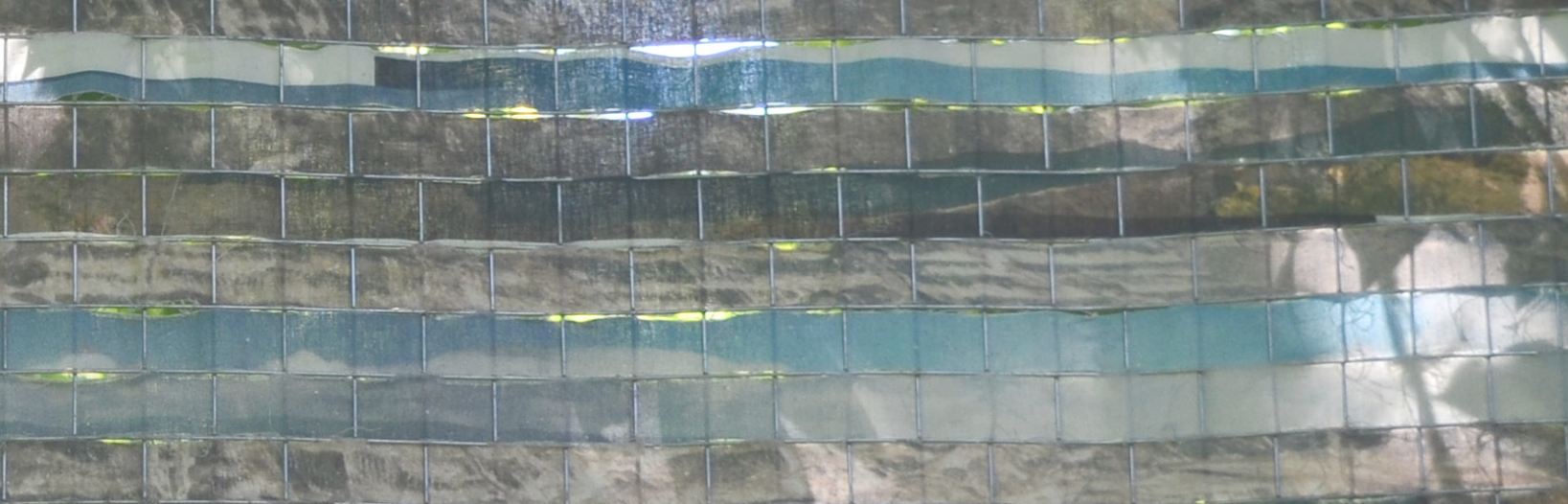
$+i$

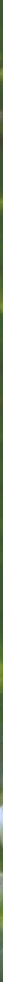
Af (t) 71 X? $+8$

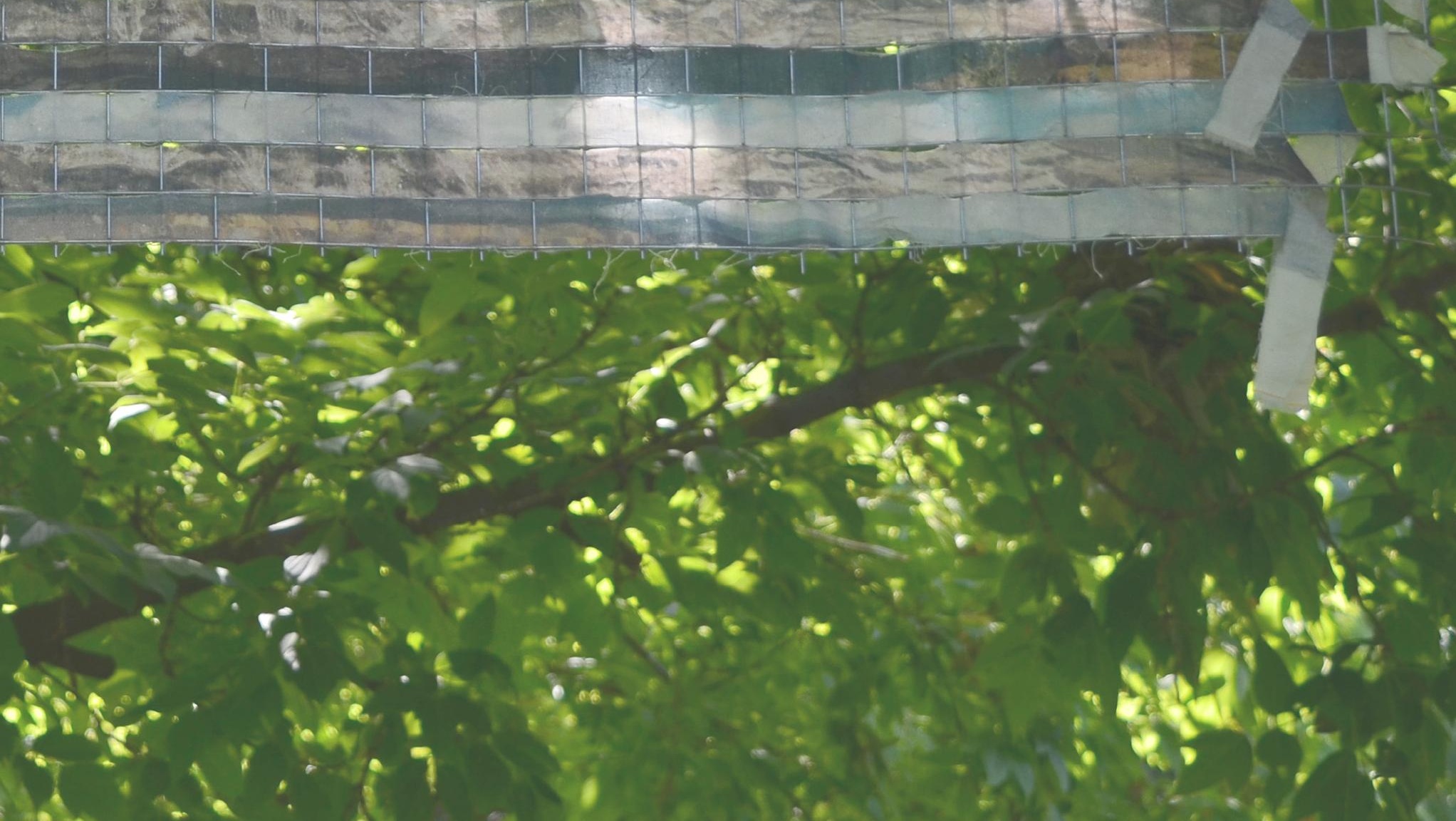


Thus, this -topia can be called hybritopia because it is combining dichotomies that might have been seen as estranged, but its union creates a new understanding and view of the world. It allows for the re-structuration of the social fabric, without losing its original values.

The rural Colombian landscape has been seeking reconciliation from the social and environmental violence caused over past decades. In this hybritopia, the traces of the past become vehicles for understanding the future and creating a neutral plane that uplifts the oppressed, and drops the oppressor. This plane is the framework for reconciliation to take place. It makes the absent present, the intangible tangible and the profane sacred. It is a synergy between the built, the unbuilt and the unbuildable, and the manufactured, the natural and the synthetic. These ambiguities are a critique to the current practices of neo-colonialism through globalization and the dominance of developed countries over the third world and developing areas. Hybritopia will become an agent of "the right of return ... the quintessential aspect of decolonization because the right of return is the right to mobility, to the capacity to move freely across the region and live in more than one space at once" (Petti, Hilal, \& Weizman, 2013). A new intervention of a place will not mean the displacement and dispossession of locals and resources, or their eradication to create a new space. It will mean the resistance, remediation, adaptability and acknowledgment of the different interests, as well as the driver for renewal and reconciliation: social, political, economic and spiritual streams through displaced people, governments, corporations and the church.

This hybritopia is represented in the manifestation, either implicit or explicit, of the typology of rural houses found in rural Colombia. The walls that constitute the house are found in the mine, but the ambiguous placement (are they coming out from the ground? Or are they being absorbed?) reveals the complexity of the mining industry in areas where development is desired and even praised. The penetration of the walls into the open-pit creates a juxtaposition of life-death, settlement-displacement, oppressed-oppressor, subjugation-freedom. Moreover, the interior walls, which constitute home, are hovering on the pit, mimicking the soul when it leaves the body. Although concentrated towards the center of the pit, the walls gradually dispersed across space and time to reflect the processes of relocation and resettlement of campesinos.

This new hybritopia becomes a pilgrimage site, where after hours, days, months or years of excursion, exploration, engagement, pilgrims are able to arrive at their house. Achieving that would mean that reconciliation between corporations, governments and locals, within the spiritual framework, have been successfully completed. 
figure $\mathbf{0 3}$ Foucault's heterotopia represented by a water body outlining the mine.

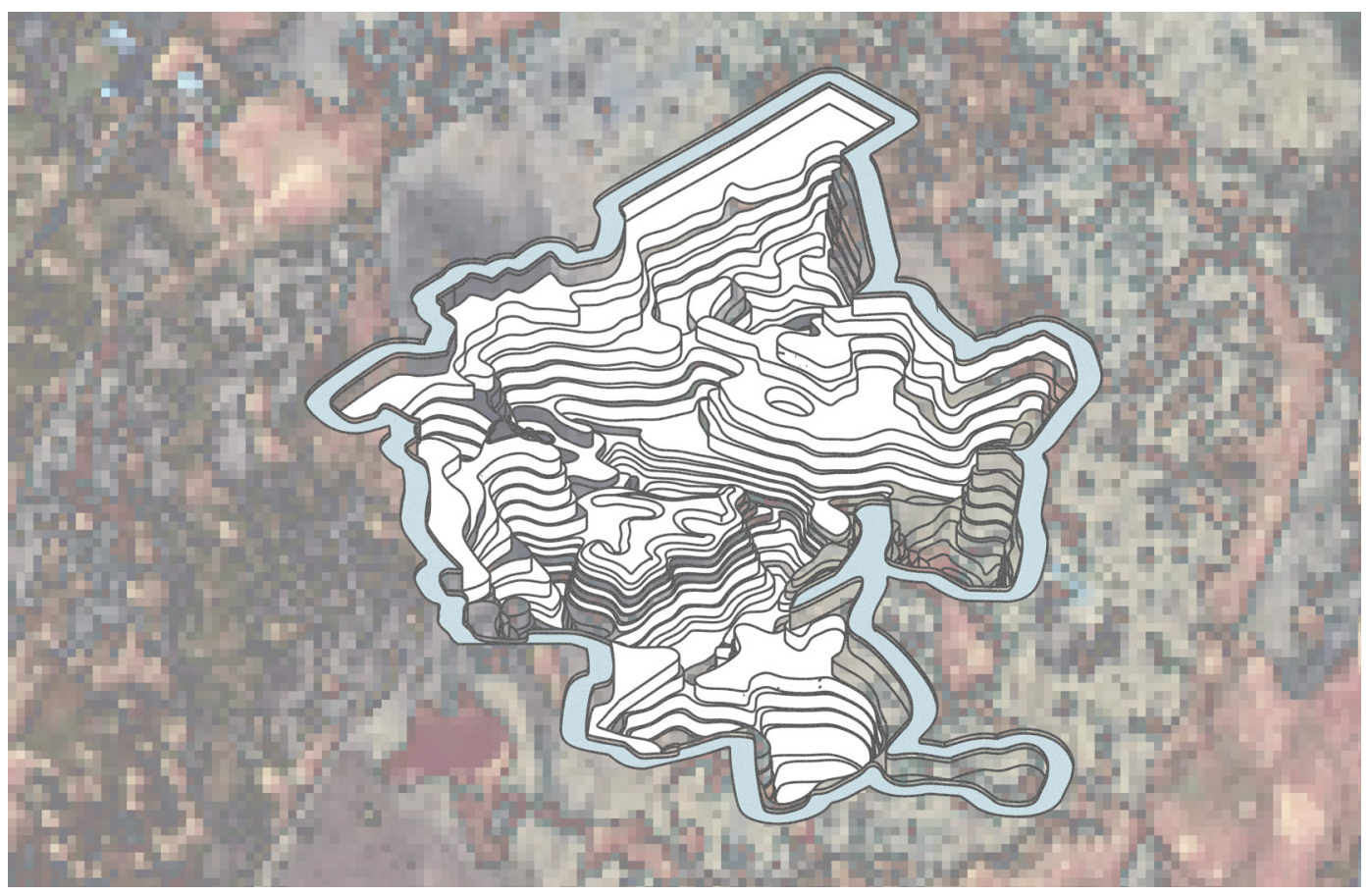




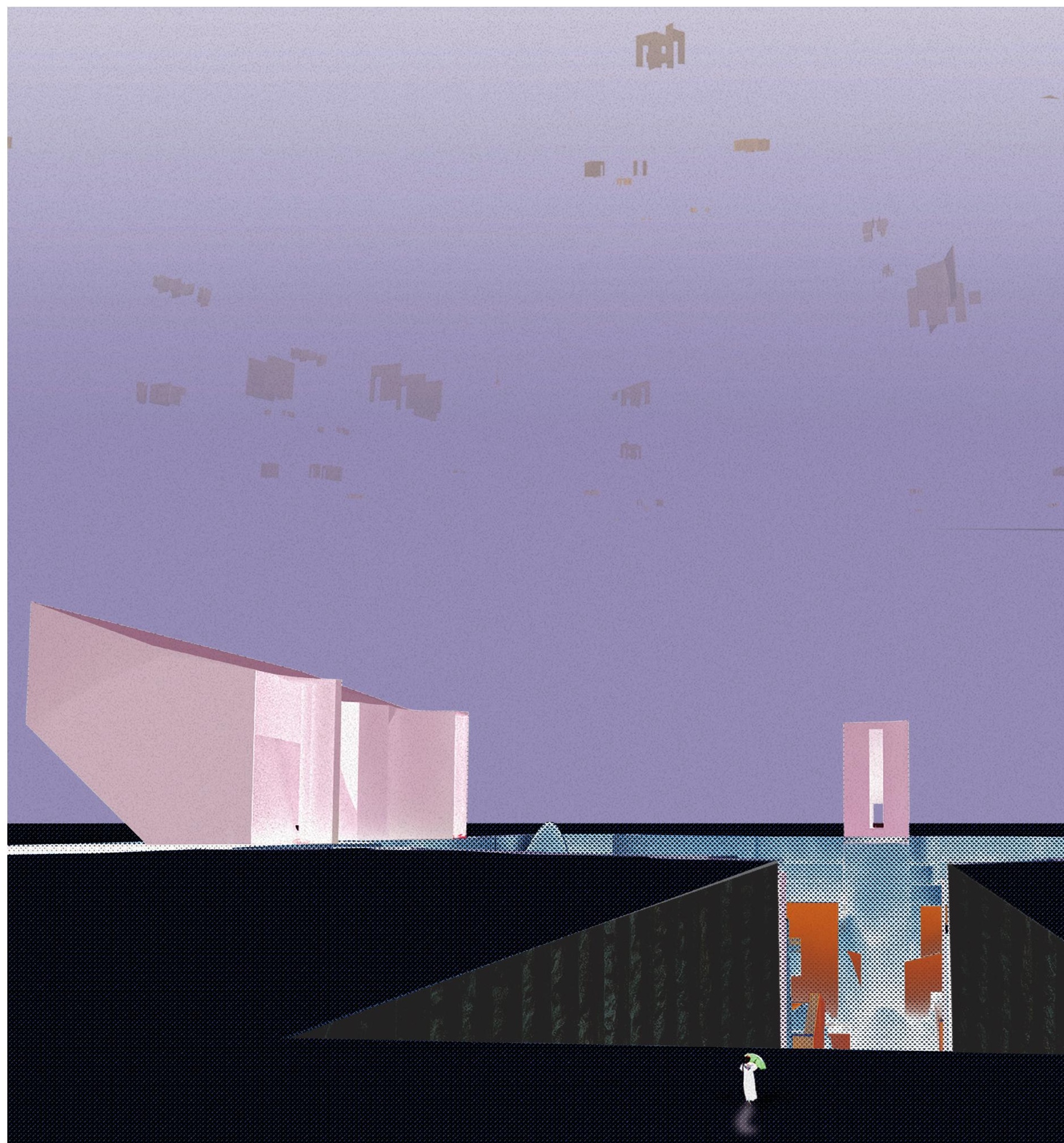




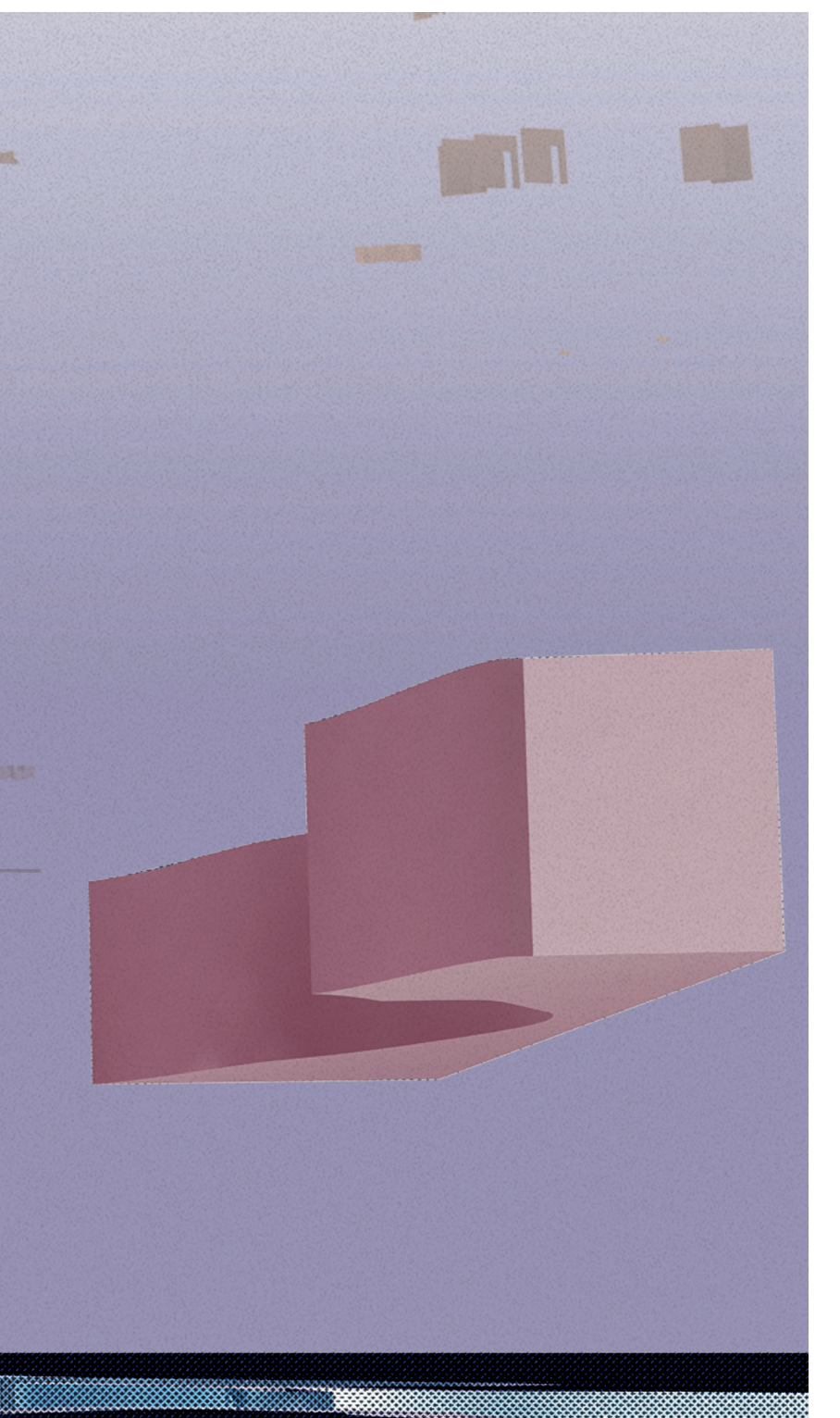

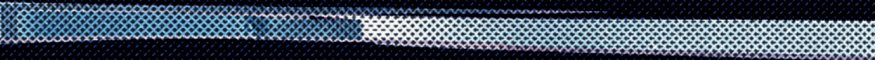

arrival 


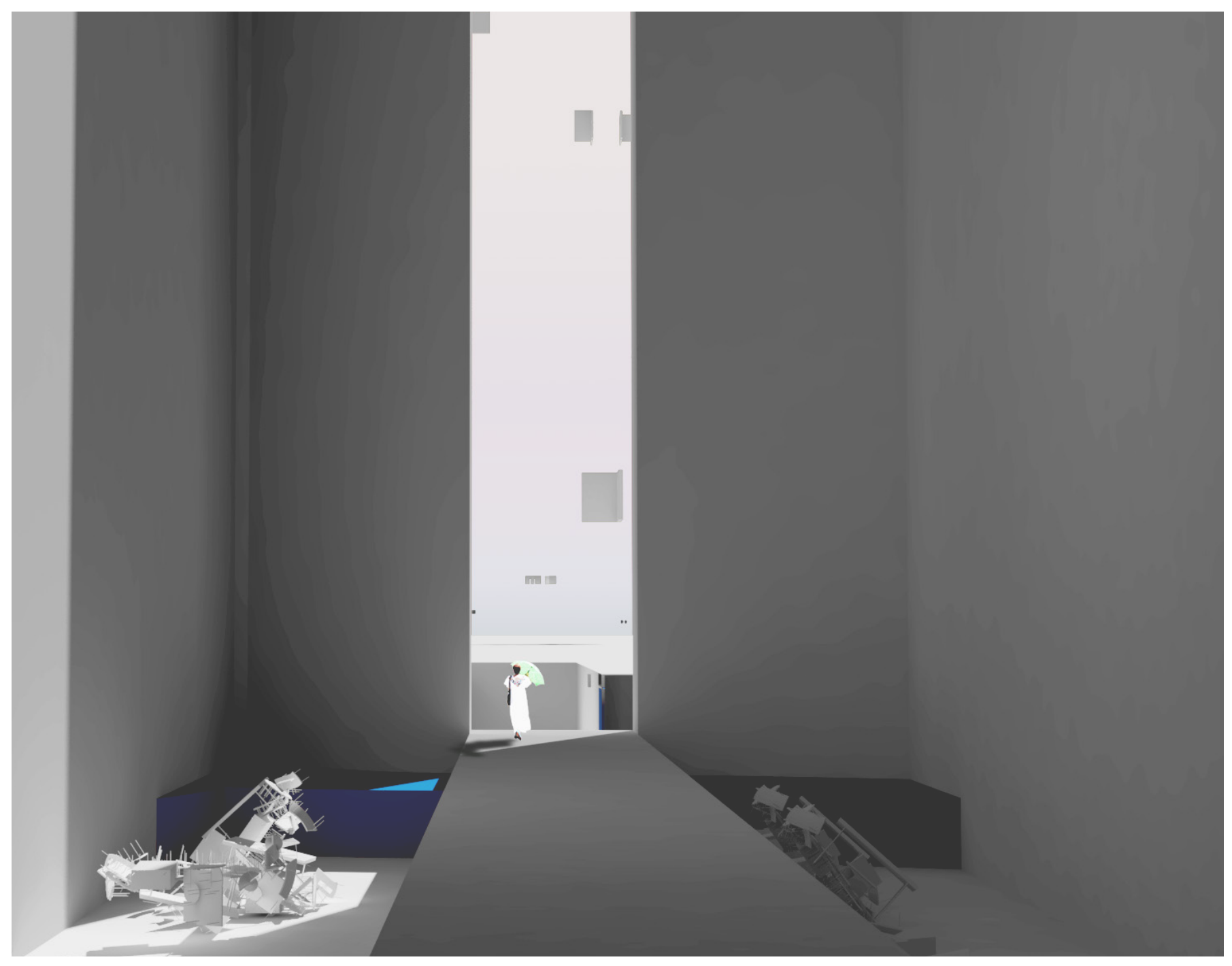

church view 

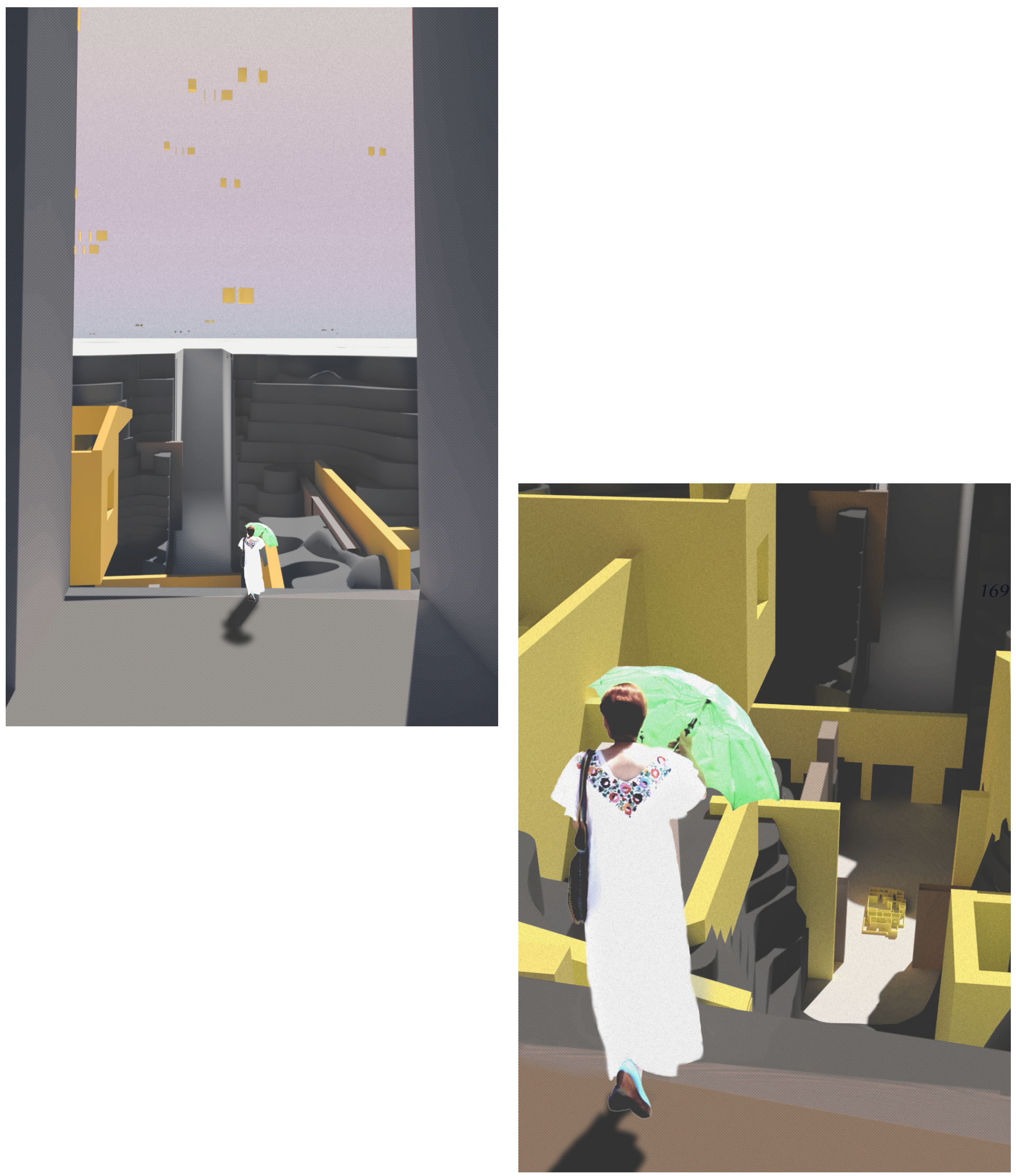


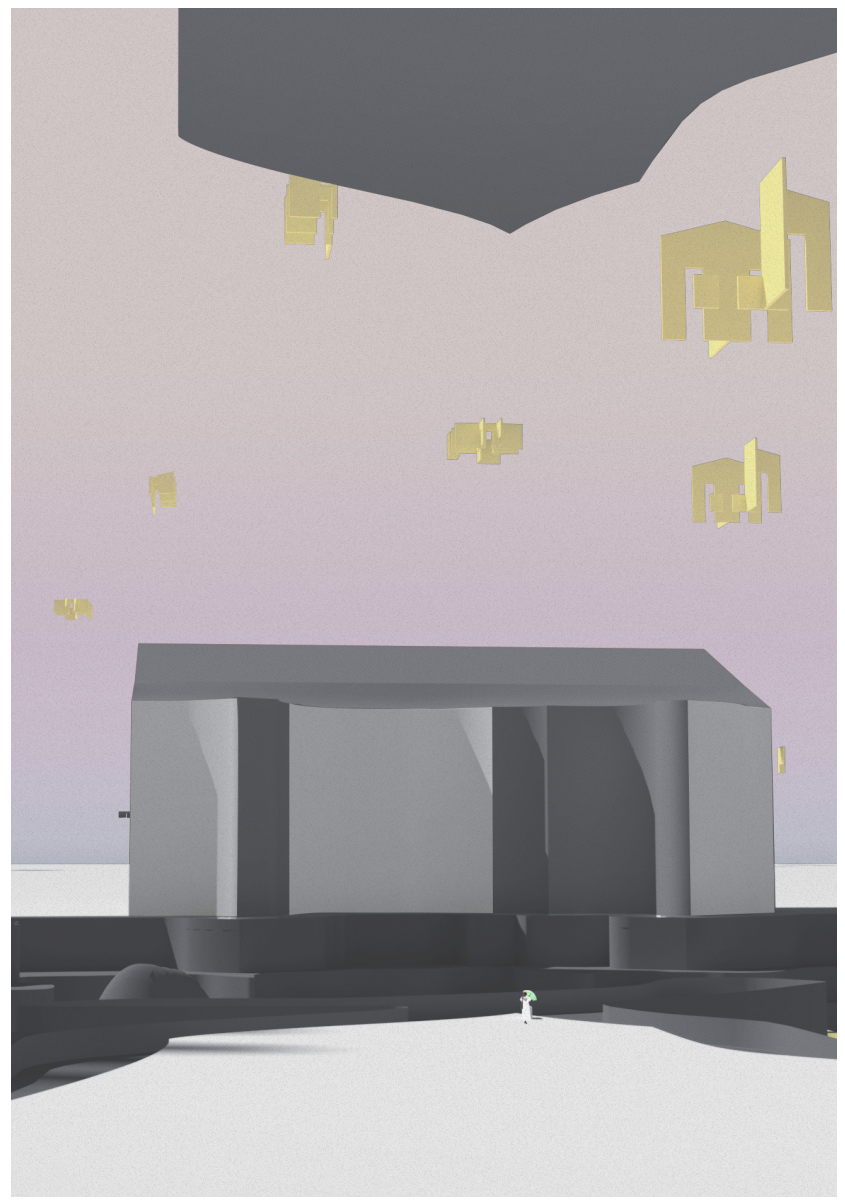

government view

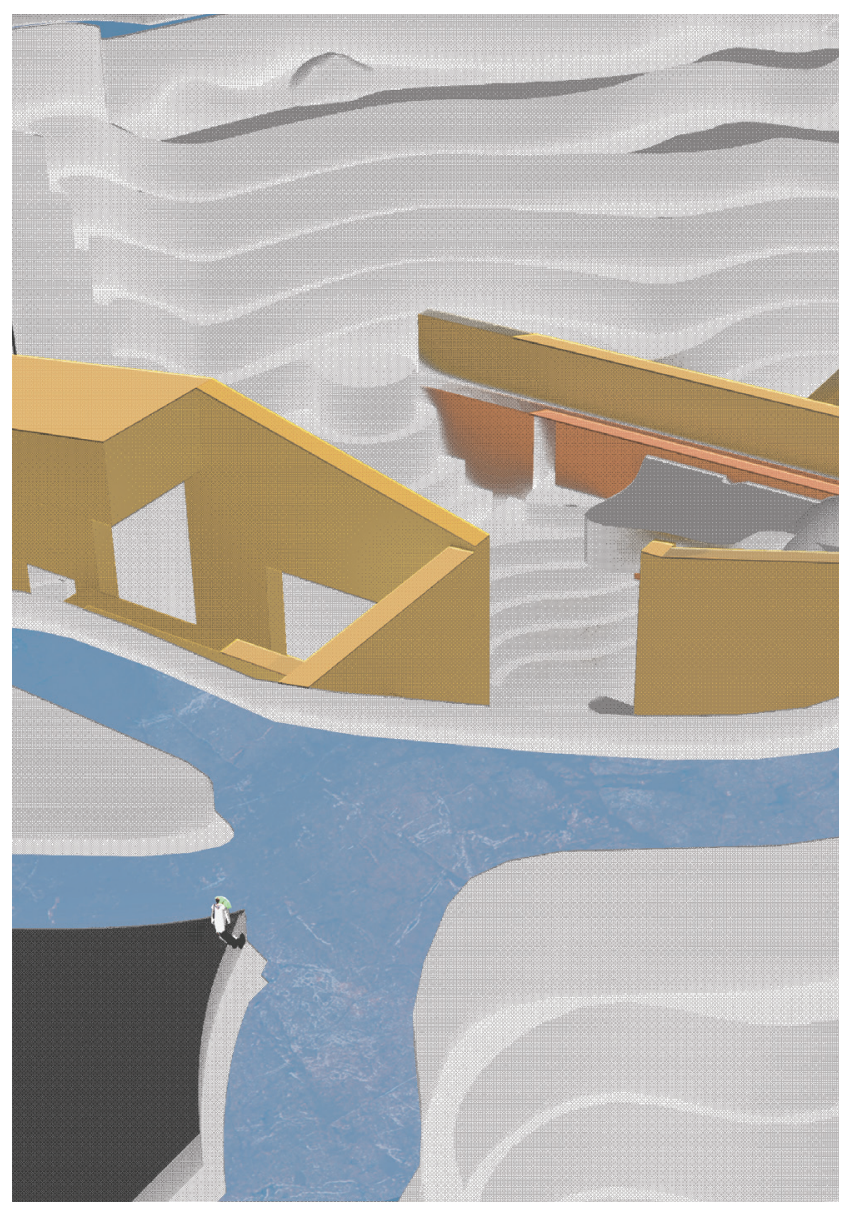




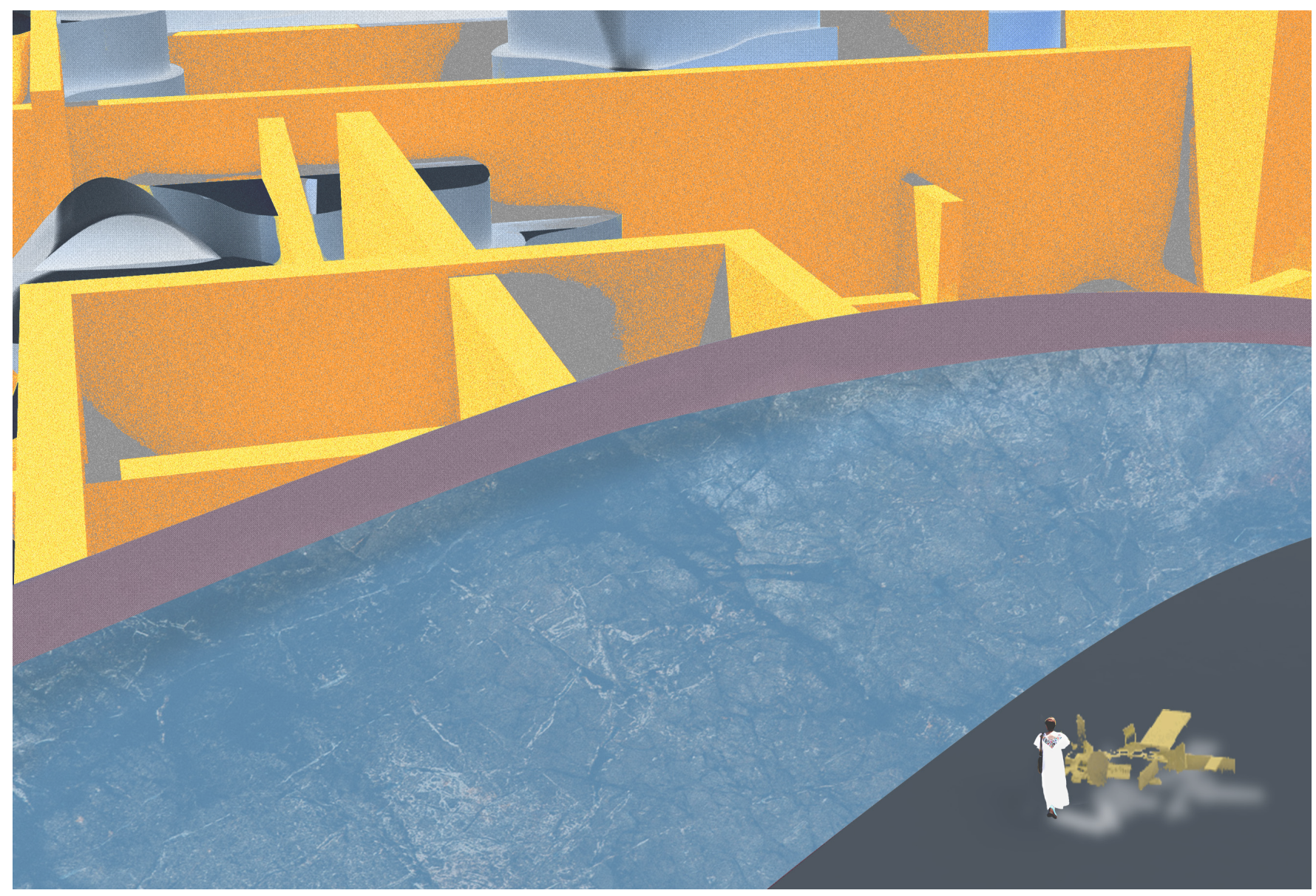



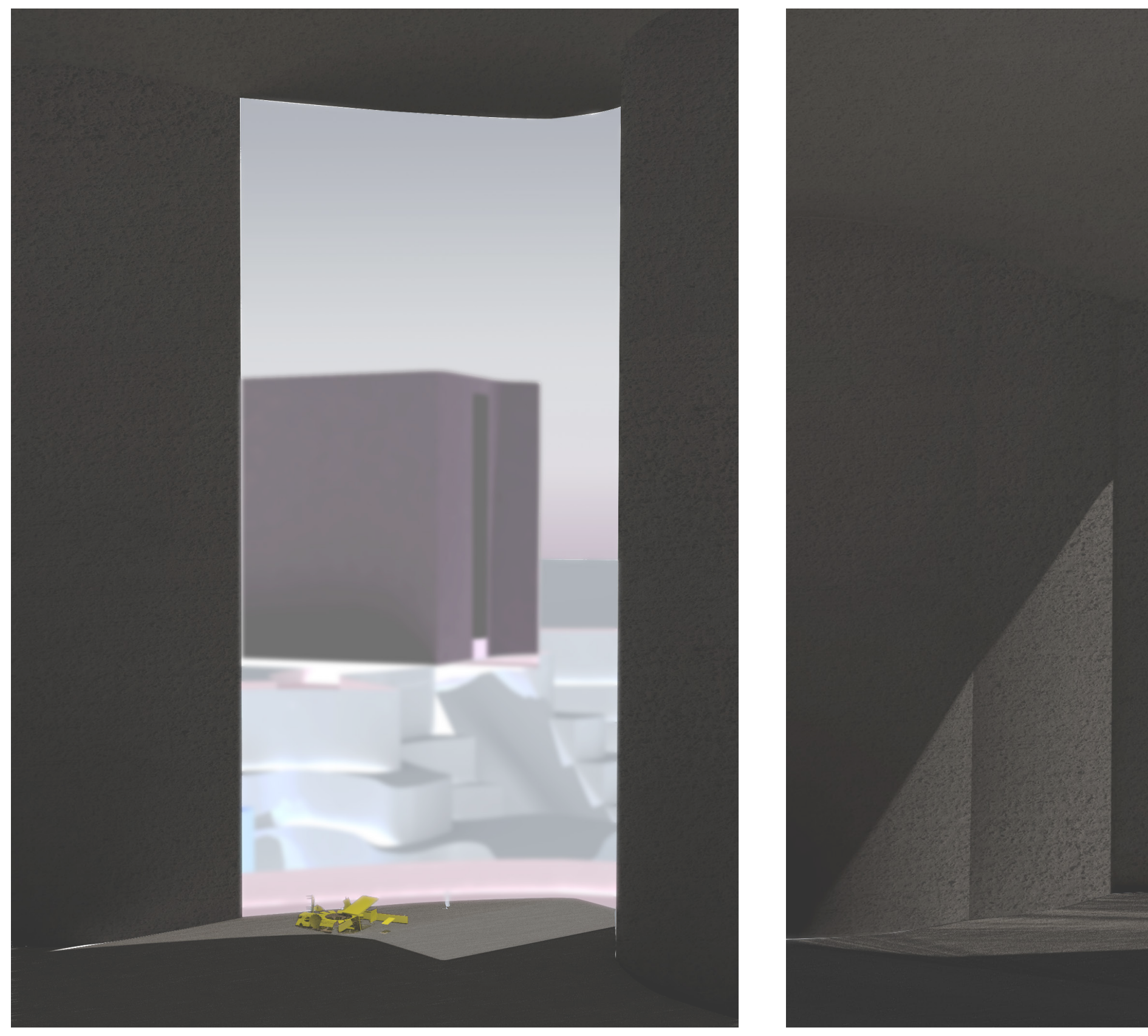

corporation view 


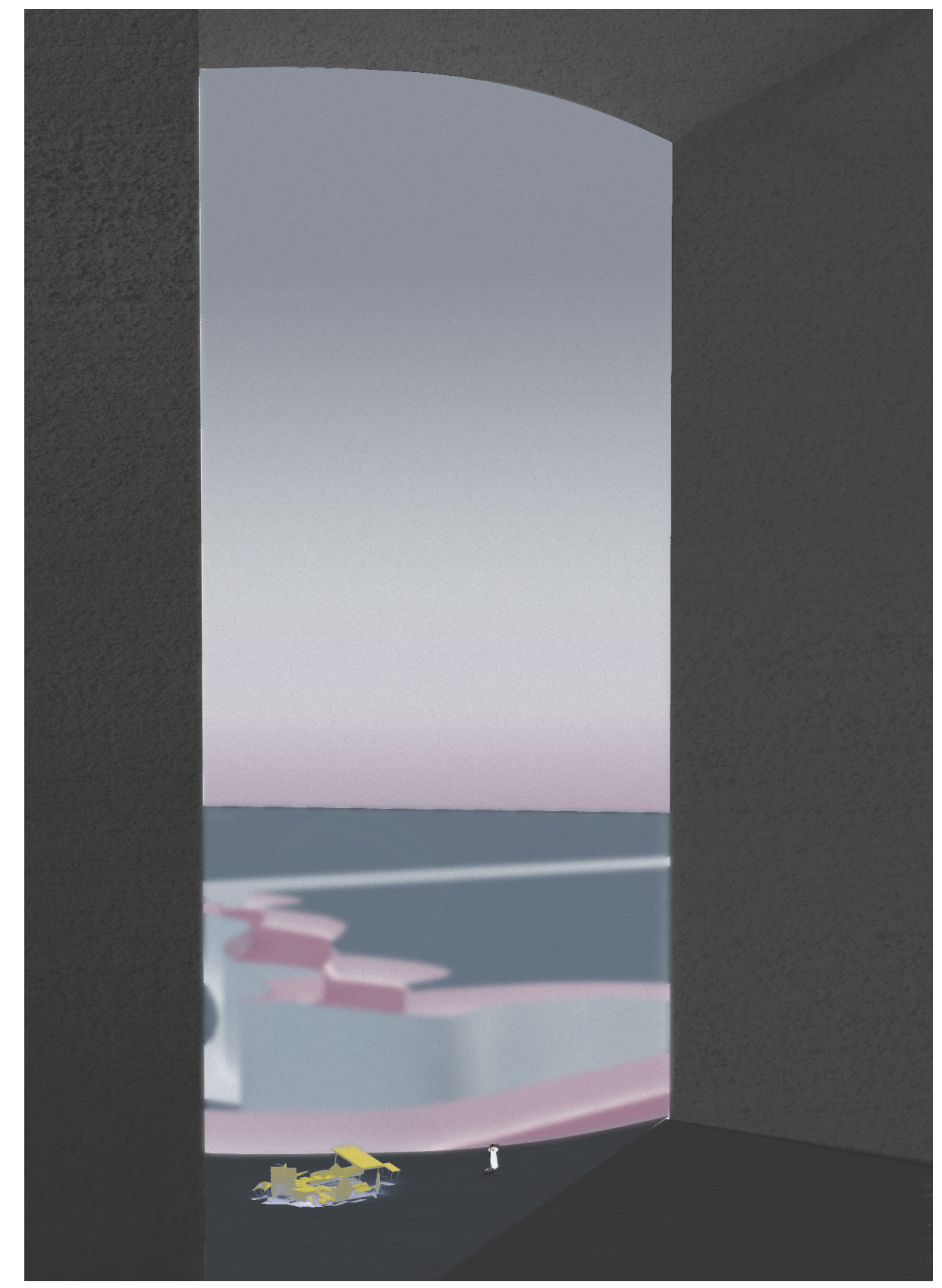




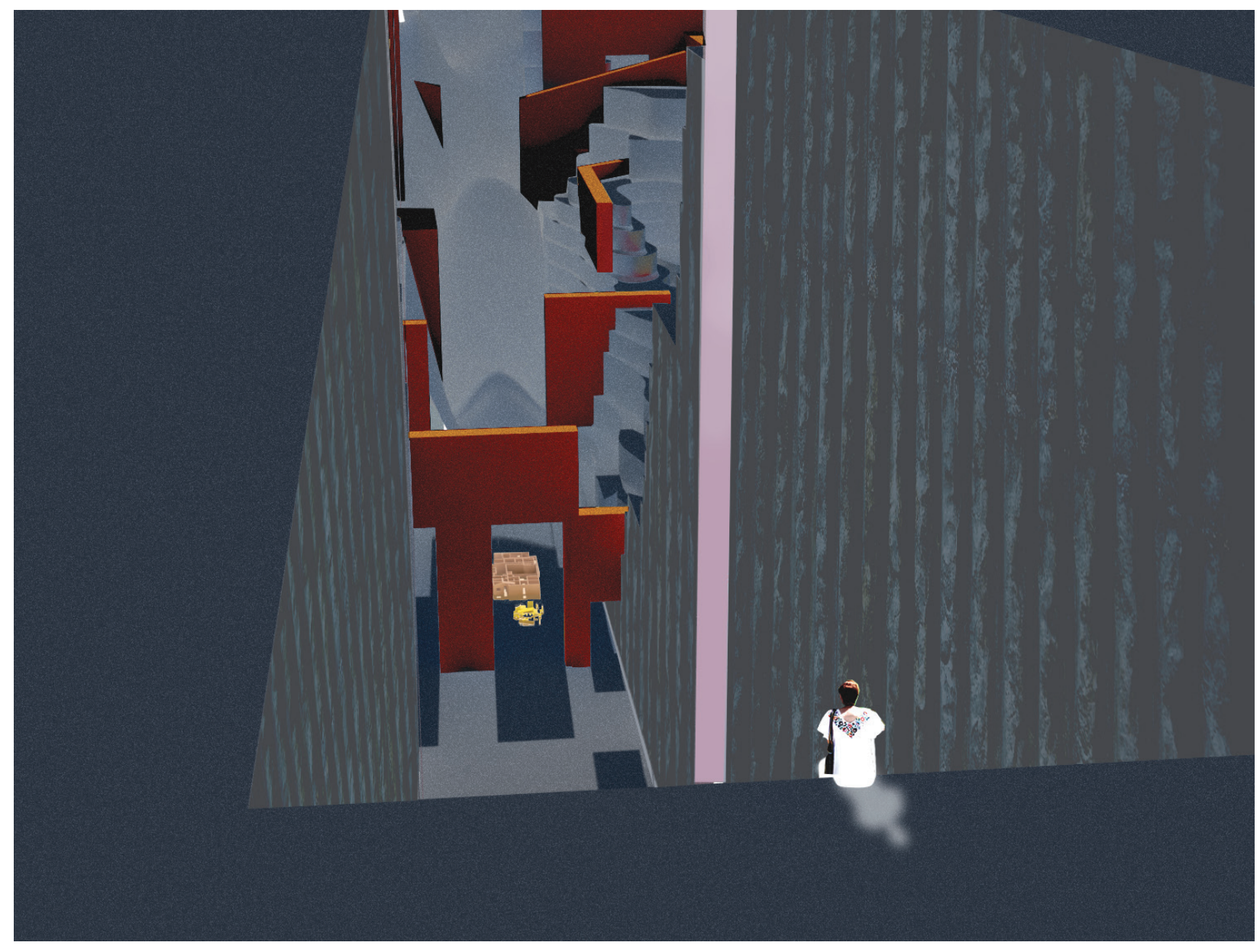

locals view 

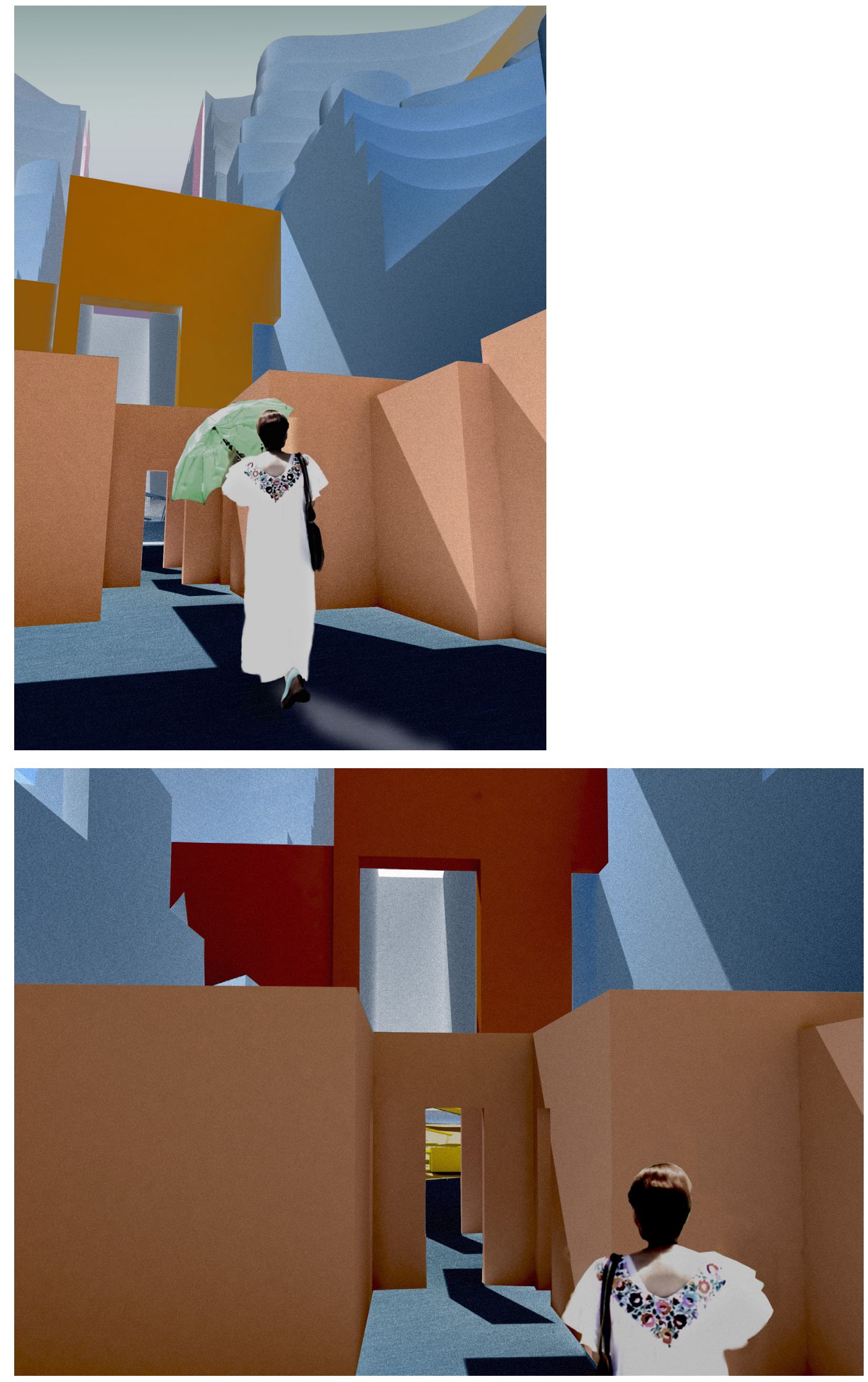


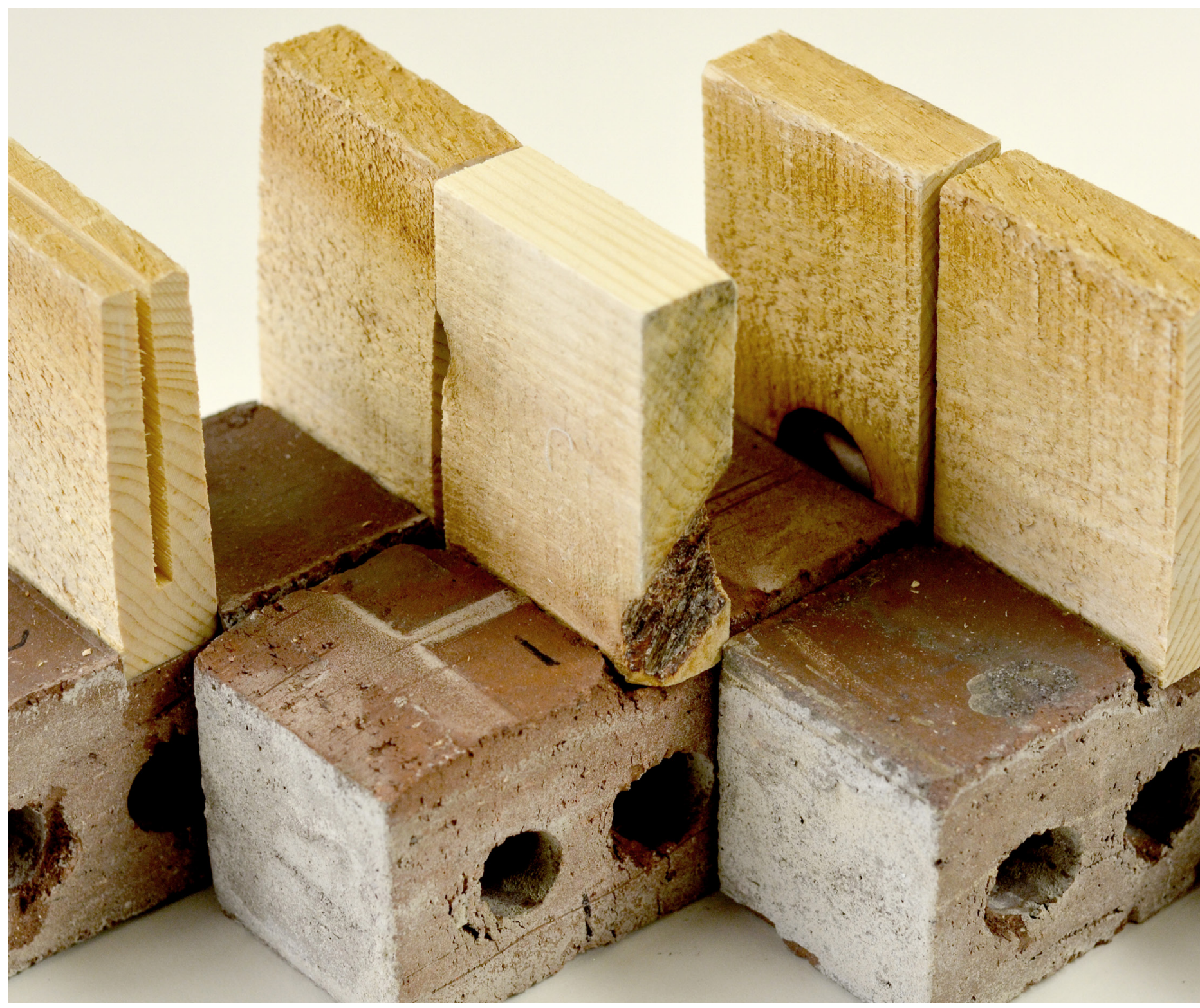




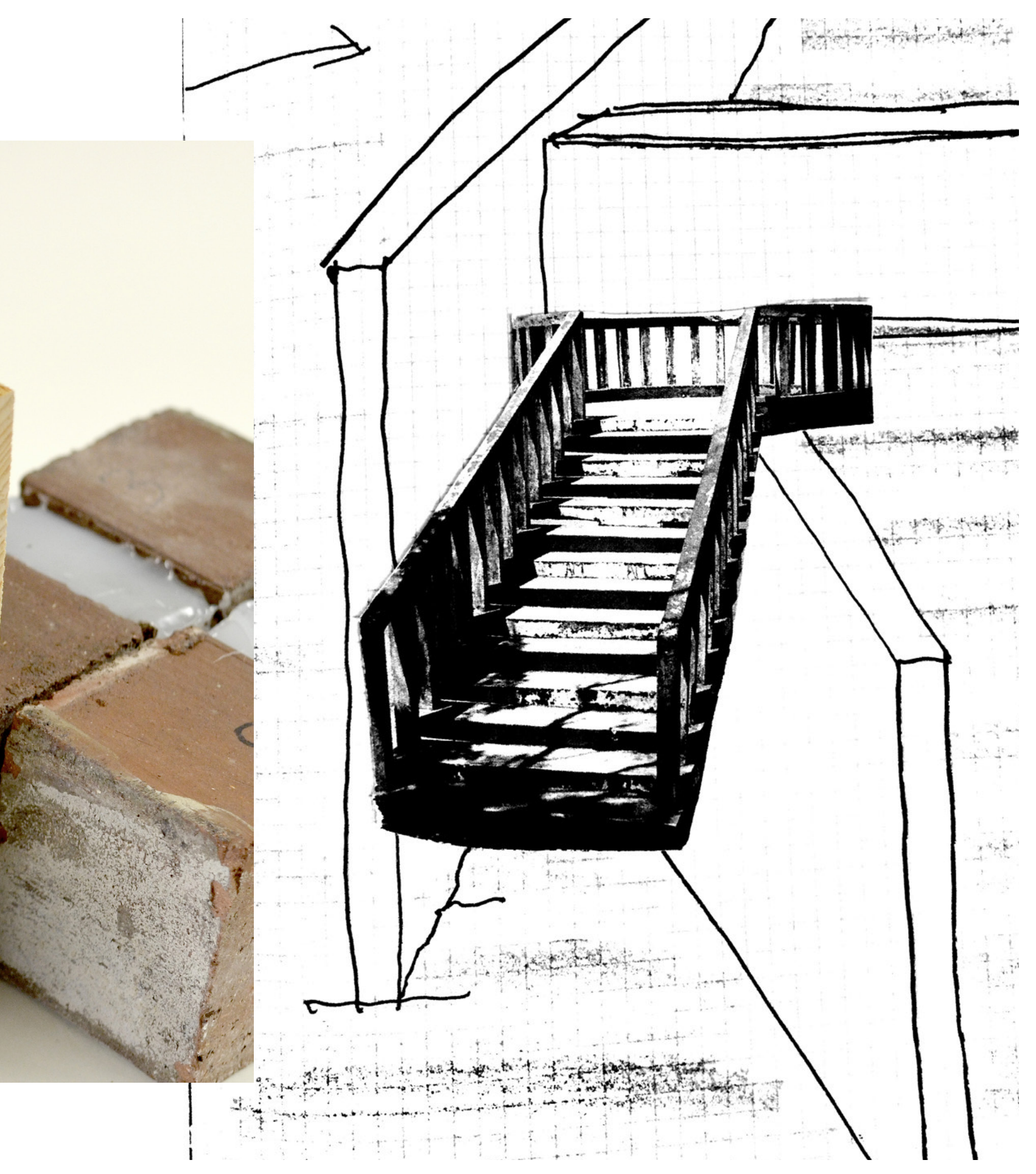




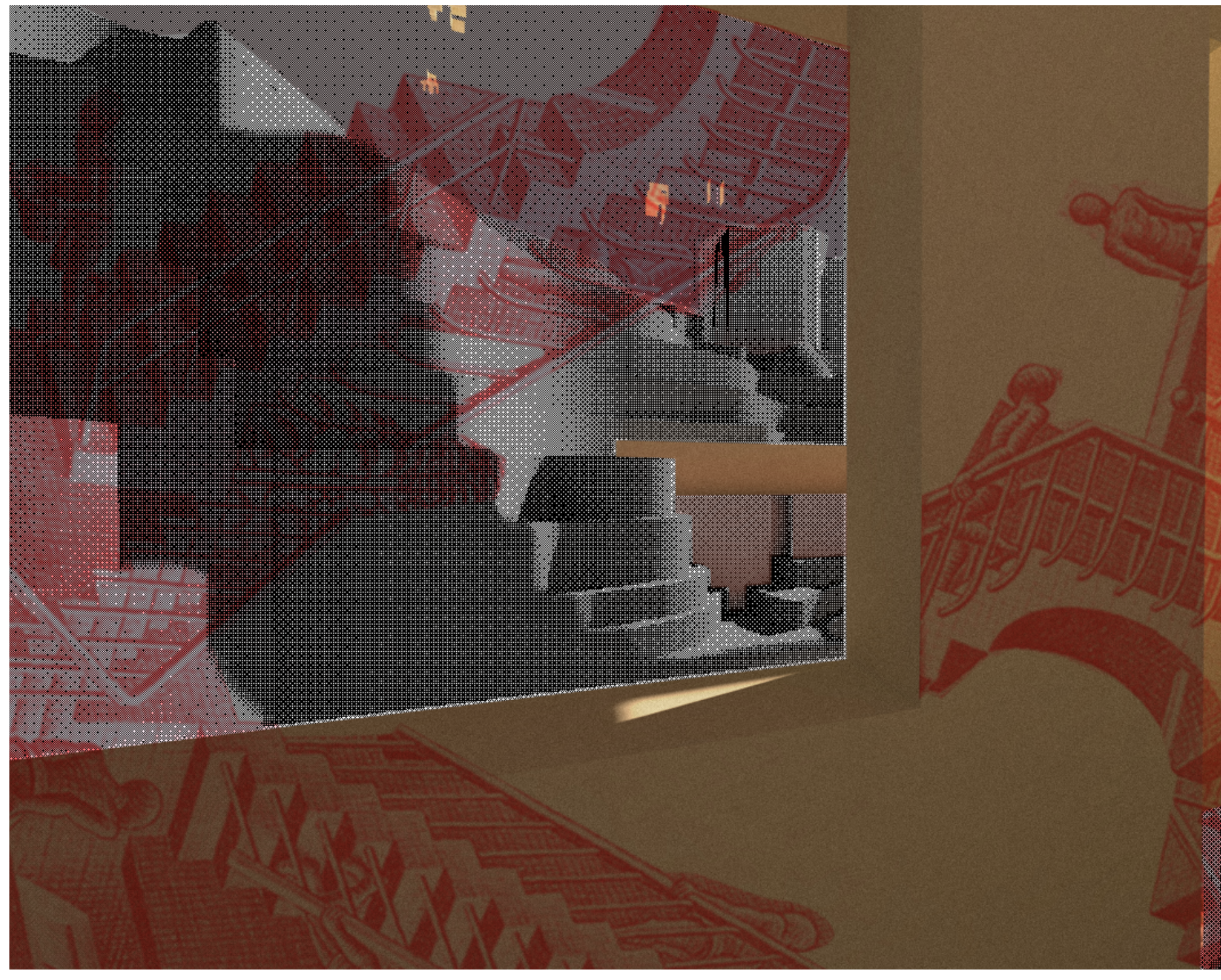




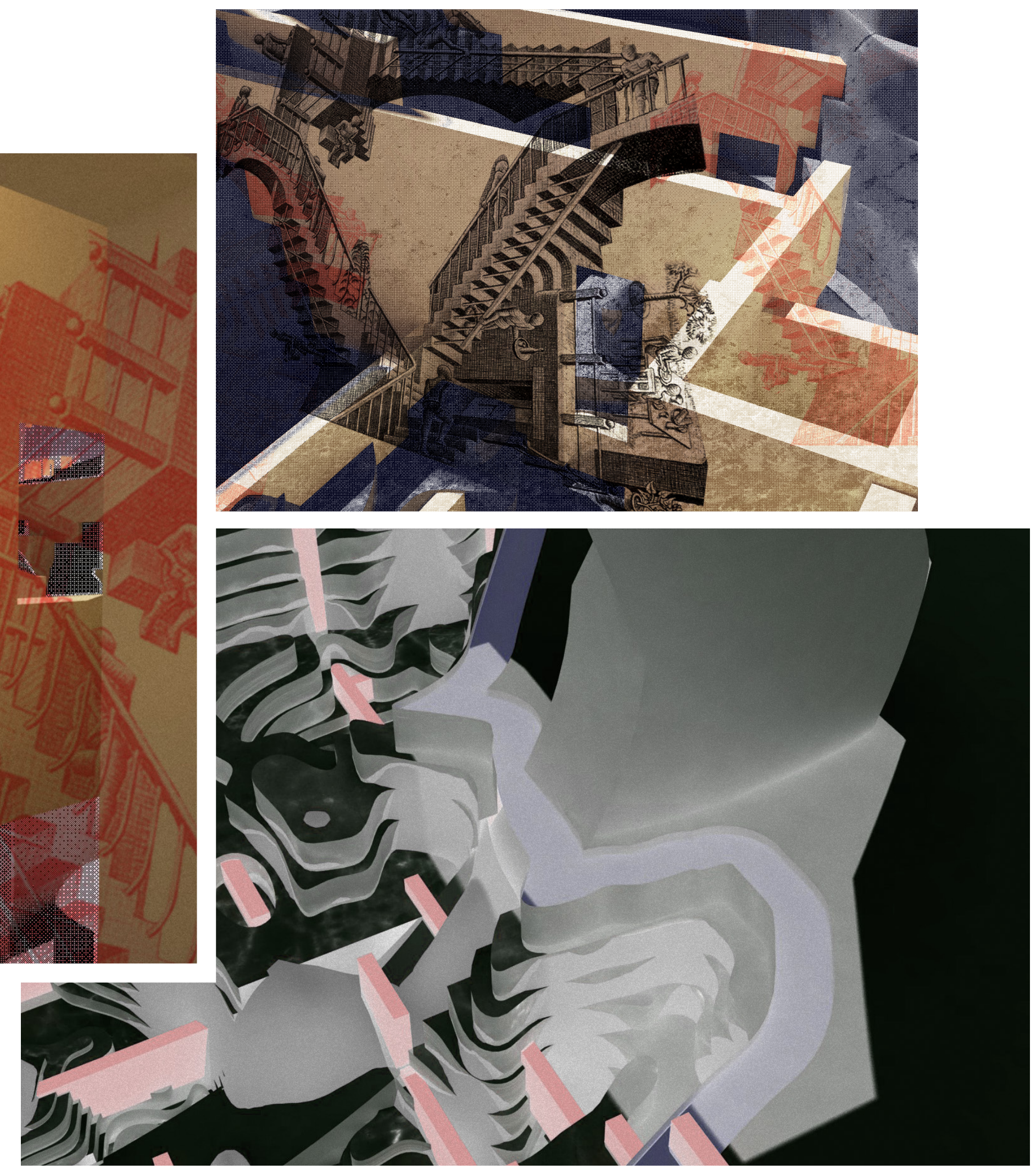



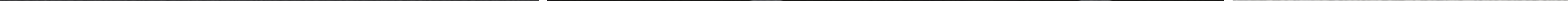


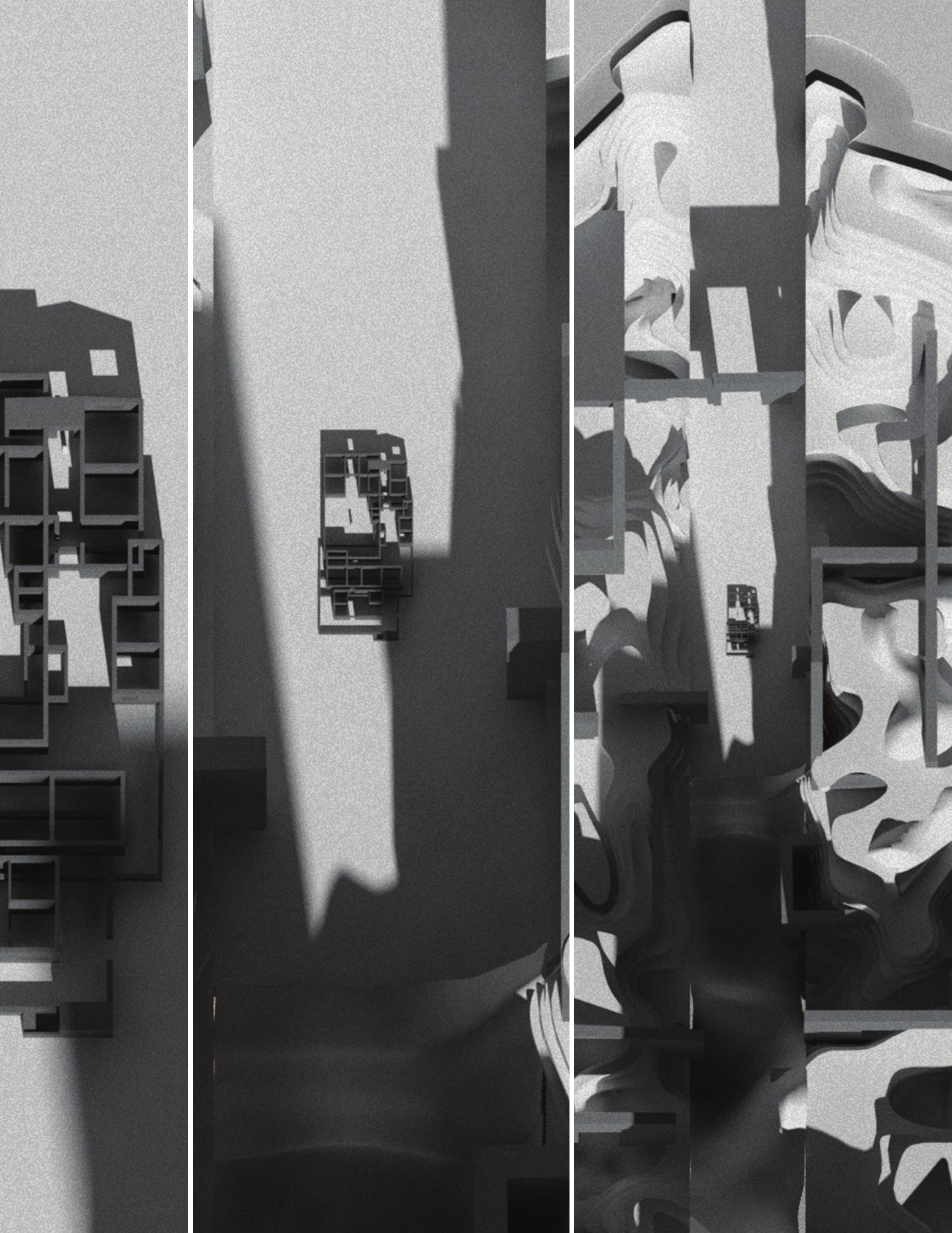




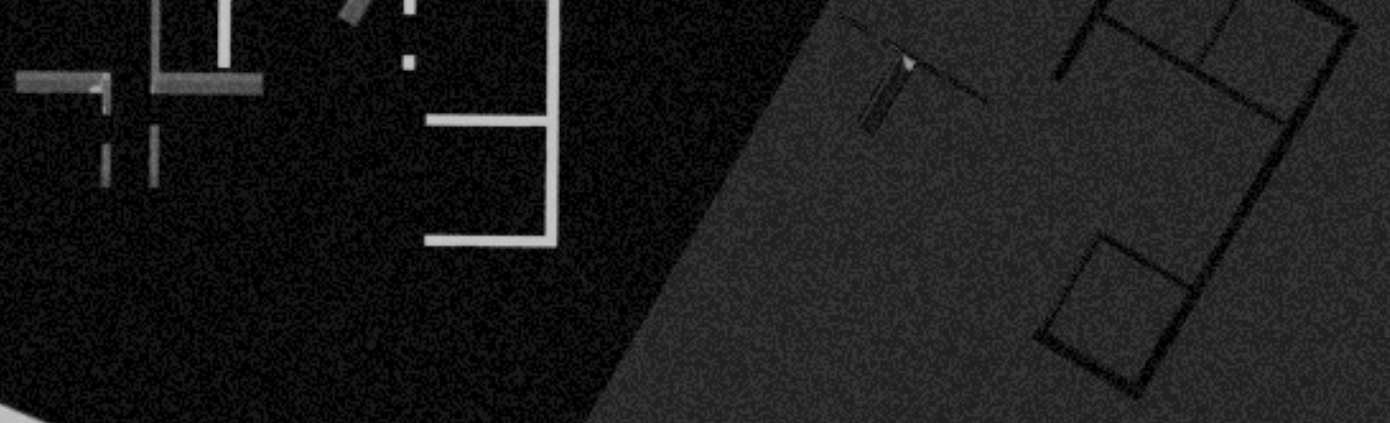

- 4 $x=2,4$ K. 2. $5 \times 1$ $\sqrt{\left.\sqrt{l^{2}}\right)^{-2}}$ 



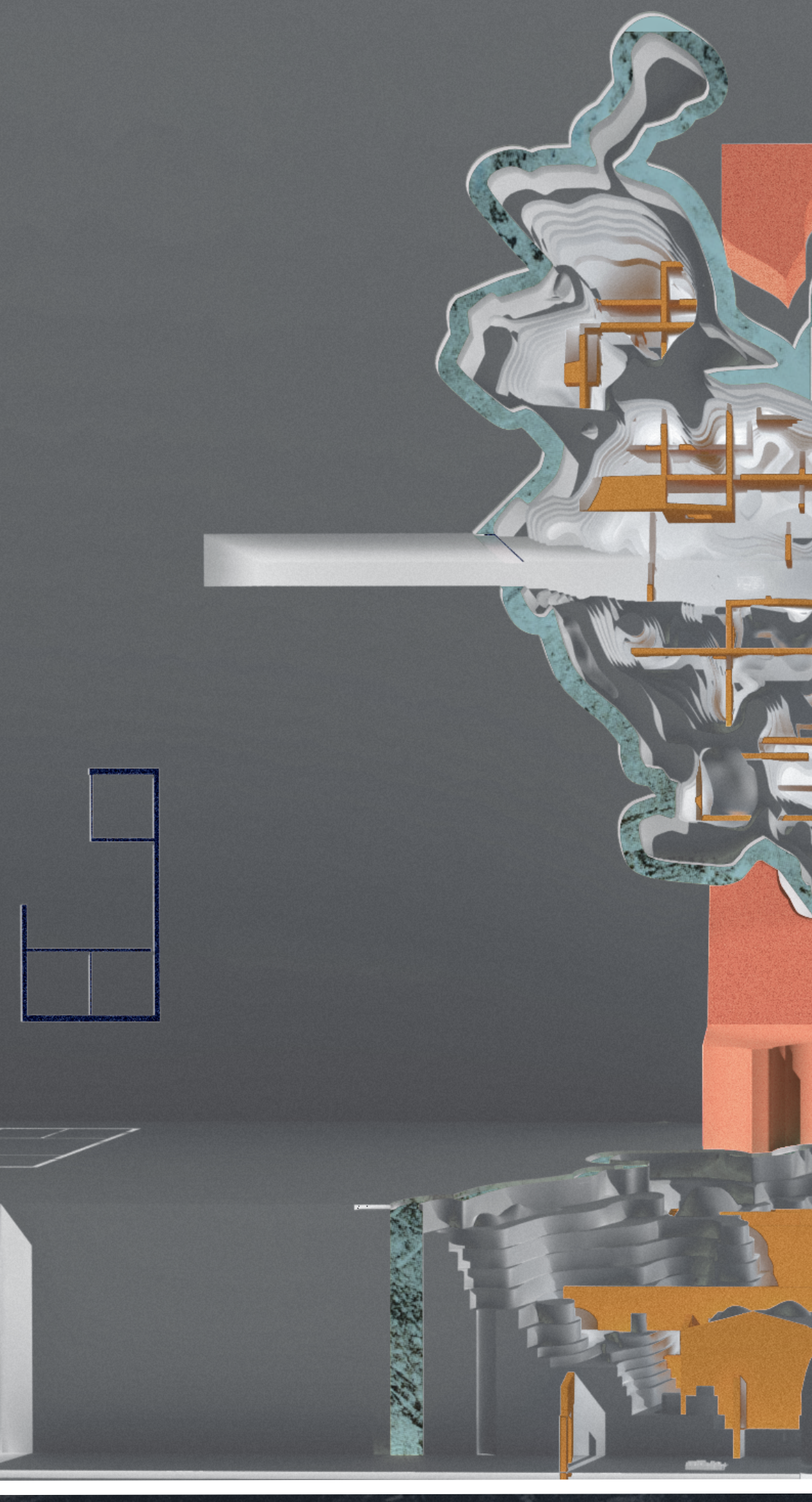




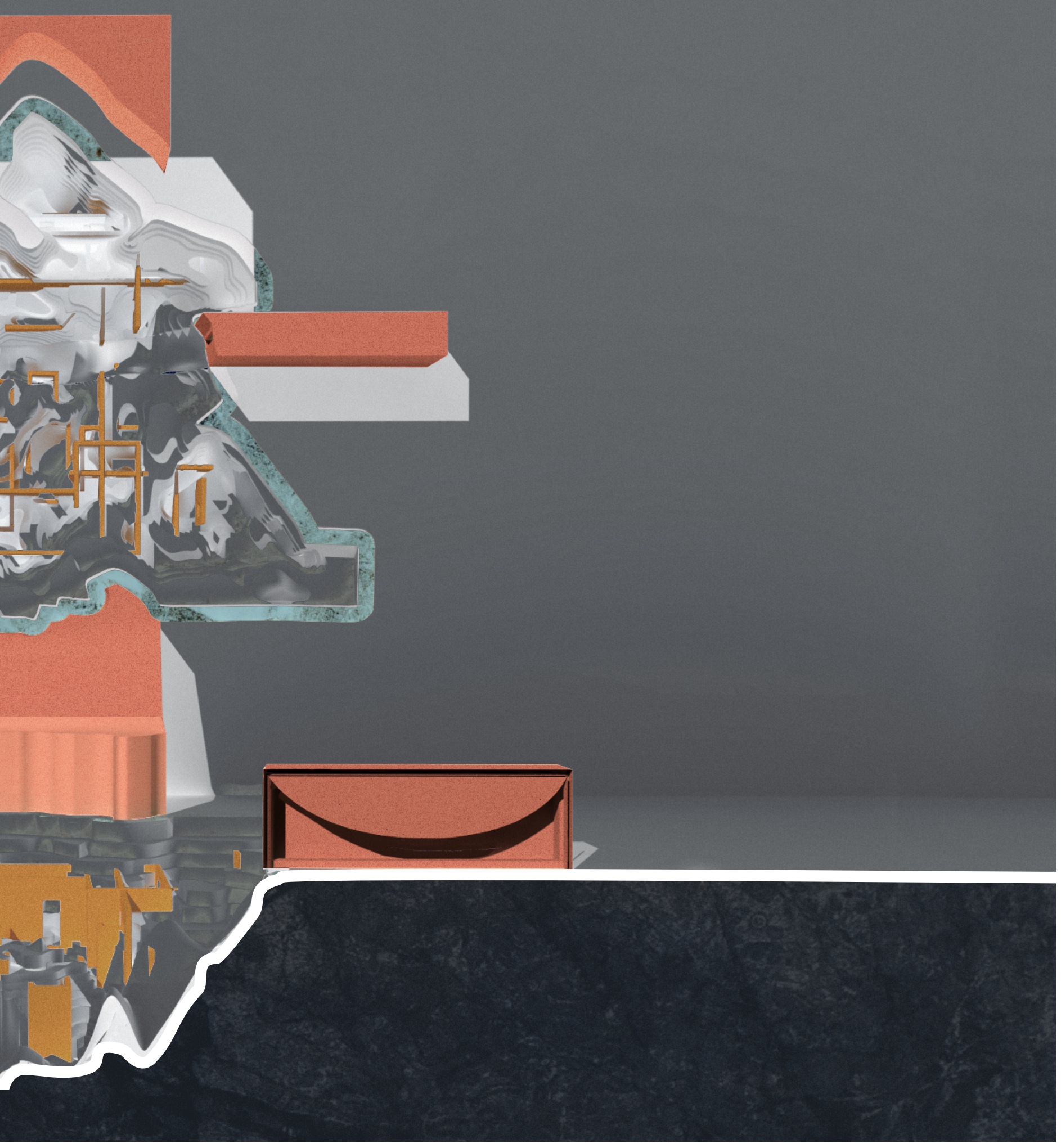



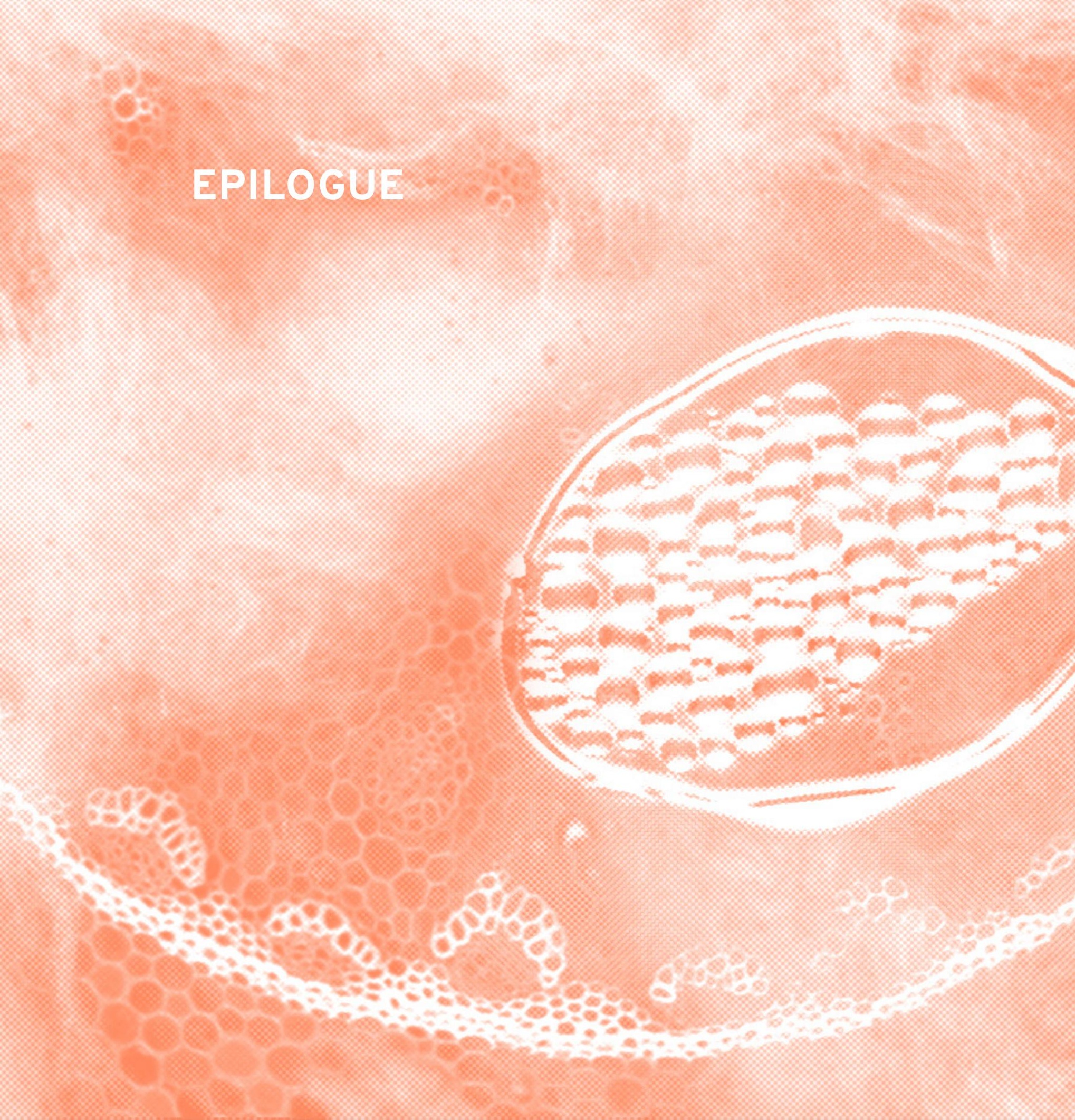
Athe 4

$80^{\circ} e^{\circ}$

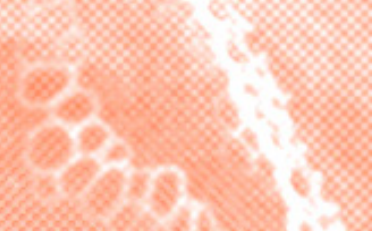
$38 \times x: 2$

$883_{3} ;$

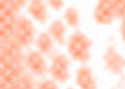

38.

$\left(2 \times 83^{3}\right.$

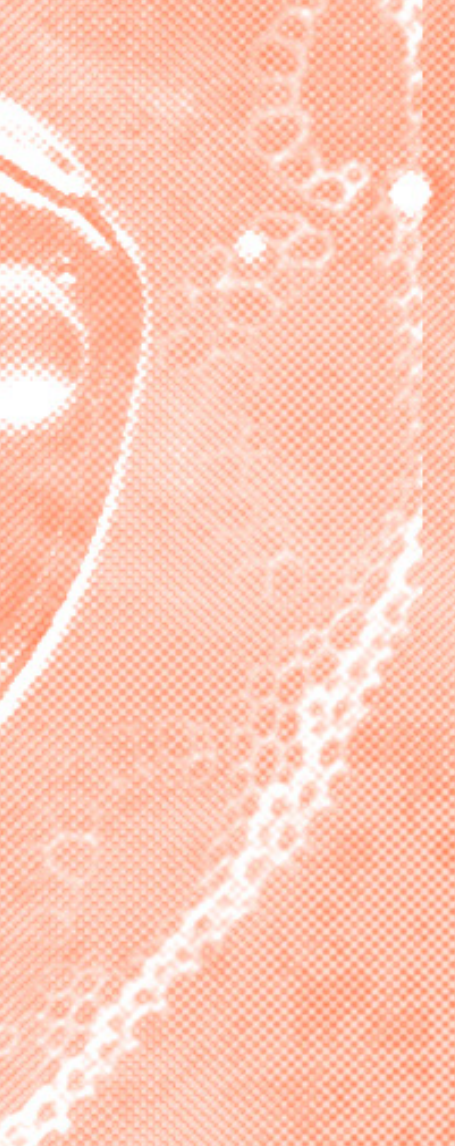

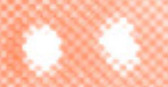

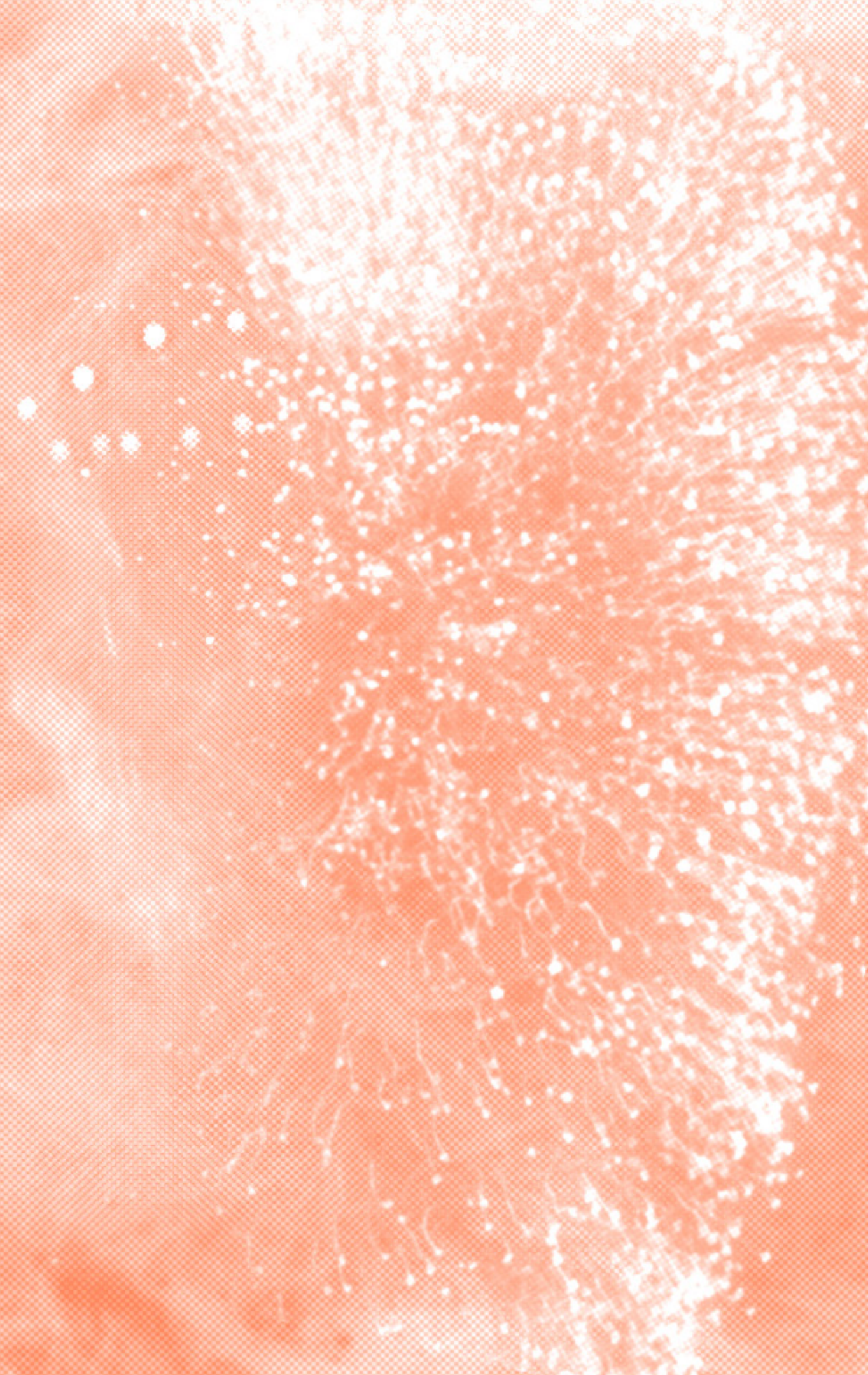


Reconciliation goes beyond forgiving and forgetting. It is about putting aside differences to aim for a mutual and common goal. The search for an architecture of reconciliation in rural Colombia deals with reshaping and reinterpreting the idea of home and place, especially for communities that have been brutally displaced and dispossessed.

The mass exodus in the last 50 years as a result of lack of opportunities and violence demonstrates that the long-term issues in the country have been barriers to the sustainable and post-colonial development of the countryside. Campesinos and other minorities, in the limbo of land ownership and settlements, are constantly alienated from the realities of the powerful. But in the search for reconciliation, a new reality emerges, bringing renewal, redemption and hope for everyone. In this process, a new door opens up for the re-imagination of home and dwelling, which are the elements that have been taken away from the rural populations.

The main tools for understanding the relationships between mining and socio-cultural impacts is through the sacred and profane, because they are the lenses for classifying actions, ideas, realities, fantasies, life, and death as they are lived in these areas. Paradoxically, sacred and profane interchange meanings once mining takes place; what is seen as death becomes a new life, what was life becomes dead and profane realities become the new realities.

This newly created space for reconciliation also provides the right to return to live in a post-colonial setting. This new environment, this hybritopia, will still be shaped by its past, by the hauntology of neo-colonialism, as seen in displacement, relocation and the scarring of the land.

Seeking an architecture of reconciliation is seeking an architecture of the home, where space becomes place and the profane becomes sacred, and where a new symbiosis is born. 
figure 01 genesis, exodus and revelation: the final synergy of the mined landscape in Colombia grows from home. [next page] figure 02 epilogue.

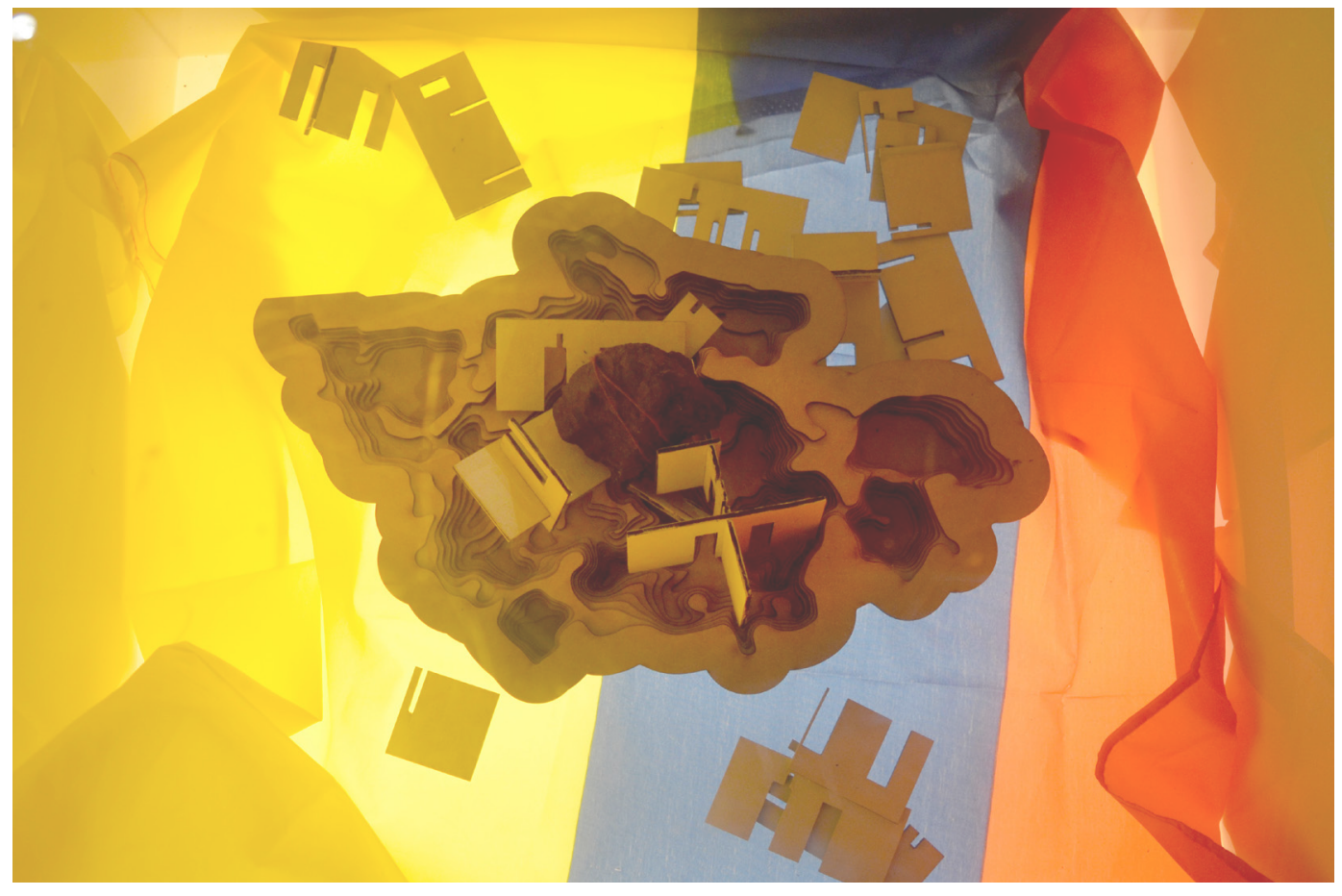




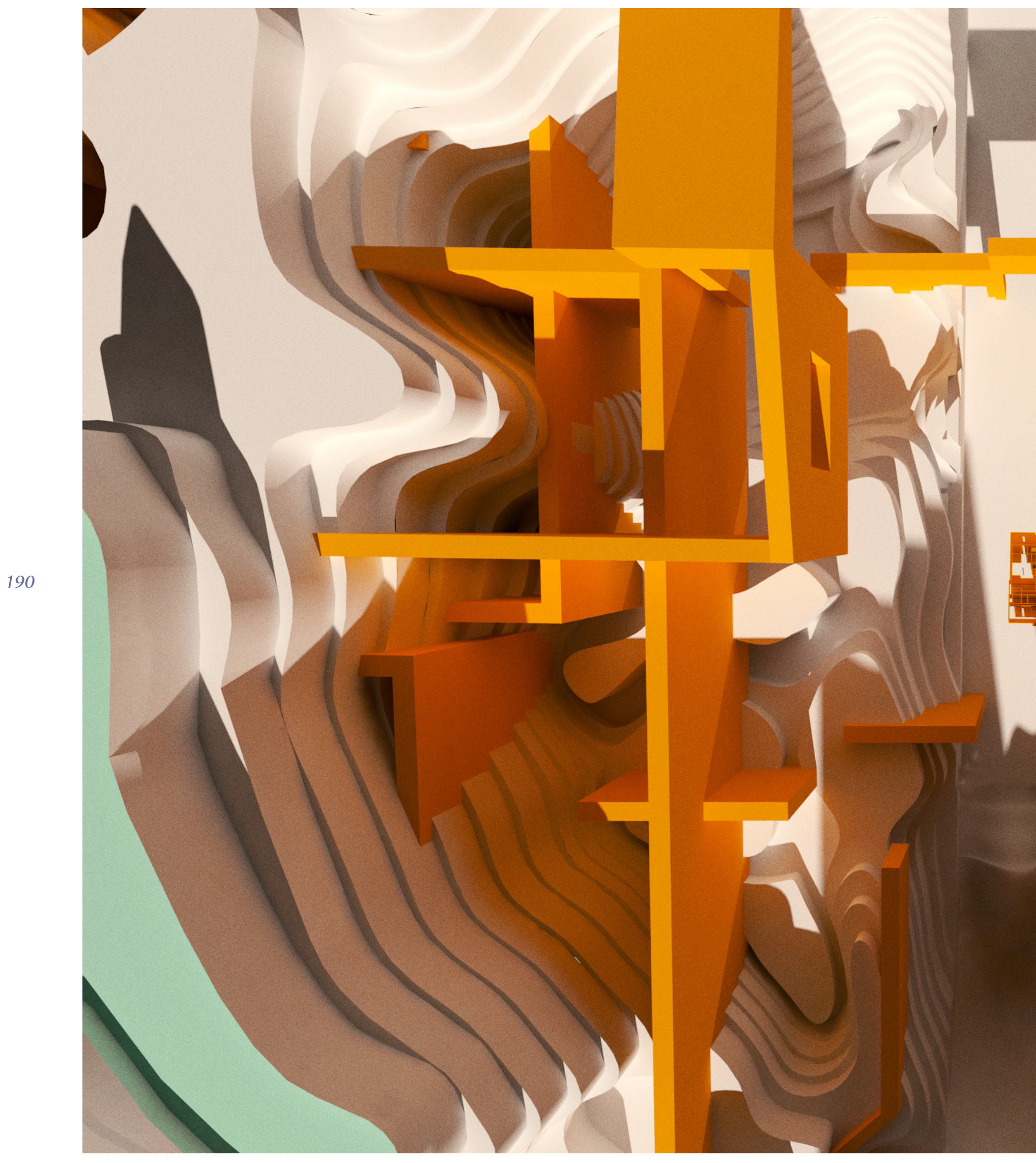




\section{Reinterpretation of paintings}
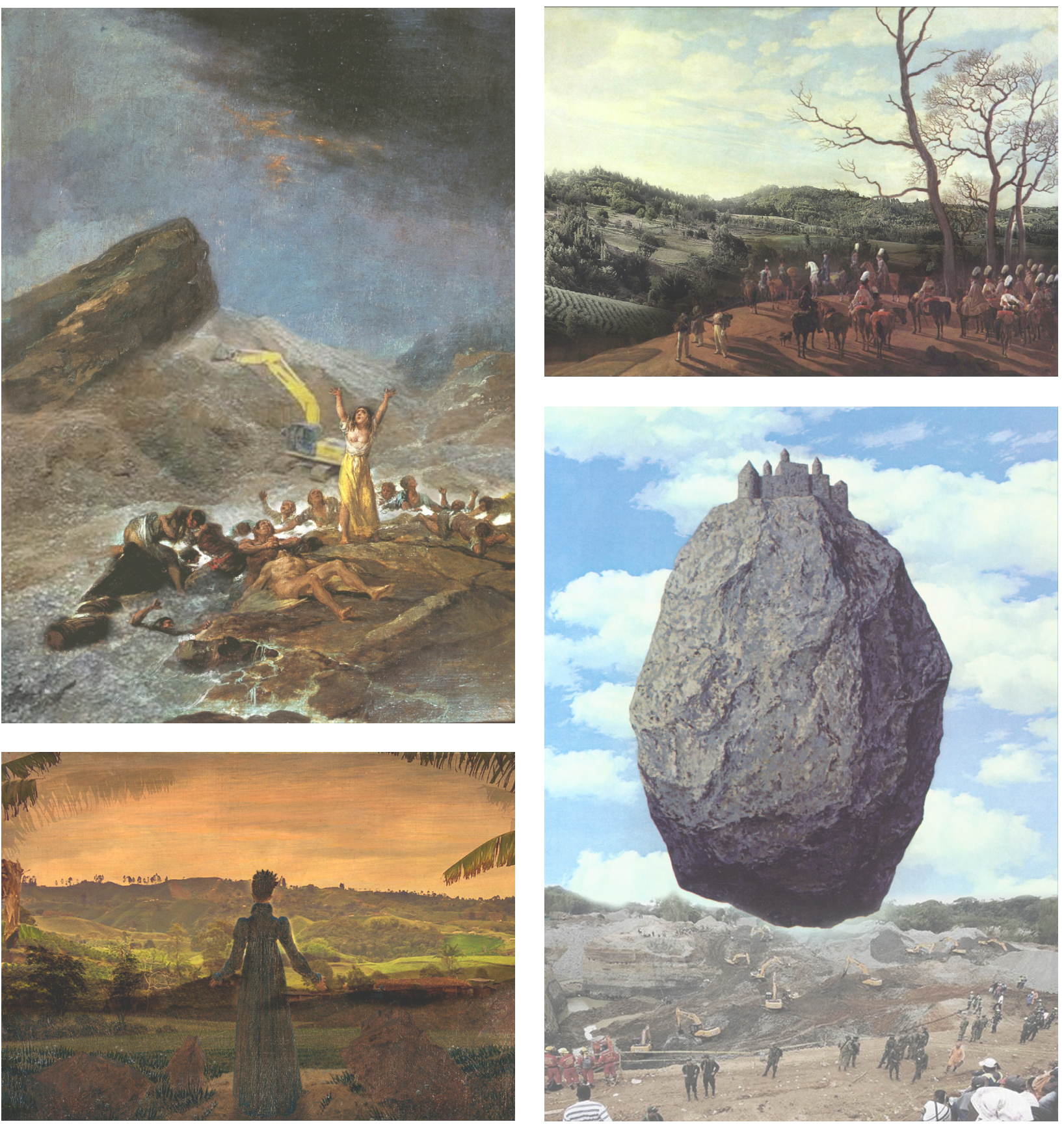

[top left] figure 1a the Colombian shipwreck by Goya.

[top right] figure $\mathbf{1 b}$ siege of Colombian Kosel by Wilhelm.

[bottom left] figure 1c woman in Colombian morning light by Caspar David.

[bottom right] figure 1d the castle in the ColombianPyrenees by Magritte. 


\section{Reconciliation}
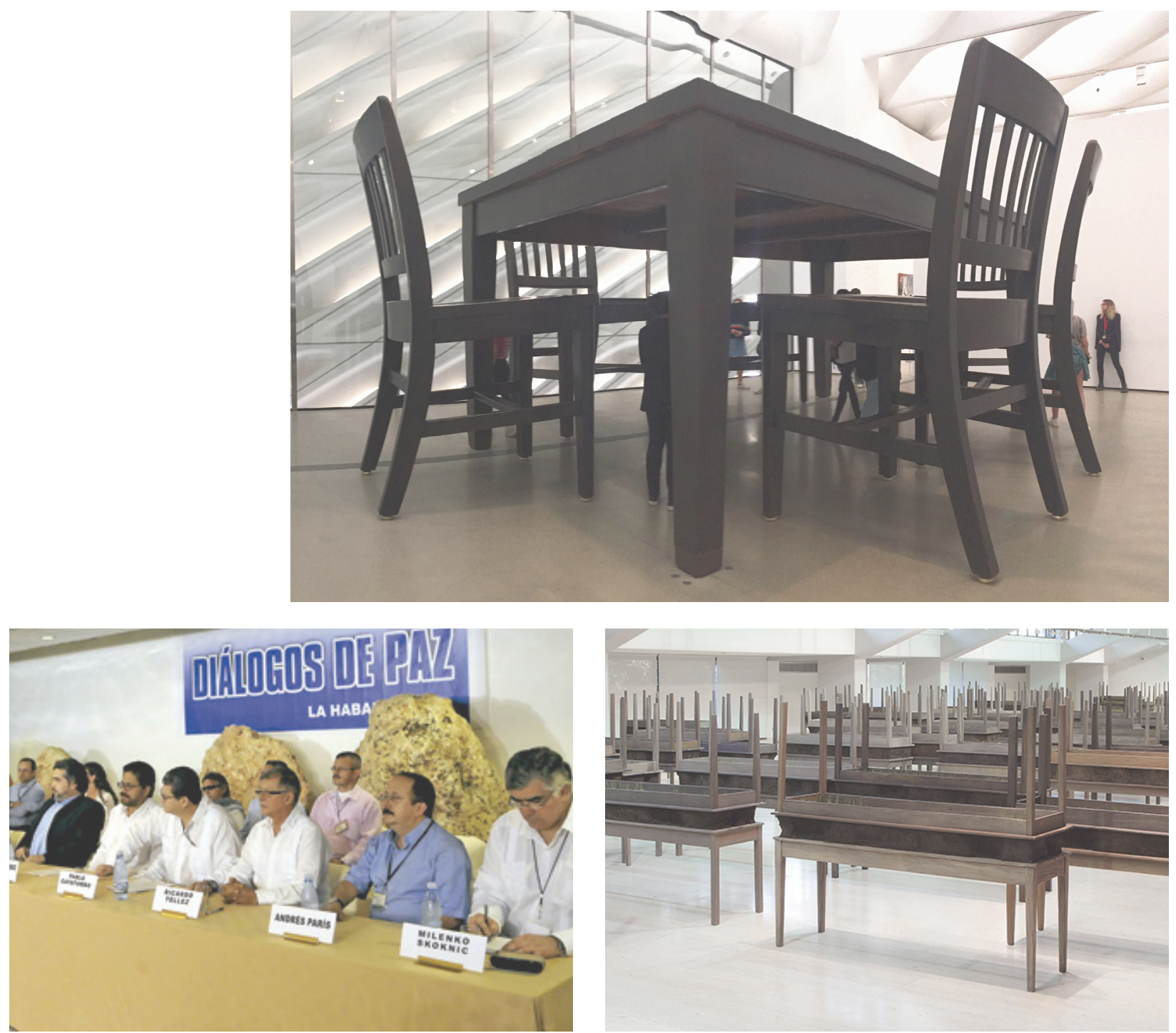

[top left] figure $\mathbf{2 a}$ under the table by Robert Therrien.

[bottom left] figure $\mathbf{2 b}$ Colombian peace dialogues.

[bottom right] figure 2c plegaria muda by Doris Salcedo. 
the in-between

pilgrimage route in Jalisco Mexico
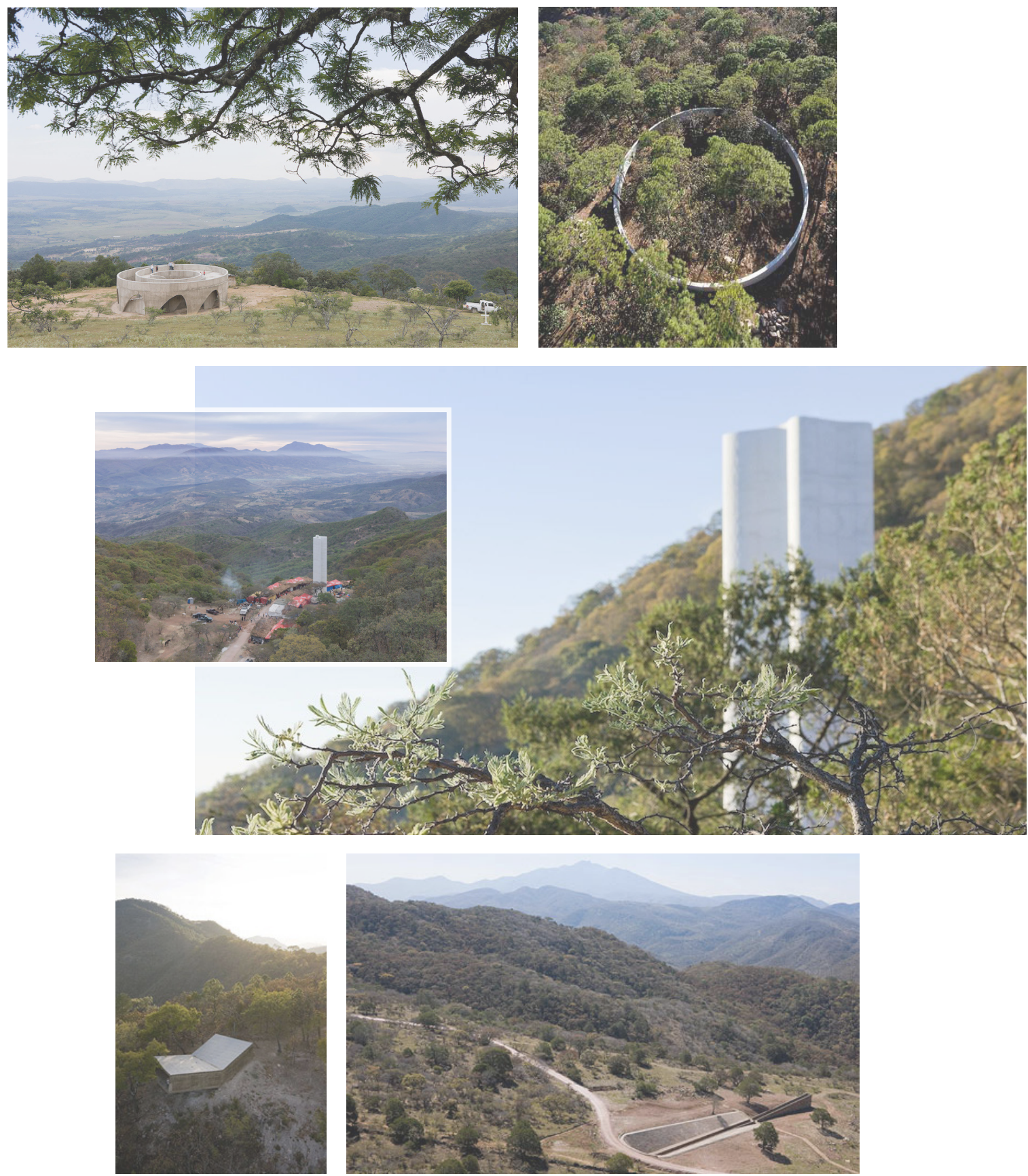

[top left] figure 3a lookout point by HHF architects.

[top right] figure $\mathbf{3 b}$ sanctuary circle by Dellekamp and Periferica.

[centre] figure $3 \mathbf{c}$ cerro del obispo lookout point by Christ \& Gantenbein.

[bottom left] figure 3d lookout point by Elemental.

[bottom right] figure $3 \mathrm{e}$ sanctuary by Ai Weiwei. 

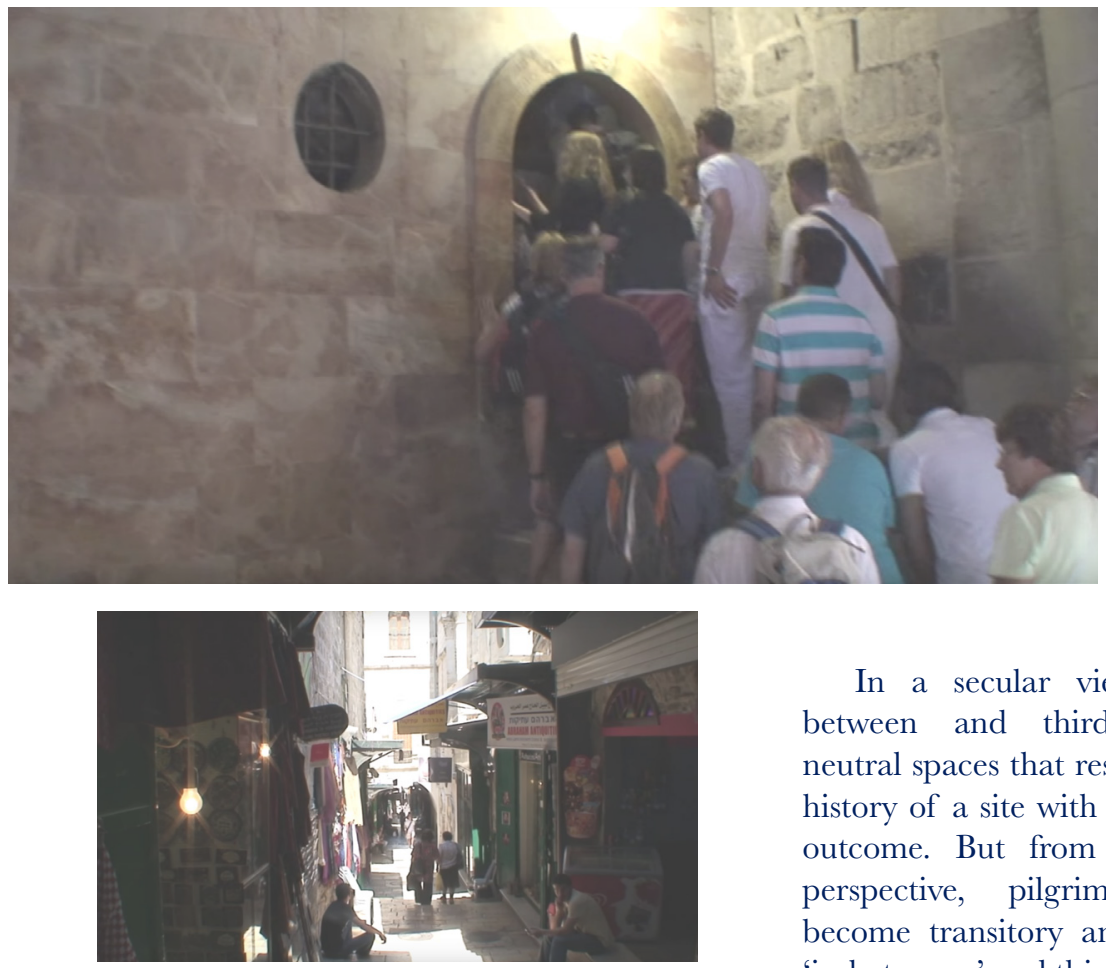

In a secular view, the in-

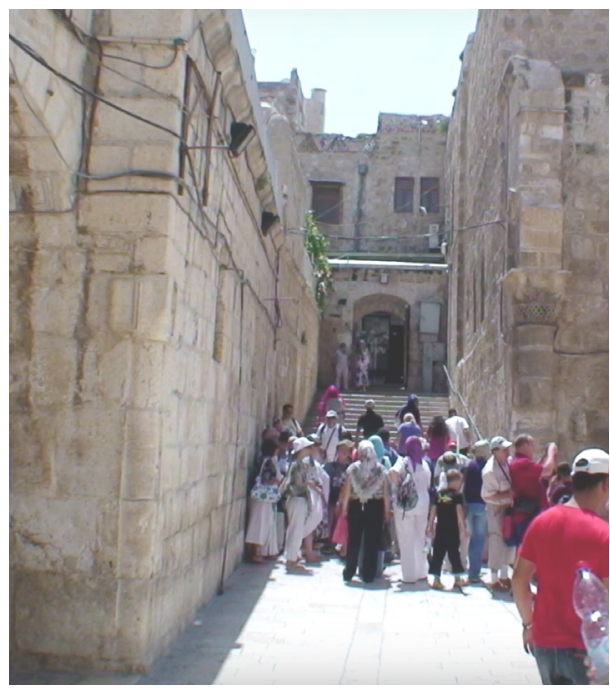
between and thirdspaces are neutral spaces that respond to the history of a site with an expected outcome. But from a religious perspective, pilgrimage zones become transitory and temporal 'in-betweens' and thirdspaces.

The celebration of the Stations of the Cross in Jerusalem shows buffer zones in between the buildings.

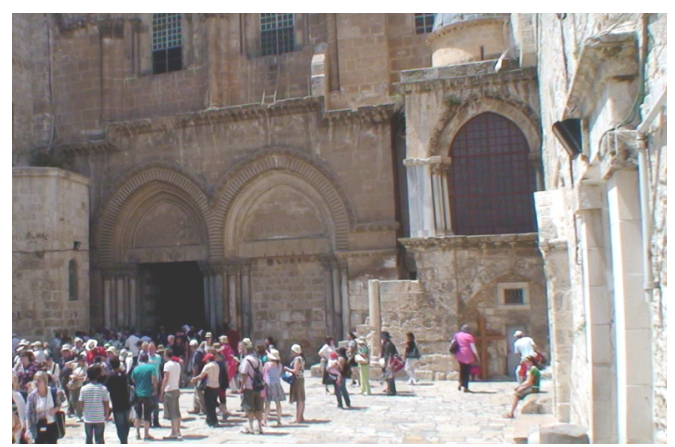

figure 4 via dolorosa in Jerusalem. 
fragmentation as kintsugi
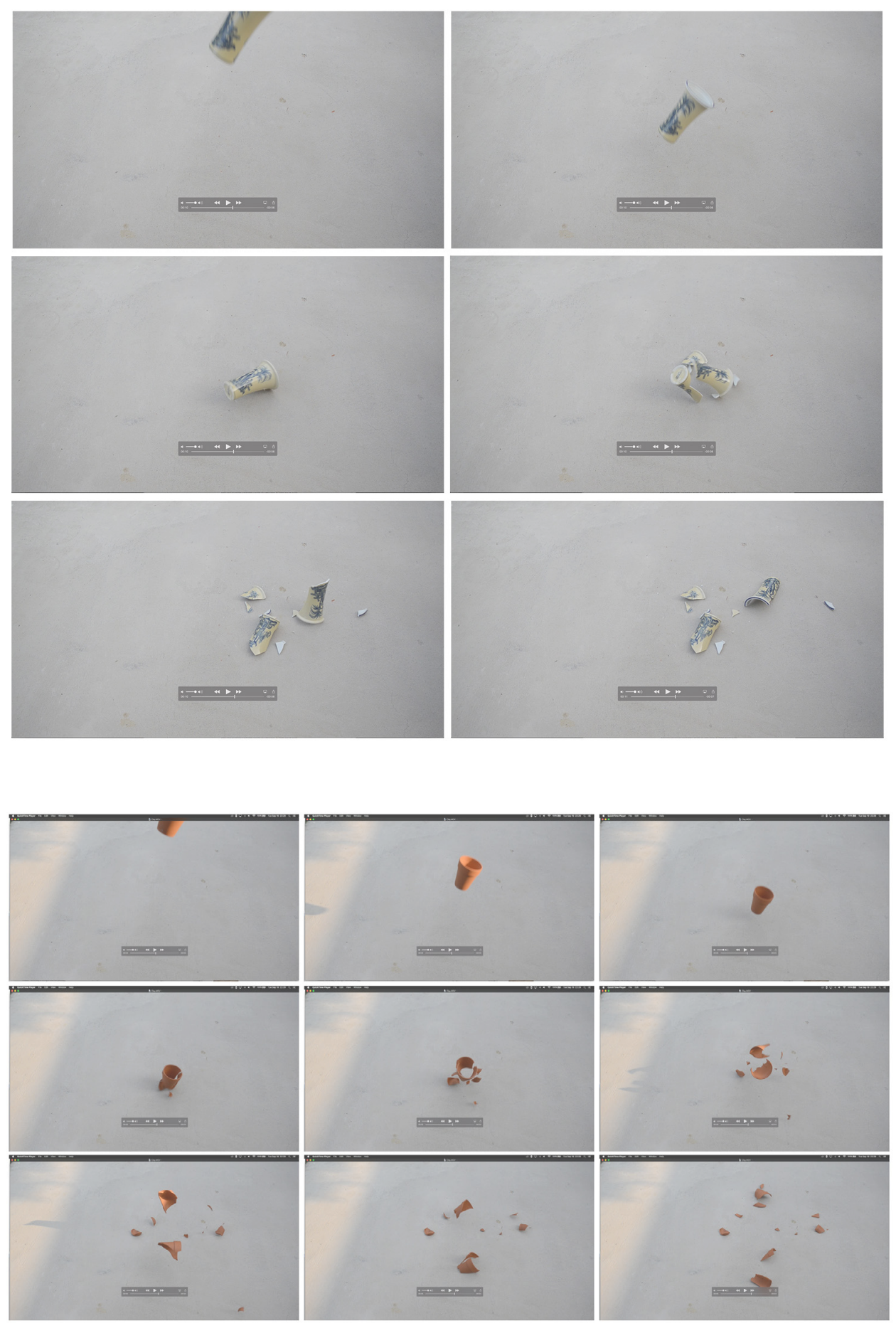

figure 5 
the brief history of colombia through models

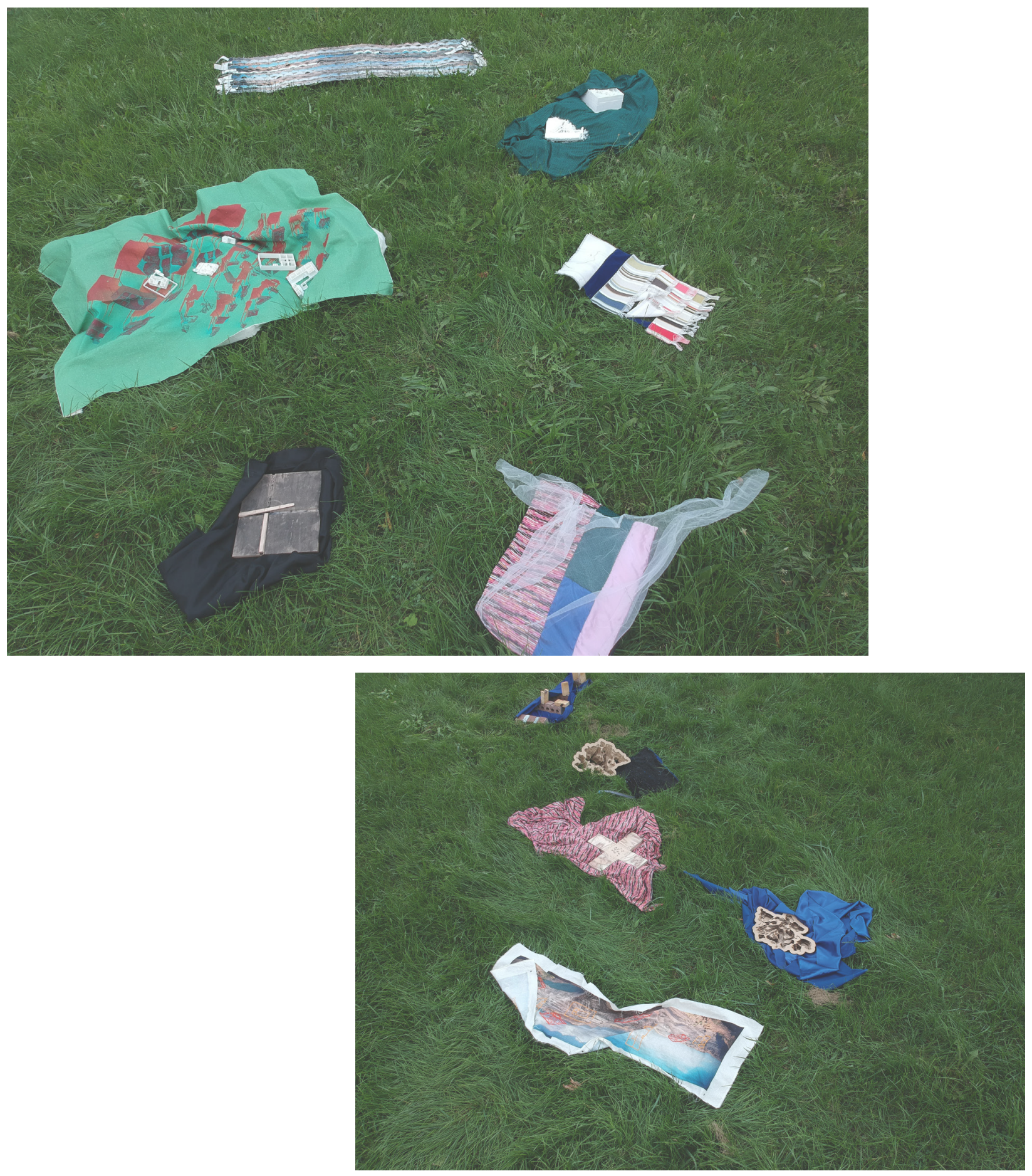


water from the soil
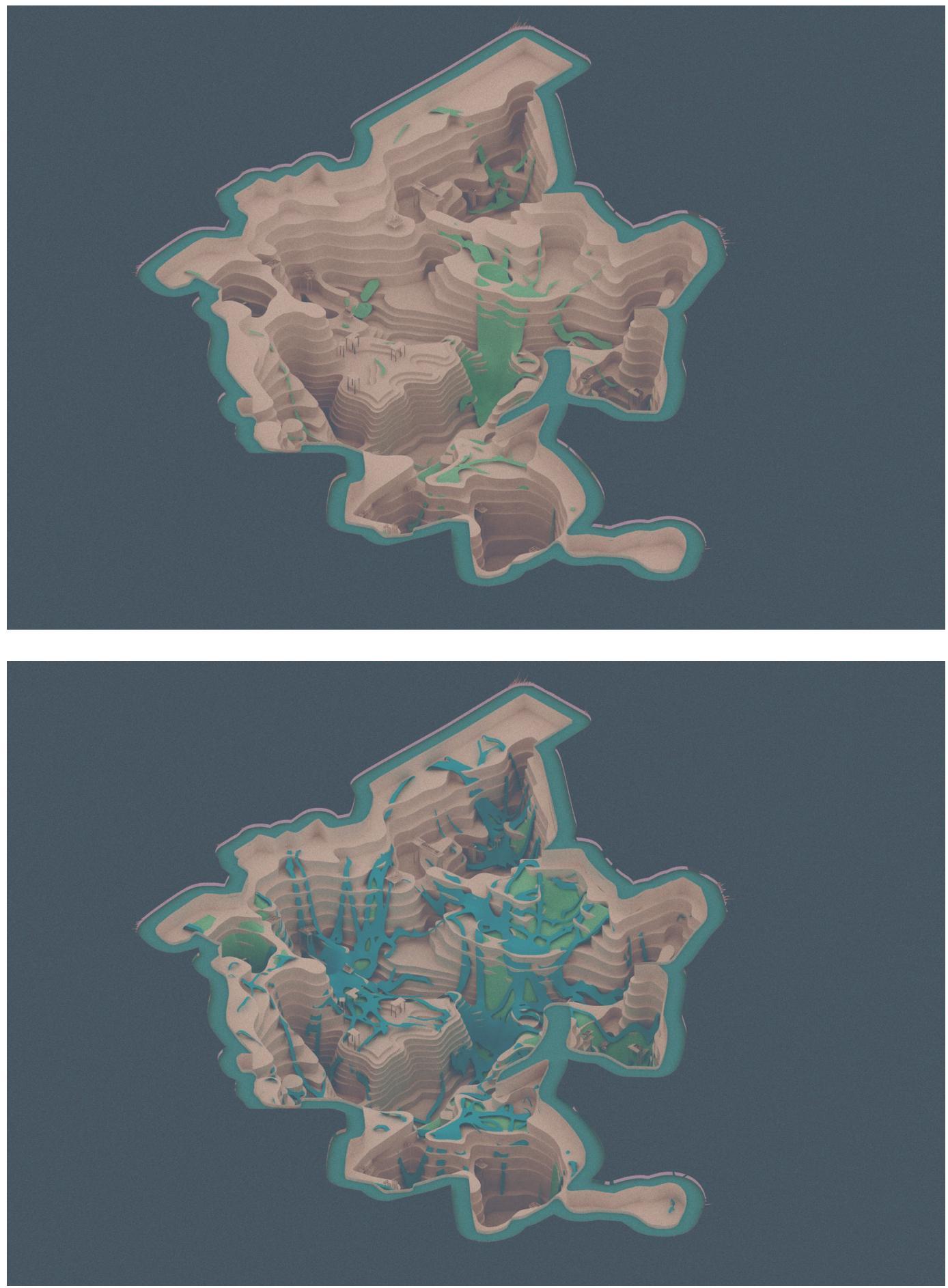

figure 7 

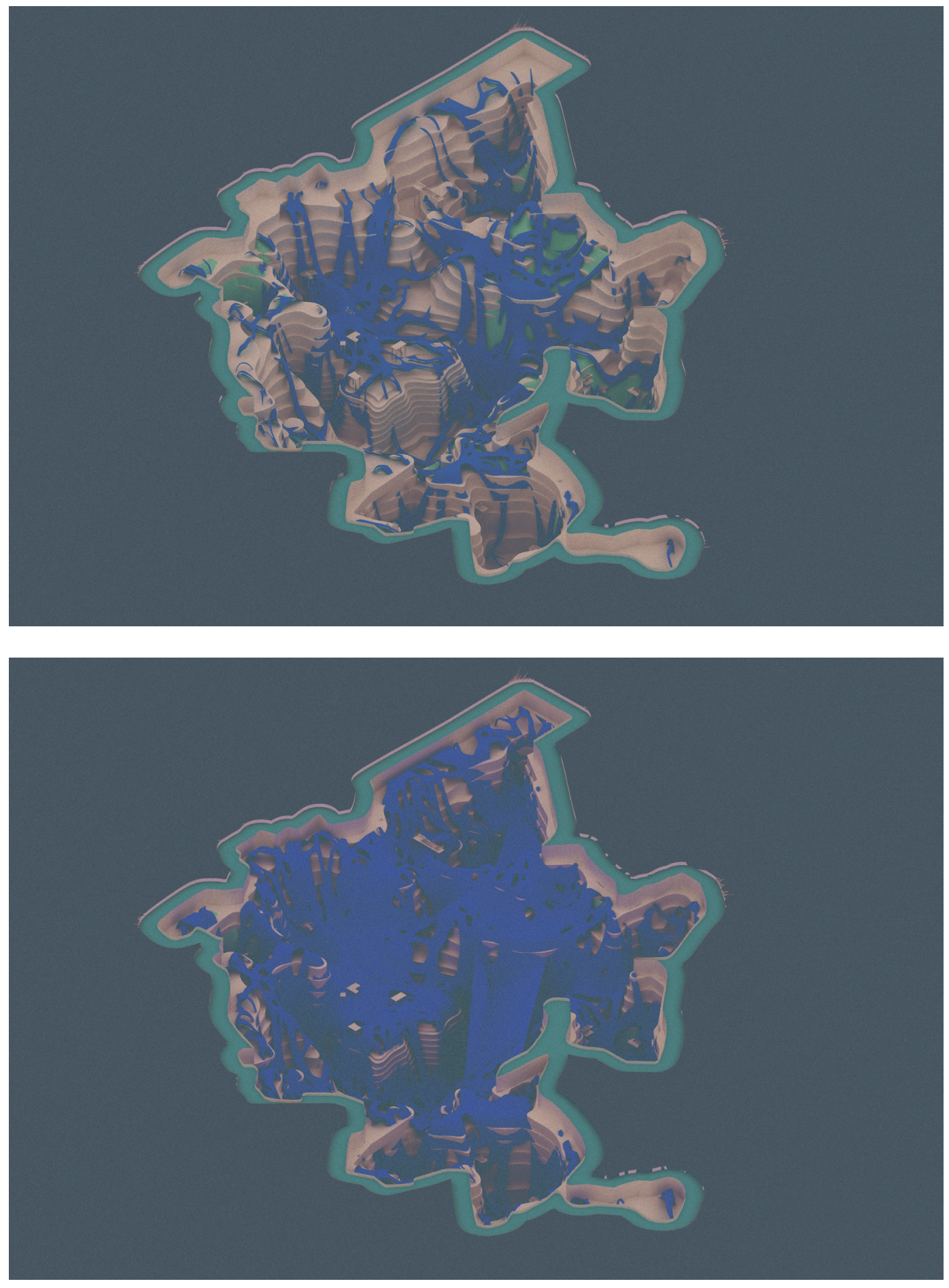
(2016). Política Minera de Colombia: Bases para la minería del futuro. Bogota: Ministerio de Minas y energía.

Abraham, R. (1983). Site: The Meaning of Place in Art and Architecture. Design Quarterly, 14-15.

Alcorn, R. (2016, October 24). What Is the Tree of Life? Retrieved from Eternal perspective ministries: https://www.epm.org/blog/2016/Oct/24/what-tree-life

Architecture, R. (2018, April 12). Superstudio 1973 - Cerimonia. Retrieved from https://www. youtube.com/watch? $=\mathrm{kXrWr8zLRNY}$

Arthur, C. (n.d.). Dialectics of Labour: Marx and his Relation to Hegel. Retrieved from Chris Arthur: https://chrisarthur.net/dialectics-of-labour-marx-and-his-relation-to-hegel/ dialectics-of-labour-appendix/

Así se hace una Mochila Wayuu. (2013, February 06). SENA Regional La Guajira. Colombia.

Balestrero, A. (2016). The shape of life. In M. Ghidoni, Fundamental acts: life, education, ceremony, love, death (pp. 28-37). Milano: a+mbookstore.

Bangs, H. (2007). The Return of the Sacred Architecture. Rochester: Inner Traditions.

Barrie, T. (2010). The Sacred In-Between: the Meditating Roles of Architecture. New York: Routledge.

Barrie, T. (2017). House and Home: Cultural Contexts, Ontological Roles. Abingdon: Routledge.

Barrie, T., \& Bermudez, J. (2016). Architecture, Culture, and Spirituality. New York, NY: Routledge.

Baumberger, C. (2009). Ambiguity in Architecture.

Becerra, L. A. (2013). La conflictividad por el territorio, el control de los RNNR y la renta minera. El choque de las locomotoras mineras en Colombia. In Minería en Colombia: Institucionalidad y territorio, paradojas y conflictos (pp. 143 - 191). Bogota: Contraloría General de la República.

Bowers, M. A. (2004). Magic(al) Realism. New York, NY: Routledge.

Castro, L. E. (2006). Plan Nacional de Desarrollo Minero - 2019. Bogota: UPME.

Chang, H. (2015). An Aesthetic and Ethical Account of Genius Lloci. In J. B. Thomas Barrie, Architecture, Culture, and Spirituality. (pp. 71-81). Ashgate . 
Chief Dr. Robert Foseph, O.B.C., O.C. (n.d.). Retrieved from Reconciliation Canada: http:// reconciliationcanada.ca/about/team/chief-dr-robert-joseph/

Colombia - Rural population. (n.d.). Retrieved from Trading economics: https://tradingeconomics. com/colombia/rural-population-percent-of-total-population-wb-data.html

Colombia enters CRIRSCO . (2018, May 28). Retrieved from National Mining Agency: http:// miningincolombia.anm.gov.co/index.php/en/colombia-enters-crirsco

Cooney, J. (2017, July 07). Mining Conflicts \& the Catholic Church: Exploring the Connections. Toronto, Ontario, Canada: Institute for the Study of Corporate Social Responsibility Ryerson University. Retrieved from https://ryecast.ryerson.ca/12/Watch/11518.aspx

Corbusier, L. (1948). New World of Space. New York : Reynal \& Hitchcock.

Davis, G. (2005). Hauntology, spectres and phantoms. French Studies, 373-379.

Demos, T. (2013). Return to the Postcolony: Specters of colonialism in contemporary art. Berlin: Sternberg Press.

Durkheim, É. (n.d.). The Elementary Forms of the Religious Life.

Eliade, M. (1983). The sacred and the profane : the nature of religion. Magnolia, Massachusetts: P. Smith.

Enel suspends blood coal imports. (2017, May 04). Retrieved from PAX for peace: https://www. paxforpeace.nl/stay-informed/news/enel-suspends-blood-coal-imports

Farneth, M. B. (2017). Hegel's Social Ethics : Religion, Conflict, and Rituals of Reconciliation. Princeton, NJ: Princeton University Press.

Fisher, M. (2013). The Metaphysics of Crackle: Afrofuturism and Hauntology. Dancecult: Fournal of Electronic Dance Music Culture, 5(2), 42-55.

Foucault, M. (1984). Of Other Spaces: Utopias and Heterotopias. Architecture /Mouvement/ Continuité.

Francis. (2015). Encyclical Letter Laudato Si' of the Holy Father Francis: On Care for Our Common Home. Vatican City: Our Sunday Visitor.

Franco-Cañas, A.-M., \& Ríos-Carmenado, I. D. (2011). Reforma agraria en Colombia: evolución histórica del concepto. Hacia un enfoque integral actual. Cuad. Desarro. Rural, 93-119. 
Gacs, D. (2013, January 29). AQDocumentary: The Relocation of the Rio Rancheria in La Guajira, Colombia. Retrieved from Americas Quaterly: http://www.americasquarterly.org/ rio-rancheria-documentary

Ghidoni, M. (2016). Fundamental Acts. Milano: a+m Bookstore.

Group, W. B. (2015). Systematic Country Diagnostic - Colombia. Washington DC: World Bank Group.

Harvey, D. (2007). The Kantian roots of Foucault's dilemmas. In J. W. Crampton, \& S. Elden, Space, knowledge and power: Fucault and geography (pp. 41-47). Burlinghton, USA: Ashgate Publishing Limited.

Hays, K. M. (1998). "The Third Typology" Oppositions 7. In K. M. Hays, Architecture theory since 1968 (pp. 284-285). Cambridge, Mass: MIT Press.

Heidegger, M. (1993). Building Dwelling Thinking. In D. F. Krell, Basic Writings (pp. 343-364). New York City: HarperCollins.

Homi K. Bhabha. (n.d.). Retrieved from http://shodhganga.inflibnet.ac.in/ bitstream/10603/4107/8/08_chapter\%203.pdf

Huang, Y.-J. (2012). Atopia: Digital Fictions of Place. University of Technology Sydney, Faculty of Arts and Social Sciences, Sydney. Retrieved from https://opus.lib.uts.edu.au/ bitstream/10453/21851/1/01front.pdf

(n.d.). Informe departamental minero La Guajira. UPME.

Jentsch, E. (1997). On the psychology of the uncanny (1906). Fournal of the Theoretical Humanities, 2(1), 7-16.

Joseph, C. D. (2016, May 24). Healing a Nation Through Truth and Reconciliation | Chief Dr Robert Foseph | TEDxEastVan . Retrieved from TEDx Talks: https://www.youtube.com/ watch?v=rJQgpuLq1LI

Kipfer, S. (2013). Urban Marxism and the Post-Colonial Question: Henri Lefebvre and 'Colonisation'. Historical Materialism, 21(2), 76-116.

La mina "La Colosa" . (2010, June 01). Retrieved from La Silla Vacia: http://lasillavacia.com/ elblogueo/blogverde/15157/la-mina-la-colosa 
La mochila Wayúu, parte de la tradición de Colombia. (2014, March 25). Retrieved from Artesanias de Colombia: http://www.artesaniasdecolombia.com.co/PortalAC/Noticia/la-mochilawayu-parte-de-la-tradicion-de-colombia_5070

Lafebvre, H. (1991). Production of Space. Oxford: Blackwell.

Lay, M. B. (2003, November). Globalisation and Povert changes in Colombia. Le Seine SaintGermain: OECD Development Centre.

Lievano, A. B. (2013, November 30). El legado de la Drummond. Retrieved from La silla vacia: http://lasillavacia.com/historia/el-legado-de-la-drummond-46203

Lievano, A. B. (2013, January 288). Minería en vilo por desenlace de primera huelga en el Cerrejón en 20 años. Retrieved from La Silla Vacia: http://lasillavacia.com/historia/mineria-en-vilopor-desenlace-de-primera-huelga-en-el-cerrejon-en-20-anos-41197

Life Application Study Bible. (2015). Carol Stream: Tyndale House Publishers, Inc.

Lukács, G. (1971). The Theory of the Novel . Cambridge, Mass: MIT Press.

Marchi (Producer), \& Superstudio (Director). (n.d.). Superstudio Supersurface an Alternative Model for Life on the Earth [Motion Picture].

Mitos y realidades. (n.d.). Retrieved from MINMINAS - Gobierno de Colombia: https://www. minminas.gov.co/mitos-y-realidades-mineria

Moir, C. J. (n.d.). The Brockenspectre: The novel as site of transcendental homelessness. . 2012: University of Glasgow.

Moor, M., \& Sandt, J. v. (2014). El lado oscuro del carbón. Utrecht: PAX for Peace.

Morgain, R. (2012). On the use of the uncanny in ritual. Religion, 42(4), 521-548.

Morgan, B. (2013, January 15). Third Space Part 2. Coming to Terms. Soja's Geographical Third Space. (M. Geneseo, Compiler)

Morgan, B. (2013, January 13). Third Space Theory Part 1. Coming to Terms. Bhabha's Cultural Third Space. (M. Geneseo, Compiler)

Morgan, B. (2013, January 15). Third Space Theory Part 3. Coming to Terms. Oldenburg's Third Space and Third Space Theory and the Internet. (M. Geneseo, Compiler) 
Multa a minas de carbón del Cesar . (2018, January 15). Retrieved from Portafolio: http://www. portafolio.co/economia/multa-a-minas-de-carbon-del-cesar-513281

Nam, M. F. (2009, May). Comparison of In-between Concepts by Aldo Van Eyck and Kisho Kurokawa -Through Theories of 'Twin Phenomena' and 'Symbiosis'-. Fournal of Asian Architecture and Building Engineering, 8(1), 17-23.

Nesbitt, K. (1996). Theorizing a new agenda for architecture: An anthology of architectural theory 1965-1995. New York: Princeton Architectural Press.

Nixon, R. (2011). Slow violence and the environmentalism of the poor. Cambridge, Massachusetts: Harvard University Press.

Nostrand, J. v. (2016). Mid-Canada boreal corridor: Planning for Canada's future. Thunder Bay: Northern Policy Institute.

Obert, J. G. (2016). The Architectural Uncanny: An essay in the postcolonial unhomely. Interventions, 86-106.

Osorio, G. (2011, September 11). Hay locomotora minera, pero no locomotora para la reubicación de los vecinos. Retrieved from La Silla Vacia: http://lasillavacia.com/historia/haylocomotora-minera-pero-no-locomotora-para-la-reubicacion-de-los-vecinos-27427

Petti, A., Hilal, S., \& Weizman, E. (2013). Architecture after revolution. Berlin: Sternberg Press.

(2011). Plan de Ordenamiento de la cuenca del Rio Rancheria.

(2015). Plan Nacional de Desarrollo: Todos por un nuevo país. Bogota: DNP-Departamento Nacional de Planeacion.

(2014). Plan Nacional de Ordenamiento Minero PNOM. Bogota: Unidad de Planeación Minero Energética - UPME.

(2014). Plan salvaguarda Wayuu - Zona sur de la Guajira . Bogota: Ministerio del Interior.

Plummer, H. (2016). The Experience of Architecture . London: Thames and Hudson.

(2018). Pobreza Monetaria La Guajira Año 2017. Bogota: DANE - Informacion Estadistica.

(2010). Projected Investment on Mine Development and Expansion Projects in Colombia; 2010 to 2020. Bogota: Asomineros Chamber of National Business Association of Colombia ANDI . 
Proyectos mineros en el socavón . (2013, October 08). Retrieved from Semana: https://www.semana. com/economia/articulo/proyectos-mineros-socavon/353676-3

(n.d.). Pueblo Wayuu. Ministerio del Interior. Retrieved from https://www.mininterior.gov.co/sites/ default/files/upload/SIIC/PueblosIndigenas/pueblo_way_u.pdf

Quiñonez, S. A. (2016). Plan Colombia: descivilización, genocidio, etnocidio y destierro afrocolombiano. Nómadas, 75-89.

Reasentamiento integral responsable . (n.d.). Retrieved from Cerrejon: mineria responsable: https:// www.cerrejon.com/index.php/desarrollo-sostenible/reasentamientos/

Rebughin, P. (2014). Subject, subjectivity, subjectivation. International Sociology , 1-11.

Religion in Latin America Widespread Change in a Historically Catholic Region. (2014, November

13). Retrieved from Pew research centre: http://www.pewforum.org/2014/11/13/religionin-latin-america/

Sanchez, G., \& Obregon, M. E. (2010). La masacre de Bahia Portete: Mujeres Wayuu en la mira. Bogota: Ediciones Semana.

Shikiar, D. A. (n.d.). Notes on Hegel's Conception of Reconciliation.

Stone, A. (2014). Alienation from Nature and Early German Romanticism. Ethics Theory Moral Practices(17), 41-54.

Stop Blood Coal. (n.d.). Retrieved from Pax for peace: https://www.paxforpeace.nl/stay-informed/ in-depth/stop-blood-coal

Tafuri, M. (1998). L'Architecture dans le Boudoir: The Language of Criticism and the Criticism of Language. In K. M. Hays, Architecture theory since 1968 (pp. 148-173). Cambridge: MIT Press.

'Tatequieto' a las multinacionales. (2013, Novemeber 05). Retrieved from Semana: https://www. semana.com/nacion/articulo/tatequieto-multinacionales/342939-3

Torres, J. D. (2016, January 12). Cuestecitas: el pueblo que se alimenta con gasolina de contrabando. Retrieved from Las 2 Orillas: https://www.las2orillas.co/cuestecitas-pueblo-se-alimentagasolina-contrabando/ 
Tragedia de Bojayá: perdonar o no perdonar. (2016, September 27). Retrieved from Semana: https://www.semana.com/la-paz/articulo/masacre-en-bojaya--perdonar-o-noperdonar/494913

(2015). Truth and Reconciliation Commission of Canada: Calls to Action. Winnipeg: Truth and Reconciliation Commission of Canada.

Valencia, F. V. (2013). Minería, conflicto armado y despojo de tierras: impactos,desafíos y posibles soluciones jurídicas. In Minería en Colombia Fundamentos para superar el modelo extractivista (pp. 57-88). Bogota: Contraloria general de la republica.

Venturi, R. (1992). Complexity and contradiction in architecture. NY: The Museum of Modern Art Parpers on Architecture.

Vidler, A. (1991). Agoraphobia: Spatial Estrangement in Georg Simmel and Siegfried Kracauer. New German Critique(54), 31-45.

Vidler, A. (1992). The Architectural Uncanny. Cambridge: Massachussetts Institute of Technology.

Vidler, A. (1998). The Third Typology. In K. M. Hays, Architecture theory since 1968 (pp. 288294). Cambridge, Mass: MIT Press.

Vidler, Anthony; The Architectural Uncanny. (1992).fen-om. Retrieved from http://www.fen-om. com/theory/theory159.pdf

Weigel, S. (2013). Walter Benjamin Images, the Creaturely, and the Holy. Stanford: Stanford University Press.

Weizman, E. (2016, August). Land as forensic evidence. (A. Thiermann, Interviewer, \& E. ARQ, Editor) Santiago, Chile.

Wills, S. (2017, May 11). Cuestecitas: Un pueblo a punto de estallar. Retrieved from Revista Don Juan: http://www.revistadonjuan.com/historias/la-guajira-y-el-contrabando-degasolina+articulo+16851296

Zamora, L. P. (n.d.). The Visualizing Capacity of Magical Realism: Objects and Expression in the Work of Jorge Luis Borges. 


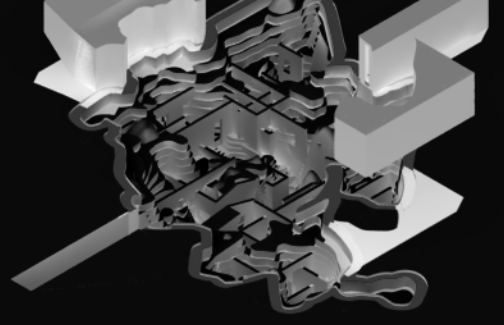

太
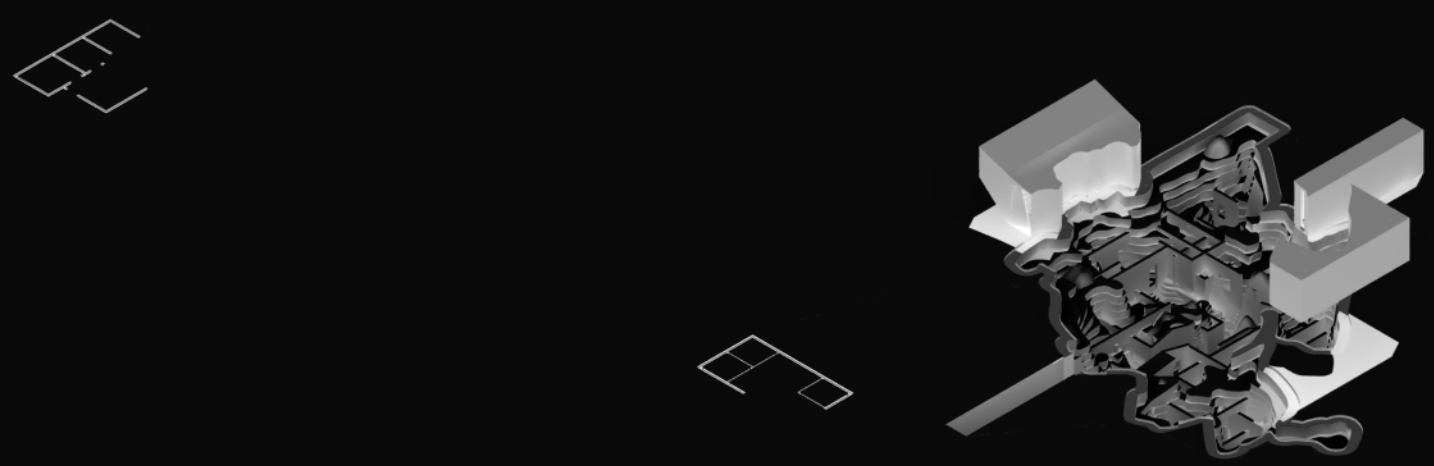<smiles>[CH]C</smiles>
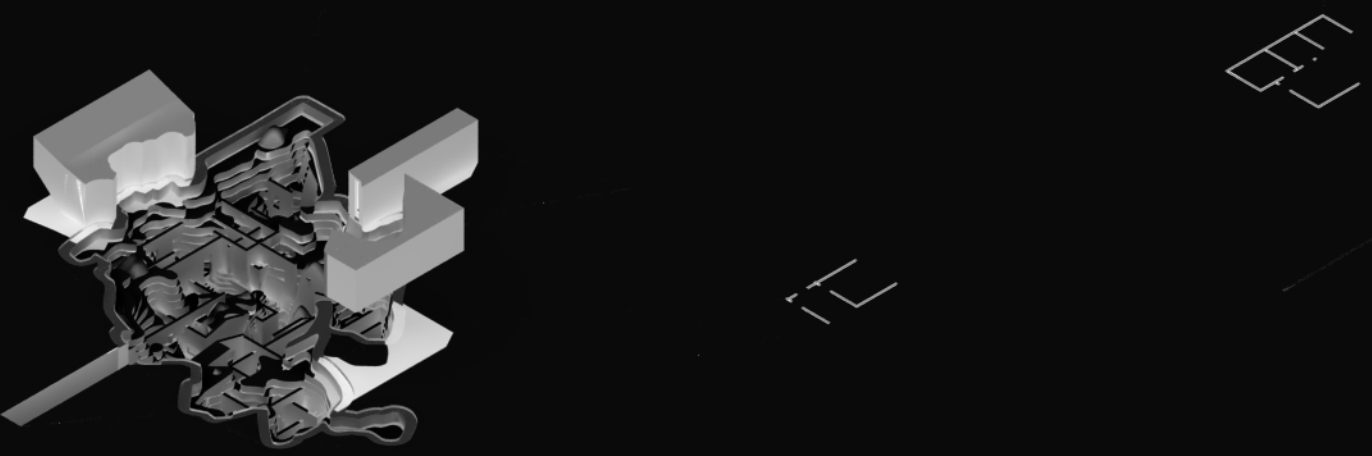<smiles>CCC1CCCCCCCC12CCC2C</smiles>

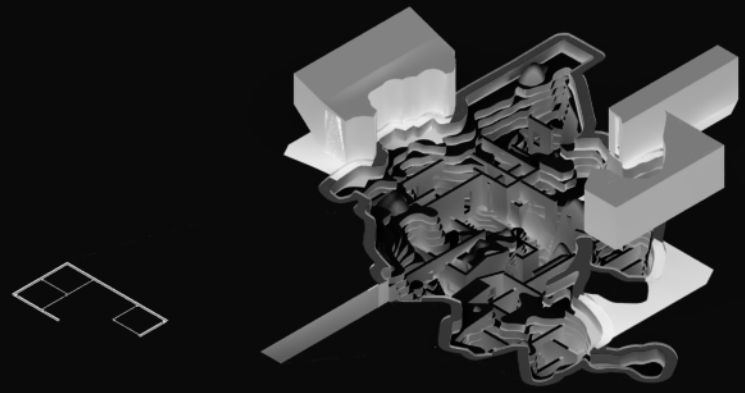<smiles>[CH]C</smiles>

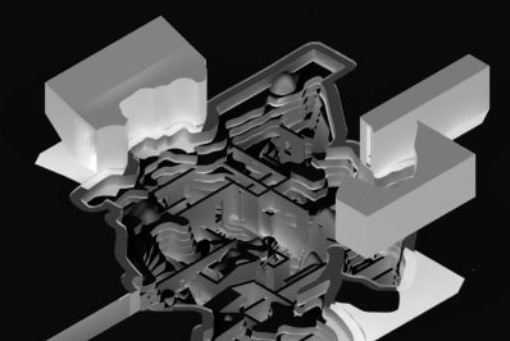<smiles>C1CC2(C1)C1CCC3CCC2C3CC1</smiles> 


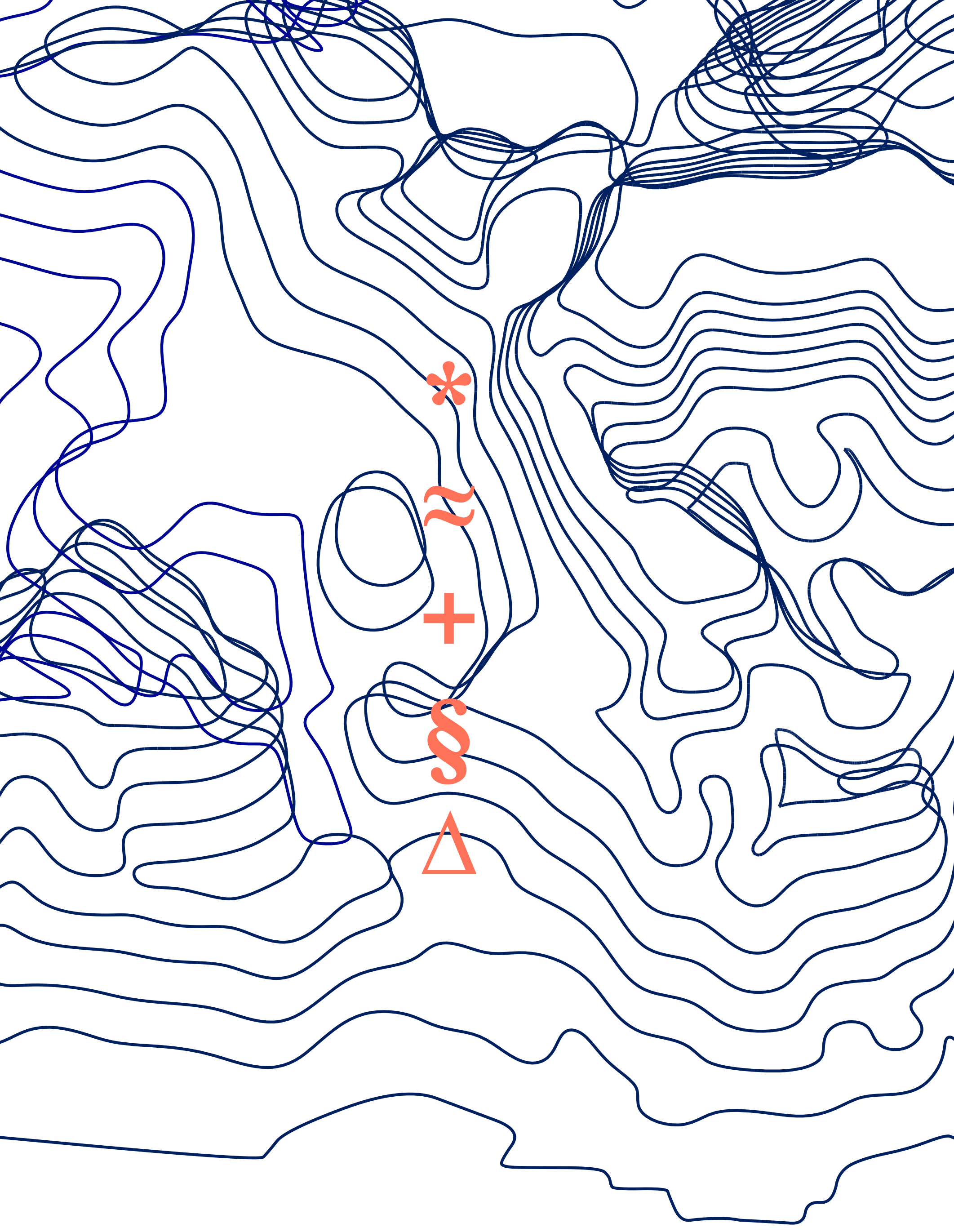

